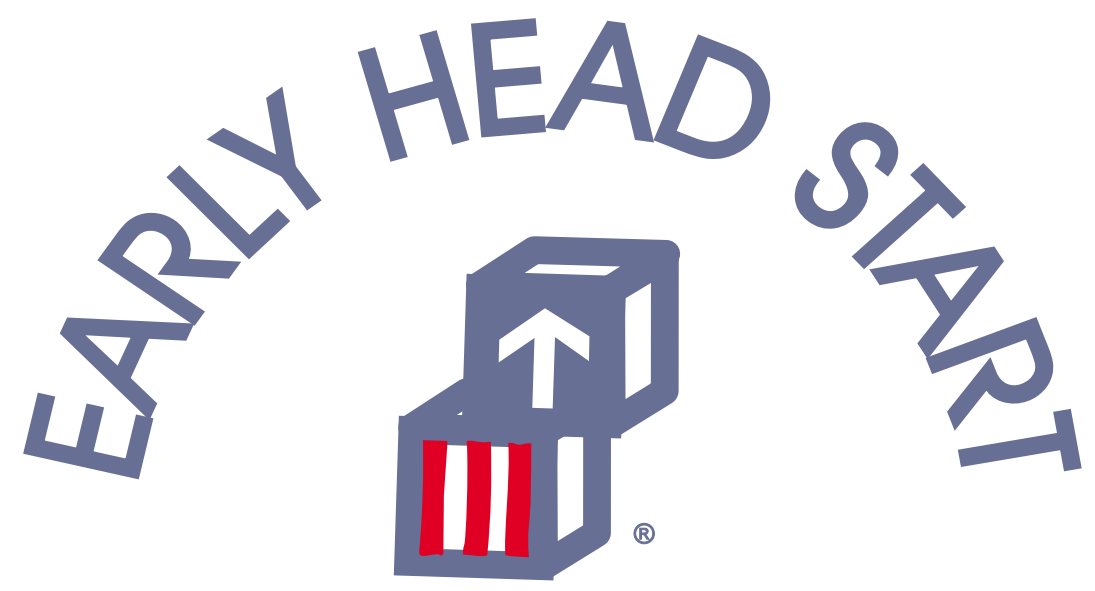

R G G A B C $\mathbf{H}$

Pathways to Quality and Full Implementation in Early Head Start Programs 


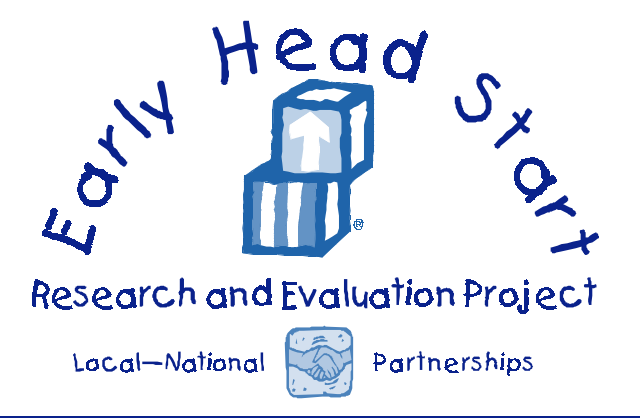

\title{
Pathways to Quality and Full Implementation in Early Head Start Programs
}

\author{
December 2002
}

Child Outcomes Research and Evaluation Office of Planning, Research, and Evaluation Administration for Children and Families And the Head Start Bureau Administration on Children, Youth and Families

Department of Health and Human Services 


\section{Early Head Start Evaluation Reports}

Leading the Way: Describes the characteristics and implementation levels of 17 Early Head Start programs in fall 1997, soon after they began serving families.

Executive Summary (December 2000): Summarizes Volumes I, II, and III.

Volume I (December 1999): Cross-Site Perspectives-Describes the characteristics of Early Head Start research programs in fall 1997, across 17 sites.

Volume II (December 1999): Program Profiles-Presents the stories of each of the Early Head Start research programs.

Volume III (December 2000): Program Implementation-Describes and analyzes the extent to which the programs fully implemented, as specified in the Revised Head Start Program Performance Standards, as of fall 1997.

Pathways to Quality and Full Implementation in Early Head Start (December 2002): Describes and analyzes the characteristics, levels of implementation, and levels of quality of the 17 Early Head Start programs in fall 1999, three years into serving families. Presents an analysis of the pathways programs followed to achieve full implementation and high quality.

Building Their Futures: How Early Head Start Programs Are Enhancing the Lives of Infants and Toddlers in LowIncome Families: Presents analysis of the impacts that the research programs have had on children's development, parenting, and family development through 2 years of age.

Summary Report (January 2001): Synopsis of the major findings.

Technical Report (June 2001): Detailed findings and report on methodology and analytic approaches.

Special Policy Report on Child Care in Early Head Start (December 2002): Describes the nature, types, and quality of child care arrangements in which Early Head Start children enrolled, and presents findings on the impacts of Early Head Start on both child care use and quality.

Special Policy Report on Children's Health in Early Head Start (February 2003): Describes children's health status and health services received by Early Head Start and control group families.

Making a Difference in the Lives of Infants and Toddlers and Their Families: The Impacts of Early Head Start (June 2002): Presents analysis of the impacts that the research programs have had on children's development, parenting, and family development through the children's third birthday (including two to three years of program participation).

Reports Are Available at:

http://www.acf.dhhs.gov/programs/core/ongoing_research/ehs/ehs_intro.html

http://www.mathematica-mpr.com/3rdLevel/ehstoc.htm 


\section{Prepared for:}

Rachel Chazan Cohen, Louisa Banks Tarullo, and Esther Kresh

Child Outcomes Research and Evaluation

Office of Planning, Research and Evaluation

Administration for Children and Families

U.S. Department of Health and Human Services

Washington, DC

\section{Prepared by:}

Mathematica Policy Research, Inc.

Princeton, NJ

Under Contract DHHS-105-95-1936

Authors:

Ellen Eliason Kisker

Diane Paulsell

John M. Love

Mathematica Policy Research, Inc.

Helen Raikes

Society for Research in Child Development Visiting Scholar Administration for Children and Families 



\section{CONTENTS}

Chapter

Page

EXECUTIVE SUMMARY xxi

I THE FIRST FOUR YEARS OF EARLY HEAD START: ORIGINS AND CONTEXT. 1

A. THE EARLY HEAD START PROGRAM ………………............................ 5

1. Origins of the Early Head Start Initiative.......................................................... 5

2. Early Head Start's Social and Political Context.............................................. 8

3. Context of the Evolving Infrastructure of Program Support.......................... 12

B. EARLY HEAD START RESEARCH AND EVALUATION PROJECT ............ 14

C. FAMILIES IN THE RESEARCH PROGRAMS …………………................... 17

D. DATA SOURCES AND METHODS FOR THE IMPLEMENTATION

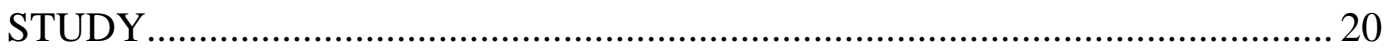

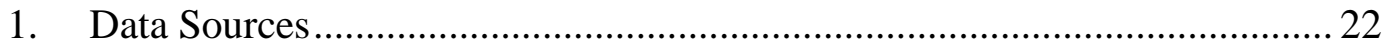

2. Overview of Analytic Methods …………………........................................ 23

II PROGRAM DEVELOPMENT AND EVOLVING PROGRAM APPROACHES 25

A. THE CONTEXT FOR PROGRAM DEVELOPMENT ………........................... 28

B. SALIENT FEATURES OF EARLY HEAD START RESEARCH PROGRAMS IN 1999 AND THEIR KEY DEVELOPMENTS OVER TIME ... 32

1. Center-Based Programs - that Remained Center-Based ................................ 32

2. Home-Based Programs that Remained Home-Based...................................... 34

3. Mixed-Approach Programs that Remained Mixed .......................................... 37

4. Home-Based Programs that Became Mixed-Approach Programs ................. 43

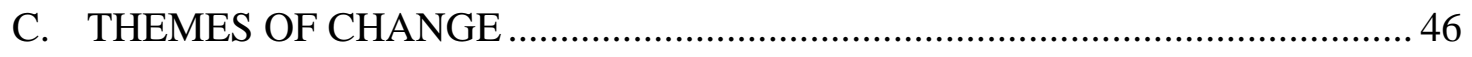

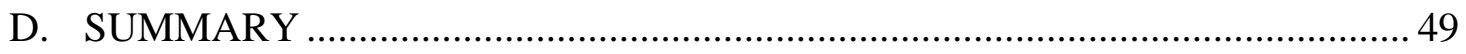




\section{CONTENTS (continued)}

Chapter

Page

III PROGRAMS' THEORIES OF CHANGE AND THEIR EVOLUTION

OVER TIME

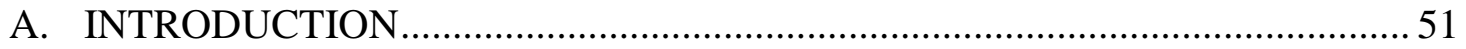

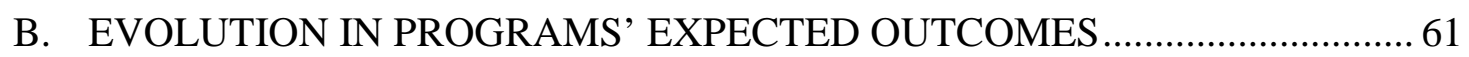

1. Specific Changes That Occurred in Programs' Focus on Priority

Outcomes in Particular Areas.

2. Changes Across All Expected Outcomes Between 1997 and 1999...............65

3. Summarizing Programs' Expected Child and Family Outcomes...................66

4. The Relationship Among Expected Outcomes, Program Approaches, and Program Impacts.

C. PERSPECTIVES FROM THEORY-OF-CHANGE DISCUSSIONS

AMONG RESEARCHERS AND PRACTITIONERS.

1. The Value of Research-Program Partnership in Developing Theories of Change.

2. Voices of the Staff: Home Visitors Describe Their "Theories of Change"

3. Local Variations in the Development of Program Theories of Change ........ 73

D. SUMMARY 78

IV PROGRAM IMPLEMENTATION: OVERALL LEVELS AND PATTERNS 81

A. MEASURING PROGRAM IMPLEMENTATION ....................................... 81

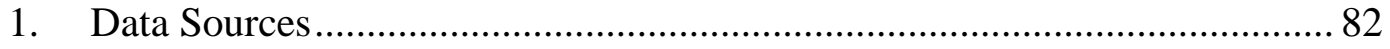

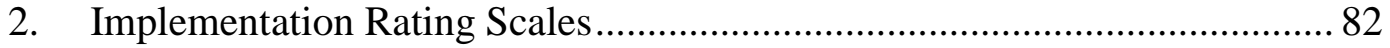

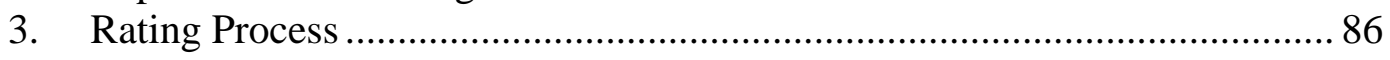

B. PROGRESS IN OVERALL IMPLEMENTATION BETWEEN FALL 1997 AND FALL 1999

C. PATTERNS IN THE TIMING BY WHICH PROGRAMS REACHED OVERALL IMPLEMENTATION 


\section{CONTENTS (continued)}

Chapter

Page

V PROGRESS IN IMPLEMENTING KEY CHILD DEVELOPMENT AND

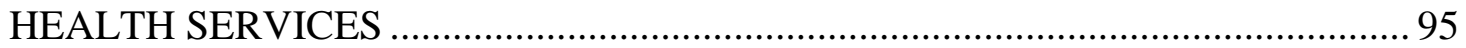

A. DEVELOPMENTAL ASSESSMENTS ..................................................... 98

B. INDIVIDUALIZATION OF CHILD DEVELOPMENT SERVICES ................ 98

C. PARENT INVOLVEMENT IN CHILD DEVELOPMENT SERVICES .......... 101

D. GROUP SOCIALIZATIONS ............................................................ 102

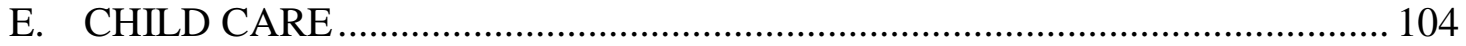

F. HEALTH SERVICES FOR CHILDREN .................................................... 110

G. FREQUENCY OF CHILD DEVELOPMENT SERVICES .......................... 111

H. SERVICES FOR CHILDREN WITH DISABILITIES .................................. 116

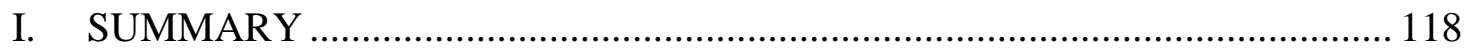

VI PROGRESS IN IMPLEMENTING FAMILY AND COMMUNITY PARTNERSHIPS

A. FAMILY PARTNERSHIPS: CHANGES IN SERVICES AND IMPLEMENTATION PROGRESS BETWEEN 1997 AND 1999

1. Individualized Family Partnership Agreements ..................................... 121

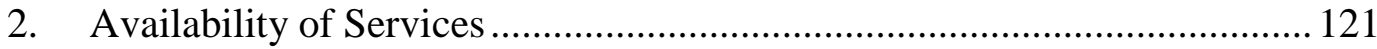

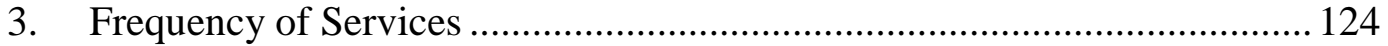

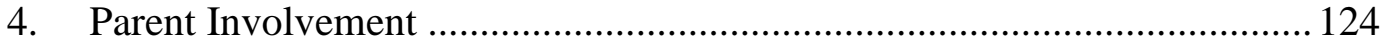

B. COMMUNITY PARTNERSHIPS: CHANGES IN SERVICES AND IMPLEMENTATION PROGRESS BETWEEN 1997 AND 1999

1. Collaborative Relationships

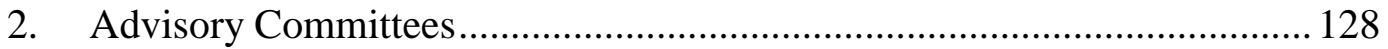

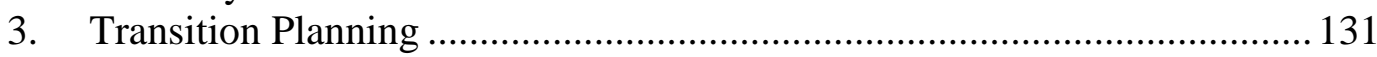

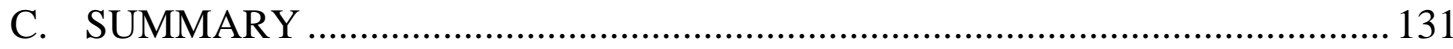




\section{CONTENTS (continued)}

\section{Chapter}

VII PROGRAM IMPLEMENTATION: STAFF DEVELOPMENT AND PROGRAM MANAGEMENT

A. EARLY HEAD START STAFF CHARACTERISTICS

B. STAFF DEVELOPMENT PRACTICES AND IMPLEMENTATION IN 1999 AND PROGRESS BETWEEN 1997 AND 1999

1. Supervision 138

2. Staff Retention

3. Staff Training and Educational Attainment ............................................ 142

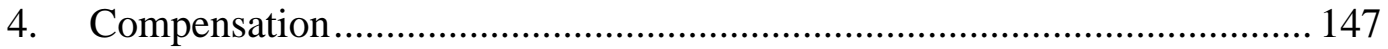

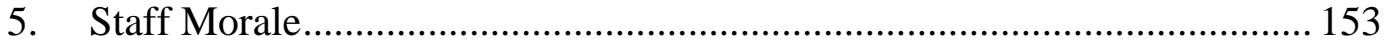

6. Staff Health and Mental Health.............................................................. 158

7. Job Satisfaction and Commitment....................................................... 160

C. IMPLEMENTATION OF MANAGEMENT SYSTEMS AND CHANGES FROM 1997 TO 1999

1. Policy Councils ............................................................................... 162

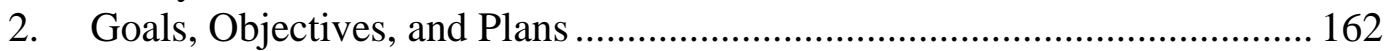

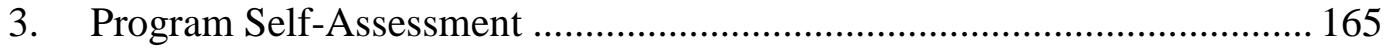

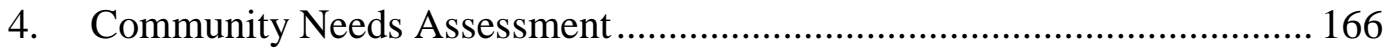

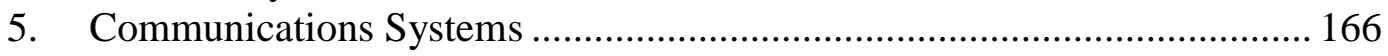

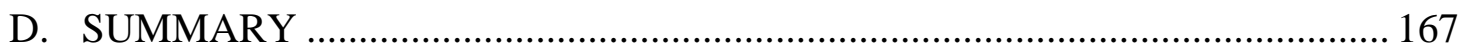

VIII THE QUALITY OF SELECTED CHILD DEVELOPMENT SERVICES.............. 169

A. METHODS FOR ASSESSING QUALITY .......................................... 169

1. Rating Inputs to Quality ............................................................ 170

2. Observations of Child Care Quality ................................................... 170

B. INPUTS TO CHILD CARE QUALITY ................................................. 172

C. OBSERVED CHILD CARE QUALITY .................................................. 176

1. Quality in Early Head Start Centers ...................................................... 176

2. Observed Child Care Quality in Community Child Care Centers .............. 178

3. Observed Child Care Quality in Family Child Care Settings .................... 182 


\section{CONTENTS (continued)}

Chapter

D. INPUTS TO THE QUALITY OF CHILD DEVELOPMENT HOME VISITS . 183

E. SUMMARY 186

IX PROGRAM PARTICIPATION AND FAMILIES' SERVICE NEEDS AND USE

A. DATA SOURCES

B. INVOLVING FAMILIES IN SERVICES: LEVELS AND INTENSITY OF PROGRAM PARTICIPATION

1. Overall Participation Levels ................................................................ 189

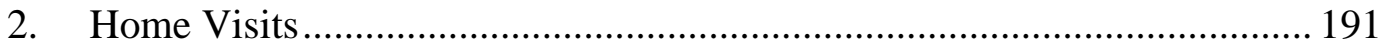

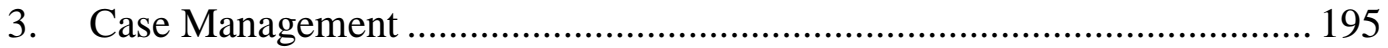

4. Parenting Information Services and Group Parenting Activities ................ 197

5. Child Care and Center-Based Child Development Services ....................... 201

6. Services for Children with Disabilities .................................................. 210

7. Child Health Services ........................................................................... 212

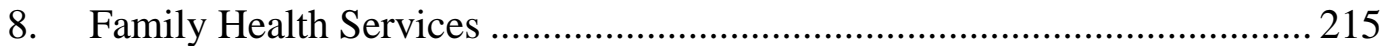

9. Other Family Development Services ................................................... 215

C. ENGAGEMENT IN SERVICES ......................................................... 219

1. Local Research on Program Engagement .................................................. 224

2. Family Risk Factors and Program Participation .................................... 225

D. THE MATCH BETWEEN FAMILIES' EARLY NEEDS AND SERVICE USE IN SPECIFIC AREAS ............................................................ 225

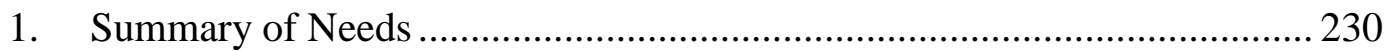

2. Match Between Needs and Services .................................................... 233

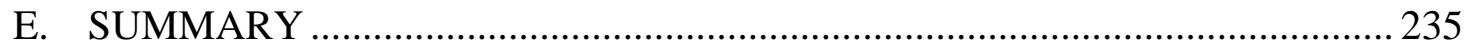




\section{CONTENTS (continued)}

Chapter

Page

X PATHWAYS TO IMPLEMENTATION AND QUALITY 237

A. CHANGES IN APPROACH AND IMPLEMENTATION LEVELS OVER TIME 238

1. Evolution in Program Approaches 239

2. Progress in Overall Program Implementation Over Time. 239

B. THEMES CHARACTERIZING EARLY PROGRAM DEVELOPMENT 241

1. Increased Attention to the Revised Head Start Program Performance Standards 241

2. Increased Service Intensity

3. Increased Focus on Child Development.

4. Refocused Efforts to Improve Child Care Quality and Availability

5. Enhanced Participation in Program Services/Activities

6. Expansion of Services 244

7. Evolution of Community Partnerships ..................................................... 244

8. Leadership Changes ........................................................................ 245

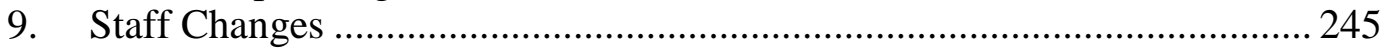

10. Shift Toward Providing Training and Technical Assistance ..................... 246

C. STRATEGIES FOR CHANGE ….............................................................. 246

1. Using New Curricula and Assessment Tools ........................................... 246

2. Creating Early Head Start Child Care Centers .......................................... 247

3. Developing New Approaches to Improving Quality in Community Child Care Settings 247

4. Creating Systems for Tracking Services More Effectively ........................ 248

5. Ending Partnerships................................................................................ 249

6. Forming New Partnerships and Strengthening Existing Ones ................... 249

7. Reorganizing or Creating New Staff Positions ..................................... 250

8. Hiring New Staff into Existing Positions ............................................ 250

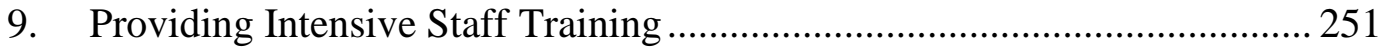

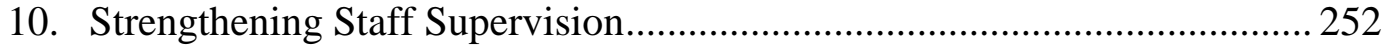

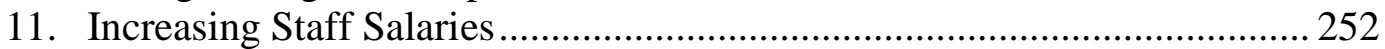

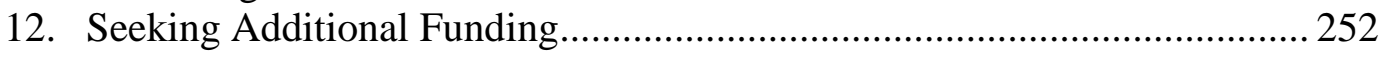

D. PROGRAM EXPERIENCES INFLUENCING PATHWAYS ........................ 253

1. Conversion from Comprehensive Child Development Programs .............. 253

2. Addition of Early Head Start to Head Start Programs ................................ 254

3. Community Programs Becoming Early Head Start Programs ................... 254 


\section{CONTENTS (continued)}

Chapter

Page

E. CHANGES IN THE POLICY AND PROGRAM CONTEXT 255

1. Revised Head Start Program Performance Standards . 255

2. Welfare Reform 255

3. Changes in State Medicaid Programs...................................................... 256

4. Local Child Care Markets 256

F. SOURCES OF GUIDANCE RECEIVED BY EARLY HEAD START PROGRAMS

G. CONCLUSIONS: MAJOR ACCOMPLISHMENTS AND REMAINING CHALLENGES.

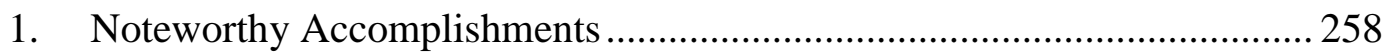

2. Looking Ahead: Noteworthy Challenges ............................................. 260

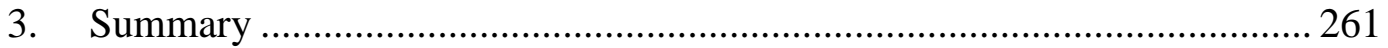

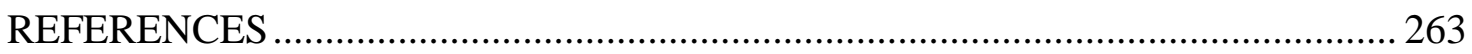

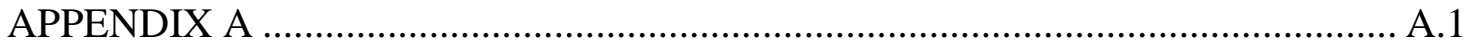

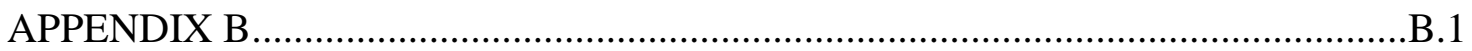

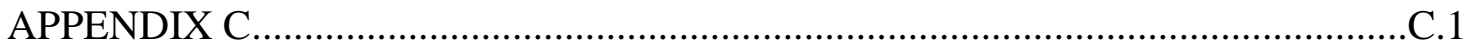





\section{TABLES}

Table

Page

I.1 COMPARISON OF RESEARCH PROGRAMS AND WAVE I AND II PROGRAMS 16

I.2 KEY CHARACTERISTICS OF CHILDREN ENTERING THE EARLY HEAD START RESEARCH PROGRAMS 18

I.3 KEY CHARACTERISTICS OF FAMILIES ENTERING THE EARLY HEAD START RESEARCH PROGRAMS

I.4 FAMILY RESOURCES AND RECEIPT OF ASSISTANCE BY FAMILIES ENTERING THE EARLY HEAD START RESEARCH PROGRAMS 21

III.1 OVERVIEW OF KEY OUTCOMES IDENTIFIED BY PROGRAMS IN 1997 AND 1999 53

III.2 EARLY HEAD START PROGRAMS’ PRIORITY OUTCOMES 62

III.3 EVOLVING PRIORITIES WITHIN THE CHILD DEVELOPMENT AREA: NUMBER (AND PERCENT OF PROGRAMS IDENTIFYING EACH ASPECT OF CHILD DEVELOPMENT AS A PRIORITY OUTCOME

III.4 CLUSTERS OF PROGRAMS WITH PRIORITY OUTCOMES IN EACH ASPECT OF CHILD AND FAMILY DEVELOPMENT

IV.1 PROGRAM ELEMENTS INCLUDED IN THE EARLY HEAD START IMPLEMENTATION RATING SCALES-FALL 1999.

IV.2 EARLY HEAD START IMPLEMENTATION RATING SCALE LEVELS 85

VII.1 PERCENTAGE OF EARLY HEAD START STAFF WITH PARTICULAR CHARACTERISTICS FOR THE FULL SAMPLE AND BY PROGRAM APPROACH IN 1997.

VII.2 EARLY HEAD START STAFF EDUCATIONAL ATTAINMENT AND PARTICIPATION IN TRAINING, FOR THE FULL SAMPLE AND BY PROGRAM APPROACH .

VII.3 EARLY HEAD START STAFF COMPENSATION AND FRINGE BENEFITS, FOR THE FULL SAMPLE AND BY PROGRAM APPROACH 150 
Table

Page

VII.4 PERCENTAGE OF EARLY HEAD START STAFF AGREEING OR STRONGLY AGREEING WITH STATEMENTS REGARDING THEIR PROGRAM'S WORKPLACE CLIMATE, FOR THE FULL SAMPLE AND BY PROGRAM APPROACH.

VII.5 STAFF HEALTH AND MENTAL HEALTH: PERCENTAGE OF EARLY HEAD START STAFF RESPONDING "YES" TO SURVEY STATEMENTS, FOR THE FULL SAMPLE AND BY PROGRAM APPROACH

VII.6 JOB SATISFACTION AND COMMITMENT: PERCENTAGE OF EARLY HEAD START STAFF RESPONDING TO SURVEY STATEMENTS, FOR THE FULL SAMPLE AND BY PROGRAM APPROACH. 161

VIII.1 EARLY HEAD START CHILD CARE QUALITY: AVERAGE ITERS AND FDCRS SCORES BY PROGRAM

VIII.2 EARLY HEAD START CHILD CARE QUALITY AVERAGE OBSERVED NUMBER OF CHILDREN PER TEACHER

VIII.3 EARLY HEAD START CHILD CARE QUALITY AVERAGE OBSERVED GROUP SIZE

IX.1 RECEIPT OF KEY EARLY HEAD START SERVICES DURING THE FIRST 16 MONTHS, FOR THE FULL SAMPLE AND KEY PROGRAM SUBGROUPS

IX.2 RECEIPT OF EARLY HEAD START HOME VISITS BY PROGRAM FAMILIES DURING THE FIRST 16 MONTHS, FOR THE FULL SAMPLE AND KEY PROGRAM SUBGROUPS

IX.3 RECEIPT OF EARLY HEAD START CASE MANAGEMENT BY PROGRAM FAMILIES DURING FIRST 16 MONTHS, FOR THE FULL SAMPLE AND KEY PROGRAM SUBGROUPS

IX.4 RECEIPT OF PARENTING INFORMATION AND PARTICIPATION IN EARLY HEAD START PARENT EDUCATION AND OTHER GROUP ACTIVITIES BY PROGRAM FAMILIES DURING THE FIRST 16 MONTHS, FOR THE FULL SAMPLE AND KEY PROGRAM SUBGROUPS.

IX.5 RECEIPT OF CHILD CARE DURING THE FIRST 16 MONTHS, FOR THE FULL SAMPLE AND KEY PROGRAM SUBGROUPS. 202

IX.6 PRIMARY CHILD CARE ARRANGEMENTS USED BY PROGRAM FAMILIES DURING FIRST 15 MONTHS, BY KEY PROGRAM SUBGROUPS 
Table

Page

IX.7 AVERAGE HOURS PER WEEK IN CHILD CARE DURING FIRST 15 MONTHS, BY PROGRAM APPROACH IN 1997 206

IX.8 PROPORTION OF THE FOLLOW-UP PERIOD THAT CHILDREN ATTENDED CHILD CARE DURING FIRST 16 MONTHS, BY PROGRAM APPROACH IN 1997. 207

IX.9 OUT-OF-POCKET CHILD CARE COSTS DURING FIRST 15 MONTHS, BY KEY PROGRAM SUBGROUPS ... 209

IX.10 RECEIPT OF SERVICES FOR CHILDREN WITH DISABILITIES DURING THE FIRST 16 MONTHS, FOR THE FULL SAMPLE AND KEY PROGRAM SUBGROUPS.

IX.11 RECEIPT OF CHILD HEALTH SERVICES BY PROGRAM FAMILIES DURING FIRST 16 MONTHS, FOR THE FULL SAMPLE AND KEY PROGRAM SUBGROUPS.

IX.12 RECEIPT OF FAMILY HEALTH SERVICES BY PROGRAM FAMILIES DURING THE FIRST 16 MONTHS, FOR THE FULL SAMPLE AND KEY PROGRAM SUBGROUPS 216

IX.13 RECEIPT OF EDUCATION, EMPLOYMENT, AND TRANSPORTATION SERVICES BY PROGRAM FAMILIES DURING THE FIRST 15 MONTHS, FOR THE FULL SAMPLE AND KEY PROGRAM SUBGROUPS 218

IX.14 RECEIPT OF HOUSING ASSISTANCE BY PROGRAM FAMILIES DURING THE FIRST 16 MONTHS, FOR THE FULL SAMPLE AND KEY PROGRAM SUBGROUPS

IX.15 STAFF RATINGS OF PROGRAM ENGAGEMENT, FOR THE FULL SAMPLE AND KEY PROGRAM SUBGROUPS 222

IX.16 SELECTED NEEDS REPORTED BY PROGRAM FAMILIES AT BASELINE, FOR THE FULL SAMPLE AND KEY PROGRAM SUBGROUPS 231

IX.17 MATCH BETWEEN SELECTED BASELINE NEEDS AND SERVICES USED BY PROGRAM FAMILIES DURING THE FIRST 16 MONTHS 



\section{FIGURES}

Figure $\quad$ Page

I.1 KEY EVENTS IN THE IMPLEMENTATION OF EARLY HEAD START ............. 7

II.1 BASIC PROGRAM APPROACHES ............................................................. 27

II.2 COMPLEXITY OF PROGRAM “APPROACHES” ........................................... 29

III.1 VARIATION IN PROGRAM APPROACH AMONG PROGRAMS WITH DIFFERENT PRIORITY OUTCOMES

III.2 PRIORITY EXPECTED OUTCOMES BY PROGRAM APPROACH....................70

III.3 PRIORITY EXPECTED CHILD DEVELOPMENT OUTCOMES, BY

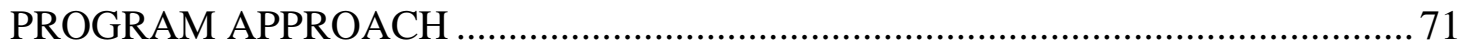

IV.1 EARLY HEAD START OVERALL IMPLEMENTATION RATINGS .................. 88

V.1 EARLY HEAD START CHILD DEVELOPMENT SERVICES IMPLEMENTATION RATINGS

V.2 TOOLS USED BY EARLY HEAD START RESEARCH PROGRAMS TO ASSESS CHILDREN'S DEVELOPMENT

V.3 EARLY HEAD START CHILD DEVELOPMENT SERVICES ASPECTS THAT WERE FULLY IMPLEMENTED. 100

V.4 ESTIMATED PROPORTION OF FAMILIES USING CHILD CARE 105

V.5 STRATEGIES USED BY EARLY HEAD START RESEARCH PROGRAMS TO MEET THE PERFORMANCE STANDARDS FOR CHILD CARE

V.6 FREQUENCY OF COMPLETED HOME VISITS IN EARLY HEAD START RESEARCH PROGRAMS FOR FAMILIES RECEIVING HOME-BASED SERVICES 114

V.7 PERCENTAGE OF TIME TYPICALLY SPENT ON CHILD DEVELOPMENT IN HOME VISITS

V.8 STRATEGIES BEYOND HOME VISITING USED BY EARLY HEAD START RESEARCH PROGRAMS TO PROVIDE PARENTING EDUCATION 
VI.1 EARLY HEAD START FAMILY PARTNERSHIPS IMPLEMENTATION RATINGS

VI.2 EARLY HEAD START FAMILY PARTNERSHIPS ASPECTS THAT WERE FULLY IMPLEMENTED

VI.3 ACTIVITIES TO PROMOTE PARENT INVOLVEMENT . 126

VI.4 EARLY HEAD START COMMUNITY PARTNERSHIPS IMPLEMENTATION RATINGS

VI.5 EARLY HEAD START COMMUNITY PARTNERSHIPS ASPECTS THAT WERE FULLY IMPLEMENTED

VII.1 EARLY HEAD START STAFF DEVELOPMENT ACTIVITIES IMPLEMENTATION RATINGS

VII.2 EXTENT TO WHICH FIVE EARLY HEAD START STAFF DEVELOPMENT ACTIVITIES WERE FULLY IMPLEMENTED

VII.3 FRINGE BENEFITS RECEIVED BY STAFF IN EARLY HEAD START RESEARCH PROGRAMS, FALL 1997 AND FALL 1999.

VII.4 WORKPLACE CLIMATE, FALL 1997 AND FALL 1999. 154

VII.5 WORKPLACE CLIMATE: COLLABORATION, SHARING, AND DECISION MAKING FALL 1997 AND FALL 1999.

VII.6 EARLY HEAD START MANAGEMENT SYSTEMS IMPLEMENTATION RATINGS

VII.7 EARLY HEAD START MANAGEMENT SYSTEMS ASPECTS THAT WERE FULLY IMPLEMENTED

VIII.1 NUMBER OF PROGRAMS WITH CENTERS IN WHICH INPUTS TO QUALITY WERE RATED AS GOOD OR HIGH.....

VIII.2 EARLY HEAD START INPUTS TO CHILD CARE QUALITY THAT WERE RATED GOOD OR HIGH FALL 1999.

VIII.3 EARLY HEAD START CENTERS AVERAGE ITERS SUBSCALE SCORES, 1998-99

VIII.4 EARLY HEAD START CHILD DEVELOPMENT HOME VISITS: OVERALL RATINGS OF QUALITY INPUTS 
FIGURES (continued)

$\begin{array}{lll}\text { Figure } & \text { Page }\end{array}$

VIII.5 EARLY HEAD START CHILD DEVELOPMENT HOME VISITS:

RATINGS OF QUALITY INPUTS …………………………………………....... 185

X.1 TIMELINE OF AN EARLY IMPLEMENTER …………...................................240 



\section{EXECUTIVE SUMMARY}

To meet multiple purposes, the National Early Head Start Research and Evaluation project included an implementation study, a study of program impacts through the children's second and third birthdays, continuous improvement feedback, local research, and special policy studies (on such topics as child care, fathers, health and disabilities, and welfare reform). In addition, longitudinal followup is under way as the children transition through Head Start and other preschool programs and enter kindergarten. Implementation data were collected through three rounds of site visits, surveys of program staff in fall 1997 and 1999, and observations in Early Head Start and community centers. The implementation study tells the story of the programs' development through their early years, examining the nature and extent of implementation in key program areas and the quality of crucial child development services. The final report of the implementation study, Pathways to Quality, describes lessons from the implementation analysis of the experiences of the 17 research programs as they developed between their initial funding in 1995 or 1996 and the final site visits in fall $1999 .{ }^{1}$

\section{MAJOR FINDINGS}

Evolving Program Approaches. Program approaches to delivering services increased in complexity over time. The research programs began about equally divided among center-based, home-based, and mixed-approach strategies; by fall 1997, the home-based approach predominated. $^{2}$ By 1999, however, only two of the home-based programs were continuing in that mode exclusively; the others had adopted a mixed approach. Four programs remained center-based throughout this period.

Progress in Overall Implementation. One-third (6) of the programs were early implementers, becoming fully implemented overall by fall 1997 and maintaining that level in late 1999, while still expanding the numbers of families served. By fall 1999, two-thirds (12) of the programs were fully implemented, with six later implementers making significant progress between 1997 and 1999. The remaining five programs were incomplete implementers, which did

\footnotetext{
${ }^{1}$ The implementation study and its findings are fully described in two sets of reports. The first report, Leading the Way (ACYF 1999a; 2000a; and 2000b), includes in-depth profiles of each of the 17 research programs (Volume II), a detailed cross-site analysis of the program services being delivered (Volume I), and analysis of the levels of implementation programs achieved and the quality of their child development services (Volume III) as of fall 1997. Pathways to Quality applies some of these same analyses to the levels of implementation and quality observed in 1999, while tracing the dynamics of program changes that led to these achievements.

${ }^{2}$ Center-based programs provide all services to families through the center-based option (center-based child care, plus other activities) and offer a minimum of two home visits per year to each family; home-based programs provide all services to families in the home-based option through weekly home visits and at least two group socializations per month for each family; mixed-approach programs provide center-based services to some families, home-based services to other families, or a mixture of center-based and home-based services to the same families.
} 
not achieve ratings of "fully implemented" during the evaluation period, even though all made strides in particular program areas and, in fact, showed a number of strengths. ${ }^{3}$

Variation in Implementation. The number of programs rated as fully implemented varied across the domains of program operations. Fifteen programs achieved that level by 1999 in community partnerships and in staff development, 14 in management systems, 12 in family partnerships, and 9 in child development and health services. There was also considerable variation within each of these areas.

Family Engagement. Program staff rated more than one-third of their families as being highly engaged in program services. Based on the parents' self-reports, programs that became fully implemented early generally succeeded in delivering more frequent and intense services to their families than the later-implemented or incompletely implemented programs.

Service Needs and Use. Most families who received services related to their reported needs at enrollment began receiving them in the initial follow-up period. In child care and education, some families who had a need at enrollment and did not receive services during the first followup period began receiving services in the second follow-up period. By the second followup, most families had received services related to the needs they expressed at enrollment. At least 85 percent of families who expressed a need in family health care, parenting information, child care, and education reported receiving services they needed. Most families who expressed a need for employment and housing reported receiving related services. However, fewer than half of families with a need in transportation and services for children with disabilities received services within the first 16 months after enrollment.

Quality of Child Development Services. Overall, the quality of both home- and centerbased child development services was good. On average, centers maintained teacher-child ratios and group sizes that met the revised Head Start Program Performance Standards, and average scores on the Infant-Toddler Environment Rating Scale were in the good-to-excellent range. ${ }^{4}$ Ratings of factors believed to influence home-visiting effectiveness (such as home visitor hiring, training and supervision; planning and frequency of home visits; staff reports of child development emphasis during home visits; and integration with other services) were "good" or "high" quality in 9 of the 13 programs with home-based services in 1997, and increased to 11 in 1999.

\footnotetext{
${ }^{3}$ In-depth site visits provided information for rating levels of implementation along key program elements contained in the Early Head Start program announcement and the Head Start Program Performance Standards (which were revised to encompass program serving infants and toddlers and took effect in 1998). Although the implementation ratings designed for research purposes were not used to monitor compliance, they included criteria on most of the dimensions that the Head Start Bureau uses in program monitoring, including child development and health, family development, community building, staff development, and management systems. Being fully implemented meant that programs achieved ratings of 4 or 5 on the 5-point scales used by the research team across most of the elements rated. Programs that were not fully implemented overall had implemented some aspects of the relevant program elements fully and had implemented other aspects, but not at the level required for a high rating. Some of the incompletely implemented programs showed strengths in family development, community building, or staff development.
}

${ }^{4}$ A policy report examining child care use and child care quality in more detail will be released in mid-2002. 
Staff Development and Management. Staff responses to the fall 1999 survey showed that staff morale was generally high. Staff reported positive workplace climates and valued their directors. Although most programs experienced annual turnover in the 15 to 32 percent range, fewer programs experienced very high turnover rates in 1999 than were reported in 1997. A number of programs focused on improving wages, with the average compensation for frontline staff improved by 9 percent over that two-year period. By 1999, programs were successful overall in meeting the performance standards requirement that at least 50 percent of frontline staff have a two-year or higher degree-even before the 2003 deadline. However, center-based programs had not yet achieved the required goal of having all teachers CDA-certified within a year of being hired.

\section{THEMES CHARACTERIZING EARLY STAGES OF PROGRAM DEVELOPMENT}

Ten themes summarize the key experiences of these programs that were funded early in the initiative. Although the circumstances of each program are unique, other programs may have similar experiences as they progress toward fuller implementation and higher-quality services.

- Increased attention to the revised Head Start Program Performance Standards. Ongoing guidance from the Head Start Bureau and technical assistance providers helped programs interpret the performance standards. Head Start Bureau monitoring visits between 1997 and 1999 clarified the standards and identified areas that programs needed to change in order to comply with the standards, and motivated staff to address these areas.

- Expanding services. Many programs expanded services to families, began serving new neighborhoods, and/or increased the number of families served.

- Increasing service intensity. Most programs became more successful over time in delivering more-intensive services to a higher proportion of families. Home-based programs provided more-frequent home visits and group socializations; programs operating centers increased the hours of operation.

- Increasing child development focus. Some programs began with a family support focus, and over time increased the child development focus of services during home visits by changing curricula and providing additional training and supervision.

- Refocusing efforts to improve child care quality. Several programs moved from community-level, collaborative quality improvement activities to focusing on the quality of the arrangements Early Head Start children were in. Programs developed myriad activities to meet the challenge of improving child care quality, such as developing partnerships with child care providers, offering training and technical assistance to providers, and monitoring arrangements.

- Enhancing family participation in program services. To address the challenge of involving families in services at the planned intensity, some programs made strong efforts to increase family involvement in home visits and group socializations. Some also focused on involving men in program activities. 
- Providing training and technical assistance. The research programs, among the first wave of Early Head Start programs, were often called on to share their experiences with newer programs in their region. Thus, several moved into a new role of providing assistance to other programs.

- Evolving community partnerships. Changes such as increasing the child development focus of services often meant that original partners were either less appropriate or insufficient for meeting the needs of families. A number of programs ended partnerships that were no longer necessary and/or formed new partnerships and interagency collaborations, especially with Part $\mathrm{C}$ agencies and child care providers.

- Changing leadership. In most of the research programs, leadership did not change. However, when changes did occur, they sometimes set back or stalled program progress but sometimes created opportunities for positive change.

- Increasing complexity. Programs examined their service mix, adapted to changing community circumstances and family needs, and learned from their experiences. Expanding services, creating a better fit between services and family needs, and other program developments (especially among those that became more "mixed" in their approaches to serving families), typically increased the complexity of the service approaches. Part of the complexity was often reflected in reorganized staffing structures, intensified training plans, and searches for additional sources of funds (such as state grants and child care subsidies).

\section{LOOKING BACK: SELECTED ACCOMPLISHMENTS}

The programs achieved many important successes over the first several years of implementation. Looking back, several accomplishments stand out:

- Nearly three-quarters of the research programs became fully implemented. Most programs were able to reach full implementation within four years of their initial funding. The others made considerable progress in several program areas but were not able to become fully implemented within the first four years.

- Implementation progress occurred even while program complexity increased and program emphases changed over time. Programs often altered their basic approaches to providing child development services to accommodate the changing needs of families. The changes in approaches usually entailed adding service options and offering their families a more complex set of options.

- The infrastructure to support Early Head Start grew alongside the programs. During the study period, the training and technical-assistance system grew to accommodate the rapidly expanding number of Early Head Start programs. Programs often cited guidance received from Head Start Bureau monitors and training and technical-assistance providers as key to their growth and development. 
- To a large extent, the programs delivered the required services. Programs delivered child development and other services to families in centers, during home visits and case management meetings, and in group parenting activities. Services included child development services (child care, assessments and screening, activities with children during home visits, and group socializations), parenting education, and family development services (case management, health services, and transportation assistance). Most families received the services that related to the needs they expressed at the time they enrolled. The majority of families received services at the required intensity during the first 16 months after enrollment. In addition, 91 percent of parents, overall, met at least a minimal criterion for being considered participants.

- The programs succeeded in providing more-intensive child development services. Programs providing home visits increased the intensity of home visits from two to three visits completed each month per family on average. Programs offering center-based services all increased to full-day, full-year services, if they had not offered these services initially.

- The Early Head Start centers provided good-quality care to infants and toddlers, and initiated efforts to enhance quality in community child care programs that Early Head Start children attended. Between the fall 1997 and fall 1999 site visits, quality scores consistently averaged in the good-to-excellent range. Several programs were rated as providing excellent care. Programs initiated many efforts to enhance quality in community child care centers attended by Early Head Start children.

- Attention to staff training, supervision, and support sustained high ratings of staff satisfaction and commitment. Over time, many programs continued to refine their training and supervisory approaches and support staff in providing consistent, high-quality services to families. The research programs succeeded in creating workplace environments that staff rated highly. Staff noted how much they had learned by fall 1999 and expressed confidence that they now have a much clearer idea of what they are trying to accomplish and how to go about it.

- Early Head Start programs contributed to their communities. In a number of ways, maturing programs began making a difference for the larger communities in which they are located. For example, they began increasing the number of infant and toddler experts in their communities, contributing to greater integration of services in the community, and establishing degree programs in early childhood development at local colleges to augment community resources in early childhood.

- Community partnerships grew in number and effectiveness. Early Head Start programs have become better known and more accepted in their communities. Special Quest has played a key role in strengthening partnerships between Early Head Start programs and Part $\mathrm{C}$ providers. In addition, more programs have contracts or agreements with child care providers. 


\section{LOOKING AHEAD: IMPORTANT CHALLENGES}

Looking beyond the Early Head Start research programs' first four years of operation, we see several challenges remaining. These challenges create opportunities for continued growth and improvement in these 17 programs and provide lessons for all Early Head Start programs:

- Continuing to adjust to changing family needs. During their first four years, the research programs adapted their services to family needs that changed as a result of welfare reform. In many states, as families reach their time limits on cash assistance and the economy weakens, programs may face new challenges as they help families cope with these changes.

- Finding effective strategies for engaging families in parenting education and group socializations. During their first four years, most of the research programs providing home-based services to some or all families were unable to achieve high participation rates in group socializations, and programs that were exclusively or partially center-based continued to have difficulty engaging parents more fully in parent education classes and support groups. Regardless of program approach, programs need to continue to find effective ways of engaging families.

- Increasing father involvement. In searching for effective approaches to involving parents in group socializations and parenting education, as well as in other program activities, the programs may also discover creative ways to involve fathers.

- Ensuring that children's child care arrangements meet the revised Head Start Program Performance Standards. Programs that relied on community child care settings to meet their families' child care needs developed a range of strategies for ensuring quality. However, most programs that are not center-based are challenged to continue to build community child care partnerships to ensure quality child care for all program children.

- Balancing program needs and the needs of staff. Programs' staffing needs are likely to continue changing as programs evolve and services change, which will require programs to prepare staff for new responsibilities and sometimes to change their staff structure. In this context, programs also must meet the financial and other needs of a more professional workforce to minimize staff turnover.

Reaching full implementation quickly presents a significant challenge for some programs. Achieving full implementation takes time, and not all programs will be successful within the first three or four years of funding. All programs, and the infrastructure that supports them, need to work together toward the goal of reaching full implementation as quickly as possible. 


\section{THE FIRST FOUR YEARS OF EARLY HEAD START: ORIGINS AND CONTEXT}

The year 1995 saw the beginning of a new federal program, with 68 grantees, aimed at enhancing the development of infants and toddlers. It was named Early Head Start by the Secretary's Advisory Committee on Services for Families with Infants and Toddlers that created it. The program has grown into today's national initiative, which comprises 664 grantees serving some 55,000 children around the country, commands an increasing proportion of the Head Start budget, and enjoys bipartisan support. ${ }^{1}$ Seventeen of these programs are participating in a national evaluation and local research studies that are documenting the implementation process and assessing program impacts and outcomes. The 17 research programs, which reflect important characteristics of all 143 Early Head Start programs funded in the first two waves (1995-1996 and 1996-1997; ACYF 1999a), were also among the first to design and implement programs under the revised Head Start Program Performance Standards (U.S. Department of Health and Human Services 1996). The 17 research programs opened their doors to the implementation research to provide lessons that might apply to all Early Head Start programs and ultimately aid program development for new Early Head Start programs across the country.

During their first four years, the research programs moved from designing services and enrolling children and families to making real the vision of the Advisory Committee on Services for Families with Infants and Toddlers (U.S. Department of Health and Human Services 1995). The developments during this period were dramatic. Programs exerted strong efforts to create

\footnotetext{
${ }^{1}$ At the October 23, 1997, White House Conference on Child Care, the President announced his proposal to double Early Head Start funding; Congress has increased Early Head Start's share of the Head Start budget from 3 percent in fiscal year 1995 to 10 percent in 2001 and 2002.
} 
the appropriate services for their families. They made numerous changes to meet the revised performance standards that were announced in late 1996 and went into effect January 1, 1998 (U.S. Department of Health and Human Services 1996). In some cases, this meant fine-tuning their mix of services to fit both the program vision (with its accompanying standards and guidelines) and the needs of their families and communities. In other cases, meeting the changing needs of families moving from welfare to work meant redesigning programs developed for a world before welfare reform. In still other cases, programs looked beyond their immediate boundaries to take on the mantle of leadership for local and statewide partnerships to enhance services for infants and toddlers. Through these and many other experiences described in this report, the research programs provide an invaluable opportunity to learn about what it takes to make the Early Head Start concept functional within a changing programmatic and policy context.

Pathways to Quality describes the programs as they existed in fall 1999 and tells the story of their development during the first three to four years of operation. ${ }^{2}$ This report describes their programmatic approaches in 1999, follows their evolution since 1997, and describes the paths they followed from their early beginnings. What emerges is a picture of a dynamic process through which 17 programs serving diverse communities found varied ways to achieve new and increasing levels of implementation and quality in their key program services. This picture comes into focus in succeeding chapters as we address the following research questions:

- How have the programs changed over time? How have they grown during their first four years? What is the story of their dynamic change and growth?

\footnotetext{
${ }^{2}$ One of the research sites was a Wave II program (funded in 1996-1997) and had only been in operation for three years when we visited in 1999. As Wave I programs (funded in 19951996), all of the other research sites had been in operation for four years by the time of the 1999 site visits.
} 
- To what extent did the Early Head Start research programs reach full implementation within four years after funding? To what extent did they achieve good quality in their child development services?

- What does it take to attain full implementation and high quality services? How long does it take? What are alternative trajectories to achieving good quality?

- What factors account for the variation in levels of implementation and quality among the research programs four years after funding?

- What are the key factors that facilitated the achievement of full implementation and high quality? What key challenges did programs face in working toward these goals?

To address these broad questions, we examined five aspects of the research programs' development in depth: (1) their approach to delivering services, (2) their theories of change, (3) the extent to which they fully implemented the Early Head Start program, (4) the quality of key child development services, and (5) families' levels of service use and program engagement. These analyses provide an enriched understanding of implementation processes by enabling us to chart implementation progress over time, discern trends in the way programs have grown and changed, and identify key implementation challenges and successes.

The implementation study findings have also contributed to our understanding of program impacts and outcomes. In addition to helping us interpret impact findings, we used the results of our implementation analyses to test hypotheses about how various aspects of implementation relate to outcomes. For example, how do program approach and the timing of program implementation relate to child and family outcomes? To answer such questions, we designed targeted impact analyses on key subgroups of programs. ${ }^{3}$ For example, we estimated impacts on

\footnotetext{
${ }^{3}$ See Building Their Futures: How Early Head Start Programs Are Enhancing the Lives of Infants and Toddlers in Low-Income Families (Administration on Children, Youth and Families 2001) and Making a Difference in the Lives of Infants and Toddlers and Their Families: The Impacts of Early Head Start (Administration for Children and Families 2002) for more information about targeted impact analyses conducted for specific subgroups of programs.
} 
child and family outcomes for programs that implemented key aspects of the Head Start Program Performance Standards early and later and for programs that implemented various approaches to service delivery.

Pathway to Quality presents the detailed results of these implementation analyses and highlights key implications for programs and policy. Chapter II identifies the main approaches programs took to delivering services and traces the evolution of approaches to service delivery over the first four years of operation. Chapter III explores the programs' theories of change and expected outcomes, focusing on how they changed during the evaluation period. Chapters IV through VII present the results of our assessment of implementation: Chapter IV presents an overview of the patterns and levels of program implementation overall; Chapter V focuses on programs' progress in implementing key child development services; Chapter VI examines implementation of family and community partnerships; and Chapter VII describes progress in implementing key aspects of staff development and program management systems. In Chapter VIII, we focus on the quality of key child development services that programs achieved. Chapter IX reports families' use of services and the program engagement patterns of their families and assesses the match between their service needs and service receipt. Finally, in Chapter X, we analyze the pathways programs followed in striving to achieve full implementation and high quality and the factors that influenced those pathways.

The rest of this introductory chapter provides an overview of the Early Head Start program and the Early Head Start Research and Evaluation Project, summarizes key characteristics of program families participating in the research, and describes the data sources and analytic methods used for the implementation study. 


\section{A. THE EARLY HEAD START PROGRAM}

\section{Origins of the Early Head Start Initiative}

Early Head Start began at a time of increasing awareness of the "quiet crisis" facing families with infants and toddlers in the United States, as identified in a report entitled Starting Points: Meeting the Needs of Our Youngest Children, by the Carnegie Corporation of New York (1994). As the report showed, a great many infants and toddlers are starting life in poor environments, without adequate stimulation, and without sufficient interactions with caring, responsive adults. The release of Starting Points followed closely on a comprehensive self-examination of Head Start services conducted by the Advisory Committee on Head Start Quality and Expansion. This committee called for Head Start programs to improve their quality, address the fragmentation of services by forging new partnerships, and expand services in a number of ways, including serving more families with infants and toddlers (U.S. Department of Health and Human Services 1993). Subsequently, the Head Start Authorization Act of 1994 mandated new Head Start services for families with infants and toddlers, authorizing 3 percent of the total Head Start budget in fiscal year 1995, 4 percent in 1996 and 1997, and 5 percent in 1998 for these services (U.S. Department of Health and Human Services 1994a). The Coats Human Services Reauthorization Act of 1998 further expanded the program, setting aside 7.5 percent of Head Start funds in 1999, 8 percent in 2000, and 10 percent in 2001 and 2002 for Early Head Start programs (U.S. Department of Health and Human Services 1998).

In 1994, the Advisory Committee on Services for Families with Infants and Toddlers provided guidelines for the new Early Head Start program. The report of the Advisory Committee set forth a vision and blueprint for Early Head Start programs and established principles and "cornerstones" for the new program (U.S. Department of Health and Human Services 1994b). 
Early Head Start programs are comprehensive child development programs. The Advisory Committee on Services for Families with Infants and Toddlers envisioned a two-generation program of intensive services that begin before the child is born and concentrate on enhancing the child's development and supporting the family during the critical first three years of the child's life. The Advisory Committee recommended that programs be designed to promote outcomes in four domains:

- Child development (including health; resiliency; and social, cognitive, and language development)

- Family development (including parenting and relationships with children, the home environment and family functioning, family health, parent involvement, and economic self-sufficiency)

- Staff development (including professional development and relationships with parents)

- Community development (including enhanced child care quality, community collaboration, and integration of services to support families with young children)

The program guidelines specify that grantees should design programs that achieve these outcomes by providing home- or center-based child development services, combining these approaches, or implementing other locally designed options.

The first wave of grantees-68 programs-was funded in September 1995. Another 75 programs were funded in September 1996, and in subsequent years additional funding brought the total in 2002 to almost 700 programs serving some 60,000 infants and toddlers and their families. Not only have the programs' development been dramatic, it has taken place within a changing context. National, state, and local changes in social policy (as well as changes in our understanding of the effectiveness of child development programs), have dramatically influenced the development of the programs and are likely to affect their future direction. Figure I.1 shows the timing of the key events in the first five years of Early Head Start's development. Important 
FIGURE I.1

KEY EVENTS IN THE IMPLEMENTATION OF EARLY HEAD START

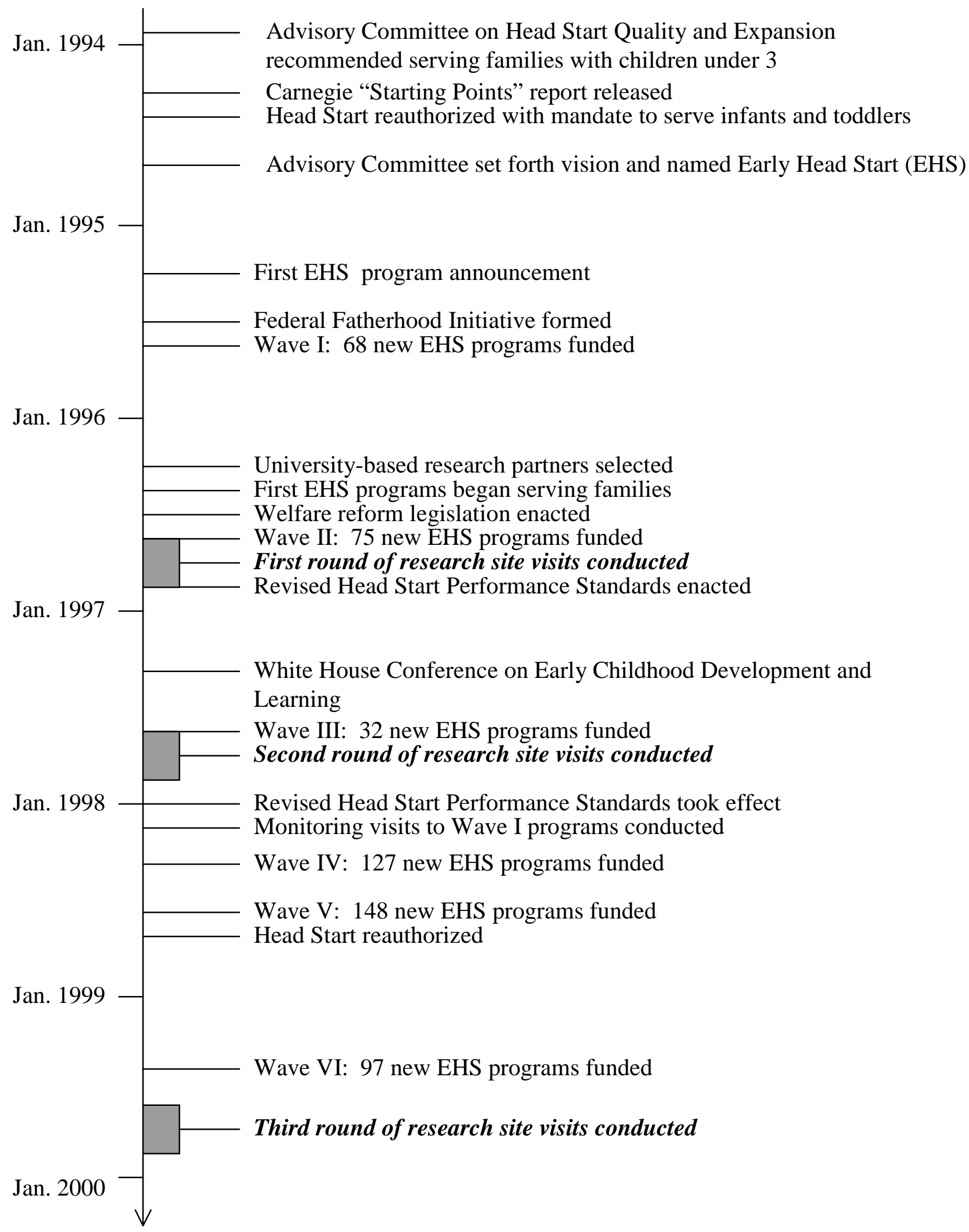


events and changes within the Head Start/Early Head Start infrastructure have also shaped the programs, including the revision of performance standards, ongoing program monitoring, and the continuing training and technical assistance that supports Early Head Start programs.

\section{Early Head Start's Social and Political Context}

Understanding the implementation of any large-scale initiative requires examining the context in which it operates. Early Head Start is being implemented during a time of fundamental changes in this country's social services systems. Some of these changes may have a dramatic effect on the approaches programs take, the ways in which families respond, and the ways in which programs interact with others in their communities. In particular, five broad social changes and contextual factors, some of which occurred after Early Head Start began, may have influenced the Early Head Start initiative: (1) increasing recognition of the importance of early development, (2) welfare reform in the context of a strong economy, (3) new child care and prekindergarten initiatives, (4) growing attention to the roles of fathers in young children's lives, and (5) recent evaluation findings that identify challenges in improving outcomes for children and families.

Early Child Development. Recent research has shown that human development before birth and during the first year of life is rapid and extensive but vulnerable to environmental influences (Shonkoff and Phillips 2000). Moreover, early development has a long-lasting effect on children's cognitive, behavioral, and physical growth (Carnegie Corporation of New York 1994). National attention focused on early brain development in spring 1997, when the White House convened the Conference on Early Childhood Development and Learning and special editions of national news magazines featured articles on the brain development of infants. All this has helped program staff gain the support of policymakers, program sponsors, and 
community members for services that start when women are pregnant and focus directly on child development.

Welfare Reform. The Personal Responsibility and Work Opportunity Reconciliation Act of 1996 (PRWORA), which went into effect just as Early Head Start programs began serving families, reformed federal welfare policy and gave states more autonomy and responsibility for setting and administering welfare policy. It also established clear expectations for families receiving welfare. Cash assistance is now provided through the Temporary Assistance for Needy Families (TANF) program and is no longer an entitlement. Adults may receive cash assistance for a maximum of 60 months over their lifetime. After two years (or less, at state option), many families have to work in order to continue receiving cash assistance. Some states exempt parents of infants from the work requirements for a short time (typically less than a year), but almost half do not.

For delivery of program services, PRWORA created a climate different from the one that existed when the first wave of Early Head Start grantees wrote their proposals. The new work requirements and time limits on cash assistance have increased demands on parents' time, increased their child care needs, increased stress for some families, and made it more difficult for parents to participate in some program services. Some parents are now more receptive to services related to both employment and child care and are motivated to find jobs and work toward self-sufficiency. Thus, in the context of the strong U.S. economy at that time, the new requirements may have improved families' economic well-being. The increasing need for good infant/toddler child care has put extra pressure on Early Head Start programs either to provide full-day, full-year child care themselves or to help develop and support it in their communities. As discussed more fully in Chapter II, these changes caused some Early Head Start programs to redesign their services to meet families' current needs. 
New Child Care and Prekindergarten Initiatives. PRWORA also consolidated federal funding for child care into the Child Care and Development Fund (CCDF), which provides increased funding for child care for low-income families and allows states to design comprehensive, integrated child care subsidy systems. These changes may make it easier both for families who need child care to obtain financial assistance and for Early Head Start staff members to help them obtain child care subsidies. The increased employment of low-income families under PRWORA has also increased the need for Early Head Start staff members to collaborate with state child care administrators and local providers to help meet families' child care needs. Staff members have had to find ways to blend funds and work with the child care system within their states and communities.

States are required to spend at least 4 percent of their total CCDF funds to improve quality and expand supply of child care for infants and toddlers. In FY 1999, CCDF received an additional \$173 million to improve care specifically for these age groups. Since 1996, several states in which Early Head Start research programs are located have used quality enhancement funds to create new and stronger initiatives for infant-toddler child care: (1) in 1998, the Kansas Legislature approved an Early Head Start project as a joint endeavor with the federal government, and awarded grants to 13 early childhood development programs across the state; (2) New York State increased funding for child care from its TANF funds and created an incentive program for centers that serve infants and toddlers to seek accreditation; (3) Missouri has been experimenting with differential reimbursement rates for infant and toddler care; and (4) Michigan provides grants to encourage expansion and quality improvement, with special attention given to programs for infants and toddlers (Blank, Behr, and Schulman 2001).

In addition to providing child care subsidies for low-income families, 42 states now fund prekindergarten programs or have a school-funding mechanism for 4-year-olds (Mitchell 2001). 
Shifting resources and increased support for the care of preschool children in many areas may offer Head Start and other preschool programs more opportunities to blend funding sources and may free resources for serving more families with infants and toddlers. Where early childhood labor markets are tight, however, these initiatives have made it more difficult for Early Head Start programs to hire and retain well-trained staff.

The Role of Fathers. During the study period, policymakers, researchers, and educators have gained increasing appreciation of the importance of fathers as contributors of emotional and economic support to their children. As a consequence, to promote the positive involvement of fathers in the lives of their children, federal agencies were developing and enhancing fatherhood policies. In addition to recent social trends and PRWORA's increased emphasis on paternity establishment and enforcement of child support judgments, the federal Fatherhood Initiative was created in 1995 to promote the involvement of fathers and acknowledge their contributions to their children's well-being. The growing focus on fathers has led some programs to devote more program resources than originally planned to strengthening fathers' relationships with their children and enhancing their parenting skills. Changing patterns of father involvement also challenge programs to develop creative strategies that are not limited by traditional conceptions of family structure.

Recent Program Evaluation Findings. The Early Head Start programs began just as new findings from evaluations of programs that served families with infants and toddlers during the 1980s and early 1990s were being released. In particular, the longer-term findings of the evaluation of ACYF's Comprehensive Child Development Program (CCDP) were released soon after the first Early Head Start programs were funded (St. Pierre et al. 1997). The CCDP, which offered case management services to low-income families with infants and toddlers, had few lasting impacts on child and family outcomes. In addition, recent research suggests that home- 
visiting programs often may not be effective and that careful attention needs to be paid to how they are implemented (Gomby, Culross, and Behrman 1999; and Olds et al. 1998).

These recent research findings highlight the difficulty of improving the lives of low-income children and families, but they also provide valuable lessons to build on. ${ }^{4}$ Research suggests that programs that provide intensive, purposeful, high-quality, child-focused services are more likely than those that provide primarily adult-focused services to effect significant changes in children's cognitive, social, and emotional development. Accordingly, ACYF directed Early Head Start programs to emphasize child development services-direct services to children in child development centers or home visits-and to pay careful attention to the quality of children's child care arrangements, in addition to supporting parents as their children's primary educators. ACYF strongly supports continuous program improvement in Early Head Start by enforcing requirements in the revised Head Start Program Performance Standards for goal setting, data collection, feedback, and formal self-assessment procedures; providing intensive training and technical assistance; drawing on early research findings in its training and technical assistance activities; and supporting program partnerships with local researchers.

\section{Context of the Evolving Infrastructure of Program Support}

Building on a national and regional infrastructure developed for the national Head Start program, ACYF created for the Early Head Start programs an infrastructure that included (1) the revised Head Start Program Performance Standards, (2) program monitoring to ensure compliance with the standards, and (3) training and technical assistance to support programs in achieving full implementation and quality.

\footnotetext{
${ }^{4}$ For a summary of findings of key studies, see Chapter I of Making a Difference in the Lives of Infants and Toddlers and Their Families: The Impacts of Early Head Start (ACYF 2002).
} 
Early Head Start programs follow the Head Start Program Performance Standards and are monitored according to their adherence to them. These standards were revised in 1996 through an extensive process that took several years and included commentary by thousands of experts in early education, health, and related areas; Head Start parents and staff members; and members of the general public. At the time of site visits to the Early Head Start research programs in fall 1997 (described in Section D), the revised standards had been published but had not yet taken effect, and the programs were still seeking clarification of some of the new regulations. The revised performance standards took effect in January 1998.

Head Start Bureau monitoring teams visit programs every three years to check compliance with program guidelines and the revised Head Start Program Performance Standards. Initially, the national office of the Head Start Bureau was responsible for awarding program grants and overseeing program operations. In fall 1997, however, this responsibility was transferred to the 10 U.S. Department of Health and Human Services Regional Offices, except for a limited number of programs involving special circumstances. Wave I Early Head Start programs were first monitored in spring 1998.

The Early Head Start National Resource Center was created in 1995 to provide ongoing support, training, and technical assistance to all waves of Early Head Start programs under a contract with ZERO TO THREE. The center has provided training conferences for Early Head Start teachers known as "intensives" in infant-toddler care; week-long training for key program staff; annual institutes in Washington, DC, for key program staff; and identification and preparation of a cadre of nationally known infant-toddler consultants who work intensively with programs on a one-to-one basis. The Early Head Start National Resource Center has worked closely with regional training grantees—-the Head Start Quality Improvement Centers (HSQICs) and the Head Start Disabilities Quality Improvement Centers (DSQICs)—and with their infant- 
toddler specialists, as well as the 10 U.S. Department of Health and Human Services Regional Offices and Indian and Migrant program branches that assumed responsibility for administrating Early Head Start grants in fiscal year 1998.

\section{B. EARLY HEAD START RESEARCH AND EVALUATION PROJECT}

The Early Head Start Research and Evaluation Project includes a national evaluation conducted in tandem with local research studies, which together address a broad range of issues. The project is assessing program impacts on an extensive set of child and family outcomes. In addition, it is investigating the role of program and contextual variations, studying the pathways to achieving program quality, examining the pathways to desired child and family outcomes, and creating the foundation for a series of longitudinal research studies.

To achieve its aims, the Early Head Start Research and Evaluation Project encompasses five major components:

1. An implementation study to examine service needs and use for low-income families with infants and toddlers, assess program implementation, understand programs' theories of change, illuminate pathways to achieving quality, and identify and explore variations across sites

2. An impact evaluation, using an experimental design, to analyze the effects of Early Head Start programs on children, parents, and families; and descriptive analyses to assess outcomes for program staff and communities. Early Head Start programs that are participating in the national evaluation recruited 150 to 200 families with pregnant women or children under age 1 to participate in the impact evaluation (half the 3,000 children and families were randomly selected to participate in the program, and half were randomly assigned to the control group)

3. Local research studies to learn more about the pathways to desired outcomes for infants and toddlers, parents and families, staff, and communities

4. Policy studies to respond to information needs in areas of emerging policy-relevant issues, including welfare reform, fatherhood, child care, health, and disabilities

5. Continuous program improvement activities to guide all Early Head Start programs through formative evaluation 
In 1996 and early 1997, ACYF selected 17 programs to participate in the national research and evaluation project. When they first applied for funds, all Early Head Start programs funded in Wave I (1995-1996) and Wave II (1996-1997) had agreed to participate in a random assignment evaluation if they were selected. In January 1996, ACYF invited Wave I programs to select local research partners and apply to be a research site for the national evaluation. To be eligible, programs had to guarantee that they could recruit 150 families for Early Head Start research (twice their program capacity). For easier identification of research partners, the Society for Research in Child Development made directories of its membership available to each new Early Head Start program, and ACYF issued a request for proposals, including the addresses and contact persons for the 68 Wave I programs, to notify researchers of the research opportunity. Forty-one program-researcher partnerships submitted proposals to be research sites (a number of other programs may have been interested but could not meet the sample size requirement). Initially, ACYF selected 15 partnerships, basing its choices on both the quality of the proposed local research and a desire to achieve a balance across programs in national geographic representation, rural and urban locations, racial/ethnic composition of families, and program approaches. The 15, however, underrepresented center-based programs, so in 1996 ACYF selected one additional center-based program from Wave I, and in late 1997 selected another center-based program (without a local research partner) from Wave II.

The final set of 17 research programs constitutes a balanced group that includes variation in the key characteristics considered in the site-selection process. All the major program approaches, family background characteristics, regions of the country, urban and rural areas, and families' racial/ethnic backgrounds are represented. Together, the selected programs also broadly resemble all Early Head Start programs funded in the first two waves (Table I.1). They have approximately the same ACYF-funded enrollment, on average, and the characteristics of 
TABLE I.1

\section{COMPARISON OF RESEARCH PROGRAMS AND WAVE I AND II PROGRAMS}

\begin{tabular}{|c|c|c|c|}
\hline & $\begin{array}{l}\text { Wave I Programs } \\
\text { (Percent) }\end{array}$ & $\begin{array}{l}\text { Wave II Programs } \\
\text { (Percent) }\end{array}$ & $\begin{array}{c}\text { Research Programs } \\
\text { (Percent) }\end{array}$ \\
\hline \multicolumn{4}{|l|}{ Total ACYF-Funded Enrollment } \\
\hline 10 to 29 children & 6 & 0 & $0^{\mathrm{a}}$ \\
\hline 30 to 59 children & 14 & 9 & 6 \\
\hline 60 to 98 children & 62 & 64 & 65 \\
\hline 100 to 199 children & 15 & 27 & 29 \\
\hline 200 to 299 children & 3 & 0 & 0 \\
\hline (Average) & (81) & (84) & (85) \\
\hline \multicolumn{4}{|c|}{ Race/Ethnicity of Enrolled Children } \\
\hline African American & 33 & 21 & $34^{\mathrm{a}}$ \\
\hline Hispanic & 22 & 27 & 23 \\
\hline White & 39 & 46 & 37 \\
\hline Other & 6 & 5 & 6 \\
\hline English Is the Main Language & 85 & 79 & 80 \\
\hline \multicolumn{4}{|l|}{ Family Type } \\
\hline Two-parent families & 39 & 46 & 40 \\
\hline Single-parent families & 51 & 46 & 52 \\
\hline Other relatives ${ }^{\mathrm{b}}$ & 7 & 5 & 3 \\
\hline Foster families & 1 & 1 & 0 \\
\hline Other & 1 & 1 & 5 \\
\hline \multicolumn{4}{|l|}{ Employment Status ${ }^{\mathrm{c}}$} \\
\hline In school or training & 20 & 22 & 22 \\
\hline Not employed & 48 & 48 & 56 \\
\hline Number of Programs & 66 & 11 & 17 \\
\hline
\end{tabular}

SOURCE: Preliminary Head Start Family Information System application and enrollment data.

NotE: The percentages for the Wave I and II Early Head Start programs are derived from available Program Information Report (PIR) data. The percentages for the Early Head Start research programs are derived from preliminary Head Start Family Information System application and enrollment data from 1,462 families.

Percentages may not add up to 100 , as a result of rounding.

${ }^{\mathrm{a}}$ The data for the research programs refer to families instead of children.

'The HSFIS data elements and definitions manual instructs programs to mark "other relatives" if the child is being raised by relatives other than his/her parents, such as grandparents, aunts, or uncles, but not if the child is being raised by his/her parents, and is living with other relatives as well.

'The research program data and PIR data are not consistent in the way that they count primary caregivers' employment status, so it is not possible to compare the percentage of caregivers who are employed. 
enrolled children and families are very similar. Thus, although this sample of programs is not statistically representative of all Early Head Start programs, the implementation study findings from these programs are likely to be indicative of implementation issues faced more broadly across all early programs (see Leading the Way, Volume I, Chapter II, for details; ACYF 1999a).

\section{FAMILIES IN THE RESEARCH PROGRAMS}

The families who enrolled in the Early Head Start research programs and in the research study (those who enrolled between July 1996 and September 1998) had diverse characteristics and needs when they enrolled:

- Most families enrolled in the research programs before their child reached the age of 6 months (Table I.2). One-fourth of the primary caregivers enrolled while they were still pregnant (Table I.3).

- Indicators based on children's low birthweight and reports by primary caregivers that someone had a concern about their children's development suggest that approximately 20 percent of the children who enrolled after birth might have had or were at risk for a developmental disability. ${ }^{5}$

- Many families included two parents—about 40 percent overall—but the extent to which the research programs served two-parent families varied widely.

- About one-third of the children's primary caregivers were teenage parents, but this also varied substantially. For example, in two programs, more than half of all families were headed by a teenage parent.

- On average, about one-third of the families were African American, one-fourth were Hispanic, slightly more than one-third were white, and a small proportion belonged to other groups. In 11 programs, enrolled families belonged predominantly to one group, while in six programs, the racial/ethnic composition of enrolled families was diverse and not dominated by one group.

${ }^{5}$ Four percent of children who enrolled after birth had been born at low birthweight, and concerns about their development were reported on the application form. Nine percent of the children had not been born at low birthweight, but their primary caregivers reported that someone had a concern about their development. Seven percent had been born at low birthweight, but their primary caregivers did not report that someone had a concern about their development. Children with these indicators at enrollment were not necessarily identified as having disabilities within the evaluation period. 
TABLE I.2

KEY CHARACTERISTICS OF CHILDREN ENTERING THE EARLY HEAD START RESEARCH PROGRAMS

\begin{tabular}{|c|c|c|}
\hline & $\begin{array}{l}\text { All Research } \\
\text { Programs } \\
\text { Combined } \\
\text { (Percent) }\end{array}$ & $\begin{array}{c}\text { Range Across } \\
\text { Research Programs } \\
\text { (Percent) }\end{array}$ \\
\hline Child's Age & & \\
\hline Unborn & 25 & 7 to 67 \\
\hline 0 to 6 months old & 42 & 12 to 57 \\
\hline 6 to 12 months old & 33 & 1 to 75 \\
\hline $\begin{array}{l}\text { Child Was Born at Low Birthweight (Under } \\
2,500 \text { grams) }\end{array}$ & 10 & 4 to 23 \\
\hline $\begin{array}{l}\text { Concerns About Child's Development Were } \\
\text { Noted on Application Form }\end{array}$ & 13 & 3 to 26 \\
\hline Number of Applicants/Programs & $\mathbf{1 , 5 1 4}$ & 17 \\
\hline
\end{tabular}

SOURCE: Preliminary Head Start Family Information System application and enrollment data. 
TABLE I.3

KEY CHARACTERISTICS OF FAMILIES ENTERING THE EARLY HEAD START RESEARCH PROGRAMS

\begin{tabular}{|c|c|c|}
\hline & $\begin{array}{l}\text { All Research } \\
\text { Programs } \\
\text { Combined } \\
\text { (Percent) }\end{array}$ & $\begin{array}{l}\text { Range Across } \\
\text { Research Programs } \\
\text { (Percent) }\end{array}$ \\
\hline Primary Caregiver (Applicant) Is Female & 94 & 88 to 99 \\
\hline Primary Caregiver Is a Teenager (under 20) & 35 & 12 to 84 \\
\hline Primary Caregiver Is Married & 28 & 2 to 70 \\
\hline Family Is a Two-Parent Family & 40 & 9 to 74 \\
\hline Primary Caregiver's Race/Ethnicity & & \\
\hline $\begin{array}{l}\text { African American } \\
\text { Hispanic } \\
\text { White } \\
\text { Other }\end{array}$ & $\begin{array}{r}33 \\
24 \\
37 \\
6\end{array}$ & $\begin{array}{l}0 \text { to } 89 \\
0 \text { to } 89 \\
2 \text { to } 91 \\
0 \text { to } 16\end{array}$ \\
\hline $\begin{array}{l}\text { Primary Caregiver's Main Language Is Not } \\
\text { English }\end{array}$ & 21 & 0 to 81 \\
\hline $\begin{array}{l}\text { Primary Caregiver Does Not Speak English } \\
\text { Well }\end{array}$ & 11 & 0 to 55 \\
\hline $\begin{array}{l}\text { Primary Caregiver Lacks a High School } \\
\text { Diploma }\end{array}$ & 48 & 24 to 88 \\
\hline $\begin{array}{l}\text { Primary Caregiver's Main Activity } \\
\text { Employed } \\
\text { In school or training } \\
\text { Unemployed } \\
\text { Other }\end{array}$ & $\begin{array}{l}23 \\
22 \\
29 \\
26\end{array}$ & $\begin{array}{r}11 \text { to } 44 \\
4 \text { to } 64 \\
13 \text { to } 43 \\
2 \text { to } 55 \\
\end{array}$ \\
\hline Number of Applicants/Programs & 1,514 & 17 \\
\hline
\end{tabular}

SOURCE: Preliminary Head Start Family Information System application and enrollment data. 
- On average, 20 percent of primary caregivers did not speak English as their main language. Some of these caregivers also spoke English well, but some did not. Overall, 11 percent of the primary caregivers did not speak English well.

- Overall, slightly more than half the primary caregivers had a high school diploma.

- On average, 23 percent of applicants were employed and another 22 percent were in school or training (usually school) as their main occupation at the time they enrolled.

- Some of the families had basic needs that were not being met when they enrolled in the research programs. Overall, the percentages reporting that they did not have adequate food, housing, medical care, or personal support ranged from 5 to 13 percent (Table I.4).

- Child care was a significant need of the families. Overall, 34 percent of the families did not have adequate child care arrangements when they enrolled. The percentage of families without adequate child care arrangements ranged from 8 to 66 percent across the research programs.

- Most of the families who enrolled in the research programs were receiving some kind of public assistance. Overall, 77 percent had Medicaid coverage, and 88 percent were receiving WIC benefits. Almost half the families were receiving food stamps, and slightly more than one-third were receiving AFDC or TANF cash assistance (some pregnant women were not eligible for cash assistance because they were not yet parents). A small proportion (7 percent) was receiving SSI benefits.

- Child care was a significant need of the families. Overall, 34 percent of the families reported that their child care arrangements seldom or never met their needs, at the time they enrolled. The percentage of families without adequate child care arrangements ranged from 8 to 66 percent across the research programs.

- Most of the families who enrolled in the research programs were receiving some kind of public assistance. Overall, 77 percent had Medicaid coverage, and 88 percent were receiving WIC benefits. Almost half the families were receiving food stamps, and slightly more than one-third were receiving AFDC or TANF cash assistance (some pregnant women were not eligible for cash assistance because they were not yet parents). A small proportion (7 percent) was receiving SSI benefits.

\section{DATA SOURCES AND METHODS FOR THE IMPLEMENTATION STUDY}

This report describes the 17 research programs as they existed in fall 1999 and focuses on the changes that developed in their features over their first four years of operation, with special emphasis on those that occurred between 1997 and 1999. Pathways to Quality builds on an 
TABLE I.4

FAMILY RESOURCES AND RECEIPT OF ASSISTANCE BY FAMILIES ENTERING THE EARLY HEAD START RESEARCH PROGRAMS

\begin{tabular}{lcr}
\hline & $\begin{array}{c}\text { All Research } \\
\text { Programs Combined } \\
\text { (Percent) }\end{array}$ & $\begin{array}{c}\text { Range Across Research } \\
\text { Programs } \\
\text { (Percent) }\end{array}$ \\
\hline Adequacy of Resources & 5 & 0 to 20 \\
Inadequate food & 12 & 4 to 24 \\
Inadequate housing & 14 & 3 to 36 \\
Inadequate medical care & 35 & 11 to 67 \\
Inadequate child care & 21 & 12 to 35 \\
Inadequate transportation & 13 & 0 to 39 \\
Inadequate parenting information & 13 & 3 to 39 \\
Inadequate personal support & & \\
Assistance Received Currently & 77 & 47 to 89 \\
Medicaid & 34 & 11 to 64 \\
AFDC/TANF & 48 & 22 to 75 \\
Food stamps & 87 & 69 to 96 \\
WIC & 7 & 0 to 16 \\
SSI & $\mathbf{1 , 5 1 4}$ & $\mathbf{1 7}$ \\
\hline Number of Applicants/Programs & & \\
\hline
\end{tabular}

SOURCE: Preliminary Head Start Family Information System application and enrollment data. 
earlier report that fully described the programs in their first year of serving families. That report, Leading the Way, included in-depth profiles of each of the 17 research programs (Volume II), a detailed cross-site analysis of the program services being delivered (Volume I), and analysis of the levels of implementation programs achieved and the quality of their child development services (Volume III). ${ }^{6}$ Pathways to Quality applies these analyses to the levels of implementation and quality observed in 1999, traces the program changes that led to these achievements, provides new analyses of service use and program engagement, and identifies the challenges and successes that the programs experienced during this period. The rest of this section describes the data sources and analytic methods used to conduct these analyses.

\section{Data Sources}

Qualitative and quantitative data for this report are from a range of sources: (1) site visits to the research programs in fall 1997 and fall 1999, (2) observations of program children's child care arrangements, (3) parent services follow-up interviews, and (4) Head Start Family Information System (HSFIS) data collected at enrollment. During the site visits, we:

- Conducted individual and group interviews with program staff, parents, community members, and local researchers

- Distributed and collected self-administered staff surveys

- Reviewed randomly selected case files to learn about service patterns of individual families

- Observed service delivery in a center or during a home visit

${ }^{6}$ The Leading the Way: Characteristics and Early Experiences of Selected Early Head Start Programs volumes include: I. Cross-Site Perspectives (ACYF 1999a); II. Program Profiles (ACYF 1999b); III. Program Implementation (ACYF 2000a); and Executive Summary (ACYF 2000b). 
Following the site visits, we prepared detailed narrative program profiles and organized information on program implementation and factors affecting the quality of child development services into tables and checklists. Program directors reviewed the draft profiles and checklists, corrected errors and supplied clarifying information, and verified the final profiles and checklists.

We also drew on data from systematic observations of the child care settings of Early Head Start children in the research sample. These observations were conducted when children in the research sample reached 14 and 24 months of age. ${ }^{7}$ These data include observed child-teacher ratios, observed group sizes, and Infant-Toddler Environment Rating Scale (ITERS) scores or Family Day Care Environment Rating Scale (FDCRS) scores as appropriate for the settings in which research sample children received child care.

Parent services follow-up interviews provided information about families' use of program and community services. These interviews were targeted for 6,15 , and 26 months after program enrollment (and completed an average of 7, 16, and 27 months after enrollment). Most of the interviews were conducted by telephone with the focus child's primary caregiver, although some interviews were conducted in person for those who could not be reached by phone. Finally, we used data from the HSFIS program application and enrollment forms that were completed by families when they applied to enroll in the program.

\section{Overview of Analytic Methods}

This report presents a blend of qualitative and quantitative research. Our analysis of site visit data yielded rich descriptions of program operations, approaches to service delivery, stories

\footnotetext{
${ }^{7}$ Observations were also conducted when children were 36 months old; they will be reported in a special policy paper focusing on Early Head Start child care.
} 
of change, and dynamics of the wide range of efforts programs developed to meet their families' needs. We applied systematic and consistent methods to define, describe, and analyze levels of implementation and indicators of the quality of child development services across all sites. In addition, we used descriptive statistical methods, including calculating means and frequencies, to analyze quantitative data from the parent services follow-up interviews, HSFIS application and enrollment forms, and child care observations. The chapters that follow contain more detailed explanations of our methods for each of the analyses described in this report. 


\section{PROGRAM DEVELOPMENT AND EVOLVING PROGRAM APPROACHES}

As the Carnegie Corporation's Starting Points report suggested, providing services to support the development of infants and toddlers in low-income families is a challenge. The framework established for Early Head Start (as we reviewed in Chapter I) encompassed several options for providing such services, and all options required extensive planning at the local level. Program staff took on the challenges with enthusiasm, implemented a variety of approaches during their early years, and raised the level of awareness about the importance of providing services for pregnant women and infants and toddlers and their families. Over time, they finetuned their approaches in response to their experiences and changing contexts for families, particularly as influenced by changes accompanying welfare reform. Through the lens of the 17 research programs, we see this new national initiative as it is today and how it developed during its short history. In this chapter, we profile the salient features of the programs' approaches to service delivery as of late 1999 and describe what they were like two years earlier. In addition, we describe the evolution in program approaches, explaining how and why they developed as they did.

Early Head Start programs strive to achieve their goals by designing program options based on family and community needs. Programs are required to reassess community needs and resources regularly (formally, every three years); following each assessment, they reassess the "goodness of fit" between community needs and program approaches. By design, programs may offer one or more options to families, including (1) a home-based option, (2) a center-based option, (3) a combination option in which families receive a prescribed number of home visits and center-based experiences, and (4) locally designed options. ACYF made this wide range of 
service delivery options eligible for funding to attract programs that could best serve families with infants and toddlers in their communities. Because a single program may offer families multiple options, for purposes of the research, we have characterized programs according to the options they offer:

- Center-based programs, which provide all services to families through the centerbased option (center-based child care plus other activities) and offer a minimum of two home visits per year to each family

- Home-based programs, which provide all services to families through the homebased option (weekly home visits and at least two group socializations per month for each family)

- Mixed-approach programs, which provide some services to some families through the center-based option and some through the home-based option, or provide services to families through the combination or locally designed option (services can be mixed in the sense either that programs target different types of services to different families or that individual families can receive a mix of services at the same time or at different times)

When initially funded, the research programs were about equally divided among these three approaches, with five center-based, five home-based, and seven mixed-approach programs (Figure II.1). By fall 1997, as we reported in Leading the Way, the programs' efforts to find appropriate ways of meeting their families' needs had shifted the balance significantly. ${ }^{1}$ Four programs were then center-based, seven were home-based, and six were mixed-approach. The changes, from the point of initial funding to 1997, were a result of such factors as subsequent funding decisions, changes in families' needs, and recommendations of technical assistance providers.

Program evolution did not stop there. By fall 1999, programs offering only a home-based approach had become the minority (down from seven to two). All four of the center-based

\footnotetext{
${ }^{1}$ For details about the programs' features and approaches in 1997, see the preceding report, Leading the Way, Vols. I to III, and executive summary (ACYF 1999a, 1999b, 2000a, and 2000b).
} 
FIGURE II.1

\section{BASIC PROGRAM APPROACHES}

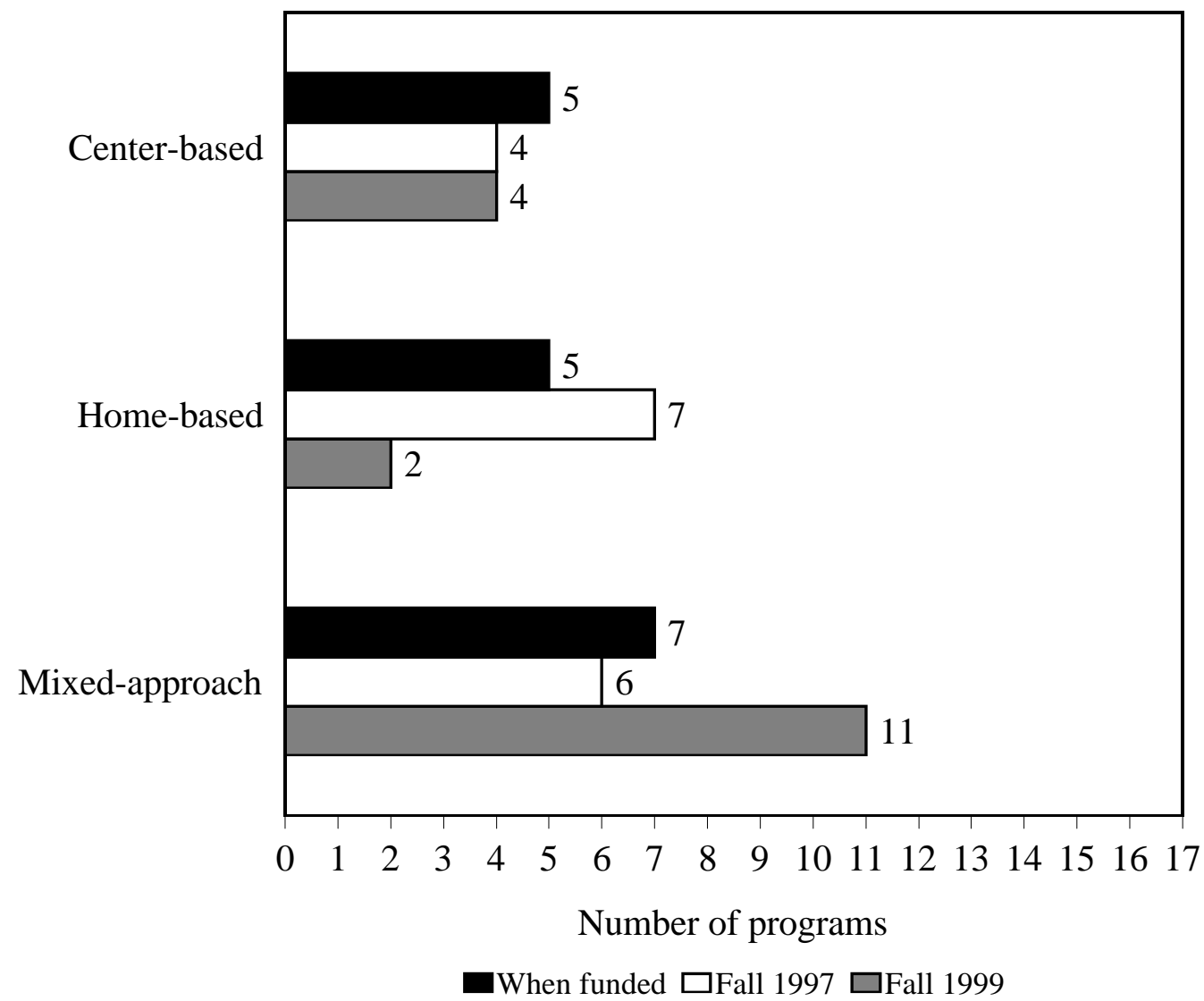

SOURCE: Information gathered during visits to the Early Head Start research programs in fall 1997 and fall 1999.

NOTE: Early Head Start programs may offer one or more options to families, including (1) a home-based option, (2) a center-based option, (3) a combination option in which families receive a prescribed number of home visits and center-based experiences, and (4) locally designed options. For purposes of the research, we have characterized programs according to the options they offer to families as follows:

- Center-based programs, which serve all families through the center-based option

- Home-based programs, which serve all families through the home-based option

- Mixed-approach programs, which serve some families through the center-based option and some through the home-based option, or serve families through the combination option 
programs continued in that mode, but by 1999, 11 programs were offering a variety of "mixed" approaches to Early Head Start services. Regardless of whether they changed their main approach to service delivery, nearly all programs added services and grew in complexity (Figure II.2)

The story of these changes is at the heart of this chapter. We begin the chapter by describing the contexts in which the research programs developed and how these contexts changed over time. We then profile each of the 17 research programs as of fall 1999, summarizing their key features and the changes they made in their approaches to service delivery between fall 1997 and fall 1999. We end the chapter with a discussion of the themes of change gleaned from our analysis of the research programs' development over time.

\section{A. THE CONTEXT FOR PROGRAM DEVELOPMENT}

The Early Head Start research program grantees were at various stages of implementing services for infants and toddlers and incorporating Head Start program features at the time they were funded. Nine had experience operating Head Start programs for preschoolers, and five of these had also served infants and toddlers. Another grantee had operated a Parent Child Center (PCC) as well as a Head Start program and seven had operated Comprehensive Child Development Programs (CCDPs). Many of the grantee agencies had experience providing services to infants and toddlers, but five of them were new to Head Start. Three of the program grantees had not operated Head Start programs, CCDPs, or PCCs, but had operated other community-based programs. These grantees included a Montessori program that had served infants, toddlers, and preschool children, as well as a school district and a well-known national agency that had not. 
FIGURE II.2

\section{COMPLEXITY OF PROGRAM "APPROACHES"}

Families Receive Child

Development Services in:

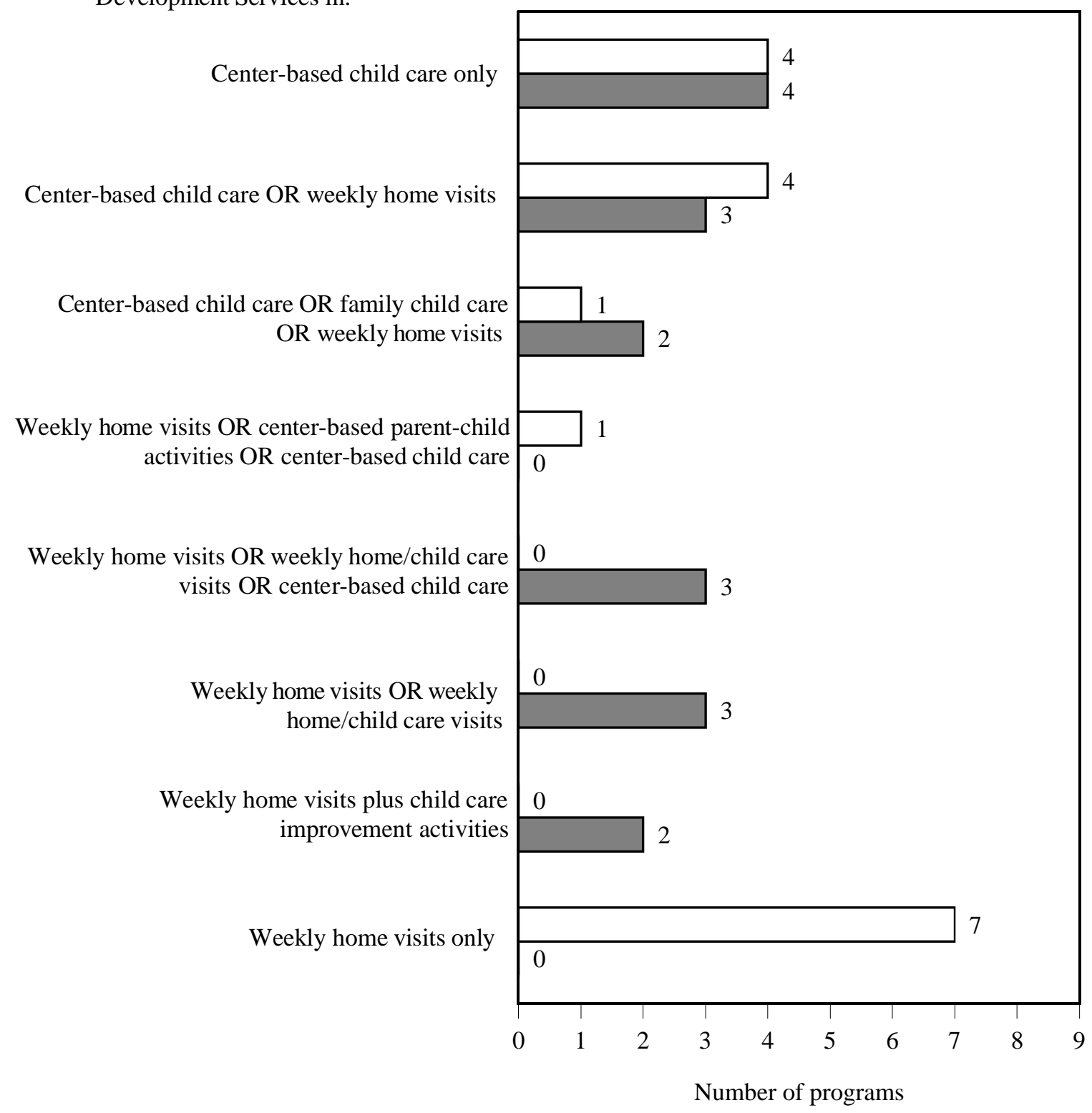

$\square$ Fall $1997 \square$ Fall 1999

SOURCE: Information gathered during visits to the Early Head Start research programs in the fall of 1997 and fall 1999. 
The research programs are distributed fairly evenly across all major regions of the country and across rural and urban areas. Six programs are located in western states (California, Washington, Colorado, and Utah). Four are in midwestern states (Iowa, Kansas, Michigan, and Missouri). Four are in northeastern or Middle Atlantic states (New York, Pennsylvania, Vermont, and Virginia). Three are in southern states (Arkansas, South Carolina, and Tennessee).

\section{Early Head Start Research Programs}

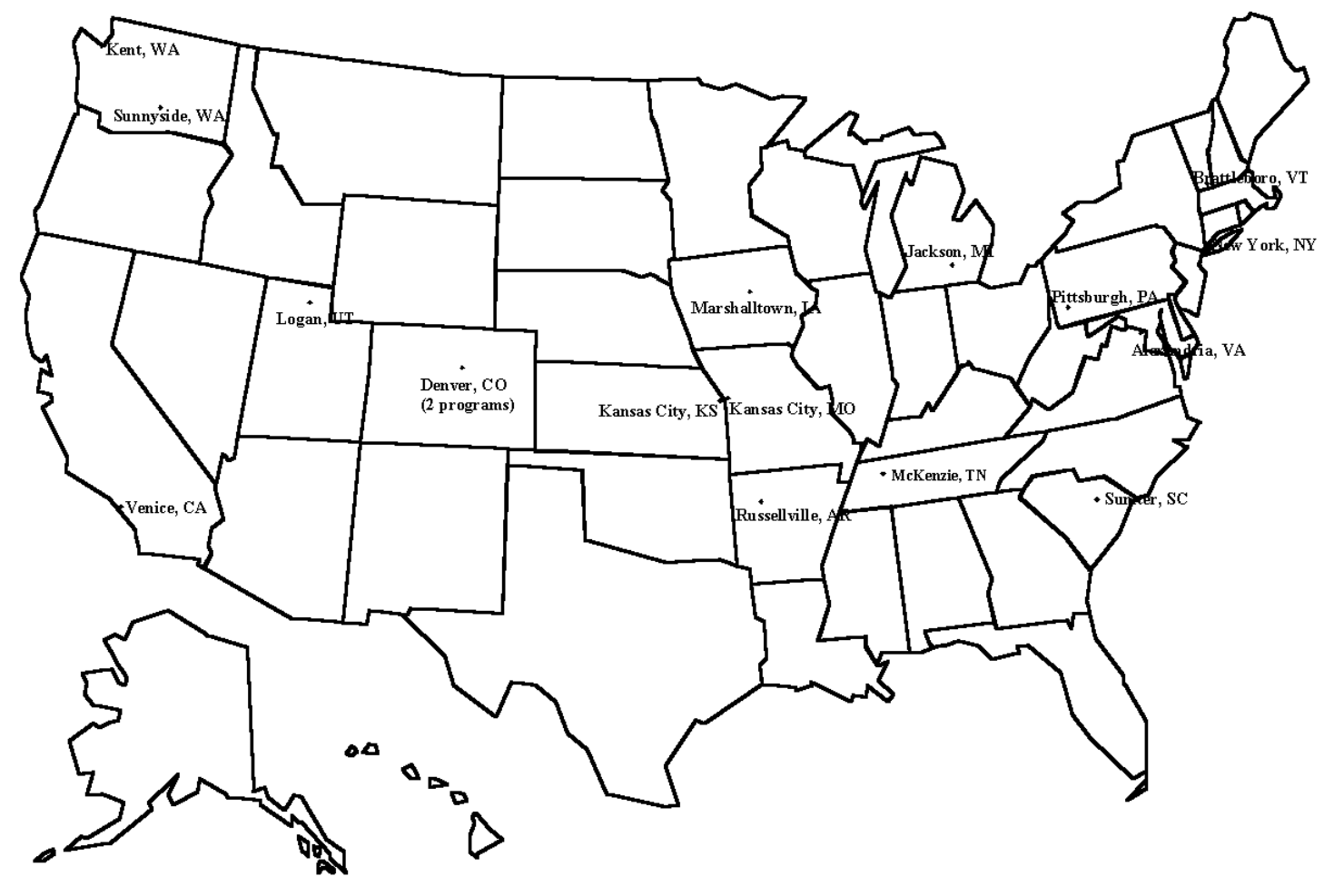

About half (eight) of the Early Head Start research programs are in urban areas, and the other half are in small towns or rural areas. Two programs have sites in both rural/small town and urban/suburban areas. Both the rural and the urban groups include a mix of home-based, center-based, and mixed-approach programs. 
Some of the Early Head Start research programs provided services in more than one site. Most home-based programs were based in one central place, but two served several communities and had multiple offices. Most of the center-based and mixed-approach programs operated a number of centers. Three of the nine programs operated two centers, three operated three centers, and one operated six centers. The programs that operated three or more centers tended to be in rural areas and to serve families in more than one county.

The vitality of the economies varies in the areas the Early Head Start research programs serve. Many of the programs operate in areas where the unemployment rate was 5 percent or higher in 1995, but seven programs are located where unemployment was lower. In four of the areas with relatively high unemployment rates, program staff members described job or job training opportunities as inadequate. By 1998, the unemployment rate in the United States had fallen to 4.5 percent (from 5.6 percent in 1995), and rates in most of the areas where the programs operate also fell below 5 percent. Four programs, however, served families in areas where the unemployment rate was between 5.5 and 10.2 percent.

Although a few of the programs described their communities as "service-rich," all of them identified some areas in which services for low-income families were inadequate. All except one program reported that the supply of affordable high-quality child care in their community was inadequate to meet the demand, at least for infants, toddlers, and children with special needs. Thirteen of the programs indicated that their community lacked sufficient affordable housing, and ten also reported that public transportation was lacking or inadequate. Smaller numbers of programs noted that health care, mental health care, or dental services were inadequate. According to staff members in several of the programs, even where services are available, some families encounter barriers, such as lack of information about the services and how to get them, eligibility criteria that exclude the working poor, language barriers, unwillingness or inability to 
seek services because of the time and commitment required, mistrust or fear of the "system," fear of stigma, and lack of confidence and experience in seeking services. Lack of transportation also deters some families from seeking other available services.

\section{B. SALIENT FEATURES OF EARLY HEAD START RESEARCH PROGRAMS IN 1999 AND THEIR KEY DEVELOPMENTS OVER TIME}

Over time, some research programs made fundamental changes in their approaches to serving families, and others made significant changes without altering their basic approach. In this section, we describe the key features of each program in 1999 and summarize the major developmental milestones each achieved since receiving Early Head Start funding. We describe (1) center-based programs that remained center-based, (2) home-based programs that remained home-based, (3) mixed programs that stayed mixed, and (4) home-based programs that became mixed.

\section{Center-Based Programs—-that Remained Center-Based}

We begin with the four center-based programs, which were among the five initially funded to implement center-based child development services and continued with this approach through 1999. Even while continuing to provide center-based services, however, these programs were not static. These programs (all of which provided full-day, week-day, full-year services, with at least two home visits per year) were a diverse group. Child Development, Inc. in Arkansas expanded services into additional counties; Educational Alliance in New York City began as a half-day program and expanded to a full-day program; Colorado's Family Star program made a number of changes to promote quality and continuity of care and to expand services; and Northwest Tennessee Early Head Start, among other changes, began closer collaboration with welfare-to-work case managers. 
Child Development, Inc. Early Head Start (Russellville, Arkansas). Child Development, Inc., a community-based organization that operates both center-based and home-based child development programs, including Head Start, operates an Early Head Start program for 108 families in centers in six rural Arkansas counties. The program serves mostly white, workingpoor families, most of which are headed by a single parent. The program provides full-year, fulltime child development services in its centers and offers parent training and case management in group sessions, during home visits, and in one-on-one sessions at the centers. When they enroll in the program, parents must agree to spend two hours a week on developmentally appropriate activities with their child. The program helps parents who need it obtain child care before or after Early Head Start in the grantee's centers and obtain state child care vouchers to pay for it. Families who cannot obtain vouchers receive priority for extended-hours slots in Early Head Start classrooms. Child development services are based on the premise that children should lead by expressing their needs and interests and that staff should be there to support them.

Between 1997 and 1999, the program received new grants to expand the number of children it can serve in Early Head Start from 45 to 108 families, and the program opened new Early Head Start centers in three additional counties. To accomplish this expansion, the program hired new staff and changed the supervisory structure. The program also strengthened staff development by providing financial support to staff who are working toward their associate's degrees and by implementing a new salary scale that will increase the pay of teachers with degrees. In addition to expanding services to more families, the program also increased the range of physical and mental health services it offers to children and families, and it began offering services for extended hours to a few children in three of the centers. Four of the six Early Head Start centers had received NAEYC accreditation by fall 1999, and the two remaining centers were expected to receive accreditation in spring 2000.

Family Star Early Head Start (Denver, Colorado). Family Star, which operates a Montessori school for infants and toddlers, operates an Early Head Start program for 75 families at two centers in northeast and northwest Denver. Many families served by the program are Latino and speak Spanish. The program provides full-year, full-time child development services in Family Star's Montessori school while parents are working or in school and offers monthly parent education meetings and semiannual home visits. Program services are child-centered, and staff members speak both Spanish and English with the children.

The program made several changes between 1997 and 1999. It reduced the maximum group sizes in all classrooms to meet the revised Head Start Program Performance Standards. To promote continuity of care, the program created a classroom in which the directress stays with the children as their classroom is transformed from a Nido (classroom for infants up to 14 months old) to an Infant Community (classroom for children older than 14 months). To facilitate transitions out of Early Head Start, the program received a waiver from the school district to allow all children in the research sample to attend the city's Montessori magnet school through the eighth grade. The staff continues to work on transition plans for other children. The program now requires eligible families to apply for state child care subsidies to offset a portion of the costs of operating the school. In addition, it expanded participation in the Child and Adult Care Food Program to provide breakfast and a snack for children during the school day. The program hired a mental health coordinator to work with staff and provide services to families and children. 
Educational Alliance Early Head Start (New York, New York). The Educational Alliance, a community-based organization that began as a settlement house and now provides many services, including Head Start and child care, in New York City, operates an Early Head Start program for 75 families in three centers. One center is located at the Educational Alliance headquarters, and two are in schools for pregnant and parenting teenagers. The families served by the program are ethnically diverse, predominantly single-parent families, about one-third of whom receive welfare cash assistance. The program emphasizes the development of supportive relationships and mental health, and in addition to center-based child development services, provides families with psychotherapy services. Families have access to employment-related and other support services provided by the Educational Alliance.

The program experienced several major changes between 1997 and 1999. Because of philosophical differences, it dissolved its partnership with a residential program for pregnant and parenting substance-abusing women and developed a new partnership with a second school for pregnant and parenting teenagers. The program received an expansion grant to extend its child care hours at the Educational Alliance site to full-time ( 37.5 hours per week), so that it can better meet families' child care needs. The original program director left and was replaced in fall 1999.

Northwest Tennessee Early Head Start (Jackson, Tennessee). Northwest Tennessee Head Start, a program of the Northwest Tennessee Economic Development Council, operates an Early Head Start program for 75 families in child development centers located in five rural Tennessee counties and in the town of Jackson. The program serves mostly African American, single-parent families who are receiving welfare cash assistance. Many parents are teenagers who live at home with their own mothers. The Early Head Start centers provide full-day, fullyear child care and parent-training activities. Program staff also provide family development services and referrals designed to help families achieve self-sufficiency, and they focus on arranging health and developmental screening and treatment services for Early Head Start children. The program focuses on providing developmentally appropriate, responsive care in a nurturing environment.

Since it began serving families in fall 1997, the program has increased its focus on health and development by providing frequent opportunities for comprehensive health and developmental screening and by advocating intensively for improved Medicaid services for infants and toddlers. Program staff also began collaborating more closely with welfare-to-work program case managers. Because there was no early childhood degree program nearby, the program worked with several local colleges to create an appropriate program so teachers can begin working toward their associate's degree. Early Head Start classrooms in four centers received NAEYC accreditation in 1998. The program's original director left and was replaced in fall 1998.

\section{Home-Based Programs that Remained Home-Based}

Two research programs that were initially funded as home-based programs continued to provide home-based services to all families through fall 1999. While continuing their efforts to complete weekly home visits and offer at least two group socializations per month, they 
extended their efforts to support families' use of high-quality child care. In Pittsburgh, Pennsylvania, Family Foundations Early Head Start remained home-based while beginning an initiative to improve the quality of child care used by its families. In Logan, Utah, Bear River Early Head Start, in its effort to improve quality and meet the performance standards, made significant refinements in its approach to enhancing parent-child relationships and began providing respite care in a small on-site center, but retained its basic home-based approach.

Family Foundations Early Head Start (Pittsburgh, Pennsylvania). The University of Pittsburgh's Office of Child Development operates an Early Head Start program for 140 families in four centers in three diverse communities in the Pittsburgh area. Across the four centers, the program serves mainly African American and white families headed by single parents, twothirds of whom were receiving welfare cash assistance when they enrolled in the program. The centers provide services to families in home visits: family advocates visit families weekly to address child development issues, and family development specialists visit families biweekly to work with them on their goals and link them with community services. Staff members organize group activities for parents and families at each center. The program also works with child care providers to develop individual quality enhancement plans and visits providers (mostly family child care providers) to work with them on implementing the plans. Child development services focus on working with parents to improve their interactions with their children and in fall 1999 were beginning to focus on working with child care providers to enhance the quality of care they provide to Early Head Start children.

Between 1997 and 1999, the Family Foundations Early Head Start program, a former Comprehensive Child Development Program, decided to continue providing home-based services but enhanced its focus on the child and began a new initiative to improve the quality of child care arrangements used by Early Head Start families. The program restructured the staff and created a new staff training curriculum to ensure that staff are knowledgeable about child development and focus on it in all home visits (including family development visits). The program also began working with centers and family child care providers to improve quality.

To illustrate this process in greater detail, Carol McAllister, a local research partner with the Pittsburgh Early Head Start program, describes the program's evolution to having a greater focus on child development while remaining home-based (see box on the following page). Through self-examination, the program modified its emphasis without altering its basic home-based approach.

Bear River Early Head Start (Logan, Utah). The Bear River Head Start agency operates an Early Head Start program for 75 families in three rural counties in northern Utah and southern Idaho. The program serves primarily white, two-parent, working-poor families. The program provides child and family development services primarily in weekly home visits and weekly Baby Buddy groups for parents and children. The program also offers respite and drop-in child care in its on-site center, and program staff are trying to improve the quality of child care by 


\section{Child-Focused Practice in the Pittsburgh Early Head Start Program: A Process of Culture Change \\ Carol L. McAllister \\ University of Pittsburgh}

The development of a strong child focus, a major goal of the Pittsburgh Early Head Start program, entailed a reorientation of both thinking and practice from the program's former status as a Comprehensive Child Development Program. The process began with a change in the basic approach to families, which came to be viewed as consisting of concentric circles with the young child in the center, surrounded by parents, older siblings, and extended family. The child became the focus, with the idea that work with the family should be aimed at supporting and guiding the child's development. A creative reinterpretation resulted in an orientation toward community change that was directed by the ultimate goal of supporting the life and development of young children.

This change in perspective was followed by a recasting of the program's basic operating principles to support a strengthened child-focus. This transformation was affected by (1) local implementation of the revised national Head Start Performance Standards; and (2) the changing context of family lives, particularly under welfare reform, the increase in wage work by Early Head Start parents, and the expanded use of out-of-home child care.

In fall 1997, staff questioned the program's home-visiting model and seriously considered developing a center-based model or moving to a mixed approach. After much discussion, they opted to keep the home-visiting model but to adapt it to "follow the child" more closely. This decision was based in large part on a reaffirmation of core program beliefs, that is, that parents are the most important influences in a child's life, that the parent-child relationship is key to the healthy development of the child, and that, therefore, all program interventions should "go through" or involve the parent and focus on supporting and strengthening the parent-child relationship.

Over time, three strands of activity contributed to the evolution of child-focused practice. The first was ongoing work, involving all Early Head Start staff, in developing the local practices that would address and implement the national Head Start Program Performance Standards. Second was the development and implementation of extensive staff training to increase the knowledge of all program staff in the areas of child development, developmentally appropriate practice, child and parent health, and parenting education. Third, the program's theory of change was revisited several times. Facilitated by the collaboration of program administrators and researchers, attempts were made to use the theory-of-change framework to reexamine and further elaborate (1) goals, especially for children; (2) pathways to goals; and (3) practices that addressed various goals or that needed to be newly created to meet goals. Most significant in terms of the last were the adoption of the PIPE curriculum as an informal guide to "real-time parenting" education, and a change in approach to out-of-home child care.

Program discussions and decisions about child care were very significant. While there were some differences of opinion, the strongest voices opposed the promotion of out-of-home child care for infants and toddlers. However, this critical perspective was counterbalanced by the reality of family lives, especially as time limits and work requirements of welfare reform increasingly shaped family options and choices. Out of this discussion emerged a commitment to ensure the best quality and continuity of out-of-home child care when a family needed it. The result was an innovative child care intervention plan that would (1) partner with formal child care programs attended by Early Head Start children to provide resources, training, and Early Head Start staff support for quality improvement; (2) provide encouragement, guidance, and support (especially transportation) to Early Head Start families to choose quality child care programs; (3) institute a form of home visiting for relatives and neighbors who were providing the most common form of care for the children; and (4) use all these to support and strengthen caregiver-child and caregiver-parent relationships.

Each of these program developments entailed changes in the conceptual perspective, knowledge base, and practice of individual direct-service staff. The specific changes depended on staff role. All home-visiting staff are now required to obtain a CDA or equivalent educational experience. New staff must now have formal training in child development. Job descriptions have been rewritten and salary scales adjusted to reflect new responsibilities and expectations. Perhaps most significant is the expectation that all staff will focus on the ultimate goal of child health and development, whether their particular role entailed working primarily with parents and children together or with adult family members on family or community issues or program governance. At the end of the research period reflected in this report, child-focused thinking and practice had been well integrated into the work of the staff, and efforts were under way to help families understand and embrace this approach more fully. 
visiting family child care and relative care settings of program children twice a year. Staff members work to foster positive parent-child interactions and increase parents' understanding of their children's development. They also work with parents to help them achieve their personal and family goals and link them with services in the community.

From 1997 to 1999, the program refined its focus on improving parent-child relationships, infant-parent play interactions, and parental knowledge of child development by adding several child development staff positions, improving home visitor training based on reviews of videotapes of home visits, focusing group activities on parent-child interactions, and providing child development services in its on-site respite center. To encourage active participation in the program, staff members have begun scheduling more home visits on weekends and in the evenings, as well as offering special incentives to families who complete Individual Family Partnership Agreements and volunteer in program activities. The program has also begun emphasizing involvement of fathers and father figures.

\section{Mixed-Approach Programs that Remained Mixed}

Six of the seven programs that planned a mixed approach to service delivery at the time of funding were still operating as mixed-approach programs in 1997 and continued to take such an approach in 1999, while continuing to evolve. They served some families in center-based settings and some through the home-based option; in addition, they provided some families with both center- and home-based services, either at the same time or at different times as families' needs changed. The Clayton/Mile High Family Futures program in Denver significantly expanded service options; Project EAGLE, in Kansas City, Kansas, obtained state funding to boost its ability to provide child care assistance; Sumter (South Carolina) School District 17 Early Head Start expanded its child care options while strengthening the child development focus of its home visits; Early Education Services Early Head Start, in Brattleboro, Vermont, increased the home-visit time spent on parent-child activities and took formal steps to ensure the child care providers met the revised Head Start Program Performance Standards; the United Cerebral Palsy program in Alexandria, Virginia, improved collaborations with the child care licensing office; and the Children's Home Society of Kent, Washington, added child care classrooms. 
Clayton/Mile High Family Futures, Inc., Early Head Start (Denver, Colorado). Clayton/ Mile High Family Futures, Inc., a partnership between a foundation and a child care resource and referral agency that operates a Head Start program, is operating an Early Head Start program for 123 families in Denver. The program serves low-income families from diverse racial and ethnic backgrounds. It provides child and family development services in four ways, depending on family needs and preferences: (1) in weekly home visits, when children are not in licensed child care; (2) in weekly visits, two in the home and two at the child care center, when children are enrolled in licensed child care centers in the community; (3) through full-year, fulltime Early Head Start center-based child development services and monthly visits, alternating between the home and the center; and (4) through child care in a contracted center and two visits monthly, one in the home and one at the center. Child development services focus on improving parent-child relationships and helping parents meet their children's needs.

From 1997 to 1999, the program changed dramatically. Soon after it received Early Head Start funding, many staff members who had been with the program when it was a Comprehensive Child Development Program, including the director, left and were replaced. To meet the revised Head Start Program Performance Standards, the new staff increased the intensity of services offered, expanded the service options to meet families' needs better, and strengthened the child focus in program services. The program began requiring eligible families with children enrolled in the Early Head Start center to apply for state child care subsidies to offset the cost of care, which freed resources and enabled the program to improve other services. The program also began tracking services more carefully and added a "continuous improvement" researcher to its staff to help the administrative team monitor progress toward goals and targeted outcomes. The Early Head Start center received NAEYC accreditation in 1999.

The flow chart on the next page was created by Chris Sciarrino and Rebecca Soden, of the Clayton Mile High Early Head Start program, to trace the program's evolution back to its "roots" in CCDP. It shows how this mixed-approach program remained "mixed" while increasing in intensity and developing its vision, questions, and expected outcomes.

Project EAGLE Early Head Start (Kansas City, Kansas). The University of Kansas Medical Center's Child Development Unit operates an Early Head Start Program, called Project EAGLE, for 160 families in Kansas City, Kansas. The program serves ethnically diverse families, half of which were receiving welfare cash assistance when they enrolled. Program staff members provide child and family development services in two ways: (1) through weekly home visits or (2) through full-day, full-year child care in a center or family child care home that meets the revised Head Start Program Performance Standards, plus biweekly home visits (for families in which the primary caregiver is working or attending school or for families whose child is at risk or whose situation places program staff at risk). The program has established collaborative agreements with several child care centers and family child care providers in the area to provide care for Project EAGLE children, and program staff provide ongoing training and technical assistance to center staff members and the family child care providers to ensure that Project EAGLE children receive high-quality child care. The child development services are designed to increase parents' responsiveness to their children, engage them in their children's development, and empower them to obtain the formal and social supports they need to create a better environment for their child. 


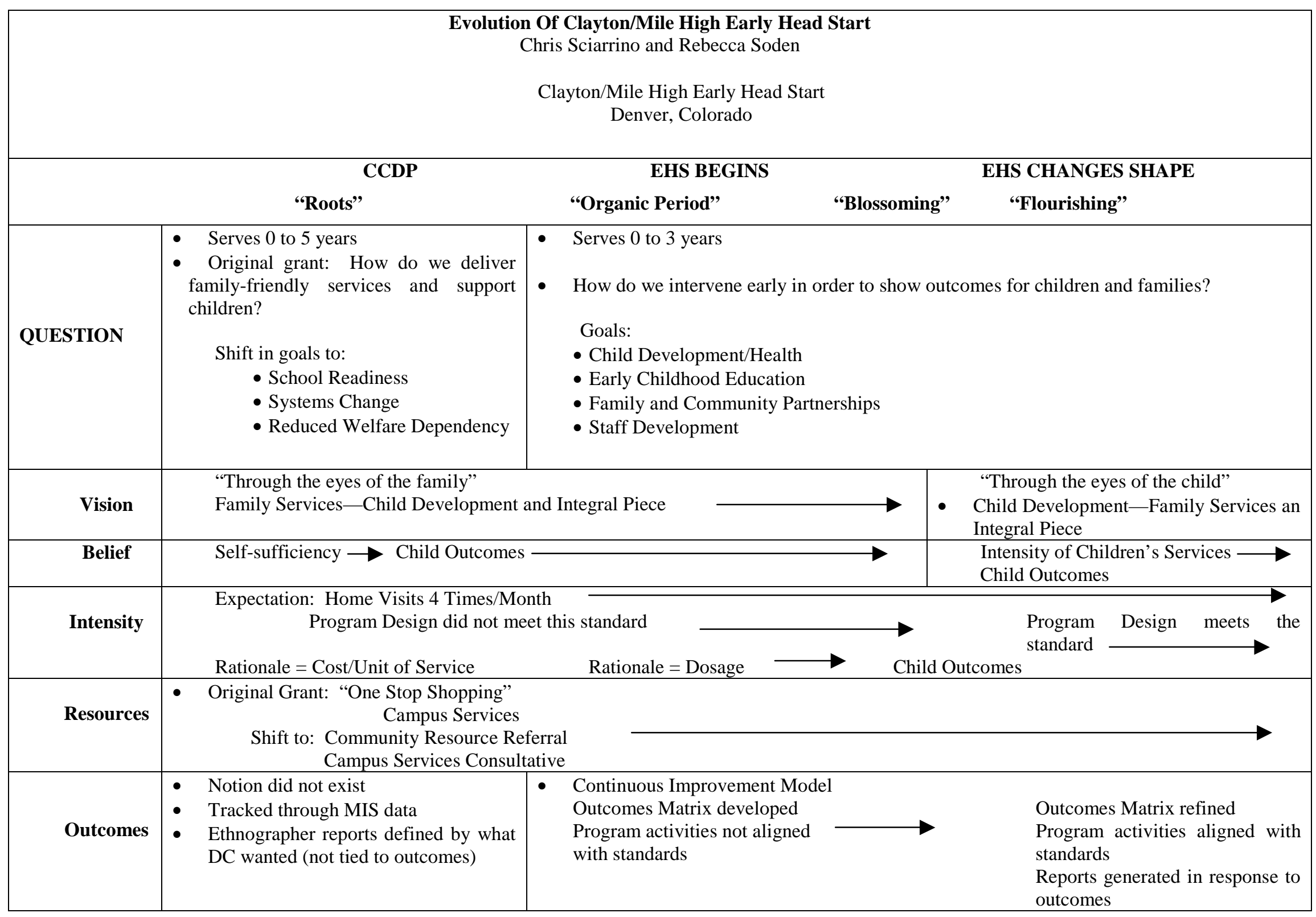


From 1997 to 1999, the program received state funds to serve more families and to add staff. The program also obtained state funding to pay for child care, so it no longer has to rely primarily on state child care subsidies for individual families and has more flexibility to provide child care assistance during changes in employment (when families may lose their eligibility for state subsidies). The program also developed and implemented a best-practices tool designed to help home visitors see themselves as agents of change, improve service quality, and make services more consistent across caseloads. The program has formed new partnerships with child care providers and is investing more resources into staff training to promote higher-quality child care. The diagram on the next page illustrates the service model for Project EAGLE. It depicts the mixed program's model of services in fall 1999, with the multiple service options that have evolved to meet the diverse needs of families.

Sumter School District 17 Early Head Start (Sumter, South Carolina). School District 17 in Sumter, South Carolina, operates an Early Head Start program for 75 families. It provides full-year, full-time center- or home-based child development services to pregnant and parenting primary and secondary school-age students and young high school graduates who are employed. Most of the parents in the program are African American teenagers. Parent educators conduct weekly home visits with families whose children are not enrolled in the centers and less-frequent home visits with other families to work with them on parenting and child development, help them identify their needs and goals, and link them to services in the community. Child development services focus on (1) teaching parents to take responsibility for themselves and their children, (2) teaching them how to obtain the resources they need to be better parents, and (3) providing high-quality child care that is child-centered, child-directed, and adult-supported.

From 1997 to 1999, the Sumter Early Head Start program reorganized its staff to ensure a stronger focus on child development in home-based services. The program also began contracting with a community child care center to provide Early Head Start care to up to eight children, and through that relationship is working to improve the quality of child care in the community. The program's relationship with the Part $\mathrm{C}$ agency has improved as staff members have worked with Part $\mathrm{C}$ service providers in center classrooms and learned about caring for children with disabilities. The program has increased its visibility and acceptance in the community.

Early Education Services Early Head Start (Brattleboro, Vermont). The Brattleboro, Vermont, school district's Early Education Services office operates an Early Head Start program for 107 families in rural Windham County. The program serves primarily white families, half of which include both parents. The program provides child and family development services, primarily in home visits. It also provides full-year, full-time center-based child development services for a small number of families and brokers child care for 20 children in family child care homes and center-based settings in the community. After the first year, the program often reduces the number of home visits to two per month and adds two visits per month to the center where the child is receiving care. The program also organizes play groups and monthly parentchild group activities. Teams of staff members work with families to build on their strengths and achieve their personal and family goals, and they link families with needed services in the community. Child development services are designed to promote strong parent-child relationships and positive interactions. 


\section{Project EAGLE Early Head Start/Head Start Program Options}

Martha Staker

Project EAGLE Early Head Start

Kansas City, Kansas

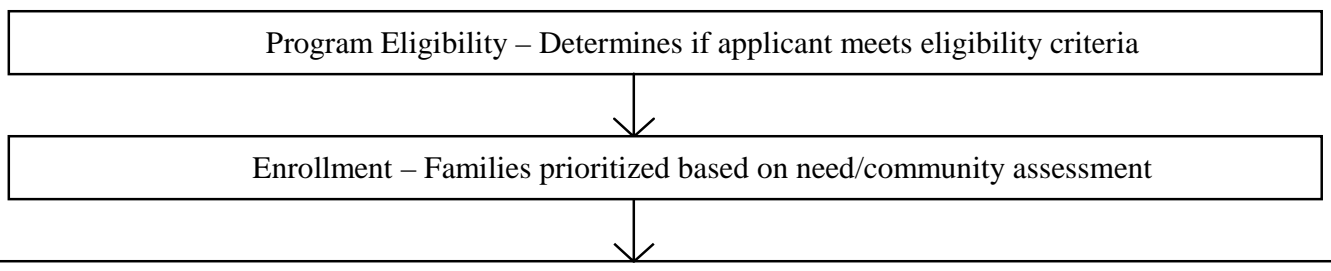

12-Week Orientation Period - The partnership and assessment process results in the family selecting the program option

\section{Option \#1 Home Based Services}

\section{Who is eligible:}

- All families enrolled in Project EAGLE.

- Primary caregiver has a willingness to meet weekly and is capable of learning, modeling, and nurturing infant/child.

- Infant/toddler appears to be thriving in a safe and nurturing environment.

Frequency of services:

- Family support advocate makes weekly home visits and engages all family members in program. that best meets their family needs/situation

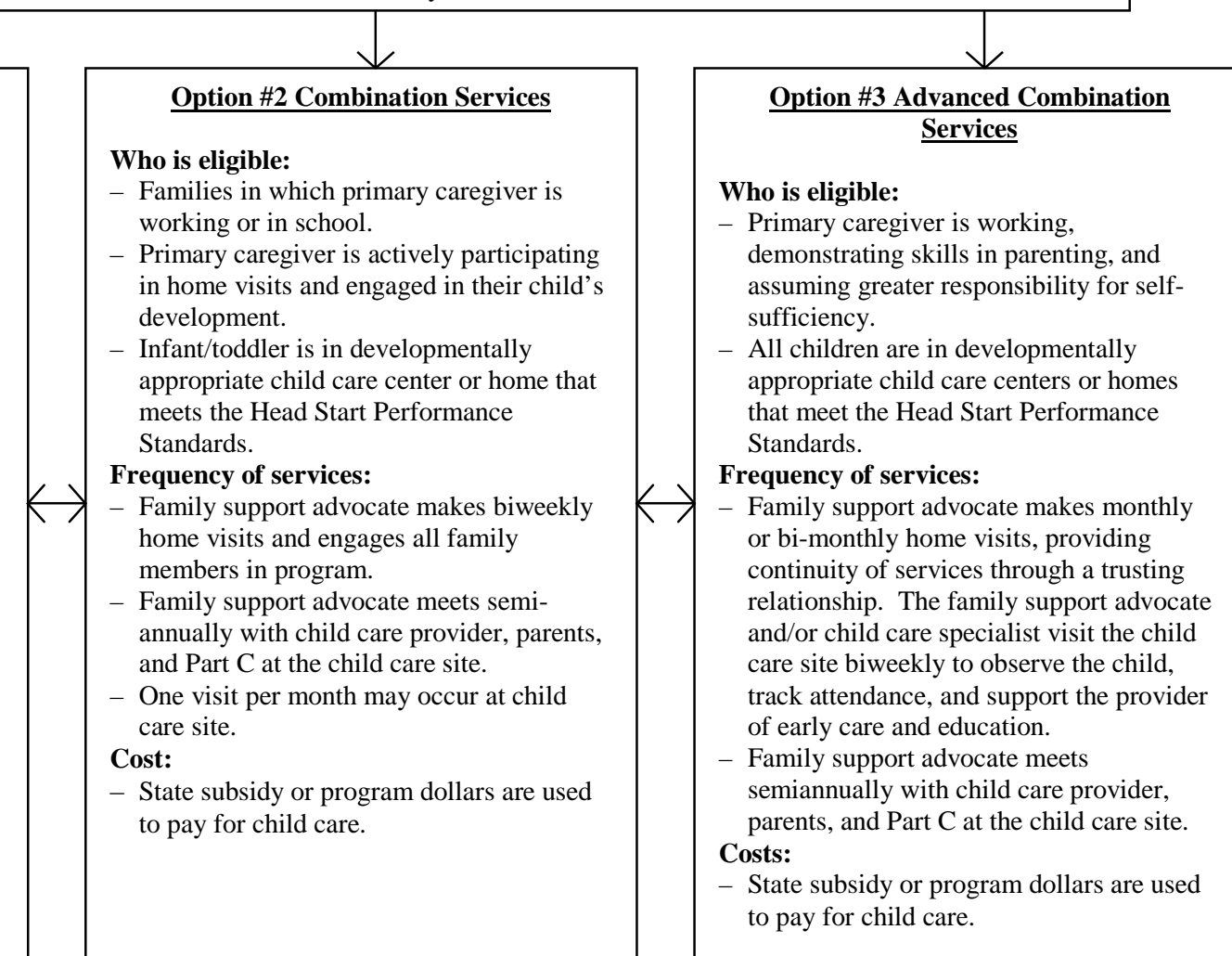


From 1997 to 1999, the program, a former Comprehensive Child Development Program, increased its child focus by spending more time during home visits on parent-child activities and sponsoring a community college course in child development, in which staff and participants receive priority in enrollment. The program also took on direct responsibility for developing written agreements with licensed child care providers to care for Early Head Start children. In these agreements, the providers agree to adhere to the relevant portions of the revised Head Start Program Performance Standards, and the program agrees to supplement subsidy rates when needed and provides materials and equipment as necessary. During the past three years, Early Education Services also became a Head Start grantee and worked toward providing continuous, seamless services to children from birth through age 5. The director took a leave of absence, returned for a year, and then left permanently.

United Cerebral Palsy Early Head Start (Alexandria, Virginia). United Cerebral Palsy of Washington, DC, and Northern Virginia operates an Early Head Start program with a special emphasis on children with disabilities for 75 families in Fairfax County, Virginia. The program serves an extremely diverse group of working-poor families, including military families. Many are immigrants who do not speak English or do not speak it well. The Early Head Start program provides child development services to some families full-time in a child care center, some families full-time in family child care, and some families in weekly home visits. Families with children enrolled in the child care center or in family child care receive family development services in monthly home visits. Families are also invited to group socialization activities three times a month. The program provides inclusive services to children with disabilities and works to foster inclusive services for all children in the community.

From 1997 to 1999, the program developed collaborations with new community partners and improved its collaborations with the county child care licensing office and Part C and Part B service providers. The program also enhanced child development services by maintaining portfolios for each child in the center, increasing the frequency of group socializations and providing transportation to them, and adding an additional child development assessment tool. The original program director left and was replaced in late summer 1999.

The Children's Home Society of Washington-Families First Early Head (Kent, Washington). The Children's Home Society of Washington operates the Families First Early Head Start program for 120 families in South King County. The Early Head Start program builds on the agency's experience as a child welfare agency and as a former Comprehensive Child Development Program. The program serves diverse families, half of which were receiving welfare cash assistance when they enrolled. It provides child and family development services in three ways: (1) through weekly home visits and biweekly group socializations; (2) in Early Head Start classrooms in full-year, full-time child care centers operated by the Children's Home Society, with monthly home visits and bimonthly group socializations; and (3) through a combination of services, either (a) in two home visits and two child care visits per month, or (b) in child-parent/parenting classes for 12 hours per week plus monthly home visits. All families also receive monthly home visits from a public health nurse. Child development services focus on building supportive relationships, especially between parents and children.

From 1997 to 1999, the Families First Early Head Start program expanded case management services and increased its emphasis on mental health. It also added child care classrooms and 
added new group socialization activities. The program has experienced considerable staff turnover, including two directors, although the original director still works for the Children's Home Society and provides some oversight. To increase staff retention and improve services, the program increased salaries, added more case management staff, and formed a support group for frontline staff.

\section{Home-Based Programs that Became Mixed-Approach Programs}

Five of the programs that were funded as home-based programs continued in this approach in 1997, but expanded the service options they offered to families so that by 1999 they were mixed-approach programs: (1) the Venice Family Clinic Children First Early Head Start, in Venice, California, increased home visitors' focus on parent-child relationships and child development and began paying for and supporting the quality of child care used by some families; (2) Mid-Iowa Community Action, in Marshalltown, Iowa, took on greater responsibility for helping families find child care and began conducting visits with child care providers; (3) Community Action Agency Early Head Start, in Jackson, Michigan, added a child care center to serve some of its families; (4) KCMC Early Head Start, in Kansas City, Missouri, began working with community partners to improve community child care and visiting children in their child care settings; and (5) the Washington State Migrant Council's Early Head Start program, in Yakima Valley, Washington, began offering center-based services at one of its sites.

Venice Family Clinic Children First Early Head Start (Venice, California). The Venice Family Clinic, a private, community health clinic that has provided health care to low-income families for many years, operates the Children First Early Head Start program for 100 families in the Venice area. The program, which serves primarily Hispanic families, provides child and family development services to most families in weekly home visits and biweekly group socialization activities. The program refers families who need child care to a state-funded resource and referral agency that screens providers, makes referrals, and monitors quality. In addition, the program now funds child care for 15 children whose families cannot afford it. Providers who care for these children must sign a contract that requires them to meet many Head Start Program Performance Standards. Families receiving program-funded child care receive child and family development services in a combination of home and child care visits and in biweekly group socialization activities. The child development services focus on strengthening parents' and caregivers' relationships with children through instruction and modeling. 
From 1997 to 1999, the program strengthened its focus on child development by hiring new staff with child development and early intervention expertise and by strengthening the training and supervision of home visitors. These changes have helped home visitors focus consistently on parent-child relationships and child development. The program also increased its focus on child care quality by funding some child care and requiring funded providers to make improvements, get ongoing training, and meet standards. All these changes have resulted in part from suggestions by Head Start Bureau monitors and from a self-assessment in which small workgroups of staff and parents addressed various program issues. In fall 1999, the program director, who had been with the program since its days as a Comprehensive Child Development Program, left and was replaced.

Mid-Iowa Community Action, Inc. Early Head Start (Marshalltown, Iowa). Mid-Iowa Community Action, Inc., a community-based organization that has provided services (including a Head Start program) to low-income families for 24 years, operates an Early Head Start program for 75 families in five rural counties in central Iowa. The families are primarily white, and many are two-parent households. The program provides child development services in weekly home visits (or home and child care visits) and family development services in separate biweekly home visits. The program also holds monthly parent meetings in each county. The child development services focus on strengthening parents' skills and abilities as their children's first teachers.

From 1997 to 1999, the program, which is a former Comprehensive Child Development Program, made a number of changes to meet families' increasing needs for child care in the wake of welfare reform. Home visitors became responsible for helping parents find child care, and child development home visitors now conduct two visits per month in the child care setting and two per month at home for families using child care. The program also began offering training and materials to community child care providers to help improve child care quality. Staff members are planning to add center-based child care services for eight children. Responsibility for program management became more decentralized, and county directors now oversee all county office activities, including collaboration and fundraising.

Community Action Agency Early Head Start (Jackson, Michigan). Community Action Agency, a community-based organization with more than 30 years of experience (some as a Head Start grantee) serving low-income families, operates an Early Head Start program for 95 families in Jackson and Hillsdale counties. The Early Head Start program builds on the agency's infant mental health program. The families in the program are mostly white, single-parent families. The program provides child and family development services primarily in weekly home visits by registered social workers and monthly play groups for parents and children. Home visitors work extensively with parents on their problems in order to enable them to be better parents. The program also provides full-year, full-day child care for 8 infants and toddlers in a center in the city of Jackson, and planned to increase the size of the center to 16 children in 2000 .

The program changed significantly between 1997 and 1999. Following a monitoring visit by the Head Start Bureau, the program intensified its focus on child development by increasing the amount of home visit time devoted to the child and by bringing learning materials to visits more often. To improve the quality of child care, the program provides some center-based care 
directly and convenes monthly meetings of child care providers to discuss developmentally appropriate practices. Along with Head Start, the Early Head Start program is a key part of the agency's 0 to 5 focus and its efforts to promote family self-sufficiency.

KCMC Early Head Start (Kansas City, Missouri). KCMC Child Development Corporation, a community-based organization that provides child care and Head Start services to low-income families, operates an Early Head Start program for 75 families in the poorest neighborhoods of Kansas City. The Early Head Start program serves primarily African American, single, teenage parents, two-fifths of whom were receiving welfare cash assistance when they enrolled. The program provides child and family development services in three ways: (1) through weekly home visits; (2) through monthly home visits and monthly child care visits, for children enrolled in licensed child care centers; and (3) through one to two home visits and one to two child care visits for families whose children are in a family child care setting in which the provider has agreed to work with the program on quality improvement. The program also offers several group socialization opportunities for parents and children each month. Child development services focus on establishing and supporting parent-child relationships and working with parents to support their children's development.

From 1997 to 1999, KCMC Early Head Start made several changes to strengthen its focus on child development. The program entered a partnership with a child care center to provide center-based services for some children. Following a Head Start Bureau monitoring visit, and after a new program director assumed leadership in early 1997, program staff took responsibility for child development home visits (previously, a program partner was responsible) and received significant training in child development to enable them to do so. Home visitors also began to develop individual child development plans with families. The program hired a child development coordinator to serve as a resource, consultant, and trainer in the areas of prenatal health and education, child health and development, disabilities/special needs, and transitions. In summer 1999, KCMC received a state grant to work with community partners on improving the quality of child care in the community.

Washington State Migrant Council Early Head Start (Yakima Valley, Washington). The Washington State Migrant Council, the largest Hispanic-operated and Hispanic-serving organization in the Northwest, operates a Migrant Head Start program as well as Early Head Start for 75 intrastate and former migrant families ${ }^{2}$ in six small towns in Yakima County. The program serves many first-generation Mexican Americans who migrated to Washington to work on farms. Many speak only Spanish. The program provides child and family development services primarily in weekly home visits and group activities for parents and children. Child development services focus on establishing supportive relationships and enhancing the social and verbal contexts for early childhood development. The program celebrates families' Mexican American heritage and culture and emphasizes sensitivity to families' concerns with acculturation.

${ }^{2}$ These families are those who stay within the state or who have "settled out" and no longer migrate across state lines. 
From 1997 to 1999, the program increased the frequency of home visits to meet the revised Head Start Program Performance Standards that took effect in January 1998, and opened a child care center to provide center-based services in one of its sites, extending services to Native American families as well as to the Hispanic population. It also increased its emphasis on mental health by hiring a specialist both to work directly with families and to improve staff's understanding of mental health issues. The program has increased outreach to fathers and worked to make program activities more appealing to them. The program experienced two changes in directors during the three years of program enrollment.

\section{THEMES OF CHANGE}

A number of themes characterize the changes we observed in programs approaches to service delivery. In this section, we describe themes related to the reasons changes in program approaches were made. These include changes in families' needs, the need to improve the fit between program services and family needs, increasing clarity of expectations, and program responses to monitoring and technical assistance. We also describe several themes related to the kind of changes programs made. To navigate changes in their approaches to service delivery, programs often needed to make changes in their approach to improving child care quality for program children, expectations for program staff, and relationships with child care providers.

Changing Family Needs. Between fall 1997 and fall 1999, many families experienced a greater need for child care as their children got older. Parents also responded to TANF work requirements and time limits by participating in education or job training programs and by seeking and obtaining employment. Increasing needs for child care led programs to develop ways of ensuring good quality in the child care arrangements families used. At the same time, in home-based programs parents became less available to meet with home visitors and were less receptive to home visits during evenings and weekends when they were tired or needed to do other things, although home visitors became more flexible in scheduling home visits. In response to these changes in family needs, some programs began offering child care directly, and some programs added the option of visiting children both at home and in their child care setting. 
Increasing Fit of Program Services to Family Needs. Even in sites where families' needs did not change, early experiences demonstrated that some programs' approaches to serving children and families did not always match well with families' needs. Programs learned from these early experiences and made changes to their approaches to better meet families' needs.

Increasing Clarity of Expectations and Goals. During the early years of Early Head Start, the Head Start Bureau clarified many expectations about how this new program should be instituted. The Head Start Bureau approved the new performance standards, provided written guidance, training, and monitoring. In addition, the Head Start Bureau clarified its expectation that programs take responsibility for helping all families who need child care find good-quality child care arrangements that comply with the performance standards. As this requirement became clearer, some of the research programs adjusted their approaches to focus more on child care quality. As Head Start Bureau expectations were clarified, programs also engaged in adjusting and refining their goals and approaches.

Responding to Monitoring and Technical Assistance. Programs often made changes in their approaches in response to feedback and encouragement from Head Start Bureau monitors and training and technical assistance consultants. Sometimes the monitors or consultants suggested specific changes, and sometimes they recommended self-assessment or planning processes that led programs to make changes. Many home-based programs received a clear message from federal project officers that the program needed to become more child-focused. In several cases programs that were once family-support oriented changed to incorporate an explicit child development focus.

Increasing Focus on Improving Child Care Quality for Individual Children. Some programs had previously worked with community collaborative groups and through partnerships with child care resource and referral or other agencies to improve the quality of child care in 
their communities. The changes programs made in their approaches reflected a shift in focus from working on overall child care quality in the community to improving the quality of specific arrangements in which Early Head Start children received care.

Changing Expectations for Program Staff. Changing approaches required substantial effort on the part of staff. Often the change entailed designing new services (such as child development and quality enhancement services to be provided in child care provider visits, or center-based child development services to be offered in a new center). New services created new expectations for program staff families with the former services. Some staff changed from being home visitors to working in centers. Others experienced changes when positions were reconfigured, when supervisory responsibilities changes, or as definitions of their jobs otherwise changed.

\section{Building Relationships and Developing New Partnerships with Community Child Care}

Providers. Many programs built new relationships with child care providers and some established formal partnerships. These new relationships and partnerships were sometimes the reason for change and sometimes the result of it. Most of the Early Head Start programs grew in outreach to the child care community during the period of change we assessed. Programs developed relationships for training, formalized partnerships for meeting the performance standards, visited Early Head Start children in their child care settings, shared information about children's developmental assessments, and worked generally in partnership with the providers on behalf of the child.

Obtaining Additional Resources. When programs added a center-based option, they usually had to obtain additional resources for creating new child development centers and hiring new staff. When programs added child care visits to home visits or began developing partnerships with child care providers, they needed resources to pay for hiring new staff, training 
staff to perform new functions, and providing resources and support to child care providers. The research programs received additional funds from a variety of sources, including expansion grants and quality improvement grants from ACYF, state Early Head Start grants, state child care subsidy funds, and other grants.

\section{SUMMARY}

The discussion in this chapter illustrates that Early Head Start programs experienced many changes during their first three years of serving families. A number of programs changed their main approach to service delivery, while others retained their basic approach but refined it. These changes were not confined to programs in a particular area of the country, or to a particular type of program auspice, but, rather, seemed to be a phenomenon common to all or nearly all programs. In subsequent chapters, we will describe in more detail the implementation issues program faced as they developed. 



\section{PROGRAMS' THEORIES OF CHANGE AND THEIR EVOLUTION OVER TIME}

\section{A. INTRODUCTION}

"Theories of change" are increasingly important in program evaluations (Birckmayer and Weiss 2000; Connell and Kubisch 1998; and Weiss 1995). They provide a way for programs to identify the specific outcomes they expect to achieve and to describe the programmatic strategies and activities that they have designed. Theories of change (sometimes called "logic models") also make it possible for program evaluators, working with program staff, to identify the outcomes that programs expect their services to influence in the various areas they focus on, select ways of measuring these expected outcomes, and plan analyses that will focus on the outcomes that the programs believe to be important. In the Early Head Start evaluation, theories

of change contribute both to our descriptions of the program intentions and processes and planning the analyses of program impacts.

From its very beginning, the Early Head Start evaluation has emphasized the importance of understanding the expected outcomes of the 17 research programs. In 1996, shortly after most of the programs were funded, the national evaluation team began to engage both local researchers and program directors from the research sites in discussions of theories of change. In many sites, research-program discussions continued. We first reported on the programs' expected outcomes in Volume I of Leading the Way: Characteristics and Early Experiences of Selected Early Head Start Programs (ACYF 1999a). That report was based on information from 1997 site visits and 1998 discussions with the 17 program directors. It presented three perspectives on the programs' expected outcomes: (1) all the "important" expected outcomes that programs articulated, as obtained from interviews conducted during fall 1997 sites visits; (2) the program directors' 
reports of the three "highest-priority" outcomes for their programs, obtained in a spring 1998 meeting; and (3) directors' descriptions of a "success story" that exemplified outcomes they had achieved with their children and families.

The theory-of-change discussions presented in Leading the Way described expected outcomes in five areas: (1) parent-child relationships, (2) child development, (3) family development, (4) staff development, and (5) community building. Since spring 1998, theory-ofchange discussions continued among the research-program partners across the sites, and in the summer/fall 1999 site visits, the national team explored any changes in the programs' expected outcomes in these five areas. We acknowledge that the approach taken to describing and understanding programs' expected outcomes contained variability. Participating staff represented different roles across sites and spent varying amounts of time on this activity, both during and between site visits. Site visitors were balancing competing demands and devoted differential attention to obtaining details on their programs' expected outcomes. Finally, the process conducted in 1999 differed somewhat from the way it was conducted in 1997, so the two sets of information are not entirely comparable. In spite of these caveats, however, the Early Head Start evaluation was successful in obtaining extensive information on the expected outcomes of all 17 research programs at different points in time. The information is useful for describing the focus and change in expected outcomes over time, as we do in this chapter.

Table III.1 presents the expected outcomes for each program as described to us in 1997 and 1998 and in 1999. ${ }^{1}$ All important program outcomes are listed in the table, with the ones identified by the programs as priority outcomes at each time point shown in italics. The rest of

\footnotetext{
${ }^{1}$ This table adds the 1999 information to the expected outcomes reported in Table II.6 of Leading the Way, Volume I.
} 
TABLE III.1

OVERVIEW OF KEY OUTCOMES IDENTIFIED BY PROGRAMS IN 1997 AND 1999

\begin{tabular}{|c|c|c|c|c|c|}
\hline Programs & Parent-Child Relationships & Child Development & Family Development & Staff Development ${ }^{b}$ & Community Building ${ }^{\mathrm{b}}$ \\
\hline $\begin{array}{l}\mathrm{A} \\
1997\end{array}$ & $\begin{array}{l}\text { Parental knowledge of child } \\
\text { development } \\
\text { Attachment, knowledge of child } \\
\text { development, and understanding the } \\
\text { parent-child relationship }\end{array}$ & $\begin{array}{l}\text { Cognitive development } \\
\text { Cognitive, language, social- } \\
\text { emotional, physical, approaches } \\
\text { toward learning, and school } \\
\text { readiness }\end{array}$ & $\begin{array}{l}\text { Physical health, mental health } \\
\text { and healthy family } \\
\text { functioning, self-sufficiency, } \\
\text { literacy and education, and } \\
\text { home environment }\end{array}$ & $\begin{array}{l}\text { Improved staff competencies } \\
\text { Staff competencies and } \\
\text { community involvement }\end{array}$ & $\begin{array}{l}\text { Quality of community child } \\
\text { care, quality of other } \\
\text { community services, } \\
\text { coordination of services and } \\
\text { collaboration, and } \\
\text { involvement of parents in the } \\
\text { community }\end{array}$ \\
\hline 1999 & $\begin{array}{l}\text { Enhanced parental competencies } \\
\text { Stronger attachment, enhanced } \\
\text { knowledge of child development, } \\
\text { more understanding of the parent- } \\
\text { child relationship }\end{array}$ & $\begin{array}{l}\text { Enhanced cognitive and } \\
\text { language development } \\
\text { Enhanced social-emotional } \\
\text { development, greater school } \\
\text { readiness, better physical } \\
\text { development, better approaches } \\
\text { toward learning }\end{array}$ & $\begin{array}{l}\text { Better mental health, physical } \\
\text { health, healthier family } \\
\text { functioning, greater self- } \\
\text { sufficiency, increased literacy } \\
\text { and education, and enhanced } \\
\text { home environment }\end{array}$ & $\begin{array}{l}\text { Improved staff competencies } \\
\text { More community involvement }\end{array}$ & $\begin{array}{l}\text { Increased quality of } \\
\text { community child care, } \\
\text { increased quality of other } \\
\text { community services, greater } \\
\text { coordination of services and } \\
\text { collaboration, and more } \\
\text { involvement of parents in the } \\
\text { community }\end{array}$ \\
\hline $\begin{array}{l}\text { B } \\
1997\end{array}$ & $\begin{array}{l}\text { Parent-child relationships } \\
\text { Attachment and knowledge of child } \\
\text { development, }\end{array}$ & $\begin{array}{l}\text { Cognitive, social-emotional, } \\
\text { physical, and school readiness }\end{array}$ & $\begin{array}{l}\text { Mental health } \\
\text { Physical health, mental health } \\
\text { and healthy family } \\
\text { functioning, self-sufficiency, } \\
\text { and home environment }\end{array}$ & $\begin{array}{l}\text { Staff self-esteem } \\
\text { Staff competencies }\end{array}$ & $\begin{array}{l}\text { Quality of community child } \\
\text { care and involvement of } \\
\text { parents in the community }\end{array}$ \\
\hline 1999 & $\begin{array}{l}\text { Parent-child relationships } \\
\text { Secure attachment, parenting efficacy }\end{array}$ & $\begin{array}{l}\text { Age-appropriate levels of } \\
\text { cognitive, social-emotional, } \\
\text { physical, and language } \\
\text { development }\end{array}$ & $\begin{array}{l}\text { Mental health } \\
\text { Physical health, self- } \\
\text { sufficiency, physical and } \\
\text { emotional quality of the home } \\
\text { environment (stable, } \\
\text { nurturing) } \\
\end{array}$ & $\begin{array}{l}\text { Staff self-esteem } \\
\text { Greater competence and } \\
\text { teamwork }\end{array}$ & $\begin{array}{l}\text { Increased availability and } \\
\text { better quality of community } \\
\text { child care, greater } \\
\text { sophistication of parents as } \\
\text { consumers of health, social, } \\
\text { and educational services } \\
\end{array}$ \\
\hline $\begin{array}{l}\text { C } \\
1997\end{array}$ & $\begin{array}{l}\text { Parent-child relationships } \\
\text { Attachment and knowledge of child } \\
\text { development }\end{array}$ & $\begin{array}{l}\text { Cognitive, social-emotional, } \\
\text { physical, approaches toward } \\
\text { learning, and readiness for Head } \\
\text { Start }\end{array}$ & $\begin{array}{l}\text { Self-efficacy } \\
\text { mental health and healthy } \\
\text { family functioning, self- } \\
\text { sufficiency, and literacy and } \\
\text { education }\end{array}$ & $\begin{array}{l}\text { Improved staff competencies } \\
\text { Staff competencies and career } \\
\text { development }\end{array}$ & $\begin{array}{l}\text { Involvement of parents in the } \\
\text { community }\end{array}$ \\
\hline 1999 & $\begin{array}{l}\text { Enhanced parent-child relationships } \\
\text { Increased knowledge of child } \\
\text { development }\end{array}$ & $\begin{array}{l}\text { Cognitive development } \\
\text { Social-emotional development } \\
\text { Healthy physical development } \\
\text { and readiness for Head Start }\end{array}$ & $\begin{array}{l}\text { Parent self-efficacy } \\
\text { Improved mental health and } \\
\text { healthy family functioning, } \\
\text { improved literacy and } \\
\text { education, and healthier } \\
\text { lifestyles }\end{array}$ & $\begin{array}{l}\text { Improved staff competencies } \\
\text { Career development }\end{array}$ & $\begin{array}{l}\text { Increased involvement of } \\
\text { parents in the community }\end{array}$ \\
\hline $\begin{array}{l}\text { D } \\
1997\end{array}$ & $\begin{array}{l}\text { Parent-child relationships } \\
\text { Knowledge of child development }\end{array}$ & $\begin{array}{l}\text { Cognitive, social-emotional, } \\
\text { approaches toward learning, and } \\
\text { school readiness }\end{array}$ & $\begin{array}{l}\text { Economic self- } \\
\text { sufficiency/employment } \\
\text { Self-sufficiency and home } \\
\text { environment }\end{array}$ & $\begin{array}{l}\text { Improved staff competencies } \\
\text { Staff competencies and } \\
\text { teamwork and morale }\end{array}$ & $\begin{array}{l}\text { Involvement of parents in the } \\
\text { community }\end{array}$ \\
\hline
\end{tabular}


TABLE III.1 (continued)

\begin{tabular}{|c|c|c|c|c|c|}
\hline Programs & Parent-Child Relationships & Child Development & Family Development & Staff Development ${ }^{\mathrm{b}}$ & Community Building ${ }^{\mathrm{b}}$ \\
\hline 1999 & $\begin{array}{l}\text { Knowledge of child development and } \\
\text { of how to stimulate young children }\end{array}$ & $\begin{array}{l}\text { Cognitive development } \\
\text { Social-emotional development } \\
\text { (social skills, willingness to } \\
\text { share, self-esteem) } \\
\text { Physical development } \\
\text { Approaches toward learning } \\
\text { (independence and self-help } \\
\text { skills) }\end{array}$ & $\begin{array}{l}\text { Parent self-sufficiency (skills } \\
\text { necessary for employment, } \\
\text { access services on own) }\end{array}$ & $\begin{array}{l}\text { Improved staff competencies } \\
\text { (successfully transitioning } \\
\text { from Head Start to EHS, } \\
\text { increased training and } \\
\text { education), increased } \\
\text { supportive supervision }\end{array}$ & $\begin{array}{l}\text { Increased collaboration and } \\
\text { partnerships with community } \\
\text { services providers }\end{array}$ \\
\hline 1999 & $\begin{array}{l}\text { Enhanced parental knowledge of } \\
\text { child development and children's } \\
\text { needs } \\
\text { Stronger attachment; better } \\
\text { understanding of the parent-child } \\
\text { relationship }\end{array}$ & $\begin{array}{l}\text { Cognitive development } \\
\text { Social-emotional; approaches } \\
\text { toward learning; emergent } \\
\text { literacy skills }\end{array}$ & $\begin{array}{l}\text { Enhanced family goal setting } \\
\text { Healthier family functioning, } \\
\text { greater self-sufficiency; } \\
\text { enhanced home environment }\end{array}$ & $\begin{array}{l}\text { Increased staff } \\
\text { professionalism (awareness } \\
\text { and assessment of family } \\
\text { needs, ability to make } \\
\text { appropriate referrals, staff } \\
\text { have goal of improving in this } \\
\text { area) } \\
\text { Greater staff skills and } \\
\text { knowledge about child } \\
\text { development and child care }\end{array}$ & $\begin{array}{l}\text { Greater awareness of } \\
\text { community child care needs } \\
\text { and importance of early } \\
\text { education issues; increased } \\
\text { supply and quality of child } \\
\text { care; more coordination of } \\
\text { services and collaboration } \\
\text { with community partners; } \\
\text { greater community } \\
\text { knowledge about low- } \\
\text { income families }\end{array}$ \\
\hline $\begin{array}{l}F_{1997} \\
\end{array}$ & $\begin{array}{l}\text { Understanding the parent-child } \\
\text { relationship }\end{array}$ & $\begin{array}{l}\text { Language development } \\
\text { Cognitive, social-emotional, and } \\
\text { physical }\end{array}$ & $\begin{array}{l}\text { Literacy/education } \\
\text { Mental health and healthy } \\
\text { family functioning, self- } \\
\text { sufficiency, literacy and } \\
\text { education, and home } \\
\text { environment }\end{array}$ & $\begin{array}{l}\text { Staff competencies and } \\
\text { teamwork and morale }\end{array}$ & $\begin{array}{l}\text { Improved quality of } \\
\text { community child care } \\
\text { Involvement of parents in the } \\
\text { community }\end{array}$ \\
\hline 1999 & $\begin{array}{l}\text { Improved understanding of the } \\
\text { parent-child relationship }\end{array}$ & $\begin{array}{l}\text { Improved language, cognitive, } \\
\text { social-emotional, and physical } \\
\text { development }\end{array}$ & $\begin{array}{l}\text { Parental mental health } \\
\text { Family education and literacy } \\
\text { Healthy family functioning } \\
\text { (stable home environment) } \\
\text { Increased self-sufficiency, } \\
\text { better quality home } \\
\text { environment }\end{array}$ & $\begin{array}{l}\text { Greater competencies, } \\
\text { teamwork, and morale }\end{array}$ & $\begin{array}{l}\text { Improved quality of } \\
\text { community child care, } \\
\text { greater involvement of } \\
\text { parents in the community }\end{array}$ \\
\hline $\begin{array}{l}\mathrm{G} \\
1997\end{array}$ & $\begin{array}{l}\text { Parent-child relationships Parenting } \\
\text { stress } \\
\text { Attachment, knowledge of child } \\
\text { development, and understanding the } \\
\text { parent-child relationship }\end{array}$ & $\begin{array}{l}\text { Cognitive, language, social- } \\
\text { emotional, and approaches } \\
\text { toward learning }\end{array}$ & $\begin{array}{l}\text { Mental health and healthy } \\
\text { family functioning, self- } \\
\text { sufficiency, and father } \\
\text { involvement }\end{array}$ & $\begin{array}{l}\text { Improved staff competencies } \\
\text { Staff competencies, teamwork } \\
\text { and morale, career } \\
\text { development, and community } \\
\text { involvement }\end{array}$ & $\begin{array}{l}\text { Quality of community child } \\
\text { care, and coordination of } \\
\text { services and collaboration }\end{array}$ \\
\hline
\end{tabular}




\begin{tabular}{|c|c|c|c|c|c|}
\hline Programs & Parent-Child Relationships & Child Development & Family Development & Staff Development $^{\mathrm{b}}$ & Community Building ${ }^{\mathrm{b}}$ \\
\hline 1999 & $\begin{array}{l}\text { Stronger and secure parent-child } \\
\text { attachment } \\
\text { Parents understand and promote } \\
\text { child development (identify } \\
\text { developmental milestones, monitor } \\
\text { and support development) }\end{array}$ & $\begin{array}{l}\text { Demonstrate gains in language } \\
\text { and social development, be ready } \\
\text { to learn }\end{array}$ & $\begin{array}{l}\text { Decreased family stress } \\
\text { Parents advocate for their } \\
\text { children, and act on } \\
\text { anticipatory guidance and } \\
\text { education related to their own } \\
\text { and child's health, fewer life } \\
\text { crises and respond to crises } \\
\text { and stress with constructive } \\
\text { decision making, live in } \\
\text { affordable safe homes free of } \\
\text { substance abuse an d illegal } \\
\text { activities, have extended social } \\
\text { support system, purchase and } \\
\text { prepare meals meeting } \\
\text { family's nutritional needs, } \\
\text { employment that meets basic } \\
\text { economic needs and provides } \\
\text { opportunities for advancement, } \\
\text { if no GED will complete adult } \\
\text { basic education or advance } 2 \\
\text { grade levels, have employable } \\
\text { skills and means of } \\
\text { transportation, be financially } \\
\text { stable and able to financially } \\
\text { plan for future }\end{array}$ & Better prepared, trained staff & $\begin{array}{l}\text { Children and parents will } \\
\text { have access to } \\
\text { developmentally appropriate } \\
\text { child care, family members } \\
\text { will volunteer in the } \\
\text { community }\end{array}$ \\
\hline $\begin{array}{l}\mathrm{H} \\
1997\end{array}$ & $\begin{array}{l}\text { Parent-child relationships } \\
\text { Parental knowledge of child } \\
\text { development } \\
\text { Attachment, knowledge of child } \\
\text { development, and parenting }\end{array}$ & $\begin{array}{l}\text { Language, social-emotional, } \\
\text { physical, approaches toward } \\
\text { learning, and school readiness }\end{array}$ & $\begin{array}{l}\text { Self-sufficiency, home } \\
\text { environment, and father } \\
\text { involvement }\end{array}$ & $\begin{array}{l}\text { Improved staff competencies } \\
\text { Staff competencies, teamwork } \\
\text { and morale, and career } \\
\text { development }\end{array}$ & $\begin{array}{l}\text { Quality of community child } \\
\text { care, quality of other } \\
\text { community services, } \\
\text { coordination of services and } \\
\text { collaboration, and } \\
\text { involvement of parents in the } \\
\text { community }\end{array}$ \\
\hline 1999 & $\begin{array}{l}\text { Enhanced parent-child relationships } \\
\text { (attachment parenting, increased } \\
\text { nurturing, increased responsiveness } \\
\text { to child) } \\
\text { Parental knowledge of child } \\
\text { development (what is } \\
\text { developmentally appropriate) } \\
\text { Infant-parent play interaction }\end{array}$ & $\begin{array}{l}\text { Enhanced functioning in domains } \\
\text { of language, social-emotional } \\
\text { development (secure attachment, } \\
\text { positive peer play interactions at } \\
\text { age 3), physical development and } \\
\text { health, approaches toward } \\
\text { learning, and school readiness }\end{array}$ & $\begin{array}{l}\text { Greater family self- } \\
\text { sufficiency, improved home } \\
\text { environment, greater male } \\
\text { involvement and social } \\
\text { networking }\end{array}$ & $\begin{array}{l}\text { Improved staff competencies, } \\
\text { teamwork, and morale; career } \\
\text { development }\end{array}$ & $\begin{array}{l}\text { Enhanced quality of } \\
\text { community child care, } \\
\text { quality of other community } \\
\text { services, coordination of } \\
\text { services and collaboration, } \\
\text { and parent involvement in } \\
\text { the community }\end{array}$ \\
\hline
\end{tabular}




\begin{tabular}{|c|c|c|c|c|c|}
\hline Programs & Parent-Child Relationships & Child Development & Family Development & Staff Development ${ }^{\mathrm{b}}$ & Community Building ${ }^{\mathrm{b}}$ \\
\hline $\begin{array}{l}\text { I } \\
1997\end{array}$ & $\begin{array}{l}\text { Attachment, knowledge of child } \\
\text { development, understanding the } \\
\text { parent-child relationship, and } \\
\text { parenting }\end{array}$ & $\begin{array}{l}\text { Cognitive development } \\
\text { Language development } \\
\text { Social development } \\
\text { Social-emotional and physical }\end{array}$ & $\begin{array}{l}\text { Physical health, mental health } \\
\text { and healthy family } \\
\text { functioning, self-sufficiency, } \\
\text { and home environment }\end{array}$ & $\begin{array}{l}\text { Staff development not } \\
\text { discussed during site visit }\end{array}$ & $\begin{array}{l}\text { Quality of community child } \\
\text { care, quality of other } \\
\text { community services, } \\
\text { coordination of services and } \\
\text { collaboration, and } \\
\text { involvement of parents in the } \\
\text { community }\end{array}$ \\
\hline 1999 & $\begin{array}{l}\text { Increased security of parent-child } \\
\text { attachment } \\
\text { Increased parental availability to the } \\
\text { child } \\
\text { Parent is available for the child } \\
\text { (emotionally and physically); } \\
\text { increase in parents ability to read } \\
\text { cues (communication needs to be } \\
\text { reciprocal and parent needs to learn } \\
\text { to speak for the child); child has a } \\
\text { secure base to return to (explore } \\
\text { and grow); empathic listening, } \\
\text { holding interactions; parent } \\
\text { expresses pleasure of child/ } \\
\text { acceptance of child }\end{array}$ & $\begin{array}{l}\text { Achievement of appropriate } \\
\text { developmental milestones } \\
\text { Ability to emotionally connect } \\
\text { with parent and others (this } \\
\text { encompasses confidence and } \\
\text { self-esteem, emerging sense of } \\
\text { self, and having a secure base); } \\
\text { for delayed/disabled children, } \\
\text { promote maximum } \\
\text { development and growth; } \\
\text { achieve developmental } \\
\text { milestones (language/ motor } \\
\text { skills/ cognitive); increased } \\
\text { self-regulation and ability to } \\
\text { withstand delayed gratification }\end{array}$ & $\begin{array}{l}\text { Increased family self- } \\
\text { sufficiency } \\
\text { Increased family access of } \\
\text { appropriate community } \\
\text { resources } \\
\text { Decreased number of unsafe } \\
\text { home environments } \\
\text { Parent has increased self- } \\
\text { regulation and ability to } \\
\text { delay gratification; increased } \\
\text { income, education, and } \\
\text { satisfaction with life; become } \\
\text { financially independent; } \\
\text { parents establish and } \\
\text { maintain healthy } \\
\text { relationships; use a healthy } \\
\text { support system, give a voice, } \\
\text { reduce isolation; understand } \\
\text { consequences of choices and } \\
\text { actions; increased safety }\end{array}$ & Advocate for and with families & $\begin{array}{l}\text { Link agencies and service } \\
\text { providers }\end{array}$ \\
\hline $\begin{array}{l}\text { J } \\
1997\end{array}$ & $\begin{array}{l}\text { Parent-child relationships } \\
\text { Knowledge of child development, } \\
\text { understanding the parent-child } \\
\text { relationship, and parenting }\end{array}$ & $\begin{array}{l}\text { Cognitive, social-emotional, } \\
\text { physical, and approaches toward } \\
\text { learning }\end{array}$ & $\begin{array}{l}\text { Literacy/education } \\
\text { Physical health, mental health } \\
\text { and healthy family } \\
\text { functioning, self-sufficiency, } \\
\text { literacy and education, and } \\
\text { home environment }\end{array}$ & $\begin{array}{l}\text { Staff competencies and career } \\
\text { development }\end{array}$ & $\begin{array}{l}\text { Quality of community child } \\
\text { care } \\
\text { Quality of community child } \\
\text { care, quality of other } \\
\text { community services, } \\
\text { coordination of services and } \\
\text { collaboration, and } \\
\text { involvement of parents in the } \\
\text { community }\end{array}$ \\
\hline
\end{tabular}




\begin{tabular}{|c|c|c|c|c|c|}
\hline Programs & Parent-Child Relationships & Child Development & Family Development & Staff Development ${ }^{\mathrm{b}}$ & Community Building ${ }^{\mathrm{b}}$ \\
\hline 1999 & $\begin{array}{l}\text { Stronger parent-child relationships } \\
\text { Parents will understand rationale of } \\
\text { CD activities and continue them after } \\
\text { specialist leaves; parent feels better } \\
\text { about self and more available to } \\
\text { child; understand where child is } \\
\text { developmentally and recognize } \\
\text { changes, understand link between } \\
\text { child's language and communication } \\
\text { and reduced violence later; increased } \\
\text { understanding of why CD is } \\
\text { important; actively teach children and } \\
\text { read to them more; more activities } \\
\text { conducive to CD; reduced abuse and } \\
\text { neglect; increased parent-child } \\
\text { interactions }\end{array}$ & $\begin{array}{l}\text { More social, initiate play; } \\
\text { verbalize feelings better; ready } \\
\text { for school academically; ready } \\
\text { for school in terms of } \\
\text { temperament; increased social } \\
\text { competency; improved health } \\
\text { (including immunization rates) }\end{array}$ & $\begin{array}{l}\text { Greater parental } \\
\text { literacy/education } \\
\text { Parents attain better sense of } \\
\text { family's needs; greater } \\
\text { confidence in parenting; better } \\
\text { environment for children; } \\
\text { more stable homes; parents } \\
\text { empowered to know and ask } \\
\text { for what they need; think of } \\
\text { solutions to own dilemmas, } \\
\text { higher self-esteem; greater } \\
\text { confidence in achieving goals; } \\
\text { greater family self-sufficiency; } \\
\text { better family health (including } \\
\text { prenatal care, knowledge of } \\
\text { own bodies, sexuality and } \\
\text { STDs); more assertive in } \\
\text { advocating for own children; } \\
\text { more-positive outlook on life; } \\
\text { more positive approach to own } \\
\text { and child's well-being; have } \\
\text { plan of action regarding } \\
\text { achieving goals; increased } \\
\text { social competency; sufficient } \\
\text { literacy to seek solutions and } \\
\text { help from agencies; greater } \\
\text { knowledge of community } \\
\text { resources/ learning } \\
\text { opportunities; fathers involved }\end{array}$ & $\begin{array}{l}\text { Increased knowledge of child } \\
\text { development, increased } \\
\text { knowledge of community } \\
\text { resources, attitude consistent } \\
\text { with philosophy of family } \\
\text { strengths rather than deficits; } \\
\text { take advantage of } \\
\text { opportunities in the } \\
\text { community }\end{array}$ & $\begin{array}{l}\text { Quality of community child } \\
\text { care } \\
\text { Parents understand } \\
\text { importance of continuity and } \\
\text { quality and can evaluate } \\
\text { quality of child care and } \\
\text { make informed choices; } \\
\text { develop relationship with } \\
\text { their child care provider; } \\
\text { systems affecting children } \\
\text { will be more sensitive to } \\
\text { child and family needs; more } \\
\text { streamlined services; parents } \\
\text { are listened to and heard in } \\
\text { relation to community } \\
\text { building; parents positive } \\
\text { role model for peers in the } \\
\text { community }\end{array}$ \\
\hline $\begin{array}{l}\text { K } \\
1997\end{array}$ & $\begin{array}{l}\text { Parenting confidence and } \\
\text { competence } \\
\text { Parent-child relationships } \\
\text { Knowledge of child development and } \\
\text { parenting }\end{array}$ & $\begin{array}{l}\text { Social-emotional development } \\
\text { Cognitive, language, social- } \\
\text { emotional, physical, and } \\
\text { approaches toward learning }\end{array}$ & $\begin{array}{l}\text { Self-sufficiency and home } \\
\text { environment }\end{array}$ & Staff competencies & $\begin{array}{l}\text { Quality of community child } \\
\text { care and involvement of } \\
\text { parents in the community }\end{array}$ \\
\hline
\end{tabular}




\begin{tabular}{|c|c|c|c|c|c|}
\hline Programs & Parent-Child Relationships & Child Development & Family Development & Staff Development ${ }^{\mathrm{b}}$ & Community Building ${ }^{\mathrm{b}}$ \\
\hline 1999 & $\begin{array}{l}\text { Enhanced parent-child relationships } \\
\text { (age-appropriate play with child, } \\
\text { positive intra-family relationships) } \\
\text { Greater parenting confidence and } \\
\text { competence } \\
\text { Greater knowledge of child } \\
\text { development and parenting (age- } \\
\text { appropriate expectations; good } \\
\text { parenting skills) }\end{array}$ & $\begin{array}{l}\text { Better social-emotional } \\
\text { development } \\
\text { Cognitive development (fewer } \\
\text { developmental delays, holistic } \\
\text { cognitive development), better } \\
\text { health, approaches toward } \\
\text { learning (increased curiosity, able } \\
\text { to conquer new challenges, able } \\
\text { to remember prior experiences } \\
\text { and relate to current tasks) }\end{array}$ & $\begin{array}{l}\text { Enhanced ability of parents to } \\
\text { meet the family's social and } \\
\text { economic needs (self- } \\
\text { sufficiency) (able to obtain } \\
\text { needed resources, make } \\
\text { informed decisions, articulate } \\
\text { and reach goals, advocate for } \\
\text { the family, achieve economic } \\
\text { self-sufficiency) } \\
\text { More supportive home } \\
\text { environment }\end{array}$ & $\begin{array}{l}\text { Stronger staff competencies } \\
\text { (obtain CDAs); enhanced staff } \\
\text { supervision and support }\end{array}$ & $\begin{array}{l}\text { Higher quality of community } \\
\text { child care; more involvement } \\
\text { of parents in community } \\
\text { (advocating for selves, } \\
\text { involved in policy council); } \\
\text { More peer support among } \\
\text { parents }\end{array}$ \\
\hline $\begin{array}{l}\mathrm{L} \\
1997\end{array}$ & $\begin{array}{l}\text { Parent-child relationships } \\
\text { Parental knowledge of child } \\
\text { development } \\
\text { Attachment, knowledge of child } \\
\text { development, understanding the } \\
\text { parent-child relationship, and } \\
\text { parenting }\end{array}$ & $\begin{array}{l}\text { Physical development/health } \\
\text { Cognitive, social-emotional, } \\
\text { physical, and school readiness }\end{array}$ & $\begin{array}{l}\text { Physical health, mental health } \\
\text { and healthy family } \\
\text { functioning, self-sufficiency, } \\
\text { literacy and education, and } \\
\text { father involvement }\end{array}$ & $\begin{array}{l}\text { Staff competencies, teamwork } \\
\text { and morale, and career } \\
\text { development }\end{array}$ & $\begin{array}{l}\text { Quality of community child } \\
\text { care, quality of other } \\
\text { community services, and } \\
\text { involvement of parents in the } \\
\text { community }\end{array}$ \\
\hline 1999 & $\begin{array}{l}\text { Parent-child relationships } \\
\text { Parental knowledge of child } \\
\text { development } \\
\text { Attachment, parenting }\end{array}$ & $\begin{array}{l}\text { Physical development/health } \\
\text { Cognitive development, social- } \\
\text { emotional development, school } \\
\text { readiness }\end{array}$ & $\begin{array}{l}\text { Physical health, mental health } \\
\text { and healthy family } \\
\text { functioning, self-sufficiency, } \\
\text { literacy and education, and } \\
\text { father involvement }\end{array}$ & $\begin{array}{l}\text { Staff competencies, teamwork } \\
\text { and morale, and career } \\
\text { development }\end{array}$ & $\begin{array}{l}\text { Quality of community child } \\
\text { care, quality of other } \\
\text { community services, and } \\
\text { involvement of parents in the } \\
\text { community }\end{array}$ \\
\hline $\begin{array}{l}\text { M } \\
1997\end{array}$ & $\begin{array}{l}\text { Parent-child relationships } \\
\text { Attachment, knowledge of child } \\
\text { development, and understanding the } \\
\text { parent-child relationship }\end{array}$ & $\begin{array}{l}\text { Social-emotional and approaches } \\
\text { toward learning }\end{array}$ & $\begin{array}{l}\text { Economic self- } \\
\text { sufficiency/employment } \\
\text { Mental health and healthy } \\
\text { family functioning }\end{array}$ & $\begin{array}{l}\text { Staff development not } \\
\text { discussed during site visit }\end{array}$ & $\begin{array}{l}\text { Quality of community child } \\
\text { care } \\
\text { Involvement of parents in the } \\
\text { community }\end{array}$ \\
\hline 1999 & $\begin{array}{l}\text { Stronger parent-child relationships } \\
\text { Stronger attachment, enhanced } \\
\text { knowledge of child development, } \\
\text { better understanding of the parent- } \\
\text { child relationship }\end{array}$ & $\begin{array}{l}\text { Enhanced child health and } \\
\text { physical development } \\
\text { Enhanced language } \\
\text { development (overarching), } \\
\text { enhanced social-emotional } \\
\text { development, stronger } \\
\text { approaches toward learning, } \\
\text { enhanced cognitive } \\
\text { development }\end{array}$ & $\begin{array}{l}\text { Greater economic self- } \\
\text { sufficiency and more } \\
\text { employment and education } \\
\text { Healthier family functioning, } \\
\text { and better physical and mental } \\
\text { health }\end{array}$ & $\begin{array}{l}\text { Better knowledge about and } \\
\text { implementation of Head Start } \\
\text { Program Performance } \\
\text { Standards, High-quality } \\
\text { performance and ability to } \\
\text { reflect on program goals }\end{array}$ & $\begin{array}{l}\text { Higher quality of community } \\
\text { child care } \\
\text { Greater involvement of } \\
\text { parents in the community,, } \\
\text { more community service } \\
\text { provider collaboration }\end{array}$ \\
\hline $\begin{array}{l}\mathrm{N} \\
1997\end{array}$ & $\begin{array}{l}\text { Knowledge of child development and } \\
\text { parenting }\end{array}$ & $\begin{array}{l}\text { Language development } \\
\text { Language, social-emotional, } \\
\text { physical, approaches toward } \\
\text { learning, and knowledge of their } \\
\text { community and diversity }\end{array}$ & $\begin{array}{l}\text { Economic self- } \\
\text { sufficiency/employment } \\
\text { Mental health and healthy } \\
\text { family functioning, self- } \\
\text { sufficiency, home } \\
\text { environment, and father } \\
\text { involvement }\end{array}$ & $\begin{array}{l}\text { Teamwork and morale and } \\
\text { career development }\end{array}$ & $\begin{array}{l}\text { Coordination of services } \\
\text { Quality of community child } \\
\text { care }\end{array}$ \\
\hline
\end{tabular}




\begin{tabular}{|c|c|c|c|c|c|}
\hline Programs & Parent-Child Relationships & Child Development & Family Development & Staff Development ${ }^{\mathrm{b}}$ & Community Building ${ }^{\mathrm{b}}$ \\
\hline 1999 & $\begin{array}{l}\text { Increased knowledge and practice of } \\
\text { positive parenting strategies } \\
\text { (especially discipline, setting firm } \\
\text { limits) } \\
\text { Increase parent-child bond and } \\
\text { responsiveness to children }\end{array}$ & $\begin{array}{l}\text { Babies are healthier and display } \\
\text { developmentally appropriate } \\
\text { growth (in all areas-cognitive, } \\
\text { self-help, language, motor, } \\
\text { social-emotional, intellectual } \\
\text { development) } \\
\text { Ability to express needs and } \\
\text { wants positively by gestures and } \\
\text { words }\end{array}$ & $\begin{array}{l}\text { Increased awareness and use } \\
\text { of community resources } \\
\text { Improved self-esteem; } \\
\text { improved ability to articulate } \\
\text { feelings and appropriately deal } \\
\text { with conflict; greater } \\
\text { knowledge of resources and } \\
\text { make progress toward own } \\
\text { goals; Greater motivation to } \\
\text { improve standard of living; } \\
\text { higher educational attainment; } \\
\text { greater knowledge of } \\
\text { community and cultural } \\
\text { diversity (develop sense of } \\
\text { pride, recognize roots and } \\
\text { share with children and } \\
\text { community, more involved in } \\
\text { community, better } \\
\text { understanding of all cultures in } \\
\text { the community) }\end{array}$ & $\begin{array}{l}\text { Obtain advanced degrees; } \\
\text { receive salaries comparable to } \\
\text { other child development } \\
\text { programs and schools }\end{array}$ & $\begin{array}{l}\text { Higher child care quality } \\
\text { (age appropriate activities, } \\
\text { nurturing staff), stronger } \\
\text { support for EHS in } \\
\text { community }\end{array}$ \\
\hline $\begin{array}{l}\mathrm{O} \\
1997\end{array}$ & $\begin{array}{l}\text { Parenting stress } \\
\text { Knowledge of child development and } \\
\text { parenting }\end{array}$ & $\begin{array}{l}\text { Physical development and health } \\
\text { Cognitive, language, social- } \\
\text { emotional, physical, and } \\
\text { approaches toward learning }\end{array}$ & $\begin{array}{l}\text { Physical health, mental health } \\
\text { and healthy family } \\
\text { functioning, self-sufficiency, } \\
\text { and home environment }\end{array}$ & $\begin{array}{l}\text { Staff competencies and career } \\
\text { development }\end{array}$ & $\begin{array}{l}\text { Collaboration } \\
\text { Quality of other community } \\
\text { services, coordination of } \\
\text { services and collaboration, } \\
\text { and involvement of parents } \\
\text { in the community } \\
\end{array}$ \\
\hline 1999 & $\begin{array}{l}\text { Enhanced parent-child relationships } \\
\text { Increased knowledge of child } \\
\text { development and parenting } \\
\text { (realistic expectations, reduced } \\
\text { child abuse, read to children more } \\
\text { often, increased confidence in } \\
\text { parenting, use appropriate } \\
\text { discipline techniques, follow } \\
\text { routines with children) }\end{array}$ & $\begin{array}{l}\text { Social-emotional development } \\
\text { (self-control, social skills) } \\
\text { Language development } \\
\text { (communication skills, self- } \\
\text { expression), cognitive } \\
\text { development (prepared for } \\
\text { reading) }\end{array}$ & $\begin{array}{l}\text { Self-sufficiency (improved life } \\
\text { skills, social skills, and } \\
\text { advocacy for self and } \\
\text { children) (progress toward } \\
\text { employability, improved } \\
\text { housing, increased planning } \\
\text { skills, better financial } \\
\text { management skills) } \\
\text { Improved physical health } \\
\text { (reduced substance abuse and } \\
\text { smoking, better nutrition); } \\
\text { improved mental health and } \\
\text { healthier family functioning } \\
\text { (healthier lifestyle, reduced } \\
\text { social isolation); safe home } \\
\text { environment }\end{array}$ & $\begin{array}{l}\text { Increased staff competencies } \\
\text { (better trained); career } \\
\text { development (better educated) }\end{array}$ & $\begin{array}{l}\text { Increased quality of } \\
\text { community child care; } \\
\text { enhanced coordination of } \\
\text { services and collaboration } \\
\text { (increased collaborative } \\
\text { work style when staff move } \\
\text { to other agencies); increased } \\
\text { awareness about importance } \\
\text { of early child development }\end{array}$ \\
\hline
\end{tabular}




\begin{tabular}{|c|c|c|c|c|c|}
\hline Programs & Parent-Child Relationships & Child Development & Family Development & Staff Development ${ }^{\mathrm{b}}$ & Community Building $^{\mathrm{b}}$ \\
\hline $\begin{array}{l}\mathrm{P} \\
1997\end{array}$ & $\begin{array}{l}\text { Attachment, knowledge of child } \\
\text { development, and parenting }\end{array}$ & $\begin{array}{l}\text { Language development } \\
\text { Social development } \\
\text { Cognitive, language, social- } \\
\text { emotional, and physical }\end{array}$ & $\begin{array}{l}\text { Physical health, mental health } \\
\text { and healthy family } \\
\text { functioning, self-sufficiency, } \\
\text { and home environment }\end{array}$ & $\begin{array}{l}\text { Staff competencies, teamwork } \\
\text { and morale, and career } \\
\text { development }\end{array}$ & $\begin{array}{l}\text { Quality of community child } \\
\text { care } \\
\text { Quality of community child } \\
\text { care, coordination of } \\
\text { services and collaboration, } \\
\text { and involvement of parents } \\
\text { in the community }\end{array}$ \\
\hline 1999 & $\begin{array}{l}\text { Stronger attachment ; enhanced } \\
\text { knowledge of child development; } \\
\text { better parenting }\end{array}$ & $\begin{array}{l}\text { Enhanced cognitive development } \\
\text { Enhanced language development } \\
\text { Enhanced social-emotional } \\
\text { development (empathy, social } \\
\text { skills) } \\
\text { Enhanced physical development } \\
\text { (reduced severity of injuries and } \\
\text { illnesses) }\end{array}$ & $\begin{array}{l}\text { Enhanced physical health; } \\
\text { better mental health; healthier } \\
\text { family functioning, greater } \\
\text { self-sufficiency; enhanced } \\
\text { home environment, greater } \\
\text { independence/ self- } \\
\text { determination/ self-confidence }\end{array}$ & $\begin{array}{l}\text { Enhance staff competencies } \\
\text { (getting CDAs, relationship } \\
\text { building, cultural sensitivity); } \\
\text { more teamwork and better } \\
\text { morale; stronger career } \\
\text { development }\end{array}$ & $\begin{array}{l}\text { Higher quality of community } \\
\text { child care } \\
\text { More coordination of } \\
\text { services and collaboration; } \\
\text { greater involvement of } \\
\text { parents in the community }\end{array}$ \\
\hline $\begin{array}{l} \\
1997\end{array}$ & $\begin{array}{l}\text { Parent-child relationships } \\
\text { Parental knowledge of child } \\
\text { development } \\
\text { Attachment, knowledge of child } \\
\text { development, and parenting }\end{array}$ & Social-emotional and physical & $\begin{array}{l}\text { Mental health and healthy } \\
\text { family functioning and self- } \\
\text { sufficiency }\end{array}$ & Teamwork and morale & $\begin{array}{l}\text { Quality of community child } \\
\text { care } \\
\text { Quality of other community } \\
\text { services, coordination of } \\
\text { services and collaboration, } \\
\text { and involvement of parents } \\
\text { in the community }\end{array}$ \\
\hline 1999 & $\begin{array}{l}\text { Parent-child relationships (secure } \\
\text { attachment) } \\
\text { Parental knowledge of child } \\
\text { development (especially realistic } \\
\text { expectations) }\end{array}$ & $\begin{array}{l}\text { Age-appropriate levels of social- } \\
\text { emotional and physical } \\
\text { development }\end{array}$ & $\begin{array}{l}\text { Families' abilities to set goals } \\
\text { Mental health and coping } \\
\text { skills; self-sufficiency; healthy } \\
\text { family functioning (goal- } \\
\text { setting, focus on change); } \\
\text { social support (especially for } \\
\text { parenting) }\end{array}$ & $\begin{array}{l}\text { Professional development and } \\
\text { advancement }\end{array}$ & $\begin{array}{l}\text { Service coordination and } \\
\text { collaboration (especially for } \\
\text { transitions); involvement of } \\
\text { parents in the community }\end{array}$ \\
\hline
\end{tabular}

NOTE: In 1997, programs were limited to identifying three priority outcomes; in 1999, several programs named more than three.

${ }^{a}$ The entries under each cornerstone indicate the key areas in which each program indicated important outcomes in the theories of change discussions during the fall 1997 and fall 1999 site visits. The outcomes highlighted in italics are the programs' "priority" outcomes.

${ }^{\mathrm{b}}$ Due to time constraints, this cornerstone was not discussed during some 1997 site visits. 
this chapter discusses and summarizes these expected outcomes, the ways they have changed over time, and the implications they have for understanding program development and impacts.

\section{B. EVOLUTION IN PROGRAMS' EXPECTED OUTCOMES}

We describe programs' priority outcomes in two ways. First, we consider the extent to which the programs, as a group, were focusing on particular areas. To do this, we report the priority outcomes that fell into each area as a percentage of all priority outcomes. This is shown in part A of Table III.2. Next, we look at the number and percentage of programs that focused on particular types of outcomes. These are shown in part B of Table III.2.

\section{Specific Changes That Occurred in Programs' Focus on Priority Outcomes in Particular Areas}

While a small number of programs did not change the priority outcomes identified in May 1998, the focus of most programs became refined and/or modified in important ways over time, reflecting changing views of the important outcomes they wanted to achieve. As shown in part A of Table III.2, the proportion of priority outcomes that were in the areas of parent-child relationships and child development did not change: in 1998, 59 percent of the priority outcomes were in the combined area of parent-child relationships and child development, and this combined area comprised 60 percent of the outcomes in 1999. It is important to consider child and parent-child relationships together, for, as we learned in discussions with program staff, programs often stress parent-child relationship goals because of the expected effects they will have indirectly on children's development.

Family development outcomes became a larger proportion of all the priority-expected outcomes in 1999 than they were in 1998, rising from 16 to 27 percent. At the same time, a substantially smaller proportion of the total expected priority outcomes were in staff 
TABLE III.2

EARLY HEAD START PROGRAMS' PRIORITY OUTCOMES

\section{A. Percentage of Priority Outcomes in Each Area, 1998 and 1999. ${ }^{2}$}

\begin{tabular}{lcc}
\hline Area & 1998 & 1999 \\
\hline Parent-Child Relationships & 37 & 34 \\
Child Development & 22 & 26 \\
Family Development & 16 & 27 \\
Staff Development & 12 & 8 \\
Community Building & 14 & 5 \\
\hline
\end{tabular}

Note: When child development and parent-child relationships are considered together, they account for 59 percent of all priority-expected outcomes in 1998 and 60 percent in 1999.

B. Number (and Percentage) of Programs with Priority Outcomes in Each Area, 1998 and 1999

\begin{tabular}{lcc}
\hline Area & 1998 & 1999 \\
\hline Parent-Child Relationships & $13(76)$ & $14(82)$ \\
Child Development & $9(53)$ & $11(65)$ \\
Family Development & $8(47)$ & $13(76)$ \\
Staff Development & $6(35)$ & $5(29)$ \\
Community Building & $7(41)$ & $3(18)$ \\
\hline
\end{tabular}

Note: When child development and parent-child relationships are considered together, five programs (29 percent) identified outcomes in both areas in 1998 and nine (53 percent) did so in 1999.

${ }^{2}$ The reason the two analyses shown under A and B appear somewhat different is that each program could (and often did) identify multiple outcomes in one area. Since programs were limited to naming three priority outcomes, the total number of priority outcomes is fixed and the percentage of outcomes in each area must equal 100 percent. In contrast, because programs could name priority outcomes in multiple areas, the percentage of programs that named priority outcomes in each area can sum to more than 100 percent across the five areas. 
development and community building — together these areas constituted about a quarter of all the priority outcomes (26 percent) in 1998. However, staff and community development became even less likely to be priority outcomes in 1999, constituting only 13 percent of all priority outcomes that programs reported to us.

Looking at the percentage of programs with priority outcomes in each area (part B of Table III.2), it is clear that an increasing number of programs were working toward outcomes in the parent-child, child development, and family development areas in 1999, compared with 1998. At the same time, fewer programs in 1999 than in 1997 considered staff development and community building to be among their priority outcomes. We should point out, however, that the lowered priority for outcomes in these areas did not mean that programs were neglecting staff and community development. We continued to see strong programmatic efforts in these areas, as noted in chapters V and VI. Rather, programs were undoubtedly responding to guidance from the Head Start Bureau and articulating the choices they made when it was not possible to have every area be high priority.

We examined, from the program perspective, the nature of these changes. First, two programs that did not identify parent-child relationships as a priority outcome in 1998 added that focus in 1999. One program dropped its parent-child priority focus, which yielded a net increase to 14 programs with priority outcomes in that area. A similar change occurred in child development. Three programs added it as a priority focus, while one program dropped it, which resulted in a net increase from 9 to 11 programs that placed child outcomes among their top priorities.

Another pattern of change was that, over time, programs with priority outcomes in staff development and community building shifted focus to outcomes in the family development area. Five programs added priority outcomes in that area, and no programs that identified family 
development outcomes in 1998 dropped them, which resulted in an increase from 8 to 13 programs identifying such outcomes.

One program added expected outcomes in staff development, and two no longer identified staff outcomes in 1999, which resulted in a net decrease from six to five programs that were giving priority to that area. Substantial change among priority outcomes occurred in the community area, however. Four programs that had identified priority outcomes in this area in 1998 no longer did so in 1999, and no program added this as a priority focus. Thus, in 1999 three programs had community building as a priority focus (compared with seven in 1998). Three of the programs that no longer identified community outcomes as priority added family outcomes.

The evolution of expected outcomes also involved changes in program thinking within each of the five areas. For example, in the child development area, programs identified specific aspects that they focused on, as shown in Table III.3. Among the 11 programs identifying child development priority outcomes in 1999, subsets of programs focused on the following specific outcomes:

- Five programs specified social-emotional development

- Five programs specified cognitive development (or both cognitive and language development)

- Two programs specified language development

- Three specified health and physical development

- Two named generic child development outcomes (for example, "achieving appropriate developmental milestones") 
TABLE III.3

EVOLVING PRIORITIES WITHIN THE CHILD DEVELOPMENT AREA: NUMBER (AND PERCENT OF PROGRAMS IDENTIFYING EACH ASPECT OF CHILD DEVELOPMENT AS A PRIORITY OUTCOME

\begin{tabular}{lcc}
\hline Child Development Outcome & 1998 & 1999 \\
\hline $\begin{array}{l}\text { Social or social-emotional } \\
\text { development }\end{array}$ & $3(33)$ & $5(45)$ \\
Cognitive development & $3(33)$ & $5(45)$ \\
Language development & $4(44)$ & $2(18)$ \\
Health and physical development & $2(22)$ & $3(27)$ \\
Generic child development & $0(0)$ & $2(18)$ \\
$\begin{array}{l}\text { Total programs with child } \\
\text { development outcomes }\end{array}$ & 9 & 11 \\
\hline
\end{tabular}

Thus, a somewhat greater proportion of programs had a priority to achieve social-emotional and cognitive outcomes in 1999 (compared with 1998), and a smaller percentage identified language as a priority child development outcome.

\section{Changes Across All Expected Outcomes Between 1997 and 1999}

In addition to considering the priority outcomes, we also documented all outcomes that programs deemed "important." These are shown in Table III.1, along with the 1997 and 1998 outcomes. One of the first things to note is that every program identified outcomes in all areas. This was an important first step for programs as they attempted to implement all four program areas as specified in the original program grant announcement.

A number of programs reported more-detailed outcomes in 1999 than in 1997; several programs have become more detailed in their identification of outcomes in parent-child 
relationships, child development, and family development. Both in 1997 and 1999, all programs identified social-emotional outcomes as ones they expected to achieve. Thirteen programs identified cognitive outcomes (a slight increase from 12 in 1997), and 11 expected language outcomes (increased from 9 in 1997). The largest increase occurred in the area of health and physical development, where 15 of the 17 programs mentioned these outcomes in 1999, in contrast to 11 in 1997.

\section{Summarizing Programs' Expected Child and Family Outcomes}

One complication of our variable approach to discussing expected outcomes is the variation in terminology. Programs reported both "important" and "priority" outcomes in 1997, 1998, and 1999. We have also shown the changes in programs' expected outcomes over time, combining priority and other outcomes, and combining information across years. Because no single approach or point in time yields an exact picture of programs' expected outcomes, we created a composite index derived from (1) 1997 expected outcomes; (2) 1998 priority outcomes; (3) all expected outcomes programs described in the fall 1999 site visits; and (4) priority expected outcomes from 1999, as confirmed by local researchers.

If an outcome area was identified in at least three of these four analyses, we considered there to be a "consensus" that it was a legitimate expected outcome of the program and could be the basis for targeted subgroup impact analysis. ${ }^{2}$ The resulting clustering of programs is shown in Table III.4. The largest number or programs (12) expected parent-child relationship outcomes. Within child development, the most common expected outcome was social-emotional development. Looking across the four child development areas, 10 programs indicated expected

\footnotetext{
${ }^{2}$ Note that for the purpose of these analyses, we focus on the child and family outcomes, as the study design does not allow for impact analyses of staff and community outcomes.
} 
outcomes in at least one child development area, 7 identified two of the four areas, and 4 reported that they expected to achieve outcomes in three or all four of the areas.

\section{The Relationship Among Expected Outcomes, Program Approaches, and Program Impacts}

The programs' expected outcomes shown in Table III.4 are generally consistent with the types of services they offered at the time of the 1997 site visits. In general, as shown in Figures III.1 and III.2, center-based programs were more likely to emphasize child development outcomes, while home-based programs were more likely to invest their efforts in enhancing parent-child relationships and parenting/home environment outcomes (which they expected to lead to impacts on children's development later). Among programs that gave priority to parentchild relationship or parenting outcomes, mixed-approach programs were most likely to emphasize enhancing parent-child relationships (Figure III.1). Many home-based programs also explicitly emphasized parent-child relationships, while others focused on aspects of parenting and the home environment, such as increasing parents' knowledge of child development or encouraging parents to spend more time with their children.

We also examined the expected outcomes within child development (Figure III.3). Among programs that gave priority to child development outcomes, the percentage of center-based programs emphasizing cognitive and social-emotional development was equal (50 percent), and, mixed approach and home-based programs were more likely to emphasize social-emotional development.

Interim findings of program impacts through the children's second birthday were generally_but not completely_consistent with the program approaches and expected outcomes (ACYF 2001). All program approaches resulted in positive benefits for children, but the types of impacts differed across approaches. Center-based programs were the only ones to enhance 
TABLE III.4

\section{CLUSTERS OF PROGRAMS WITH PRIORITY OUTCOMES IN EACH ASPECT OF CHILD AND FAMILY DEVELOPMENT}

\begin{tabular}{|c|c|c|c|}
\hline \multirow[b]{2}{*}{ Area } & \multirow[b]{2}{*}{ Specific Outcome } & \multicolumn{2}{|c|}{ Programs in Cluster } \\
\hline & & Number & Percent \\
\hline Parent-child & Parent-child relationships & 12 & 71 \\
\hline relationships & $\begin{array}{l}\text { Knowledge of child } \\
\text { development }\end{array}$ & 6 & 35 \\
\hline \multirow[t]{4}{*}{ Child development } & Social-emotional development & 7 & 41 \\
\hline & Cognitive development & 5 & 29 \\
\hline & Language development & 4 & 24 \\
\hline & $\begin{array}{l}\text { Physical development and } \\
\text { Health }\end{array}$ & 3 & 18 \\
\hline \multirow[t]{2}{*}{ Family development } & Family self-sufficiency & 11 & 65 \\
\hline & Family mental health & 6 & 35 \\
\hline
\end{tabular}


FIGURE III.1

VARIATION IN PROGRAM APPROACH AMONG PROGRAMS WITH DIFFERENT PRIORITY OUTCOMES

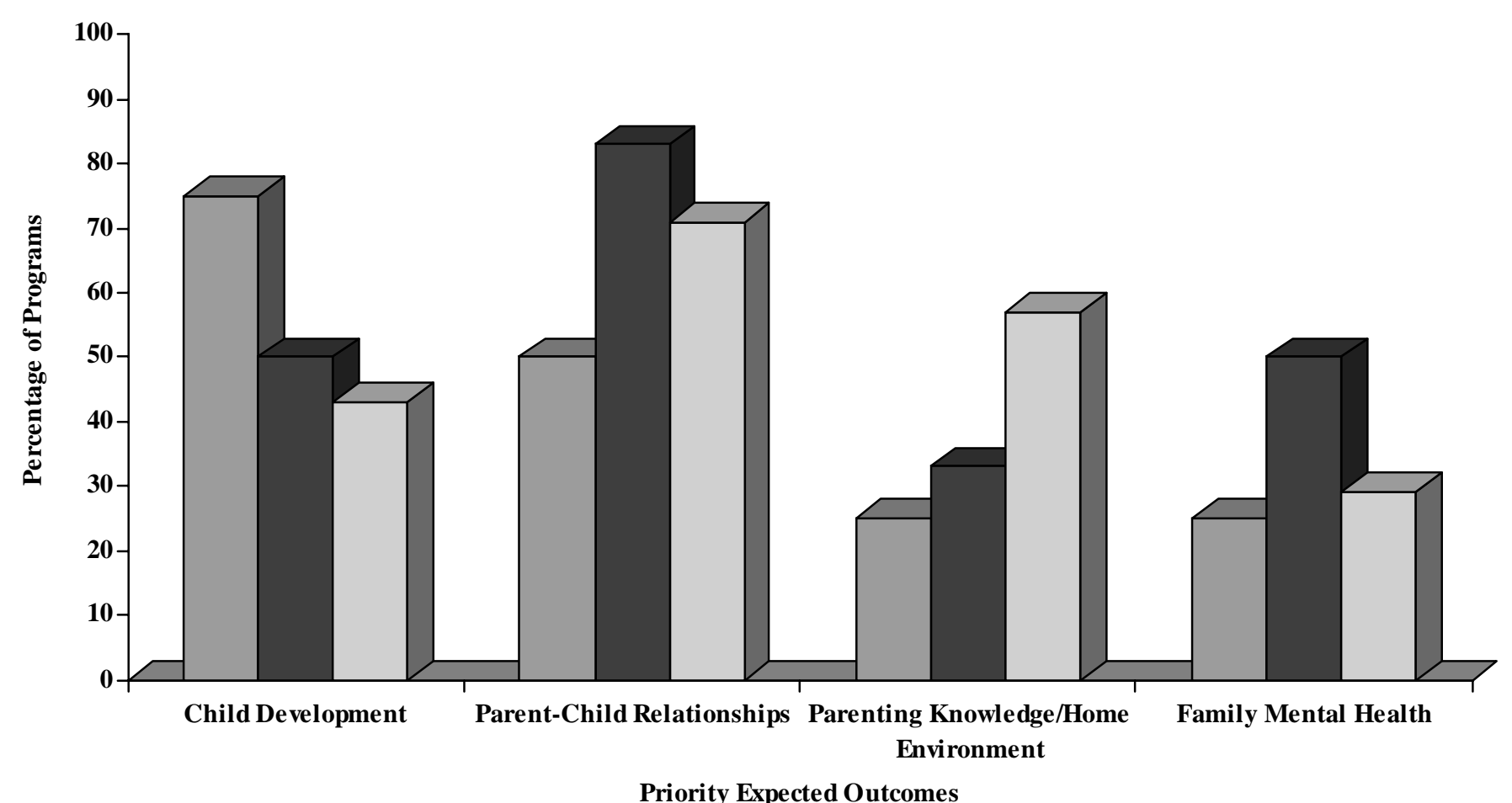

$\square$ Center-Based $\square$ Mixed-Approach $\square$ Home-Based 
FIGURE III. 2

PRIORITY EXPECTED OUTCOMES BY PROGRAM APPROACH

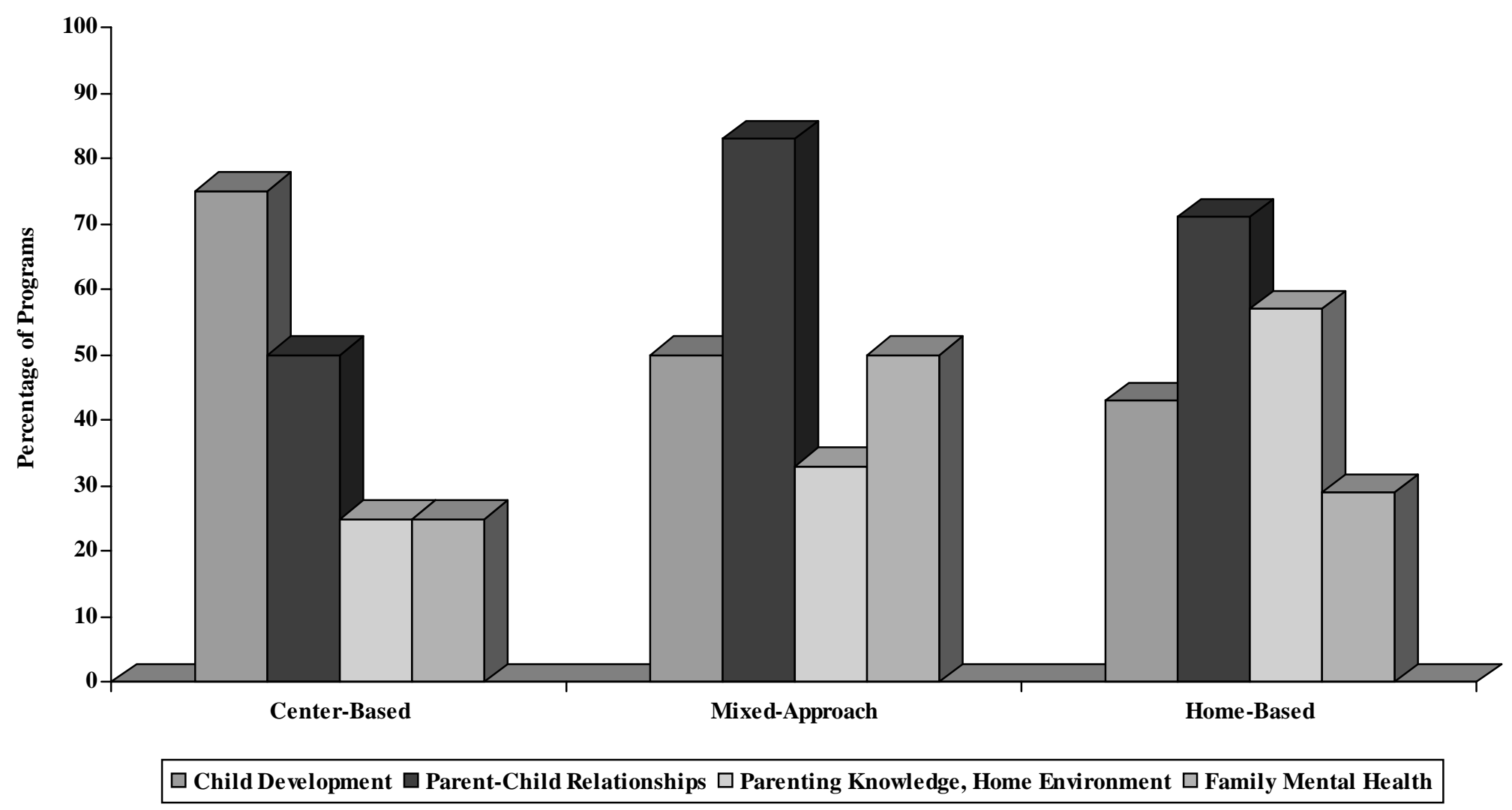




\section{FIGURE III.3}

PRIORITY EXPECTED CHILD DEVELOPMENT OUTCOMES, BY PROGRAM APPROACH

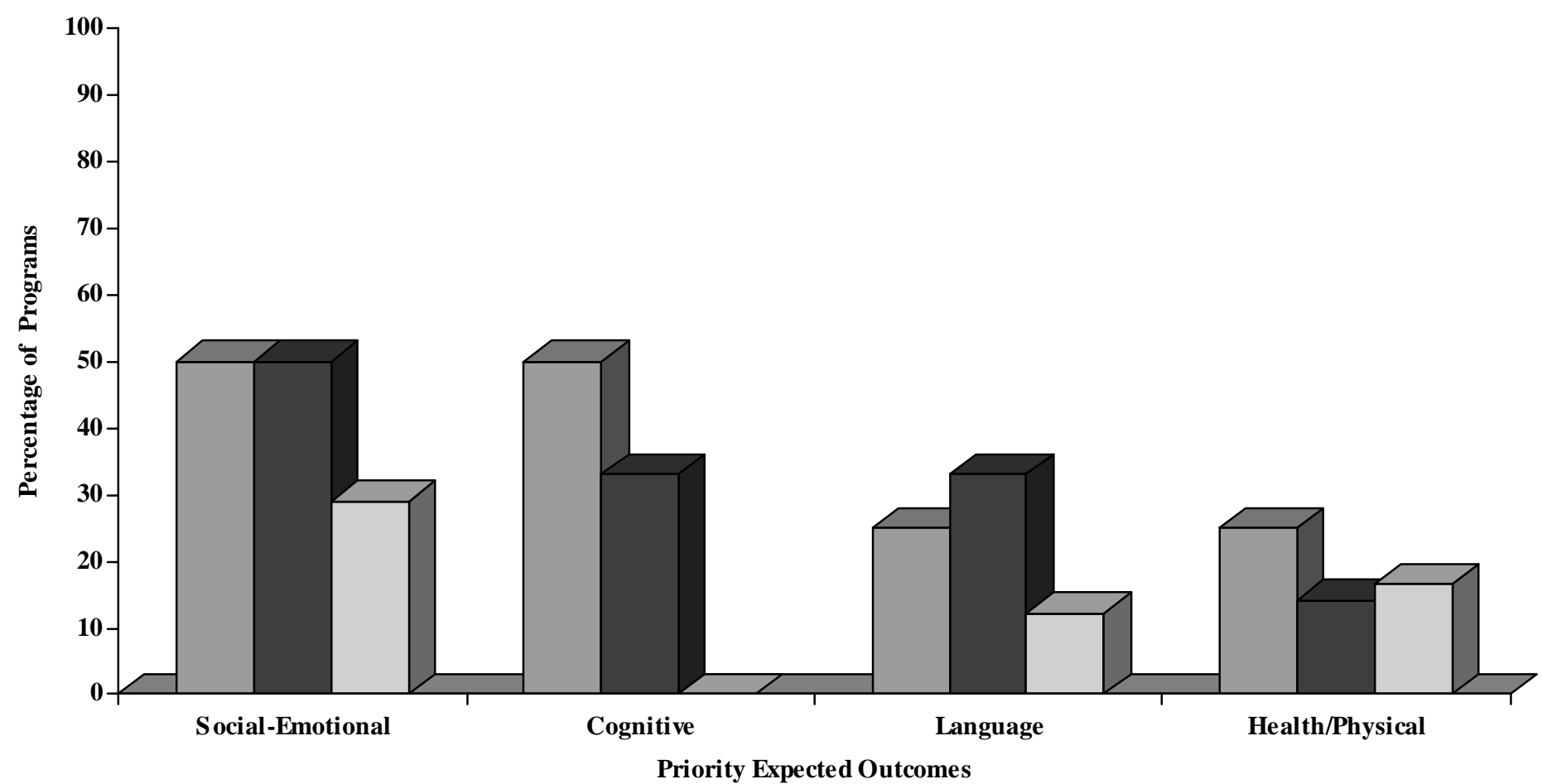

$\square$ Center-Based $\square$ Mixed-Approach $\square$ Home-Based 
children's cognitive development significantly, while home-based programs improved children's language development and mixed-approach programs improved both language and socialemotional development. Early Head Start impacts on parenting and the home environment were concentrated in home-based and mixed-approach programs (with a few exceptions).

\section{PERSPECTIVES FROM THEORY-OF-CHANGE DISCUSSIONS AMONG RESEARCHERS AND PRACTITIONERS}

A special feature of the Early Head Start Research and Evaluation project has been the presence of local research teams to work with 16 of the 17 programs. As noted earlier, researchers to varying degrees in different locations engaged their program partners in discussions of expected outcomes and theories of change. In this section, we highlight the theory-of-change work within the Early Head Start programs and between the program and research staffs in the local partnerships.

\section{The Value of Research-Program Partnership in Developing Theories of Change}

The experience of the research-program partnership at the Bear River Early Head Start program in Logan, Utah, illustrates how this process can occur and what the benefits may be for both the programs and the researchers and, ultimately, for the children and families. Lori Roggman, the local researcher at Utah State University, who has worked with the Bear River staff from the beginning of Early Head Start, noted that even though program staff members often do not articulate a "theory of change," they develop strategies for working with families based on a general philosophy or "theory" about how to make changes in the lives of families and children. Dr. Roggman has served as the continuous program improvement partner with the Bear River staff. This program, serving rural and semirural areas in and around Logan, Utah, emphasized home visits as a critical element in their theory of change. The process and the outcomes of the theory-of-change discussions in Utah reveal the importance of an active, 
interactive process. Although there may be many ways in which theory-of-change discussions between researchers and program staff might unfold, this provides an example of how the process developed in one site.

\section{Voices of the Staff: Home Visitors Describe Their "Theories of Change"}

Frontline staff members in Early Head Start programs are dedicated to their jobs and to their families (see discussion of Early Head Start staffing in Chapter V). Sometimes, even when staff members are not explicitly discussing a "theory of change," as they did in Utah, they often reveal an implicit theory of change when they talk about their families and the successes their families have achieved. An example appears in the next box, taken from the words of a home visitor with the Community Action Agency Early Head Start program in Jackson, Michigan.

\section{Local Variations in the Development of Program Theories of Change ${ }^{3}$}

Susan Pickrel, a local researcher with the Sumter, South Carolina, Early Head Start program, led a cross-site effort to learn about the ways in which program staff think about and articulate their theories of change. Local researchers in nine of the research sites held discussions with their program partners in 1999-2000, following a standard set of questions. Questions asked about program successes and outcome areas in which the program was less than successful. They audiotaped the discussions and transcribed the tapes, and Pickrel's South Carolina team coded the discussions. The coding identified the key concepts that program staff used in describing barriers to and facilitators of success in working with their families. Through this process, researchers gained greater understanding of the programs' theories as to how changes in

\footnotetext{
${ }^{3}$ This section was contributed by Susan G. Pickrel, a local researcher working with the
} Sumter, South Carolina, Early Head Start program, who is currently with the Mercy Medical Center in Roseburg, Oregon. 


\title{
Creating a Theory of Change at Bear River Early Head Start, Logan, Utah
}

\author{
Lori A. Roggman
}

Utah State University

The first time I, as the local researcher, talked about a "theory of change" with the staff at Bear River Early Head Start, I asked two questions: "How will families who are in your program end up different from those who are not in your program?" and "How exactly will this program make that happen?" In response to the first, staff had a long list of outcomes they believed would be changed by their program. They believed the families in the program would be happier parents with happier babies. They believed parents would be more knowledgeable and less stressed and feel better about themselves as parents. They believed the babies would be healthier, happier, more secure, and smarter. The second question was more difficult. After a long pause, someone said, with conviction, "Because we believe in this program and we believe in these families."

Through weeks of training, staff who were about to begin making home visits to families learned about child development, the Head Start Program Performance Standards, infant and family health, social services, and how to do all the necessary documentation. They had learned how to use the lesson plan forms and how to fill out forms for mileage reimbursement. They understood the research design and believed that the children and families in Early Head Start would end up better off in many ways. But they lacked a clear idea of the actual mechanisms of change. They knew they were supposed to make home visits to parents, and they knew how parents and infants were supposed to be affected by the program, but they did not seem to have a clear idea of how exactly one connected to the other. The authors of the program's grant proposal had a clear vision of the program, but those who would have the responsibility for working directly with families weren't seeing it as clearly.

Since then, the Early Head Start staff members have worked together to write (and regularly review and revise) a "theory of change." By clearly specifying "how families will end up different" and "how exactly this program will make that happen," staff described a "vision" that then guided their decision making. For example, for their primary goal, "to increase positive parent-infant play interactions, nurturant and responsive parenting, and parents' knowledge about child development," staff identified a specific strategy: that three-fourths of home visit time will be spent in "direct play interactions to enhance the parent-child relationship." The vision that guides program activities also guided the researchers to focus their evaluation on staff-parent relationships.

Bear River Early Head Start staff members have described home visits and the role of home visitors with increasing clarity over the years. From Year 1 to Year 2, descriptions of home visits shifted toward a more-active intervention process that emphasized direct interactions between parents and infants (instead of interactions that were primarily discussions with parents). From Year 2 to Year 3, the descriptions shifted toward a greater emphasis on father involvement and family independence that involved helping both mothers and fathers plan their own activities with infants, both during home visits and between home visits.

By writing a description of the connections between staff activities and what happens to families, the program was able to get off to a good start serving families with infants and toddlers. Beyond their selfconfidence, staff members had specific ideas about what strategies to use. By regularly reviewing and revising this written "vision," the program is able to continue improving and fine-tuning its efforts. 


\title{
A Home Visitor's View of Her Family's Successes
}

\author{
Christina Katka \\ Community Action Agency Early Head Start \\ Jackson, Michigan
}

Carol (not her real name) called to request early intervention services for her 27-month-old son, "Jack," who had been born prematurely, at just under 5 pounds. The toddler was receiving speech therapy from the local children's hospital and participating in Part C services. Jack lives with Carol, his father, Peter, and a 14-year-old brother. This family's situation is unusual-entering Early Head Start with less than a year of services possiblebut enrollment was considered important, given the needs of the child and the family. ${ }^{1}$ Carol is herself disabled, from burns suffered as a child; Peter works full-time at a local university and part-time as a sheriff.

Jack appeared small, shy, and guarded during our first meeting. He was easily frustrated, experiencing difficulty in expressing his wants and needs. As he became more familiar with me, his energy level increased. He actively engaged me in his play. And Jack often gave me a sense of "invitation" to "join" him in his world, a special place for a sensitive, loving child.

During our home visits, both parents talked openly about their concerns and worries about Jack's development. I realized I needed to begin with an alliance that offered Carol a strong and consistent relationship. I attempted to nurture and respect the family and be sensitive to their needs, providing a weekly presence in their home. I also felt they needed information, so I provided some on child development and age-appropriate toys, and offered help with guided activities that would enhance Jack's large and small muscles. I introduced information about self-help skills, as well as cognitive development and the opportunity to use weekly play that would facilitate positive parent-child interactions. I was encouraged that the family also joined in on biweekly socialization groups, where Jack began to interact with other children-first in individual play, then in parallel play, and finally in cooperative play.

I eventually began to see the results of these interactions. Carol's confidence improved, and Jack's language and communication developed. As Carol found the courage to face her fears, Jack found his own courage, supported by his ever-present drive toward independence. His play became more organized as he used appropriate exploration. Jack is affectionate, expressive, and interactive, while demonstrating a strong capacity for attachment and trust. Carol, in addition to taking great pleasure in her son's growth, is caring and compassionate, and provides a safe, nurturing environment for Jack's continuing development. Peter provides a strong male influence, providing an active role model in Jack's life. As Jack enters the Head Start preschool program in the fall, he is being placed in the half-day inclusion classroom, where his new caregivers expect the progress we've seen in Early Head Start to continue.

${ }^{1}$ For participation in the research, programs enrolled families when children were 12 months of age or younger.

families come about. These elements related to (1) the characteristics of the mothers; (2) the

features of the program; and (3) the program process characteristics (operational features, staff

behavior, and staff-family interactions) that might relate to the outcomes expected within the particular theory of change.

Six of the nine programs identified characteristics of the mothers as key to Early Head Start program outcomes, and three considered the program or program process characteristics as key. 
In other words, one-third were oriented toward taking responsibility for the success of Early Head Start, independent of the participant characteristics. In the first set of programs, responsibility for change was articulated to be such characteristics of the mother as (1) desire or willingness to participate in the Early Head Start program, (2) focus on being a good parent, (3) ability to see positive developmental changes quickly in her child, (4) readiness to receive program information, (5) desire to make her and her child's life better, and (6) enjoyment in being with her baby.

When staff members mentioned program characteristics as the factors producing the change, they tended to focus on generic features. Those programs features mentioned in more than one site included (1) case management (six sites), (2) home visits (four sites), (3) center-based child development services (three sites), (4) other child development services (two sites), and (5) onsite medical/pediatric and dental assessments and information (two sites). Although, for coding purposes, program characteristics were defined as static characteristics of a program (in contrast to the process characteristics, which reflect activities that occur between two persons or organizations), there was some overlap between the static and process characteristics. For example, case management, home visits, and child development services mentioned by multiple sites all involve interchanges between Early Head Start staff and program participants. Characteristics were coded as process, however, only if the discussions directly described personal process features rather than labels for program elements. The process elements listed next make this distinction clearer.

The programs that identified program process characteristics indicated a "theory of change" based on what program staff did to meet participant needs rather than on parent characteristics. The program or process characteristics included such factors as (1) staff skills in mental health interventions, (2) accepting and managing difficult behaviors in participants, (3) adapting to 
parent and family circumstances, and (4) persistence in trying to establish a relationship with the family in spite of obstacles.

Whether or not the dominant factors in the programs' implicit theories of change were characteristics of participants or of the program/program process, staff members at all nine program sites mentioned process elements in their discussions. Those mentioned by staff at three or more sites were: ${ }^{4}$

- Building a relationship of trust with the mother (mentioned in all but one of the sites)

- Providing support for mother or family (all but one site)

- Educating (six sites)

- Focusing on strengths (five sites)

- Modeling (four sites)

- Teaching and problem solving (four sites)

- Working as a team (for Early Head Start staff) (three sites)

These discussions indirectly yielded a qualitative sense as to how well developed the staffs' theories of change were. The emerging "theories" could be assessed in terms of the coherence of the stories that Early Head Start staff generated and the manner in which staff used terms to describe program success and nonsuccess. Coherence was judged by how clearly staff articulated what their program activities were, why they conducted these activities, and how they defined program success (the families' responses to the Early Head Start intervention). Just as the researchers evaluated staff discussion of barriers and facilitators in terms of characteristics of the mother, the program, or the program process, the terms program staff used to describe

\footnotetext{
${ }^{4}$ Twenty-four other process features were mentioned by just one or two programs each.
} 
program successes could be categorized along the same dimensions. A program's theory of change was considered to be less well developed if the program described success only in terms of characteristics of the mothers. Theories of change were considered better developed when success was described in terms of both program and process characteristics.

Two of the nine programs were considered to have well-developed theories of change, two had moderately well-developed theories, and four were judged to have underdeveloped theories. In the two programs that had the best-developed theories of change, staff members went into greater detail in describing the change process. One program detailed the relationship between Early Head Start staff and the mothers, and then described how that resulted in specific child development outcomes. The other program articulated a step-by-step process by which each family achieved its success. When theories of change were judged to be less well-developed, they failed to link important process factors (such as the staff-mother relationship) to the program's expected outcomes (such as child development) or failed to articulate the outcomes clearly, or staff were inconsistent in describing the outcomes and process elements.

\section{SUMMARY}

Programs that wish to understand and communicate their goals and their strategies for achieving them increasingly use theories of change. At the same time, researchers who desire to understand better the programs they are evaluating adopt a theory-of-change approach so they can target their analyses on the outcomes that are most important to the programs, and then be better positioned to explain the results. In the Early Head Start evaluation, we have assessed programs' theories of change using a variety of methods across various points in the programs' implementation. The Early Head Start research programs have been working toward outcomes primarily in the areas of parent-child relationships, child development, and family development. Within child development, the greatest priorities lie in the areas of social-emotional and 
cognitive development, yet considerable variation exists across programs. Programs that are center based tended to emphasize child development outcomes while those that are home based were more likely to emphasize parent-child relationships and parenting outcomes. Mixedapproach programs tended to emphasize parent-child relationship outcomes. This chapter has illustrated the variety of perspectives that contribute to understanding programs' theories of change, based on discussions among research and program partners at various sites participating in the national evaluation. 



\section{PROGRAM IMPLEMENTATION: OVERALL LEVELS AND PATTERNS}

This chapter and the three that follow report the levels and patterns of program implementation in 1999, as well as the progress in implementation that programs made over time. For these analyses, we defined the degree of implementation as the extent to which programs offered services that met the requirements of the Early Head Start grant announcement (U.S. Department of Health and Human Services 1995) and selected key elements of the revised Head Start Program Performance Standards (U.S. Department of Health and Human Services 1996). We defined "full implementation" as substantially implementing, or exceeding expectations for implementing, these key program elements.

We begin this chapter by describing our methods for measuring program implementation and then summarize the progress programs made in their overall levels of implementation between fall 1997 and fall 1999. In addition, we describe patterns in the timing by which programs reached full implementation of particular program elements. Succeeding chapters address implementation progress in broad program areas—child development and health services (Chapter V), family and community partnerships (Chapter VI), and staff development and program management systems. (Chapter VII).

\section{A. MEASURING PROGRAM IMPLEMENTATION}

To assess the extent of program implementation, we developed implementation rating scales, checklists for organizing the information needed to assign ratings to programs, and a rating process. We designed this rating system to help us reduce a large amount of information on program implementation into summary variables for testing hypotheses about how implementation relates to outcomes and to systematically analyze the research programs' 
progress toward full implementation over time. This section describes our data sources, the rating scales we developed, and the rating process we followed for assessing implementation.

\section{Data Sources}

For these analyses, we relied primarily on information collected during site visits conducted in fall 1997 and fall 1999 and self-administered surveys completed by program staff at the time of the site visits. To facilitate the systematic assignment of implementation ratings for each program, site visitors assembled the site visit and staff survey information in checklists organized according to key program elements of the performance standards (Appendix A). In addition, site visitors wrote detailed program profiles based on information obtained during the site visits. Program directors and their local research partners reviewed the profiles and checklists for their programs, provided corrections of erroneous information, and in some cases provided additional clarifying information.

\section{Implementation Rating Scales}

To develop implementation rating scales, we identified specific criteria for determining the degree to which programs implemented Early Head Start's three major program areas as defined in the performance standards: (1) early childhood development and health services, (2) family and community partnerships, and (3) program design and management. To refine our assessment, we created distinct criteria for both family and community partnerships. Likewise, within program design and management we created separate criteria for staff development and program management systems.

The criteria encompass key program requirements contained in the Early Head Start grant

announcement and the performance standards. Because the purpose of the ratings was to identify and track over time the implementation of key program requirements and not to monitor 
compliance, we focused on key requirements needed to help us identify pathways to full implementation and to summarize and quantify a large amount of qualitative information on program implementation. We reviewed our initial criteria with representatives of the Head Start Bureau and the Early Head Start technical assistance network to ensure that the criteria included the most important subset of program requirements. We also solicited comments from members of the Early Head Start Research Consortium. Table IV.1 summarizes the 25 program elements we assessed in 1999, organized according to program area. The rating scales were slightly different in 1997, but were revised based on the initial site visit experience. In 1997, we rated 24 program elements. The only differences were that in 1997 (1) follow-up services for children with disabilities were rated as a part of developmental assessments (under child development and health), (2) "father initiatives" was a separate rating element within family development (whereas in 1999 it was included in parent involvement), and (3) in the area of management systems, communication systems was not rated.

Prior to our fall 1997 site visits, we created a rating scale for each of the 24 program elements. In 1999, we made some minor revisions to these scales to reflect clarifications in program guidance from the Head Start Bureau and our evolving understanding of the performance standards, which took effect after our fall 1997 site visits. The 1999 rating scales are shown in Appendix B. ${ }^{1}$ Each rating scale contains five levels of implementation, ranging from minimal implementation (level 1) to enhanced implementation (level 5) (Table IV.2). We considered programs rated at level 1 through 3 to have reached partial implementation and programs rated at levels 4 and 5 to have reached full implementation of the particular program element rated.

\footnotetext{
${ }^{1}$ The 1997 rating scales appear in Leading the Way, Volume III, Appendix B (ACYF 2000).
} 
TABLE IV.1

PROGRAM ELEMENTS INCLUDED IN THE EARLY HEAD START

IMPLEMENTATION RATING SCALES-FALL 1999

\begin{tabular}{ll}
\hline Program Component & Program Element \\
\hline \multirow{3}{*}{ Child Development and Health } & Frequency of child development services \\
& Developmental assessments \\
& Follow-up services for children with disabilities \\
& Health services \\
& Child care \\
& Parent involvement in child development services \\
& Individualization of services \\
& Group socializations (for home-based and mixed- \\
& approach programs) \\
& Individualized family partnership agreements \\
& Availability of services \\
& Frequency of regular family development services \\
Family Development & Parent involvement \\
& Collaborative relationships \\
Community Building & Advisory committees \\
& Transition plans \\
& Supervision \\
Staff Development & Training \\
& Turnover \\
& Compensation \\
& Morale \\
& Policy council \\
& Communication systems \\
& Goals, objectives, and plans \\
Self-assessment \\
Community needs assessment \\
\hline
\end{tabular}


TABLE IV. 2

EARLY HEAD START IMPLEMENTATION RATING SCALE LEVELS

\begin{tabular}{|c|c|c|}
\hline Level & & Definition \\
\hline \multicolumn{3}{|c|}{ Partial Implementation } \\
\hline 1 & Minimal implementation & $\begin{array}{l}\text { Program shows little or no evidence of effort to } \\
\text { implement the relevant program element. }\end{array}$ \\
\hline 2 & Low-level implementation & $\begin{array}{l}\text { Program has made some effort to implement the } \\
\text { relevant program element. }\end{array}$ \\
\hline 3 & Moderate implementation & $\begin{array}{l}\text { Program has implemented some aspects of the } \\
\text { relevant program element. }\end{array}$ \\
\hline \multicolumn{3}{|c|}{ Full Implementation $^{\mathrm{a}}$} \\
\hline 4 & Full implementation & $\begin{array}{l}\text { Program has substantially implemented the relevant } \\
\text { program element. }\end{array}$ \\
\hline 5 & Enhanced implementation & $\begin{array}{l}\text { Program has exceeded expectations for implementing } \\
\text { the relevant program element. }\end{array}$ \\
\hline
\end{tabular}

"We use the term "full implementation" throughout this report as a research term to reflect our judgment that a program had achieved a rating of 4 or 5. We recognize that programs not "fully" implemented were nevertheless often implementing many features of the performance standards. In addition, even when rated as "fully" implemented, programs may have been striving to do more and be involved in continuous improvement activities. 


\section{Rating Process}

Following each round of site visits, we used a consensus-based process to assign implementation ratings to each Early Head Start research program. We assembled a rating panel that included four national evaluation team members, a representative of the Early Head Start technical assistance network, and another outside expert. For each program, three people-the site visitor and two panel members-assigned ratings independently, based on information contained in the checklists and the program profile compiled by the site visitor. Ratings were assigned for each of the 24 (or 25 in 1999) program elements, the five program areas (as shown in Table IV.1), and for overall implementation. In completing the ratings of overall implementation, we established the following guidelines for creating the overall ratings based on the ratings of the individual program components:

- Low-level Implementation: Programs that reached only a low level of implementation had achieved moderate implementation in only one or two program areas. Other programs areas were poorly or minimally implemented.

- Moderate Implementation: To achieve this rating overall, programs were (1) fully implemented in a few program areas and moderately implemented in the other areas, (2) moderately implemented in all areas, (3) moderately implemented in most areas with low-level implementation in one area, or (4) fully implemented in every area except child development and health services.

- Full Implementation: To be rated as fully implemented overall, programs had to be rated as fully implemented in most of the five component areas. Reflecting the Head Start Bureau's focus on child development, panel members gave special consideration to the rating of child development and health services, and weighted it more heavily in arriving at their consensus rating of overall implementation.

- Enhanced Implementation: A program demonstrating enhanced implementation was fully implemented in all areas and exceeded the standards in some of the component areas.

After these independent ratings were completed for all programs, the panel met to review the three sets of independent ratings, discuss differences in ratings across panel members, and assign consensus ratings for each program. We checked the validity of the our 1997 ratings by 
comparing them to independent ratings. After the Head Start Bureau completed its monitoring visits to all 17 research programs in spring 1998, we asked a member of the monitoring team to use information collected during the monitoring visits to rate programs using the rating scales we developed. We did not provide the monitoring team member with our rating results or the information we collected during site visits. The independent ratings assigned by the bureau's monitoring team member were very similar to those assigned by our rating panel, yielding an indication that our ratings provide a valid assessment of program implementation.

\section{B. PROGRESS IN OVERALL IMPLEMENTATION BETWEEN FALL 1997 AND FALL 1999}

By fall 1999, all but one of the research programs had been serving families for three years, and the Head Start Bureau had monitored each one for compliance with the performance standards, which went into effect in January 1998. Most programs had also received technical assistance following monitoring. Consequently, ACYF expected that by fall 1999, programs would be substantially in compliance with the performance standards, or very near compliance in most areas.

Indeed, across all program areas, the research programs made great strides in implementing Early Head Start between fall 1997 and fall 1999, with the number of programs rated as "fully implemented" overall doubling from 6 to 12 over the two years (Figure IV.1). ${ }^{2}$ Of the 12 programs that achieved full implementation, two were rated as having an enhanced level of implementation overall by fall 1999 (up from one in 1997). All five programs that had not reached full implementation by fall 1999 had reached moderate implementation. In most cases,

\footnotetext{
${ }^{2}$ Implementation ratings from 1997 site visits were first described in Leading the Way: Characteristics and Early Experiences of Selected Early Head Start Programs, Volume III, Program Implementation (ACYF 2000a). 1999 ratings are described in detail in Chapters V through VII of the current report.
} 


\section{FIGURE IV.1}

\section{EARLY HEAD START \\ OVERALL IMPLEMENTATION RATINGS}

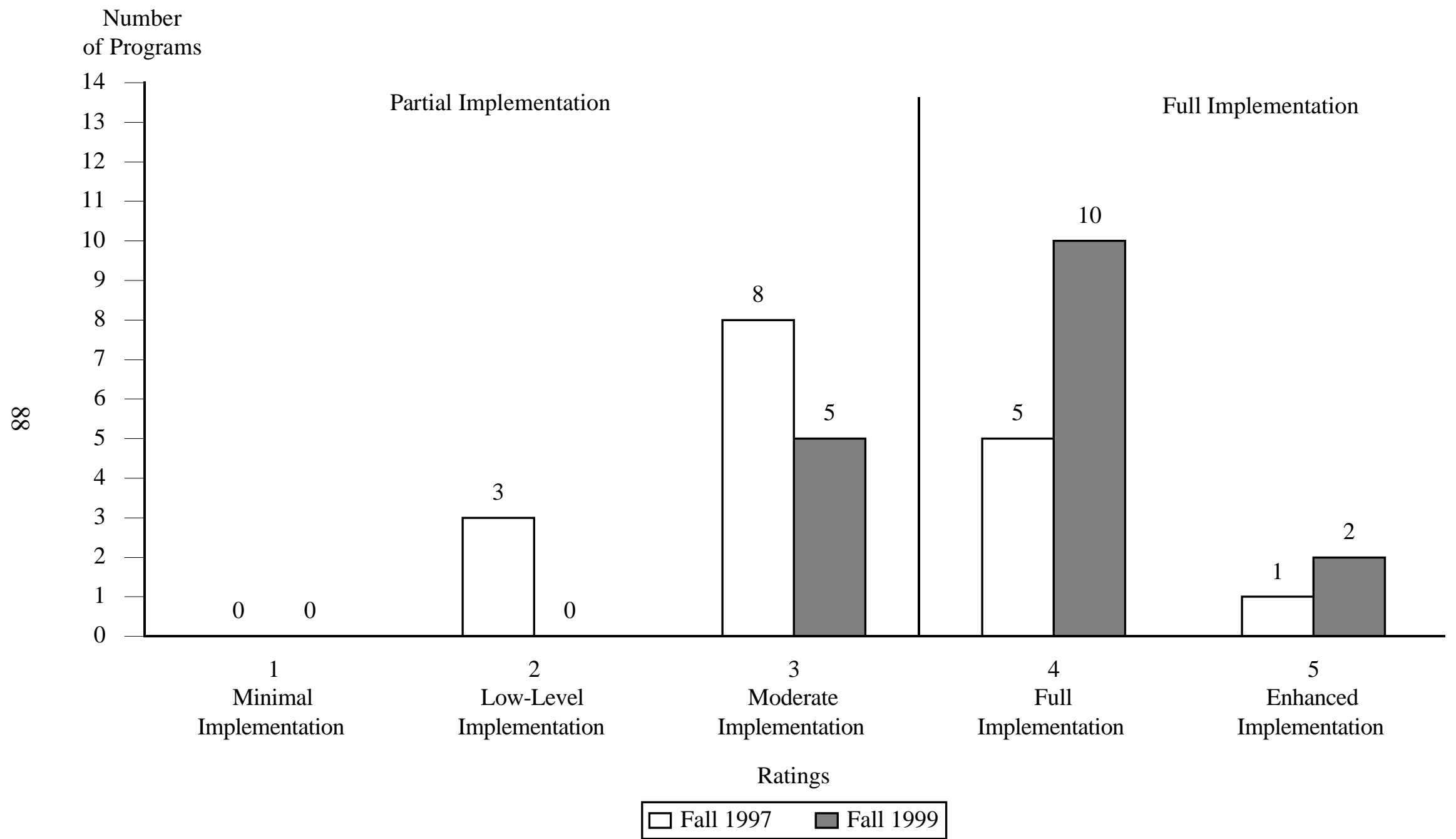

Source: $\quad$ Site visits conducted in fall 1997 and fall 1999 to 17 Early Head Start research programs.

Note: Overall implementation ratings represent the average rating across all the dimensions we examined. Programs rated as fully implemented achieved full implementation in most of the dimensions we examined, but did not necessarily achieve full implementation in every dimension. 
they achieved moderate levels in child development and health services and moderate or higher level in at least one other area. In 1997, in contrast, eight programs were rated as moderately implemented, and three (with low ratings in multiple areas) were rated as poorly implemented.

\section{PATTERNS IN THE TIMING BY WHICH PROGRAMS REACHED OVERALL IMPLEMENTATION}

The Early Head Start research programs made substantial progress in implementing key areas of the performance standards between 1997 and 1999. Altogether, nearly three-quarters of the research programs were rated as fully implemented within four years of being funded. Some accomplished this level of successful implementation relatively quickly, while others took longer. Three patterns characterize the implementation progress of the 17 research programs: those that were "early implementers," "later implementers," and "incomplete implementers."

The early implementers are those programs that were rated as fully implemented in fall 1997 and remained so in fall 1999. About one-third (six programs) were in this category. Although these programs became fully implemented early in the evaluation period, they continued to develop over the two years. For example, between 1997 and 1999 three of them expanded the number of children and families they served. These early implementers demonstrated how services for infants and toddlers can be expanded within their communities.

The later implementers are the programs that had not achieved an overall rating of "fully implemented" in fall 1997 but reached that level by fall 1999. Six programs (another third) were in this group. In many cases, these were programs that were well implemented in most areas by 1997 except child development and health, but improved their implementation of child development and health services and reached full implementation overall by 1999 .

Finally, five programs, which we refer to as the incomplete implementers, were not fully implemented in fall 1997 and had not reached full implementation by fall 1999. In some cases, 
the incomplete implementers did not meet the requirements for a rating of "fully implemented" in child development and health services or in other areas but did provide strong family development services. In every case, however, these programs had made strides in some areas, even though they still faced important challenges.

A number of factors may explain why programs achieved different levels of overall implementation at different rates. For one, experience serving infants and toddlers may have helped some programs reach full implementation of Early Head Start more quickly. Among the 11 programs that had served infants and toddlers before, 5 were early, 4 were later, and 2 were incomplete implementers. In contrast, of the six programs that were new or were Head Start programs serving infants and toddlers for the first time, only 1 was an early implementer, while 2 were later and 3 were incomplete.

Low staff turnover during the first year-including turnover in leadership positions-also appears to have been instrumental in helping programs reach full implementation more quickly. Of the six programs with a staff turnover rate of 20 percent or higher during the year prior to fall 1997, only one was an early implementer, two were later, and three were incomplete. On the other hand, among the 11 programs with staff turnover under 20 percent during the year prior to fall 1997, five were early implementers, four were later, and two were incomplete implementers. Later staff turnover does not appear to have been as important an influence on programs' progress in becoming fully implemented.

Although the timing of reaching full implementation might be expected to vary systematically according to program approach, that does not appear to be the case. Whether or not programs became fully implemented within four years of funding, and whether they did so earlier or later, does not appear to be related to their basic approach to serving families or whether they changed their approach between fall 1997 and fall 1999. Each group of programs 
defined by implementation pattern includes home-based, center-based, and mixed-approach programs as well as at least one program that had changed its approach.

Some aspects of Early Head Start were easier to implement than others. Most programs were able to implement a large number of program elements well by fall 1997 and continued implementing them well in fall 1999. These "early strengths" include: ${ }^{3}$

- Individualization of Child Development Services. From the beginning, most research programs were able to implement a strategy for individualizing child development services according to the needs of children. A strength of the programs was providing child development services to almost all children and families in their native languages. Many programs also individualized services according to children's developmental assessments.

- Developmental Assessments. Most research programs selected instruments for assessing children's development and were successful in conducting assessments with most enrolled children by fall 1997.

- Parent Involvement in Child Development Services. Most research programs were fully involving parents in planning for child development services by fall 1997. They did so by involving parents in their children's developmental assessments, reviewing the results with them, and using them to plan services. In center-based programs, some parents also participated in parent committees that planned center activities.

- Frequency of Parent-Child Group Socializations Offered. From the beginning, most home-based programs offered the required group socializations each month. However, although the programs offered these group socializations, attendance was often low.

- Efforts to Include Fathers. Most programs made special efforts to involve fathers and father figures in program activities. However, levels of participation in special activities for fathers were often low. The involvement of fathers in Early Head Start programs is explored in depth in Father Involvement in Early Head Start Programs: Summary Report (Raikes et al. 2002).

- Collaborative Relationships. Most of the Early Head Start research programs established many relationships, some based on formal written agreements, with other service providers early in their development. These programs communicated

\footnotetext{
${ }^{3}$ These program elements are defined and described in the implementation rating scales contained in Appendix B.
} 
regularly with other service providers to coordinate services for families and participated in at least one coordinating group of community service providers.

- Staff Supervision. Two-thirds of the research programs had fully implemented staff supervision requirements by fall 1997, and more than half were providing an enhanced level of staff supervision by fall 1997. Supervisors in these programs were conducting both group and individual supervision sessions and, partly from observation of service delivery, providing feedback on performance.

- Staff Training. By fall 1997, two-thirds of the research programs were providing staff training according to a plan based on assessment of staff training needs, and all staff had received training in multiple areas. Most programs also encouraged staff members to take advantage of national, state, and local training opportunities that would equip them to provide high-quality services.

- Community Needs Assessment. Nearly all the research programs had fully implemented the requirements for conducting community needs assessments by 1997 and continued to update them as required.

Many aspects of Early Head Start were more challenging to implement. Nevertheless, most programs had implemented them well by fall 1999. These "later strengths" include:

- Health Services. Between 1997 and 1999, the number of research programs that had fully implemented health services for children nearly doubled, and most programs had fully implemented these services by fall 1999. All programs helped families find medical homes for their children. By 1999, most programs were also tracking receipt of health services to help ensure that children received all recommended well-child examinations, immunizations, and needed treatments.

- Frequency of Child Development Services. Programs improved considerably over time in completing the required schedule of home visits. By fall 1999, most research programs with home-based services were completing an average of at least three home visits a month with enrolled families, and all center-based programs offered full-day, full-year child development services and child care.

- Individualized Family Partnership Agreements. By the second rating period, most programs were creating individualized family partnership agreements with all or most of their families and updating them as needed.

- Availability of Family Development Services. Over time, the number of research programs that fully implemented requirements to make a wide range of services available to families, either directly or by referral, and to follow up systematically to ensure that families receive needed services, nearly doubled.

- Frequency of Family Development Services. By fall 1999, most programs were meeting regularly with all or most families to provide case management services. 
Many programs also provided some family development services on site and made referrals to other community service providers.

- Advisory Committees. In 1997, some programs were still putting together community advisory committees in health and other areas, or the committees had formed but were not active. By 1999, most programs had established committees that met regularly and provided advice on infant and toddler issues.

- Transition Planning. Early on, most research programs did not focus on planning for children's transitions to preschool when they left Early Head Start. By 1999, however, children were beginning to transition out of the program, and most programs had procedures in place for planning with families for children's transitions.

- Staff Compensation. By 1999, more than half the Early Head Start research programs reported that staff salaries and benefits were above the average for similar community programs. Several programs were still in the process of increasing salary scales and revising them to reward staff who obtained associate's degrees.

- Staff Morale. Staff in the research programs generally reported a very positive view of their workplace. Based on site visits and staff reports, morale appeared to be very high in half the programs.

- Policy Council. Initially, only half the research programs had fully implemented Policy Council requirements, but by 1999, nearly all had established Policy Councils that included parents and community members and met regularly to make key decisions about the program.

- Goals, Objectives, and Plans. Initially, many programs had not formally set goals and objectives, nor had they developed written implementation plans. By 1999, however, most programs had set or updated their goals and objectives and developed written implementation plans.

- Self-Assessment. In 1997, one-third of the research programs had conducted an annual assessment of their progress toward their goals and of their compliance with the Head Start Program Performance Standards. By 1999, the proportion of programs that had conducted a self-assessment in consultation with Policy Council members, parents, staff, and other community members doubled. 
A third group of program elements appears to represent "ongoing challenges" for Early Head Start programs. Three elements were particularly challenging to implement, and the majority of programs had not fully implemented them by fall $1999 .^{4}$ These are:

- Child Care. Many Early Head Start parents were employed and needed child care services. Programs that offered center-based services were able to meet the child care needs of families more easily than were home-based programs. Home-based programs made considerable progress in developing child care options that meet the performance standards, and some even added their own center-based services. Despite progress from 1997 to 1999, however, few home-based or mixed-approach programs could ensure that the child care attended by "all or nearly all" Early Head Start children was of high quality. Helping parents arrange high-quality child care and working with child care providers to meet the quality standards in the Head Start Program Performance Standards remains a challenge.

- Parent Involvement ${ }^{5}$ : Although all programs offered opportunities for parents to participate in program governance, many offered opportunities for parents to volunteer, and many worked hard to involve fathers, only a few were able to involve most parents in some capacity. In part because of welfare reform, many parents were working and finding it difficult to make time for volunteering and participating in other program activities.

- Staff Retention: Like child care programs in general, many of the Early Head Start research programs struggled to retain frontline staff, and in both 1997 and 1999, experienced staff turnover rates of 20 percent or more. Although most programs did not achieve low turnover rates by 1999, the number of programs that experienced very high turnover rates did decline.

The following chapters explore the levels and patterns of program implementation in more depth and describe the factors that influenced program implementation.

${ }^{4}$ Although health services were among the program elements that programs implemented well by fall 1999, one aspect of these services, namely mental health services, presented an ongoing challenge. Shortages of mental health services in the community made it very difficult for programs to link all families to mental health services they needed.

${ }^{5}$ This excludes involvement in child development services but includes volunteering, serving on Policy Councils, and participating in parent committees. 


\section{PROGRESS IN IMPLEMENTING KEY CHILD DEVELOPMENT AND HEALTH SERVICES}

Early Head Start and Head Start programs are designed to promote healthy development during children's early years. In the revised Head Start Program Performance Standards, the Head Start Bureau lays out specific Head Start and Early Head Start program requirements for achieving this overall goal. ${ }^{1}$ In the domain of child health and development, the standards specify the following types of services, designed to ensure that the services are of high quality:

- Child health services, including assessments of health status; developmental, sensory, and behavioral screenings that involve parents and enable staff and parents to individualize services for the child; and plans for followup and treatment of health conditions

- Education and early childhood development services, including developmentally and linguistically appropriate services that include children with disabilities, involve parents, and support children's development in a range of domains

- Child nutrition services, including assessments of nutritional needs, meals and snacks in center-based settings and/or during group socialization activities, and nutrition education

- Child mental health services, including assessments of children's behaviors, consultations with mental health professionals to address mental health concerns, and education of parents and staff on mental health issues

In developing implementation rating scales, we focused on selected elements of the standards. We rated each program's level of implementation of the following key aspects of the performance standards and program guidelines pertaining to child health and development:

- Developmental assessments

- Individualization of child development services

\footnotetext{
${ }^{1}$ Throughout this chapter we quote appropriate sections of the standards. For the complete performance standards, go to http://www.acf.hhs.gov/programs/hsb/performance/index.htm.
} 
- Parent involvement in child development services

- Group socializations

- Child care

- Health services

- Follow-up services for children with disabilities

- Frequency of child development services

To be rated as "fully implemented" overall in child development and health services, programs had to be rated as fully implementing services (that is, substantially implementing the relevant program element) in most of these dimensions. In this chapter, we review the progress the Early Head Start research programs made in implementing child development and health services in relation to the requirements of the performance standards.

The number of programs rated as fully implementing Early Head Start child development and health increased slightly between fall 1997 and fall 1999. By fall 1999, 9 of the 17 research programs were fully implementing services in this area (Figure V.1), compared with 8 in $1997 .^{2}$ The following sections tell the story behind this progress as we describe activities in each of the eight aspects that the implementation study examined.

\footnotetext{
${ }^{2}$ Although nearly all the programs improved their implementation of child development and health services between 1997 and 1999, clarifications in program guidance from the Head Start Bureau led us to revise the rating scales in this area, so that, in effect, the "bar" for full implementation was raised between 1997 and 1999. Most notably, the 1999 rating scales require a higher number of completed home visits per month for a rating of "fully implemented" on that dimension and require that most families participate in group socializations regularly to attain a "fully implemented" rating on that dimension. See Appendix Table A.1 for a detailed description of the changes in the rating scales between 1997 and 1999.
} 


\section{FIGURE V.1}

\section{EARLY HEAD START CHILD DEVELOPMENT SERVICES IMPLEMENTATION RATINGS}

Number of Programs
Partial Implementation
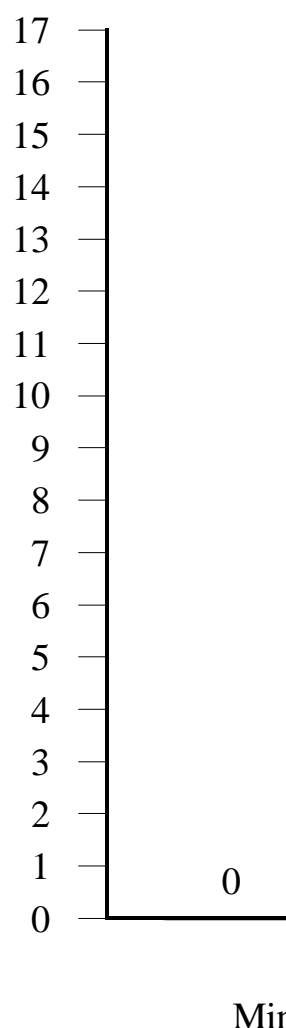

Implementation

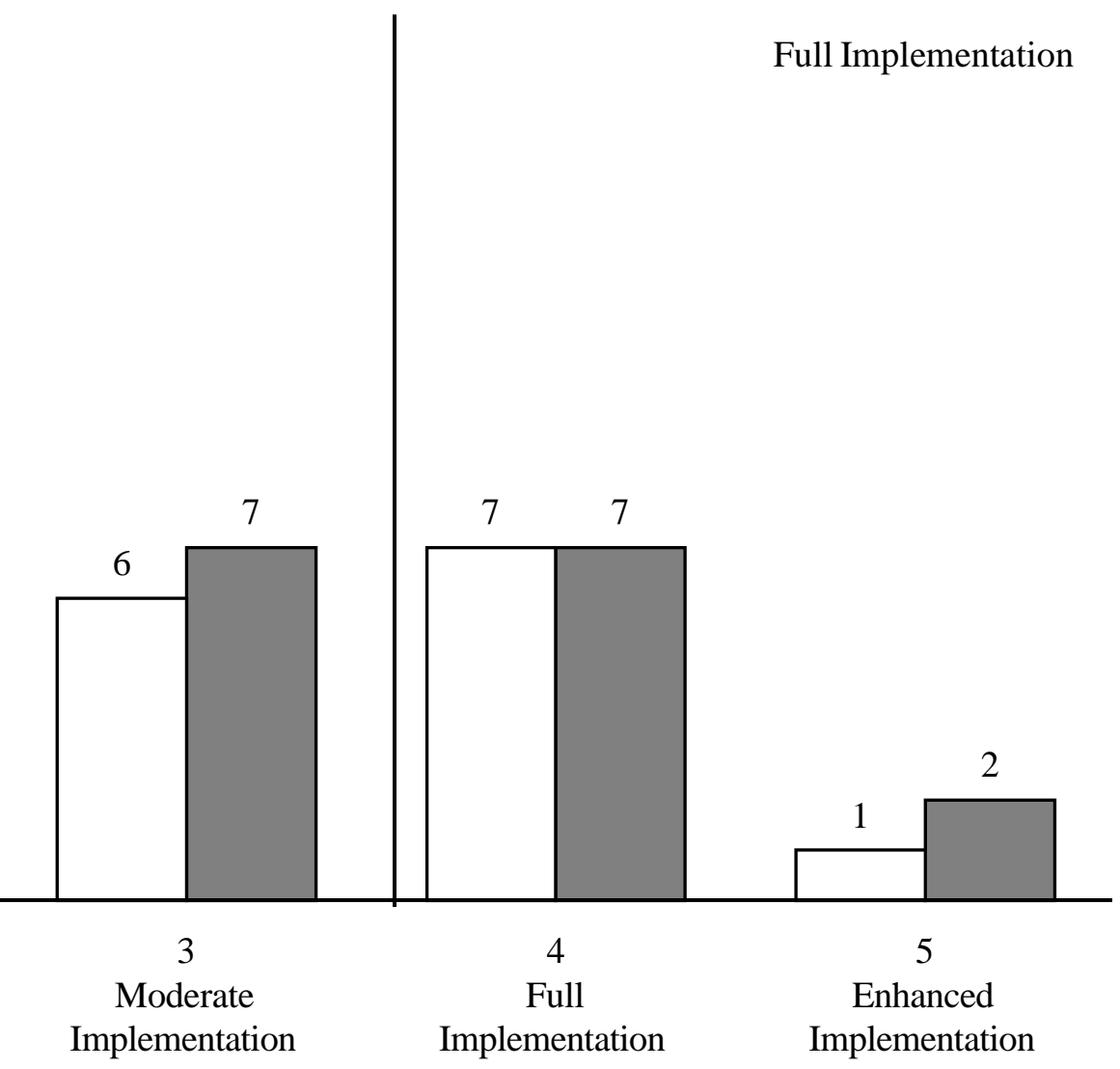

Ratings

Source: Site visits conducted in fall 1997 and fall 1999 to 17 Early Head Start research programs.

Note: Implementation ratings for child development services represent the average rating across all the dimensions we examined. Programs rated as fully implemented achieved full implementation in most of the dimensions we examined, but did not necessarily achieve full implementation in ever dimension. The 1999 ratings are based on revised rating scales that reflect clarifications in program guidance from the Head Start Bureau between 1997 and 1999. 


\section{A. DEVELOPMENTAL ASSESSMENTS}

The revised Head Start Program Performance Standards require programs to conduct periodic assessments of children's motor, language, social, cognitive, perceptual, and emotional skills.

The most common tools the research programs used to assess children's development were the Ages and Stages Questionnaires (ASQ), the Denver II Developmental Screening Test (DDST II), the Early Learning Accomplishment Profile, and the Hawaii Early Learning Profile (Figure V.2). Between fall 1997 and fall 1999, more programs adopted the ASQ and DDST II. Programs indicated that they used the ASQ because they are parent-friendly and facilitate parent participation in the assessment process; some adopted the DDST II because they believed it facilitated working with early intervention service providers (the Part $\mathrm{C}$ agency) to identify children with disabilities.

By fall 1999, most of the research programs (14 of the 17) had fully implemented developmental assessments as required (up from 10 programs in fall 1997) (Figure V.3). In fact, 11 research programs had reached an enhanced level of implementation in this area: all staff who worked with a child used that child's developmental assessment results to plan services for the child and the family. Three research programs were rated as achieving a moderate level of implementation of developmental assessments, because they had given most children (but fewer than 90 percent) a developmental assessment during the year preceding the site visit.

\section{B. INDIVIDUALIZATION OF CHILD DEVELOPMENT SERVICES}

The revised Head Start Program Performance Standards require programs to implement child development services in a way that respects children's individual rates of development, temperament, gender, culture, language, ethnicity, and family composition.

All the research programs had fully implemented a strategy for individualizing child development services by fall 1999 (up from 14 programs in fall 1997). Many programs (15) had reached an enhanced level of implementation in this area by fall 1999. These programs provided 
FIGURE V.2

\section{TOOLS USED BY EARLY HEAD START RESEARCH PROGRAMS TO ASSESS CHILDREN'S DEVELOPMENT}

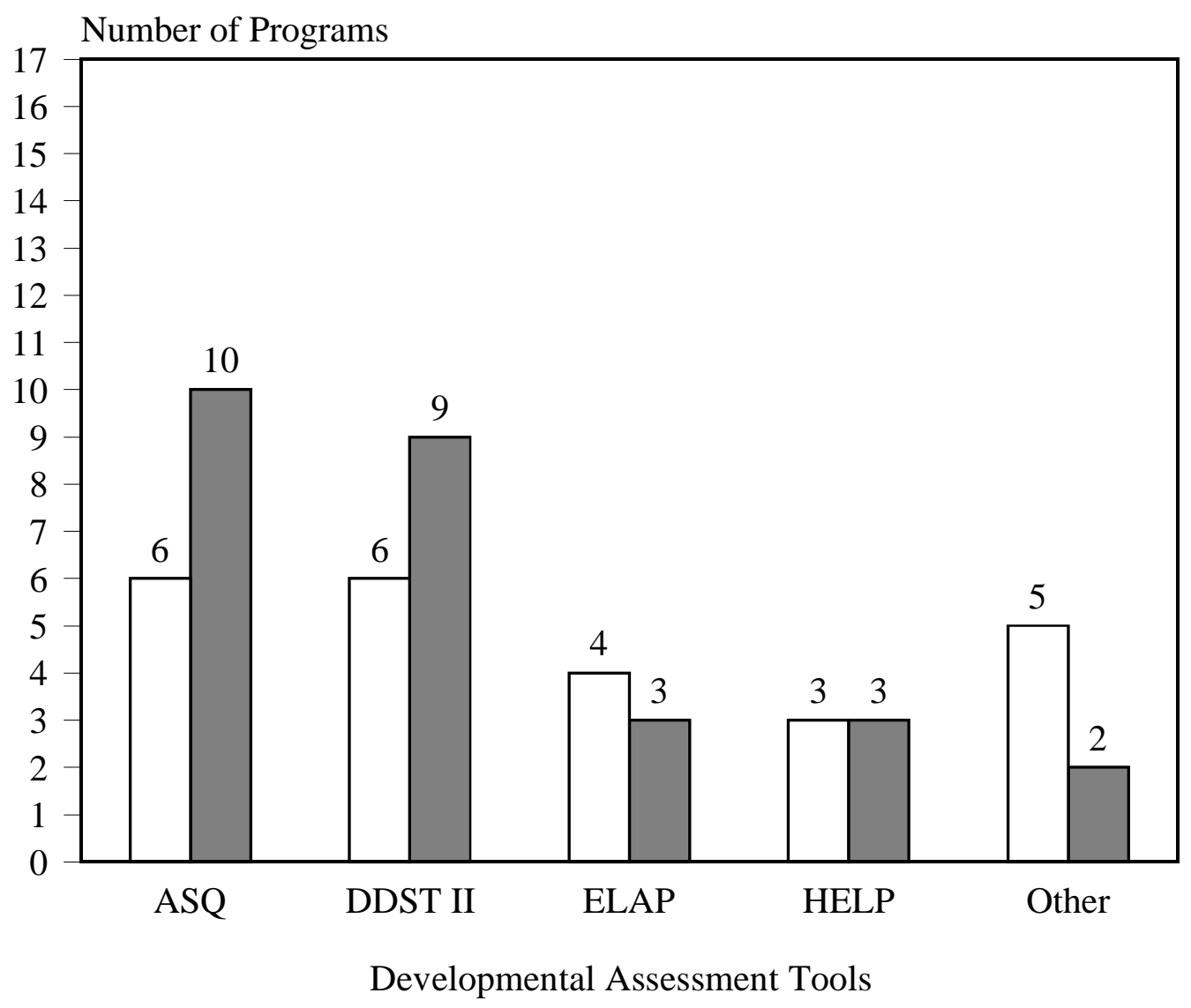

$\square$ Fall $1997 \quad \square$ Fall 1999

ASQ = Ages and Stages Questionnaires.

DDST II = Denver II Developmental Screening Test.

ELAP = Early Learning Accomplishment Profile.

HELP = Hawaii Early Learning Profile.

SOURCE: Information gathered during visits to the Early Head Start research programs in fall 1997 and fall 1999. 
FIGURE V.3

That Reached Full

Implementation

EARLY HEAD START CHILD DEVELOPMENT SERVICES ASPECTS THAT WERE FULLY IMPLEMENTED

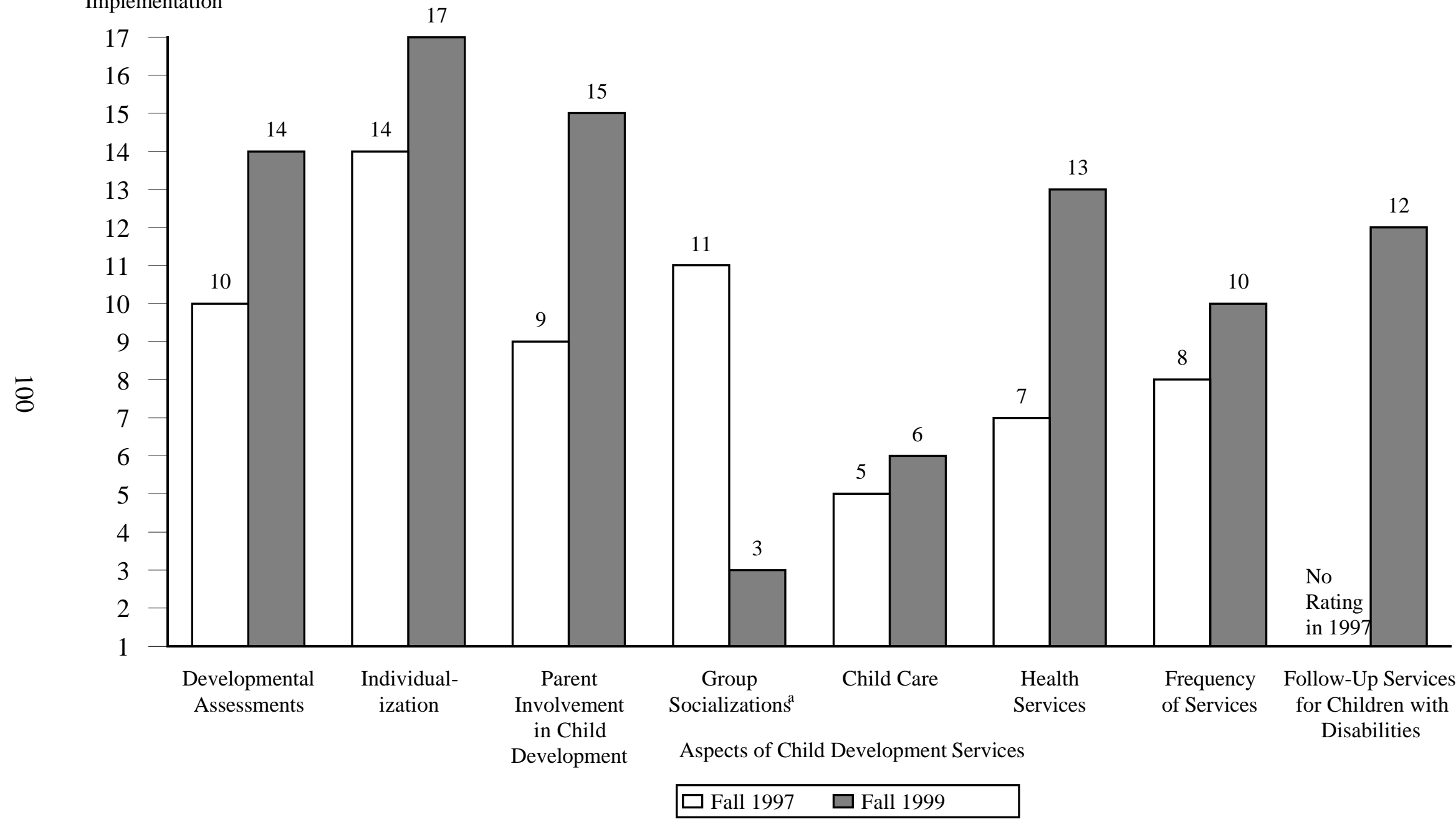

Source: $\quad$ Site visits conducted in fall 1997 and fall 1999 to 17 Early Head Start research programs.

${ }^{a}$ The rating scales in these areas were changed significantly between 1997 and 1999 to reflect clarifications in guidance from the Head Start Bureau. To the rating scale for group socializations we added the requirement that most families participate in group socializations on a regular basis. We also increased the number of home or center visits required for a "fully implemented" rating on frequency of child development services from two to three times per month. 
child development services to almost all children and families in their own language, usually Spanish or English. In some cases, programs provided services in three or more languages.

The research programs used a variety of strategies for individualizing child development services. In addition to serving almost all enrolled families and children in the language they spoke at home, many programs used the results of developmental assessments to plan future child development services and activities. Typically, home visitors and center teachers reviewed the results with parents and worked with them to plan activities appropriate for the child's stage of development and to strengthen any areas the assessment identified as weak. Home visitors often worked with parents to select education topics based on parents' concerns or interest in specific developmental areas (such as sleeping, nutrition, toilet training, or motor skills). Within

the framework of a center curriculum or classroom theme, center teachers usually planned specific activities in response to the needs and interests of their group of children. Many even planned individualized activities that addressed specific developmental areas for each child.

\section{PARENT INVOLVEMENT IN CHILD DEVELOPMENT SERVICES}

According to the revised Head Start Program Performance Standards, programs should involve parents in child development services by involving them in planning child development activities, helping them improve their child observation skills, and discussing children's development with them.

The research programs involved parents in child development services in a variety of ways. Some programs involved parents directly in conducting developmental assessments, and many involved parents in reviewing the results and planning services. In families receiving center-based services, parents participated in parent committees that planned center activities, and some parents volunteered in center classrooms.

By fall 1999, 15 of the research programs (up from 9 in 1997) had fully implemented strategies to involve parents in planning and providing child development services. All 15 
involved at least one parent in most families and some fathers in child development services. Seven programs had reached an enhanced level of implementation in this area, which entailed involving at least one parent from almost all families and many fathers in child development services.

\section{GROUP SOCIALIZATIONS}

The revised Head Start Program Performance Standards require programs to offer at least two group socialization activities per month to families who receive home-based child development services. We rated programs with a home-based option as fully implemented if they offered these group socialization activities and most families attended them regularly.

In fall 1999, 3 of the 13 research programs that provided home-based child development services to some or all families had fully implemented group socializations for those families. Most programs offered group socializations at least twice a month, but in many programs participation was low. The apparent drop in the number of programs fully implementing group socializations (from 11 programs in 1997 to 3 programs in 1999) reflects the addition between 1997 and 1999 of the requirement that most families participate regularly for a rating of "fully implemented." 3

Programs found it very difficult to achieve high participation rates in group socialization activities. Some of the challenges related to the logistics of scheduling and conducting group socializations, and others related to lack of clear direction from the Head Start Bureau about how group socialization activities should be carried out. Scheduling these activities when most parents could attend was very difficult. Many parents had busy work schedules and lacked free time. Other parents had irregular schedules that often conflicted with group socialization

\footnotetext{
${ }^{3}$ The addition of the requirement of regular participation by most families for a rating of "fully implemented" was based on the researchers' judgments, not a change in the requirements in the revised Head Start Program Performance Standards.
} 
schedules. Transportation problems also made it difficult for some parents to attend group socializations, so program staff had to find ways to provide transportation assistance. Some programs found it challenging to find a good location for these activities, either because of general program space limitations or because program families lived far from the program offices.

In addition to logistical challenges, lack of clear direction from the Head Start Bureau and some programs' uncertainty about how to carry out the group socialization requirements probably hampered some programs' efforts to achieve high participation in these activities during the initial years of program operations. Some programs were uncertain about how to staff and organize the socializations, and over time tried several different approaches. For example, one program tried convening monthly two-hour parent meetings that included parent-child activities, referring parents to play groups in the community, offering play groups twice a month at various times, holding annual parent-child events organized around a theme, and planning small group activities for families in each home visitor's caseload. In some programs, staff and/or parents did not have a clear or common understanding of the purpose and intended content of the group socializations. Sometimes staff did not think that group socializations were appropriate for infants, because infants were thought to be too young to participate in meaningful group activities.

In striving to achieve high participation levels in group socialization activities, one program also had to address issues related to young parents' experiences in group activities where they did not feel comfortable or accepted. In addition, staff members in some programs were hesitant to push families to participate in group socializations when families complained about the substantial time requirements for participation in other program activities such as home visits. 
Throughout the evaluation period, programs were trying to meet these challenges and increase participation in group socializations by:

- Changing the scheduled days and times of group socializations to make them more accessible to families

- Increasing the number of group socialization opportunities at varying times and days

- Hiring a part-time staff member to plan and organize group activities

- Making group socialization activities more structured, for example, by focusing on a particular age group or need area, such as pregnancy

\section{E. CHILD CARE}

Since the fall 1997 site visits, the Head Start Bureau has clarified its expectation that programs are to ensure that all child care arrangements used by enrolled families meet the revised Head Start Program Performance Standards, whether the care is provided directly by the program or in another community setting. We rated programs as fully implementing the child care requirements if they helped families who needed it arrange child care, assessed and monitored the child care arrangements to ensure that they met the standards, helped families prevent interruptions in child care subsidies, and/or provided good-quality child care directly.

The proportion of children reported to be in child care arrangements increased slightly over time (Figure V.4). In six programs, fewer than half of Early Head Start children were in child care in fall 1999. In 11 programs, more than half of all children were in child care, and in 6 of these programs ( 4 of which were center-based), many or all of the children were in child care. This section of Chapter $\mathrm{V}$ focuses on program strategies to arrange for quality care, assess and monitor arrangements, and ensure continuity. We devote Chapter VIII to describing child care quality. 
FIGURE V.4

ESTIMATED PROPORTION OF FAMILIES

USING CHILD CARE

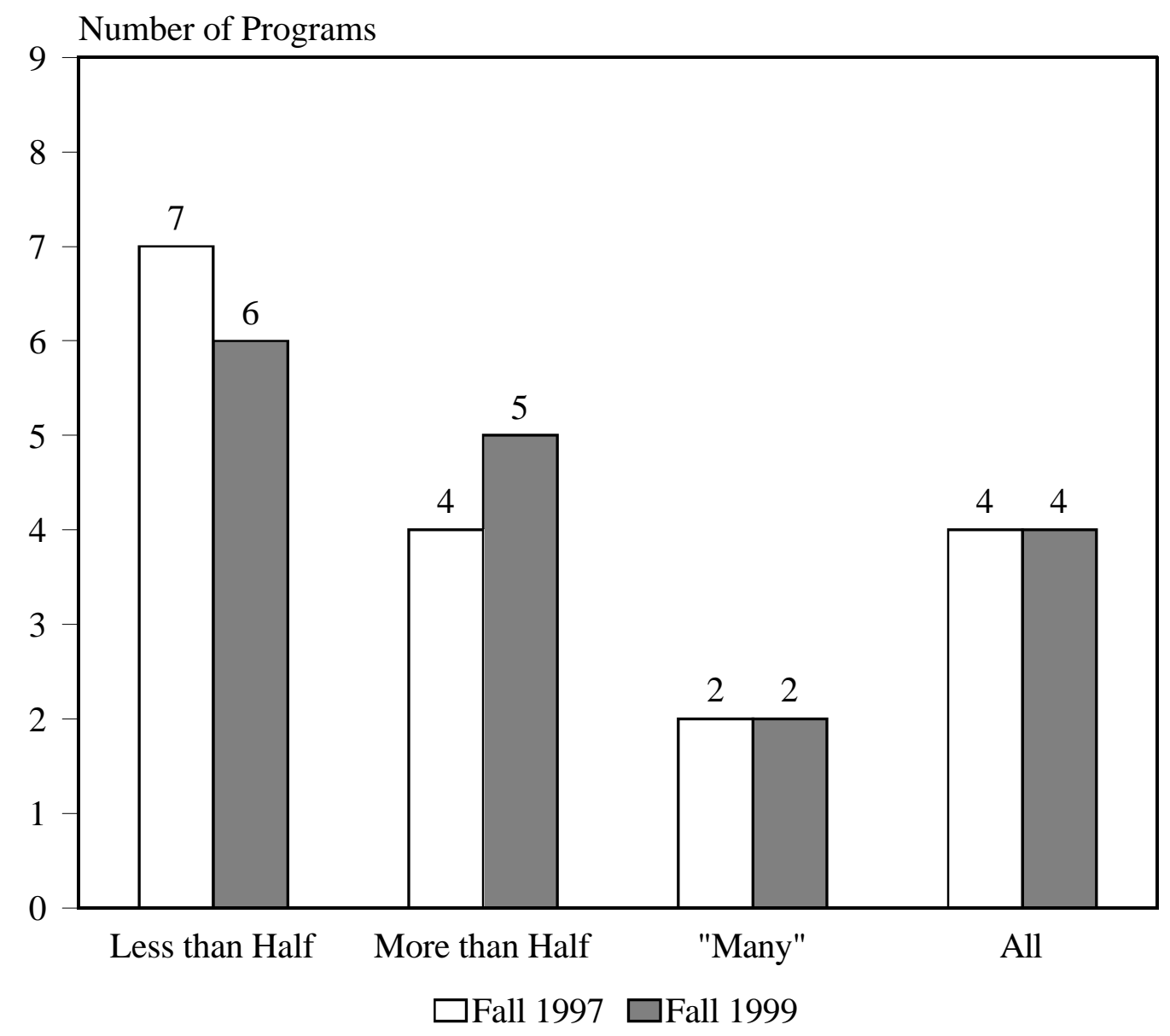

Proportion of Families Using Child Care

SOURCE: Information gathered during visits to the Early Head Start research programs in fall 1997 and fall 1999. 
In fall 1999, six programs had reached full implementation of the child care requirements, up from five in fall $1997 .^{4}$ Five of these programs provided child care directly in Early Head Start centers to most families who needed it. Another program had established formal agreements with community child care providers to provide care for Early Head Start children and work toward meeting the performance standards. This program regularly assessed the quality of care that community child care partners provided.

Seven programs had reached a moderate level of implementation of the child care requirements. Some of these programs provided some child care directly to some (but not all) families who needed it. In addition, some monitored the quality of some community child care arrangements, but they did not have procedures in place to ensure that all or nearly all child care used by Early Head Start families met the performance standards.

The research programs adopted a variety of strategies to work towards ensuring that the child care arrangements in which Early Head Start children received care met the performance standards (Figure V.5). These strategies included:

- Helping families identify and select high-quality child care arrangements

- Making referrals to specific child care arrangements that they had determined provide high-quality child care

- Referring families to local resource and referral agencies

- Assessing the quality of care before making placements

${ }^{4}$ Between 1997 and 1999, the child care implementation rating scale changed in several ways. First, we added consideration of the quality of care provided by Early Head Start centers, with a rating of "full implementation" requiring the provision of good-quality care. For a rating of "full implementation," we added two requirements: (1) that if families use child care subsidies, there must not be interruptions in child care services; and (2) that most children must be in care that the program assesses and monitors to ensure that it meets the performance standards. 
FIGURE V.5

\section{STRATEGIES USED BY EARLY HEAD START RESEARCH PROGRAMS TO MEET THE PERFORMANCE STANDARDS FOR CHILD CARE}

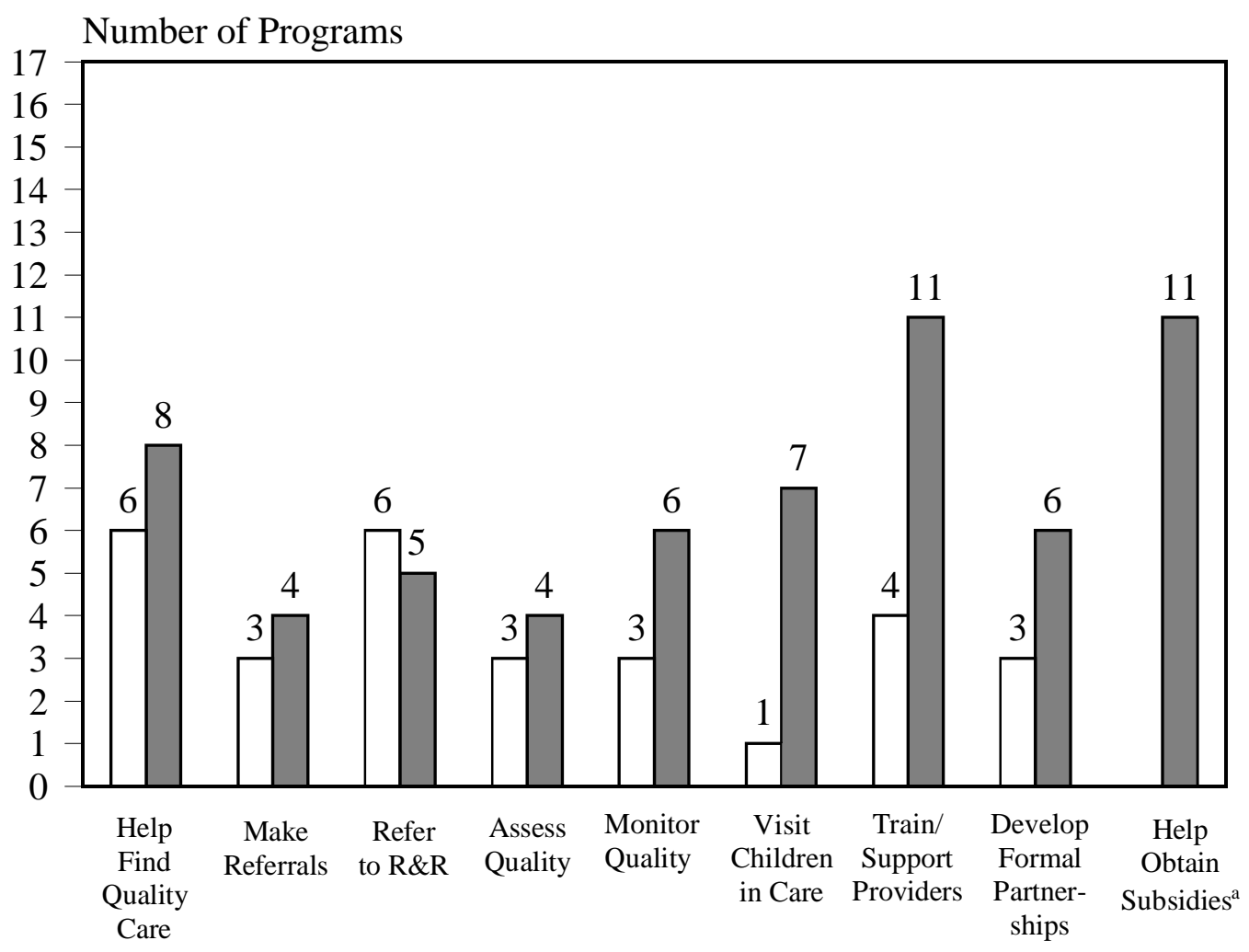

Strategies to Ensure Child Care Quality

$\square$ Fall $1997 \square$ Fall 1999

SOURCE: Information gathered during visits to the Early Head Start research programs in fall 1997 and fall 1999.

${ }^{a}$ We did not collect information on programs' efforts to help families obtain state child care subsidies in our 1997 site visits. Thus, we report the number of programs implementing this strategy in 1999 only. 
- Systematically monitoring at least some of the child care arrangements children were in

- Visiting children in their care settings, where they could observe the care children were receiving and develop relationships with the child care providers

- Offering training and/or support to child care providers caring for Early Head start children

- Developing formal partnerships with child care providers that care for Early Head Start children

- Helping families apply for and obtain state child care subsidy funds

Over time, the number of strategies that programs implemented to work on meeting the performance standards in community child care settings increased substantially. In 1997, the 17 research programs reported using a total of 29 strategies. By 1999, programs reported using a total of 62 strategies, or an average of nearly 4 per program.

In the course of implementing strategies to work with community child care partners on meeting the performance standards, programs faced a number of challenges. Programs had to start with the care that was available in the community, which in some cases was not sufficient in supply and generally not of good quality.

Program staff also found that it takes time to work toward meeting the performance standards in community child care settings, even under the best of circumstances. Community providers may not be set up to meet the performance standards quickly, even if they are eager to do so. Moreover, it takes time to build the relationships with community child care providers that serve as the foundation for solid partnerships through which compliance with the performance standards can be addressed.

For most child care providers, making the changes necessary to meet the performance standards required additional resources. For example, resources are required for staff training and for reducing child-staff ratios and group sizes. Many programs initially did not have the 
resources needed to pay for such changes. Some programs obtained additional funds from a variety of sources (such as expansion and quality improvement grants from ACYF and state Early Head Start grants) to support child care quality, but obtaining these resources took time.

In the past several years, new state child care initiatives and increases in state child care subsidy funds have made it easier for families to obtain financial assistance to pay for child care. In fall 1999, 11 programs helped families apply for and obtain state subsidy funds, which also helped to increase resources available to pay for good-quality care. Six helped families obtain subsidies to pay for child care in community settings, three helped obtain subsidies for centerbased care provided directly by the program, and two helped obtain subsidies for extended-hours care. Four programs used child care subsidy funds to cover a portion of the cost of their Early Head Start centers.

Despite the availability of subsidies, some families still had difficulty paying for child care. In fall 1999, 10 research programs were implementing strategies to prevent interruptions in child care and help parents pay for good-quality child care. Four programs used subsidies to pay for Early Head Start center care but covered the full cost of care with program funds when families experienced interruptions in subsidies. Three programs set aside program funds to help families make co-payments, pay the difference between the provider's rate and the subsidy rate, and/or pay for child care during gaps in subsidy coverage. Other strategies included funding community child care slots as a last resort for families who could not obtain subsidies, providing extended-hours slots for families who could not obtain subsidies, and using a state grant to pay for community child care.

Another challenge the programs sometimes faced was ensuring good quality in the child care settings that parents selected. Parents sometimes chose care without input from program staff, either because they had to find care quickly when they found a job or because they 
preferred a familiar arrangement with an informal provider whom they knew and trusted. These informal providers are not always interested in or even willing to work with program staff to assess or improve the quality of care they provide.

\section{F. HEALTH SERVICES FOR CHILDREN}

The revised Head Start Program Performance Standards charge programs with ensuring that all children have a regular source of health care and access to the health, dental, and mental health services they need. Programs must also track health services to ensure that children receive all recommended well-child examinations, immunizations, and needed treatments.

By fall 1999, the number of research programs that had fully implemented the health services requirements nearly doubled, from 7 programs in fall 1997 to 13 in fall 1999. Six had reached an enhanced level of implementation-they systematically tracked receipt of well-child examinations, immunizations, and treatment, and children received health services without delay. In fall 1999, four programs were rated as reaching only a moderate level of implementation of child health services. One of the four did not provide adequate access to mental health services. In three of the four, less than 90 percent of children were up-to-date on immunizations and well-child examinations, which indicates that adequate tracking systems were not in place or that program staff had not been able to work effectively with all parents to ensure that they obtained the health services their children needed. In one of these programs, problems with the management information system made it difficult to discern whether immunization rates were low or record-keeping was incomplete.

The research programs took a variety of approaches to ensuring that children received needed health services:

- All programs helped families find regular sources of medical care ("medical homes") for their children, and some helped families navigate their state's Medicaid managed care system. 
- Several programs provided mental health services through agency staff and community partners to families who needed it. Some programs provided child mental health services on site at their centers.

- Several programs had nurses on staff who provided some health services (especially well-child examinations), tracked receipt of health services, and helped families arrange for services.

- One program held special health screening days at its centers and recruited area physicians, dentists, and other specialists to conduct the screenings.

- Programs often used the HSFIS and other software packages to track receipt of health care services.

- Several programs provided transportation to medical appointments when families needed it.

\section{G. FREQUENCY OF CHILD DEVELOPMENT SERVICES}

The performance standards require programs to provide one home visit per week (48 to 52 visits per year) to families receiving home-based services. For center-based services, the performance standards require programs to offer classes at least four days per week, for between 3.5 and 6 hours per day. We rated programs as fully implemented on this dimension if almost all children received child development services at least three times per month (through three completed home or center visits or regular attendance at a center) and parent education at least monthly. ${ }^{5}$

The number of programs that had reached full implementation of child development services at this frequency increased slightly, from 8 in fall 1997 to 10 in fall 1999. Although they were closer in fall 1999 than in fall 1997 to meeting the requirements for completing planned home visits with home-based families, the research programs continued to struggle with meeting these requirements throughout this period. In fall 1999, 8 out 13 programs providing home-based

\footnotetext{
${ }^{5}$ This rating was designed to help us assess whether most children and families were receiving services of sufficient intensity to have an impact on child development. The frequency of child development services required for a rating of "fully implemented" was raised from two completed home visits per month in the 1997 rating scale to at least three completed home visits per month in the 1999 rating scale to reflect the Head Start Bureau's increased emphasis on completing the number of visits required in the performance standards. For the evaluation's purposes, we set the requirement for being "fully implemented" lower than the four per month of the performance standards based on input from consultants suggesting that three per month is more realistic.
} 
services reported that home-based families received an average of 3 home visits per month, whereas in fall 1997, the majority reported completing an average of 1 or 2 per month. Only one program reported completing the required four per month in fall 1999, on average. Four programs reported completing an average of two per month (Figure V.6).

The research programs worked hard to increase the frequency of completed home visits. Their efforts included:

- Conducting home visits during evenings and on weekends to accommodate parents' schedules (although some programs found that evening visits are difficult because parents are tired and children want to be with their parents exclusively, and that Saturdays are difficult because parents are often busy with chores and errands)

- Conducting some home visits with children (and sometimes parents) in their child care settings

- Persistently and consistently scheduling home visits and inviting families to program activities

- Requiring families to meet with home visitors, and terminating families who do not start meeting with their home visitor within a certain period

- Reconfiguring service options so that families in the home-based option were receiving the most appropriate services for their needs

- Building children's enthusiasm for home visit activities and causing them to look forward to visits (children can be powerful agents in engaging parents in home visits)

Along with the frequency of completed home visits, the amount of time typically spent on child development during these visits also determines the intensity of child development services delivered to families receiving home-based Early Head Start services. A focus on child development means that home visitors spent time in activities with the child alone or with the child and parent together, or on parenting education with the parent. Nearly all programs reported that home visitors spent more than half the typical visit on child development (Figure V.7). In the accompanying box, Carla Peterson, a research partner with the Marshalltown, Iowa, program, gives an in-depth analysis of how home visitors spent their time during home visits. 


\section{Looking Closer: Interactions During Home Visits}

Carla Peterson

Iowa State University

The Mid-Iowa Community Action, Inc. (MICA) Early Head Start program uses home visits as its primary mode of service delivery. All families work with two professional staff members: a family development specialist (FDS) and a child development specialist (CDS), whose roles are largely described by their titles. MICA's theory of change, as well as its programmatic resources, are focused on facilitating child development through strengthening parents' skills for their roles and supporting them in their parenting roles. The families being served in central Iowa are primarily Caucasian, with a few Hispanic families and even fewer of other ethnicities. Most live in small towns or rural areas, and approximately half are single-parent families.

Data to describe the process and content of home visits were collected using the Home Visit Observation Form (HVOF). The HVOF enables the observer to record information simultaneously on three major aspects of the home visit process: (1) interaction partners (parent and child; interventionist and parent; joint interaction with the parent, child, and interventionist; interventionist with another adult; parent with another adult), (2) content of interaction (child's development, parenting issues, family relationship issues, community resources/referral, parent education/employment), and (3) nature of the interventionist's interaction (working directly with the child, modeling for the parent, facilitating parent-child interaction, observing an interaction, asking for and/or providing information).

Within each category, data were collapsed across observed visits, and the percentages of overall time spent in each of the various interaction and activity arrangements was calculated. When the CDSs interact with the child, it is generally within the context of joint interactions with the parent and child. However, the parent spends little time interacting directly with the child. The CDSs spend about onethird to half of their time interacting with adults. The interventionists spend time on content areas that are consistent with their roles.
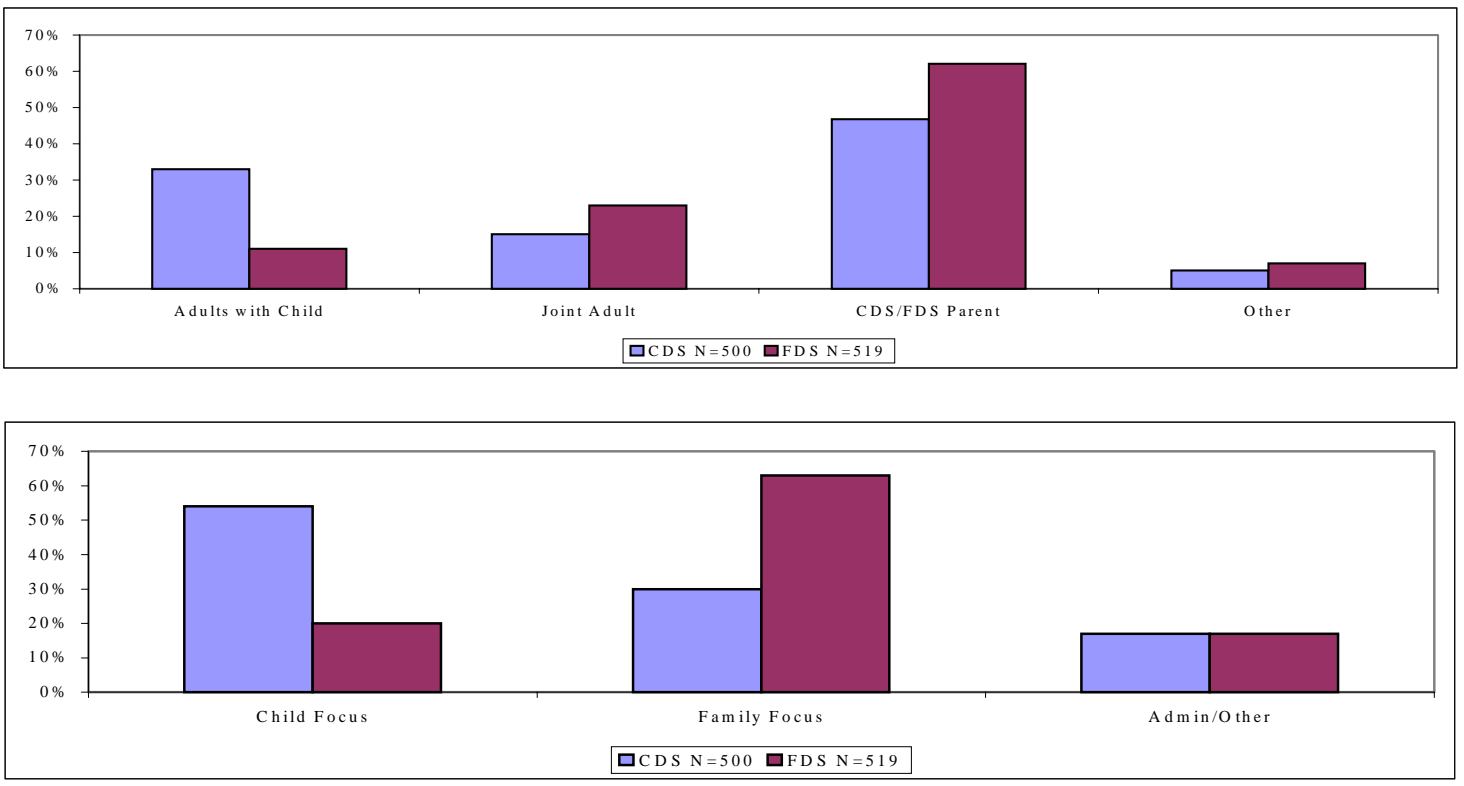

Both CDSs and FDSs spend most of their time supporting adult communications, largely in providing and asking for information. The content of the communication varies with the person's role, but both FDSs and CDSs spend large amounts of time involved in discussions with parents.

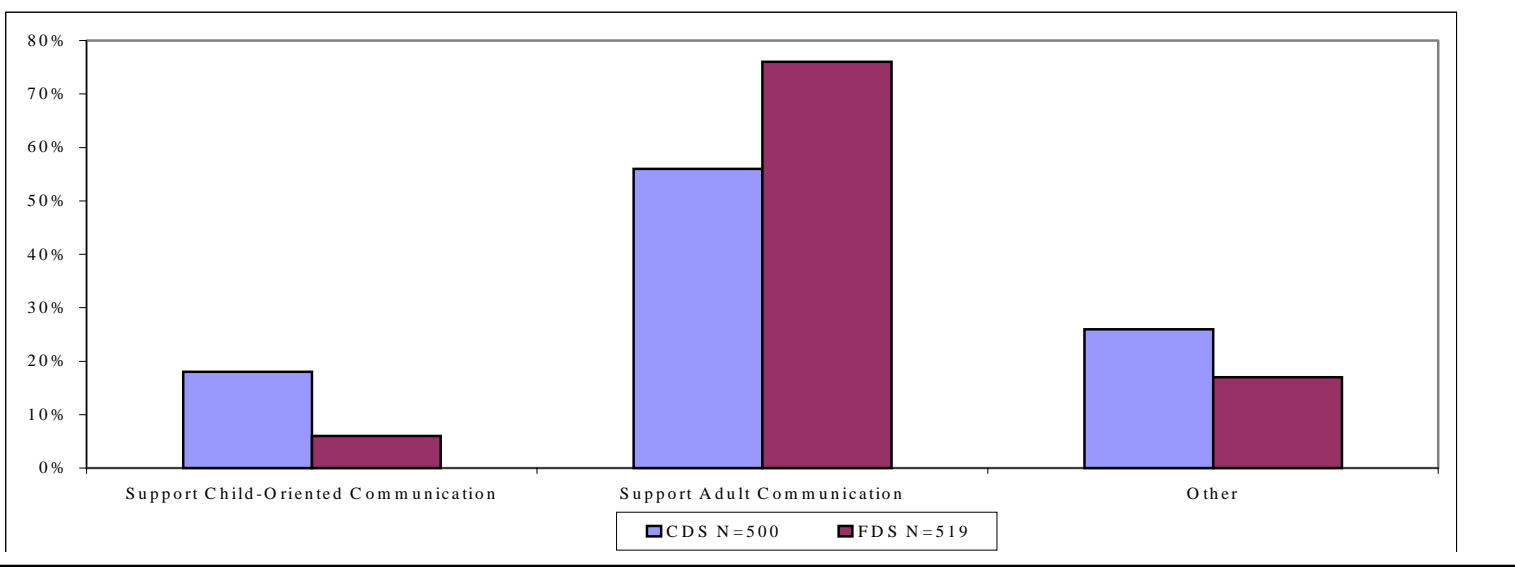


FIGURE V.6

FREQUENCY OF COMPLETED HOME VISITS IN EARLY HEAD START RESEARCH PROGRAMS FOR FAMILIES RECEIVING HOME-BASED SERVICES

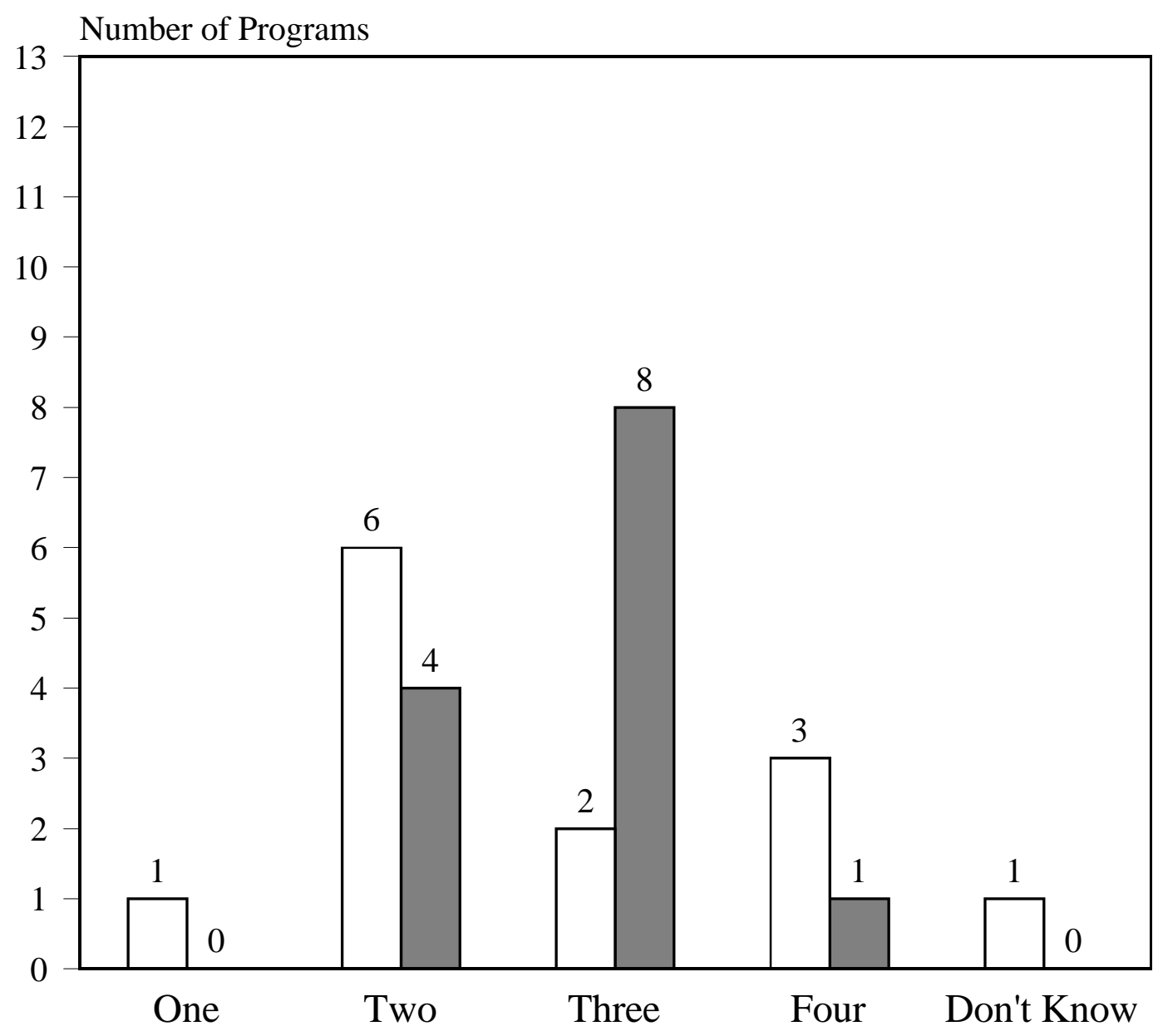

$\square$ Fall $1997 \square$ Fall 1999

Average Number of Home Visits per Month for Families that Received Home-Based Services

SOURCE: Information gathered during visits to the Early Head Start research programs in fall 1997 and fall 1999. 
FIGURE V.7

\section{PERCENTAGE OF TIME TYPICALLY SPENT ON CHILD DEVELOPMENT IN HOME VISITS}

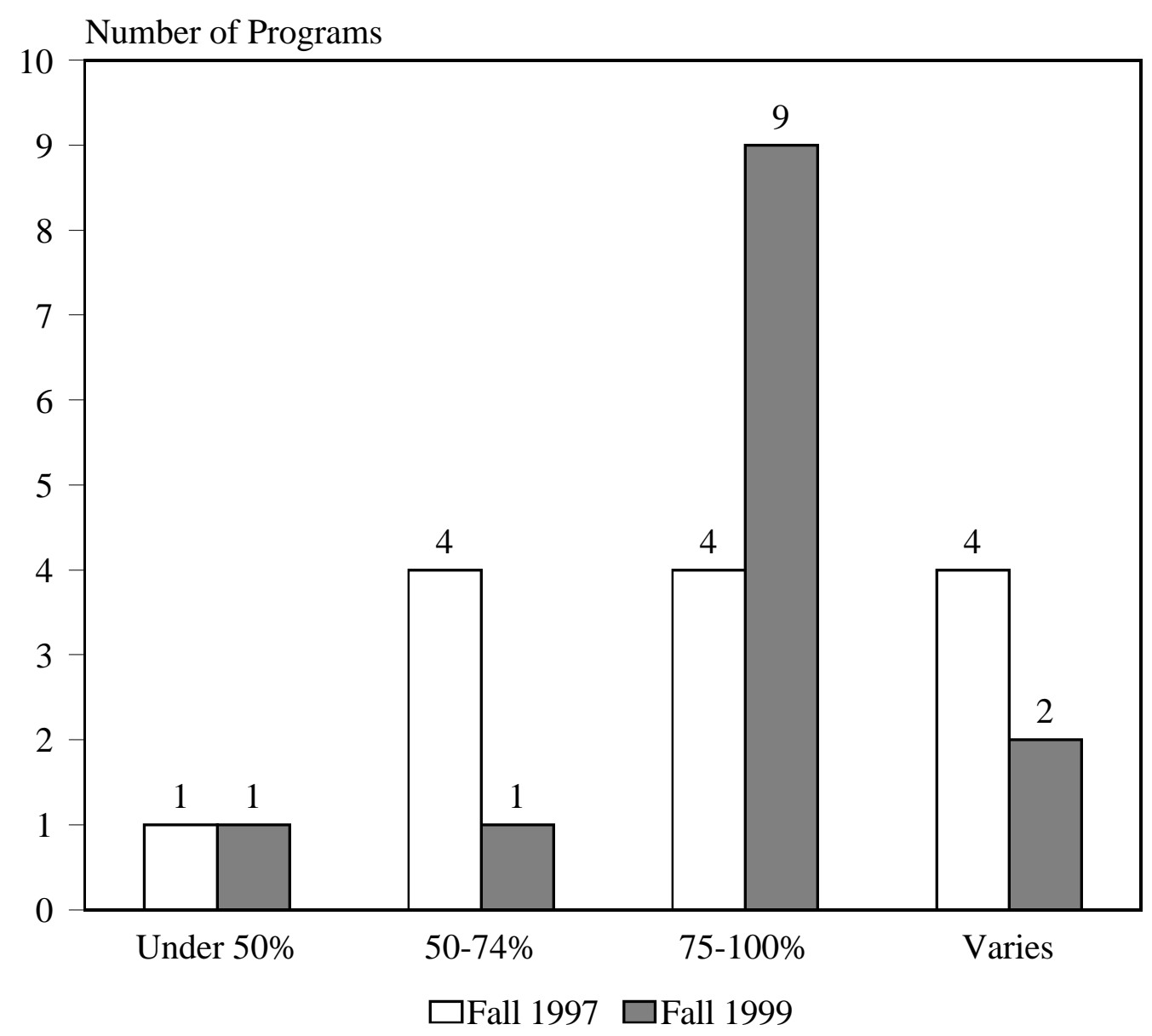

Percentage of Home Visit Time Typically Spent on Child Development

SOURCE: Information gathered during visits to the Early Head Start research programs in fall 1997 and fall 1999. 
Besides home visits, programs provided parenting education in a variety of settings, including group sessions for parents, group socialization activities, individual meetings or counseling sessions, and daily contacts with parents at Early Head Start centers, as well as through newsletters, resource libraries, and journal writing (Figure V.8).

\section{H. SERVICES FOR CHILDREN WITH DISABILITIES}

The revised Head Start Program Performance Standards require programs to refer families to Part $C$ when they suspect a child has a disability. Staff must also work closely with the Part $C$ provider to coordinate services, and the performance standards encourage them to develop joint service plans whenever appropriate. At least 10 percent of enrolled families must have a child with an identified disability. We rated programs as fully implemented in this area if (1) they referred families to Part $C$ providers and followed up with families promptly, (2) they worked closely with Part $C$ staff to coordinate services, and (3) at least 10 percent of enrolled families had a child with an identified disability (or the program made vigorous efforts to recruit children with disabilities). ${ }^{6,7}$

By fall 1999, 12 of the 17 research programs had fully implemented services for children with disabilities (Figure V.3). Strategies for coordinating with Part C included:

- Developing joint service plans

- Arranging therapy services to be provided in Early Head Start classrooms

- Arranging for Early Head Start staff to serve as the service coordinator for Individual Family Service Plans (IFSPs)

- Participating with parents and Part $\mathrm{C}$ providers in service coordination meetings

${ }^{6}$ This rating was included together with the rating of developmental assessments in the 1997 rating scales. Therefore, there was no separate rating of this aspect of child development services in 1997.

${ }^{7}$ Part $\mathrm{C}$ providers are agencies designated under Part $\mathrm{C}$ of the Individual with Disabilities Education Act (IDEA) Amendments of 1997 (PL 105-17) to be responsible for ensuring that services are provided to all children with disabilities between birth and age 2 . 
FIGURE V.8

\section{STRATEGIES BEYOND HOME VISITING USED BY EARLY HEAD START RESEARCH PROGRAMS TO PROVIDE PARENTING EDUCATION}

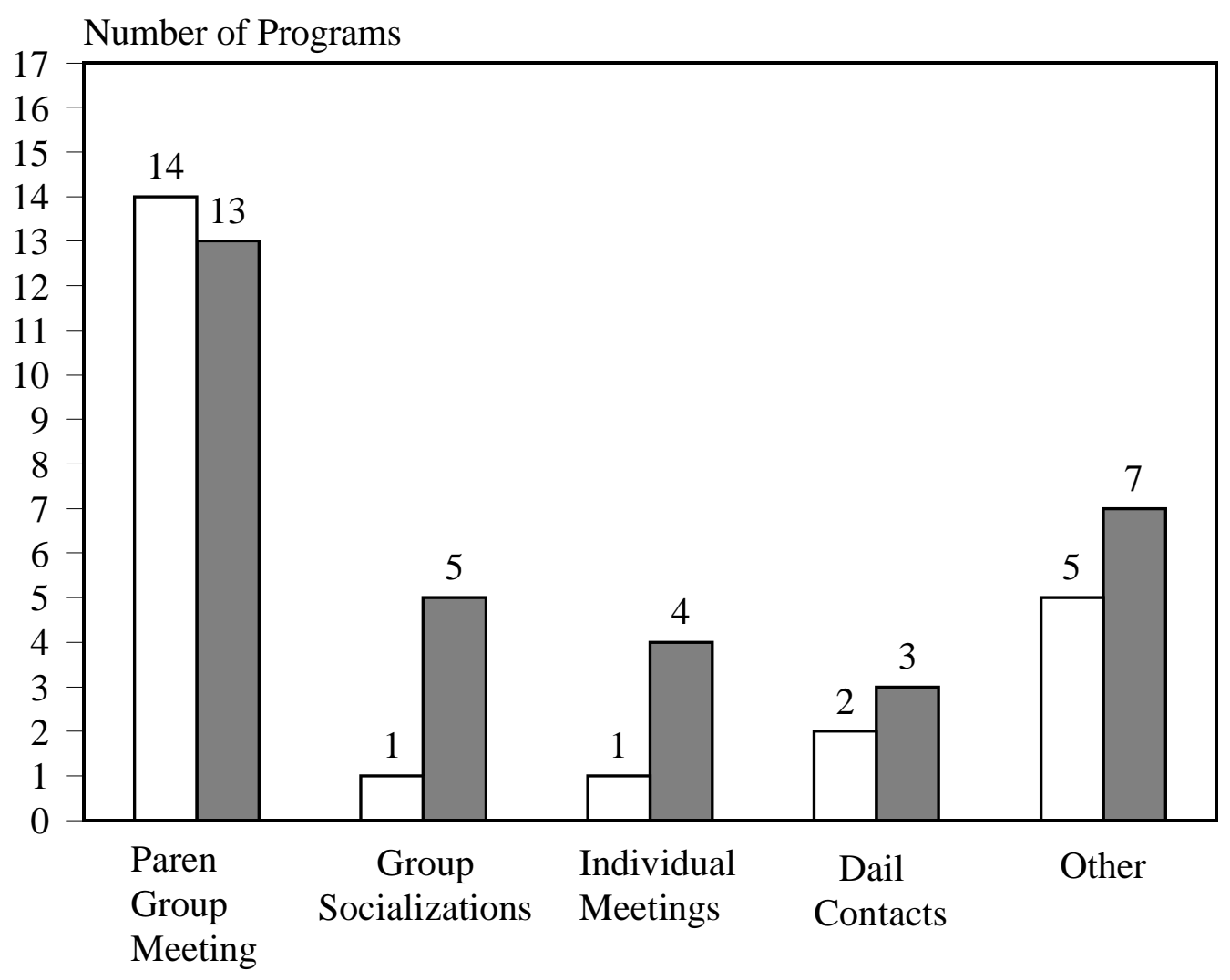

Parenting Education Strategies Beyond Home Visits

$\square$ Fall $1997 \square$ Fall 1999

SOURCE: Information gathered during visits to the Early Head Start research programs in fall 1997 and fall 1999. 
- Forming Special Quest teams with local Part C providers to work on enhancing coordination between the two programs ${ }^{8}$

\section{SUMMARY}

Between fall 1997 and fall 1999, the research programs made substantial progress in implementing the key aspects of the revised Head Start Program Performance Standards that we examined. Although implementing several aspects of child development services continued to present challenges to many of the programs (especially achieving good attendance at group socializations and ensuring good-quality child care for families receiving home-based services), most programs achieved a rating of "full implementation" for other aspects of child development services. The pathways that programs took as they progressed toward full implementation are examined in Chapter X.

${ }^{8}$ Special Quest joined the Head Start training and technical assistance system this year as the Hilton/Early Head Start Training Program. This program, a public/private partnership between the Conrad N. Hilton Foundation and the Head Start Bureau, is administered by the California Institute on Human Services at Sonoma State University. Its mission is to help professionals and family members involved in Early Head Start and Migrant Head Start programs develop skills and strategies for working with infants and toddlers who have significant disabilities. 


\section{PROGRESS IN IMPLEMENTING FAMILY AND COMMUNITY PARTNERSHIPS}

Ongoing family and community partnerships are critical for supporting Early Head Start and Head Start programs in their efforts to promote children's healthy development. The Head Start program is "family centered and is designed to foster the parent's role as the principal influence on the child's development and as the child's primary educator, nurturer, and advocate" (Department of Health and Human Services 1996, p. 57186). Similarly, the revised Head Start Program Performance Standards emphasize that Early Head Start and Head Start programs are intended to be "community-based, with different specific models of service delivery flowing out of the differing needs of differing communities." The performance standards envision programs as "central community institutions for low-income families, building linkages and partnerships with other service providers and leaders in the community" (Department of Health and Human Services 1996, p. 15187). Thus, central questions for the implementation study were: Were Early Head Start programs implementing family and community partnerships by their third year of delivering services?, Were aspects of these activities especially challenging?, and Did programs experience particular successes in these areas?

In the area of family partnerships, the performance standards address program practices in several domains:

- Setting goals for families

- Gaining access to community services and resources

- Providing services to pregnant women who are enrolled in Early Head Start

- Encouraging parent involvement in the program 
- Providing child development and education; health, nutrition, and mental health education; transition activities; and home visits

- Advocating in the community

To be rated as fully implementing family partnerships, programs had to be rated as fully implementing services in most dimensions that we rated, including frequency of family development services, development of individualized family partnership agreements (IFPAs), availability of services, and parent involvement. ${ }^{1}$

The performance standards address the following aspects of community partnerships:

- Partnerships

- Advisory committees

- Transition services

To be rated as fully implementing EHS community partnerships, programs had to be rated as fully implementing services in most of the dimensions that we rated, including collaborative relationships, advisory committees, and transition planning.

\section{A. FAMILY PARTNERSHIPS: CHANGES IN SERVICES AND IMPLEMENTATION PROGRESS BETWEEN 1997 AND 1999}

The research programs made significant strides in implementing Early Head Start's family partnerships, and by fall 1999, three years after they began serving families, two-thirds had

\footnotetext{
1.

${ }^{1}$ In Chapter IV we reported ratings of parent involvement in child development activities, which refers to their involvement in the planning and delivery of such services. In this chapter, parent involvement refers to parents' participation in program policymaking, operations, and governance. These activities may include child development and other components of the Early Head Start Program.
} 
reached full implementation in this area. The number that achieved full implementation increased from 9 to 12 between fall 1997 and fall 1999 (Figure VI.1).

\section{Individualized Family Partnership Agreements}

The revised Head Start Program Performance Standards require that programs develop IFPAs in collaboration with families, review them regularly, and update them as needed.

Fourteen research programs had fully implemented these requirements in fall 1999 (Figure VI.2), up from 8 in fall 1997. Nine were rated as having reached an enhanced level of implementation in this area in fall 1999 because they had learned about the other services that families received, coordinated with other service providers, and conducted joint planning when appropriate. The programs that had reached only moderate implementation of the IFPA requirements in fall 1999 had developed IFPAs with fewer than 90 percent of the families in their caseloads.

\section{Availability of Services}

The revised Head Start Program Performance Standards require programs to make a wide range of services available to families, either by providing them directly or through referral to other community service providers, and to follow up systematically to ensure that families receive the services they need.

Between fall 1997 and fall 1999, the number of programs that were fully implementing these requirements nearly doubled, from 6 to 11 (Figure VI.2). Eight had reached an enhanced level of implementation of the service availability requirements by fall 1999 because, in addition to following up on services families received, they assessed and monitored the quality of family development services offered. The programs that were rated as moderately implemented did not systematically follow up on referrals. 


\section{FIGURE VI.1}

\section{EARLY HEAD START FAMILY PARTNERSHIPS IMPLEMENTATION RATINGS}

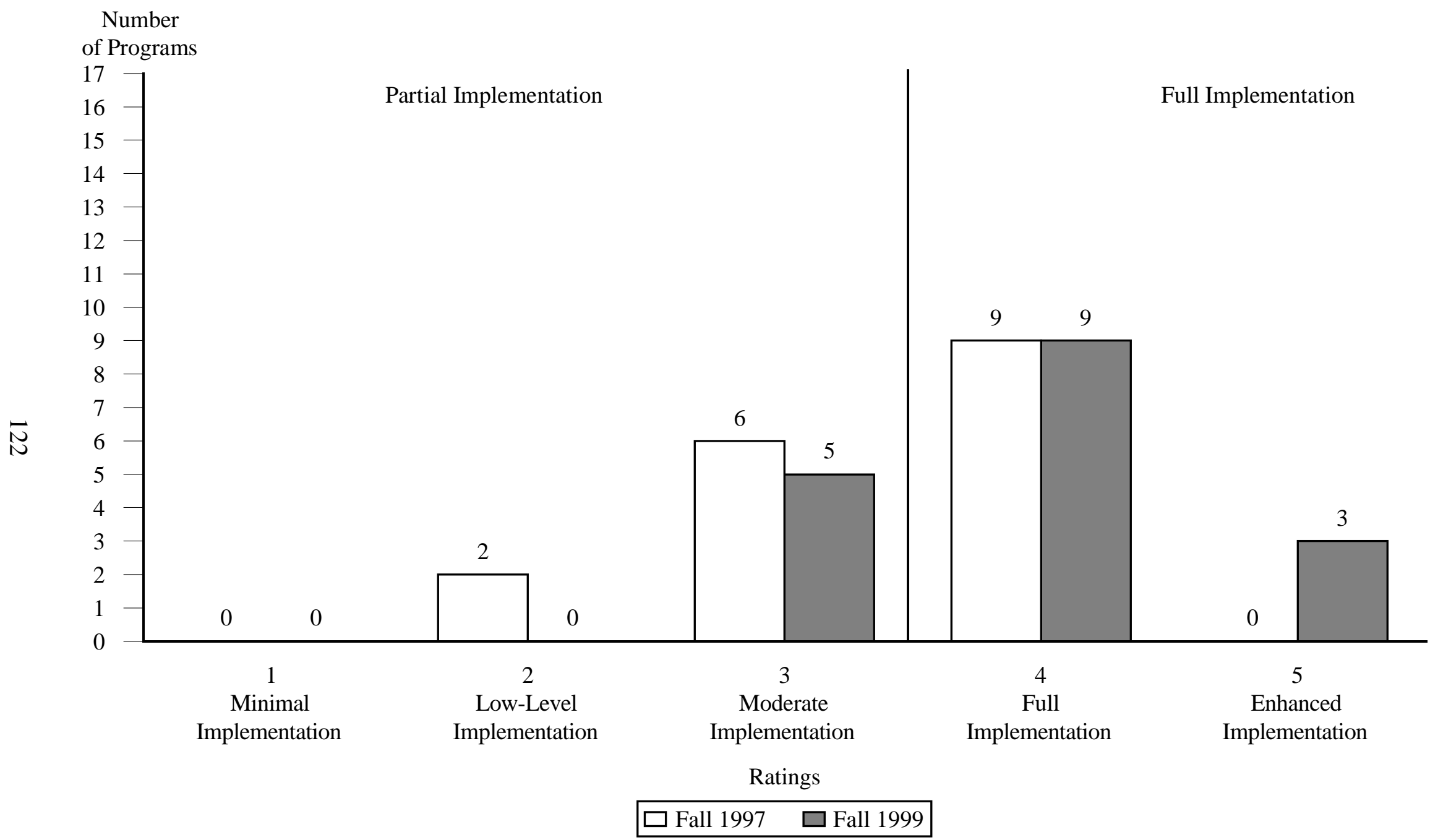

Source: $\quad$ Site visits conducted in fall 1997 and fall 1999 to 17 Early Head Start research programs.

Note: Implementation ratings for family partnerships represent the average rating across all the dimensions we examined. Programs rated as fully implemented achieved full implementation in most of the dimensions we examined, but did not necessarily achieve full implementation in every dimension. 
EARLY HEAD START FAMILY PARTNERSHIPS

ASPECTS THAT WERE FULLY IMPLEMENTED

Number of Programs

That Reached Full

Implementation

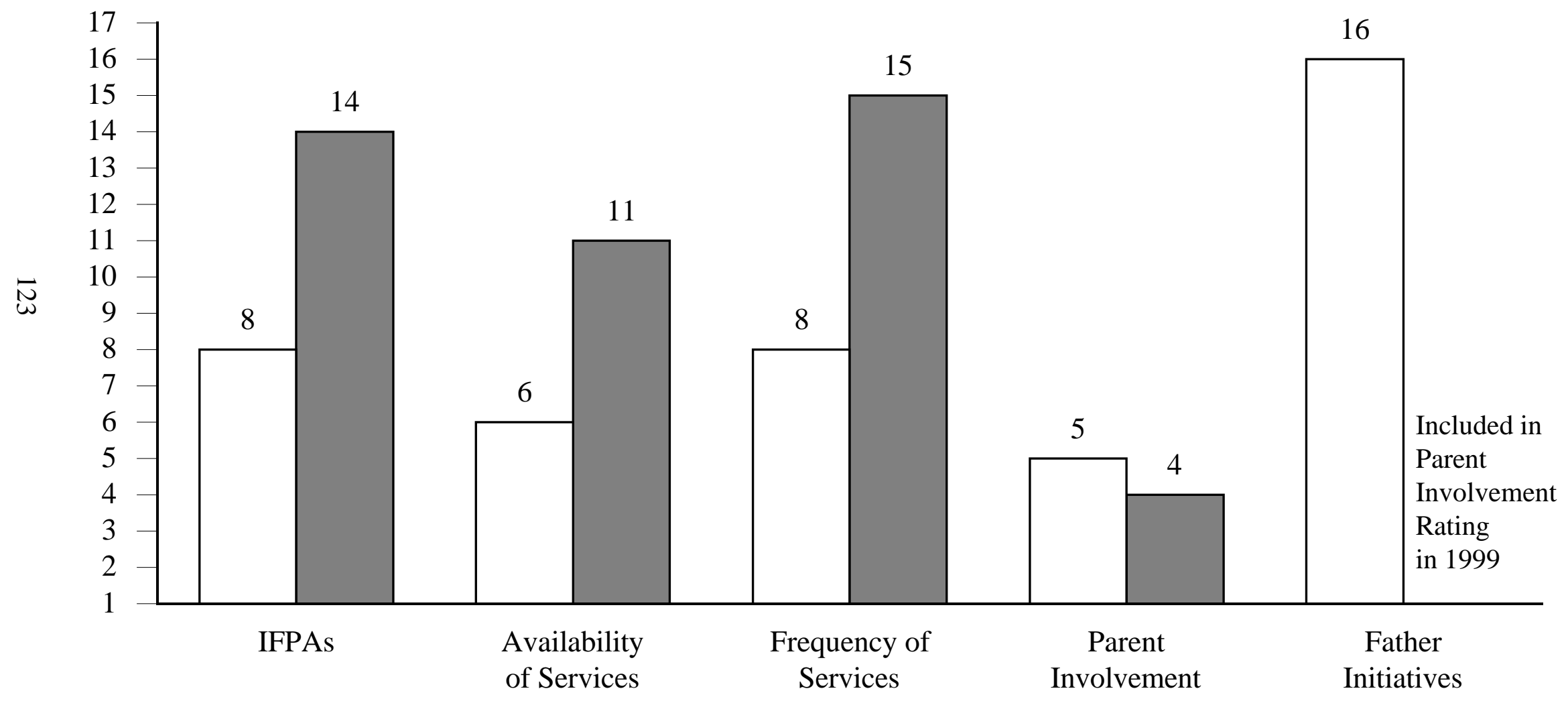

Aspects of Family Development Services

$\square$ Fall $1997 \quad \square$ Fall 1999

Source: Site visits conducted in fall 1997 and fall 1999 to 17 Early Head Start research programs. IFPA = Individual Family Partnership Agreement. 


\section{Frequency of Services}

Although the performance standards do not specifically address frequency of family development services, we rated programs as fully implemented with respect to the frequency of family development services if most families regularly received such services.

As in other areas, the number of programs that were fully implemented nearly doubled, from

8 to 15 (Figure VI.2). The fully implemented programs held regular case management meetings (at least monthly) with families, either during home visits or in conferences at program centers, parents' workplaces, or parents' school sites. In addition, many programs provided some services—such as health, employment, or counseling services—directly and also made referrals to community providers. Two programs were rated as moderately implemented on this dimension because some families did not have case management meetings at least monthly with program staff.

\section{Parent Involvement}

The revised Head Start Program Performance Standards require programs to involve parents in child development services (this type of parent involvement is discussed in Chapter V, Section B.3), to involve them in policymaking and program operations, and to give them multiple opportunities to participate as volunteers or employees (this type of parent involvement is rated under family partnerships). In addition to the requirements for parent involvement in the performance standards, the Head Start Bureau clarified its expectation that programs try to increase father involvement. We rated programs as fully implemented in this area if the program provides multiple opportunities for involvement in policy groups and volunteer activities (with most parents involved in some capacity) and makes special efforts to encourage father involvement (with some fathers participating). ${ }^{2}$

1.

${ }^{2}$ In 1997, we rated parent involvement and father initiatives separately, with the rating of father initiatives indicating simply whether or not the program made any special effort to involve fathers. Nearly all the programs had a special father initiative in 1997. In 1999, we made the rating criteria more rigorous to assess whether programs had established comprehensive approaches to involving both mothers and fathers and were succeeding in involving them. 
In fall 1999, four programs had fully implemented these parent involvement requirements, down from five in fall 1997 (Figure VI.2). In part because of welfare reform, many parents were working and finding it more difficult to make time for volunteering and participating in other program activities. Six programs achieved moderate implementation of the parent involvement requirements. These programs involved many parents, including some fathers, in policy groups and volunteer activities.

The research programs promoted parent involvement in a variety of ways (Figure VI.3). All programs had Policy Councils that involved varying numbers of parents in program decision making in areas such as policies and procedures, staff roles and responsibilities, staff employment-related decisions, budgets, and curricula. By fall 1999, in addition to Policy Councils, most programs had Parent Committees to involve more parents in program planning and activities. In programs with centers, these were formed separately for parents at each center. In rural areas, Parent Committees were often formed based on geographical location. In some programs, the Policy Council established committees to address specific topics or oversee particular areas, such as personnel, finance/budgets, funding, field trips, center activities, fundraising, and grievances.

Most programs also offered opportunities for parents to volunteer, such as by assisting in classrooms, doing office work, making repairs, organizing fundraising or social activities, contributing to newsletters, helping to plan meetings, providing peer support, and serving as bus monitors.

All programs encouraged fathers and father figures to participate in regular services and activities. In fact, the majority of programs (16 in 1997 and 13 in 1999) made special efforts to involve fathers and father figures in program activities. Four programs had a designated staff position, usually a coordinator or specialist, assigned responsibility for involving fathers in 


\section{FIGURE VI.3}

\section{ACTIVITIES TO PROMOTE PARENT INVOLVEMENT}

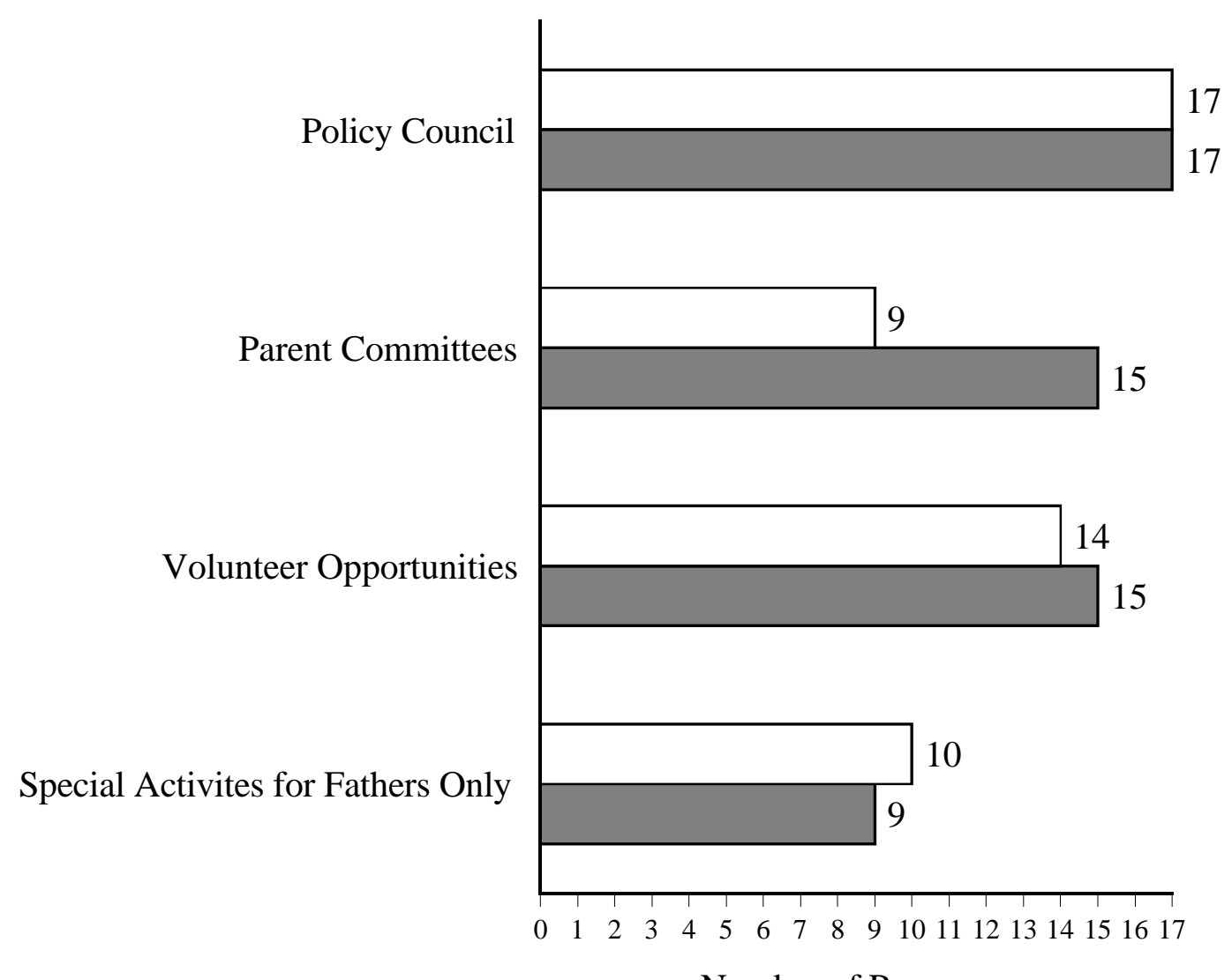

Number of Programs

$\square$ Fall $1997 \square$ Fall 1999

SOURCE: Information gathered during visits to the Early Head Start research programs in the fall of 1997 and fall of 1999 . 
program activities; two additional programs had male staff members with other responsibilities who promoted efforts to involve fathers. Six programs offered group activities for men or for men and their children. These groups usually met monthly. Five additional programs organized recreational activities for men only. In addition, many programs had special activities designed for fathers only (Figure VI.3). These included such activities as father support groups, fatheronly nights out, father sports teams and events, and "daddy-and-me" volunteer days at the child development center.

Although many programs experienced growth in father involvement, a few were not making special efforts to involve fathers in fall 1999. In a few cases, programs eliminated staff positions for father involvement due to low participation by the fathers. Other programs faced several obstacles in their efforts to involve fathers. Some fathers were uncomfortable being the only male present at program activities, or they perceived that activities were for mothers, not fathers. Some programs had no (or not enough) male staff, and fathers were sometimes reluctant to attend events led by female staff. In addition, some mothers did not want nonresident fathers to be involved with their children or the program. Resident fathers sometimes were not at home when home visits were scheduled, or visits could not be scheduled when fathers were at home. When staff with responsibility for involving fathers left the program, they could not always be replaced quickly. Finally, in some programs other issues simply took priority. Some programs recognized the importance of special efforts to involve fathers but focused on other aspects of program services that that they believed were more pressing at the time.

\section{B. COMMUNITY PARTNERSHIPS: CHANGES IN SERVICES AND IMPLEMENTATION PROGRESS BETWEEN 1997 AND 1999}

The research programs improved their implementation of community partnerships dramatically over the evaluation period. The number that had fully implemented their 
community partnerships component nearly doubled between fall 1997 and fall 1999, from 8 to 15 (Figure VI.4).

\section{Collaborative Relationships}

The revised Head Start Program Performance Standards require programs to establish collaborative relationships with other community service providers, with the goal of increasing access to services that are responsive to the needs of children and families.

The number of research programs that had fully implemented collaborative relationships increased from 11 to 16 between fall 1997 and fall 1999 (Figure VI.5). The fully implemented programs had established many relationships with other service providers, including some formal written agreements. These included partnership with Part $\mathrm{C}$ agencies and with child care providers (see Chapter V). They also communicated regularly with service providers to coordinate services for families and participated in at least one coordinating group of community service providers. One program received a lower implementation rating in the area of collaborative relationships because it had established few relationships with other service providers (it provided center-based child care, and the grantee offered many other services inhouse).

\section{Advisory Committees}

According to the revised Head Start Program Performance Standards, programs must establish a health advisory committee that involves community health services providers and meets regularly to discuss infant and toddler health.

The number of programs that had fully implemented these requirements nearly doubled between fall 1997 and fall 1999, from 7 to 13 (Figure VI.5). Five were rated as having reached an enhanced level of implementation in this area because they had established at least one additional advisory committee to advise them on infant and toddler matters. Several programs 
FIGURE VI.4

\section{EARLY HEAD START COMMUNITY PARTNERSHIPS IMPLEMENTATION RATINGS}

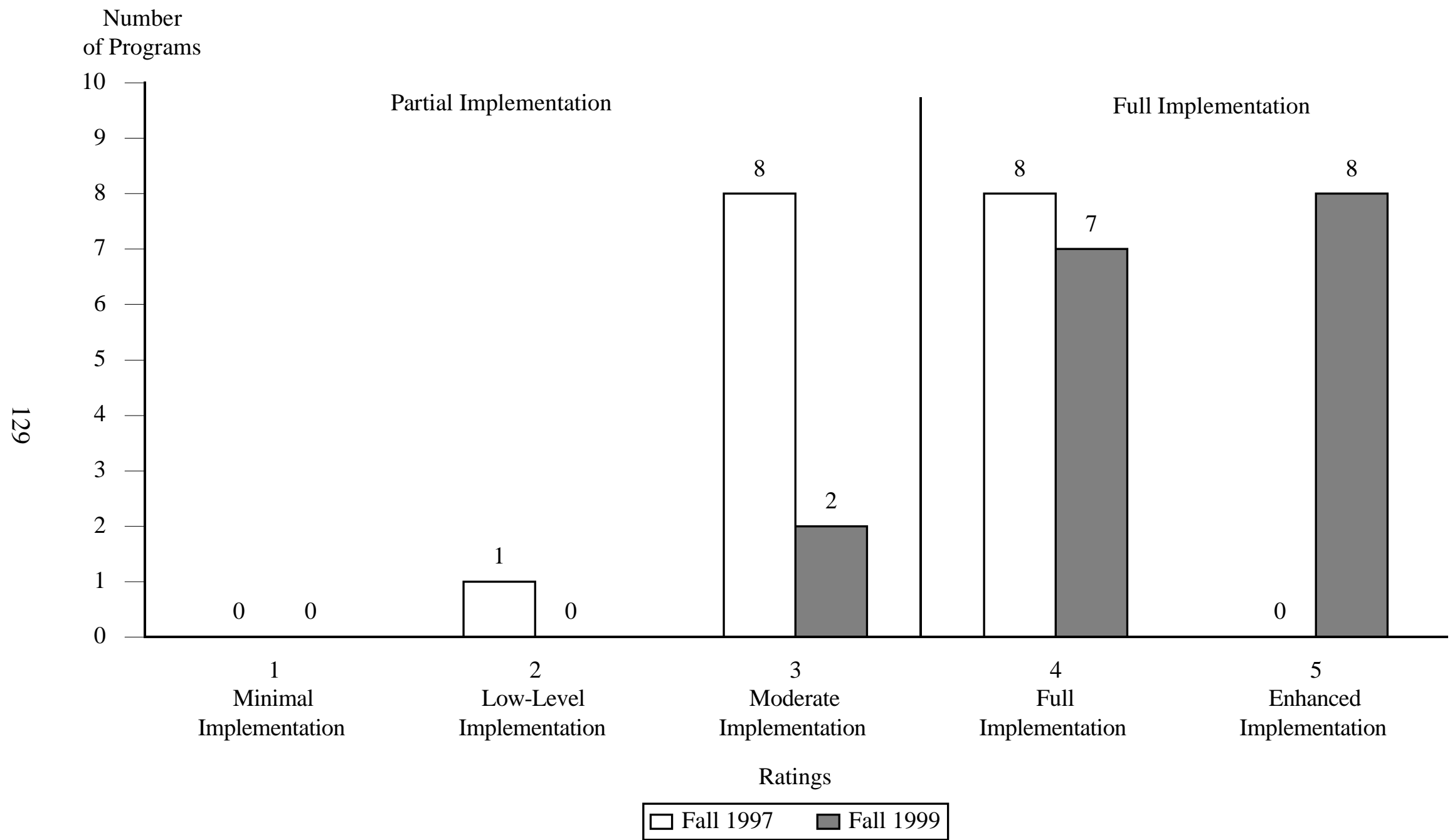

Source: $\quad$ Site visits conducted in fall 1997 and fall 1999 to 17 Early Head Start research programs.

Note: Implementation ratings for community partnerships represent the average rating across all the dimensions we examined Programs rated as fully implemented achieved full implementation in most of the dimensions we examined, but did not necessarily achieve full implementation in every dimension. 


\section{EARLY HEAD START COMMUNITY PARTNERSHIPS}

ASPECTS THAT WERE FULLY IMPLEMENTED

Number of Programs

That Reached Full

Implementation

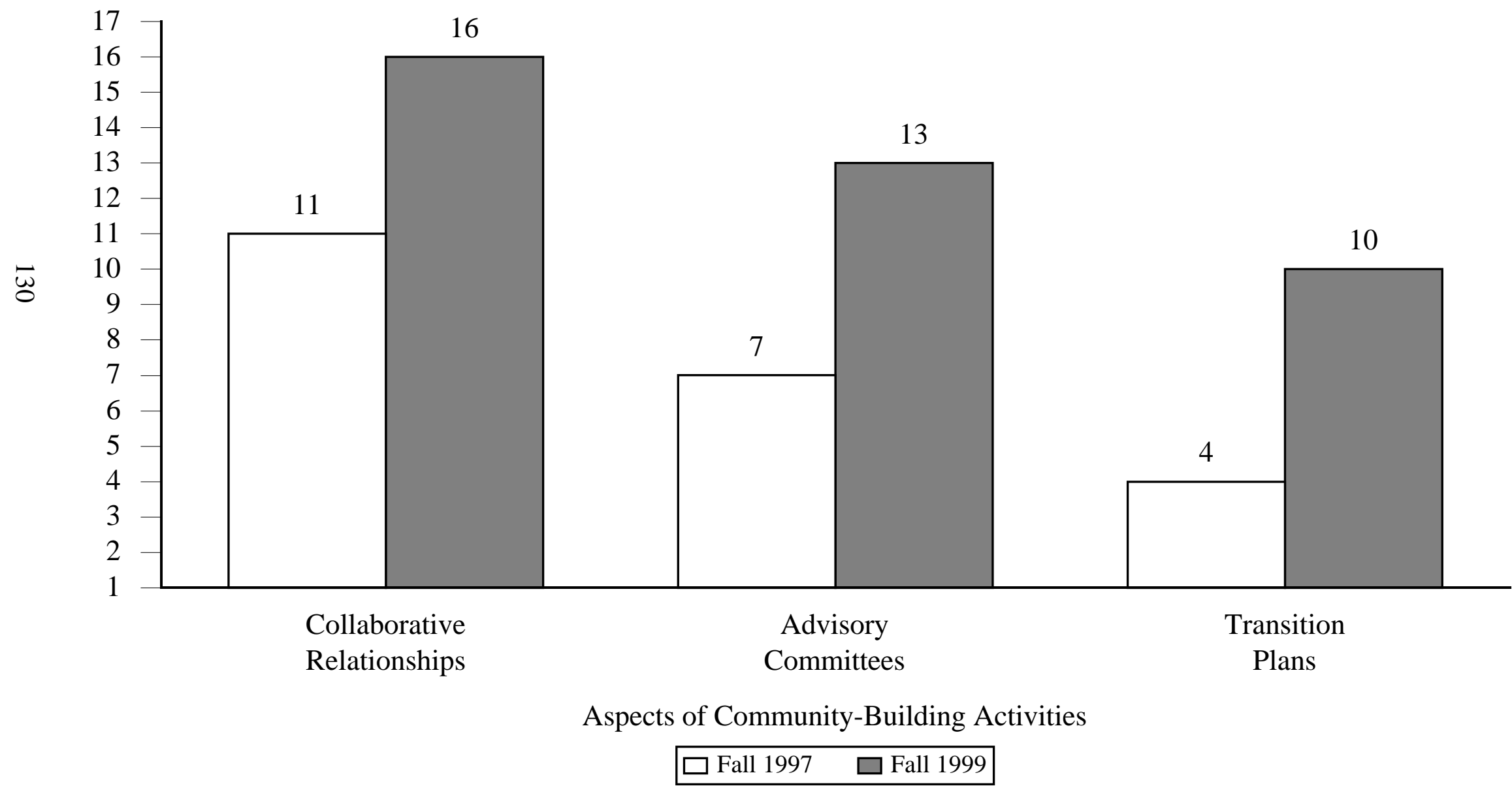

Source: Site visits conducted in fall 1997 and fall 1999 to 17 Early Head Start research programs. 
had not reached full implementation of advisory committees by fall 1999. At one program, the health advisory committee had been established shortly before the fall 1999 site visit and was not yet meeting regularly. The health advisory committees at three other programs advised the agencies on broader health issues but did not discuss infant and toddler health on a regular basis.

\section{Transition Planning}

To ensure a smooth transition from Early Head Start to Head Start or another preschool program, the revised Head Start Program Performance Standards require programs to develop individualized transition plans in collaboration with parents for all children at least six months before their third birthday.

The number of research programs that had fully implemented these transition-planning requirements more than doubled between fall 1997 and fall 1999, from 4 to 10 (Figure VI.5). Of these, 7 had reached an enhanced level of implementation: all children in these programs had transition plans in place by age $2 \frac{1}{2}$, and parents were active participants in the transition planning. Seven programs were rated as moderately implemented in this area in fall 1999, either because not all children had a transition plan in place by age $2 \frac{1}{2}$ or because the program had not identified alternatives for families who could not enroll or did not wish to enroll their child in Head Start.

It appears that many Early Head Start children enrolled in Head Start. Information on where children who had transitioned out of Early Head Start went was not available for all programs, but slightly more than half the research programs reported that at least half the children who remained in the program until they were transitioned out went to Head Start.

\section{SUMMARY}

As in the case of child development and health services, the research programs made substantial progress in implementing the elements of family and community partnerships that we 
examined. Although involving parents—-both mothers and fathers—continued to challenge the programs, most had fully implemented the other aspects of family partnerships. The programs also made substantial progress in implementing community partnerships, and by fall 1999, nearly all had reached full implementation. These partnerships played a key role in programs' progress toward full implementation of child development services, as will be seen in Chapter X. 


\section{PROGRAM IMPLEMENTATION: STAFF DEVELOPMENT AND PROGRAM MANAGEMENT}

Qualified, committed staff members are the backbone of any service program. In the case of Early Head Start, the revised Head Start Program Performance Standards emphasize the importance of well-qualified staff and effective program management for achieving the overall goal of improving the social competence of children in low-income families. The performance standards and the Early Head Start Program Grant Availability Notice both stress the key role of staff supervision, training, and support, and the grant announcement directs programs to select staff and design staff development approaches with the knowledge that high-quality staff performance is linked to rewards such as salary, compensation, and career advancement. The performance standards also lay out requirements for program management and governance to ensure that programs operate effectively to accomplish their goals.

In human resources management, the performance standards include requirements in the areas of organizational structure, staff qualifications, staffing patterns, staff performance appraisals, staff training and development, and staff health. We focused the implementation ratings on supervision (including performance appraisals) and staff training and development; however, we examined descriptive data in the other areas. To be rated as "fully implemented" in staff development, programs had to be fully implementing the performance standards in most of the dimensions of staff development that we rated, including supervision, training, compensation, morale, and staff retention. ${ }^{1}$

\footnotetext{
${ }^{1}$ Staff morale is not specifically addressed in the performance standards, but we included it in our ratings because it is an important indicator of the supportiveness of the work environment.
} 
The revised Head Start Program Performance Standards also address a number of aspects of program management, including:

- Program governance, including Policy Councils and Parent Committees

- Management systems and procedures, including program planning, communications, and program self-assessments and monitoring

To be rated as fully implementing Early Head Start management systems, programs had to be fully implementing the performance standards in most dimensions of management systems that we rated, including functioning of the Policy Council; community needs assessment; communication systems; goals, objectives, and plans; and self-assessment.

In this chapter we describe the implementation of staff development and management, and review progress and changes that programs experienced between fall 1997 and fall $1999 .^{2}$ Information for this review comes from both the implementation study site visit interviews and the self-administered survey that most Early Head Start staff responded to at the time of the 1997 and 1999 visits. We begin with the areas in which information is exclusively from site visits (supervision and staff retention). We then discuss areas, such as staff training and education, in which we have data from both sources, and conclude with the areas examined only through the staff survey. First, however, we describe the characteristics of the staff who were responsible for carrying out the Early Head Start mission in the 17 Early Head Start research programs.

\footnotetext{
${ }^{2}$ The 1997 staff information can be found in the earlier implementation report, Leading the Way: Characteristics and Early Experiences of Selected Early Head Start Programs, Volume I: Cross-Site Perspectives, Chapter III (Administration on Children, Youth and Families 1999a).
} 


\section{A. EARLY HEAD START STAFF CHARACTERISTICS}

Early Head Start staff members are diverse in many ways, but they also share a number of characteristics (Table VII.1). Overall, their characteristics changed little between 1997 and 1999. In 1999, three-fourths of all staff members (76 percent) had children of their own, and about a third had children who participated in Early Head Start or Head Start; 61 percent were currently married. Although the vast majority were women (94 percent in 1999, with the staff at five programs being entirely female), they were ethnically diverse. Overall, 53 percent of Early Head Start staff members were white, 28 percent were African American, and 14 percent identified themselves as of Hispanic origin, the remaining being Asian or other ethnicity.

The racial/ethnic composition of program staff generally reflected that of the families their program served. Although the percentage of staff in each racial/ethnic group within a site rarely matched the percentage of families, the distributions were similar in most programs. Considering the three major racial/ethnic groups among Early Head Start families-white, African American, and Hispanic - in 10 of the programs, the ranking of these groups by their percentage was the same for staff and families (for example, if the most families were Hispanic, the second-most white, and the fewest African American, then the highest proportion of staff was Hispanic, followed by white and African American). Whenever programs had at least 10 percent of their families in a particular racial/ethnic group, they also had at least one staff member who identified themselves as members of that group.

It is also important for staff to be able to communicate with their families, and in general, the percentage of staff who reported speaking Spanish paralleled the percentage of families in the programs whose primary language was not English. Across all 17 programs, about 20 percent of parents reported that their primary language was not English, and this ranged from 0 to 81 percent across the programs. Overall, about one-quarter (23 percent) of staff spoke Spanish, and 
TABLE VII.1

PERCENTAGE OF EARLY HEAD START STAFF WITH PARTICULAR CHARACTERISTICS FOR THE FULL SAMPLE AND BY PROGRAM APPROACH IN 1997

\begin{tabular}{lccccc}
\hline & & & \multicolumn{2}{c}{ Program Approach in 1997 } \\
\cline { 5 - 6 } & $\begin{array}{c}\text { Full } \\
\text { Sample }\end{array}$ & $\begin{array}{c}\text { Range of } \\
\text { Percentage } \\
\text { Across Programs }\end{array}$ & $\begin{array}{c}\text { Center- } \\
\text { Based }\end{array}$ & $\begin{array}{c}\text { Home- } \\
\text { Based }\end{array}$ & $\begin{array}{c}\text { Mixed } \\
\text { Approach }\end{array}$ \\
\hline Had Children of Their Own & 76 & $45-100$ & 82 & 72 & 73 \\
$\begin{array}{l}\text { Had Children Who Participated in } \\
\text { Head Start or Early Head Start }\end{array}$ & 35 & $0-71$ & 52 & 24 & 25 \\
$\begin{array}{l}\text { Currently Married } \\
\text { Women }\end{array}$ & 61 & $25-88$ & 62 & 63 & 59 \\
$\begin{array}{l}\text { White } \\
\text { African American }\end{array}$ & 94 & $60-100$ & 98 & 88 & 97 \\
$\begin{array}{l}\text { Hispanic Origin } \\
\begin{array}{l}\text { At Some Time Lived in } \\
\text { Neighborhood Served by Program }\end{array}\end{array}$ & 53 & $22-100$ & 46 & 62 & 51 \\
$\begin{array}{l}\text { Member of Religious, School, } \\
\text { Political, or Social Group in } \\
\text { Community Program Served }\end{array}$ & 28 & $0-78$ & 28 & 19 & 37 \\
\hline
\end{tabular}

SOURCE: $\quad$ Survey of program staff conducted in fall 1999. 
another 5 percent spoke another language (other than English). At the site level, the percentage of staff who spoke Spanish ranged from 0 (at two programs) to 91 percent (at the program that served predominantly migrant families).

Early Head Start staff members had ties to the communities they served, which provided a basis for their being able to understand the needs and circumstances of the families they served. Almost half of Early Head Start staff members (46 percent) reported that at some time in their life they had lived in a neighborhood served by the program. Almost four-fifths of these were living in their program's neighborhood at the time of the survey, and one-fifth reported that they grew up in that neighborhood. One-third of Early Head Start staff were currently members of a religious, school, political, or social group within the community their program served. Some differences occurred by program approach. Staffs in home-based programs were more likely to have membership in such a group (43 percent, compared with 34 percent for mixed-approach and 23 percent for center-based program staff). Home-based program staff members were also more likely to have ever lived in their program's neighborhood (53 percent, compared with just over 40 percent for staff in center- and home-based programs).

\section{B. STAFF DEVELOPMENT PRACTICES AND IMPLEMENTATION IN 1999 AND PROGRESS BETWEEN 1997 AND 1999³}

As a group, the Early Head Start research programs strengthened their implementation of staff development during the evaluation period, and by fall 1999 , nearly all the programs had fully implemented the staff development areas that we examined. In fall 1999, 15 research

\footnotetext{
${ }^{3}$ The data on staff development issues are both qualitative (from the site visits) and quantitative (from a staff self-administered survey completed at the time of the site visits in 1997 [by 356 research program staff members] and 1999 [by 416 research program staff members]). The two staff surveys provide cross-sectional data at the two points in time; they do not permit longitudinal analysis of the same staff over time.
} 
programs had fully implemented the Head Start staff development requirements (that is, had achieved a status of full or enhanced implementation), compared with 11 programs in fall 1997

(Figure VII.1). No research programs remained at a low level of implementation in fall 1999, whereas three programs had been at that level in 1997.

\section{Supervision}

The revised Head Start Program Performance Standards and the Early Head Start grant announcement mandate that programs implement a system of supervision, training, and mentoring that emphasizes relationship building, employs experiential learning techniques, and provides regular opportunities for feedback on performance.

By fall 1999, all the research programs had fully implemented these requirements, up from 12 programs in fall 1997 (Figure VII.2). Ten programs had reached an enhanced level of implementation of these requirements by fall 1999-they provided both individual and group supervision sessions, as well as feedback on performance that was based in part on observation of service delivery (in centers or during home visits).

\section{Staff Retention}

The revised Head Start Program Performance Standards and the Early Head Start grant announcement emphasize the importance of developing and maintaining secure, continuous relationships between staff, children, and parents and avoiding frequent turnover of key people in children's lives. We rated programs as fully implemented in the area of staff retention if less than 20 percent of the staff had left the program and been replaced in the previous year. ${ }^{4}$

In fall 1999, 8 research programs were rated as fully implemented in the area of staff retention, down from 10 programs in fall 1997 (Figure VII.2). Although the number of programs that met the requirement for a rating of "fully implemented" in the area of staff retention

\footnotetext{
${ }^{4}$ We chose 20 percent as the benchmark for full implementation because it is low relative to the average staff turnover rates in child care centers, yet it allows for some turnover for reasons outside the program's control and for some turnover that can be healthy for a program.
} 


\section{FIGURE VII.1}

\section{EARLY HEAD START STAFF DEVELOPMENT ACTIVITIES \\ IMPLEMENTATION RATINGS}

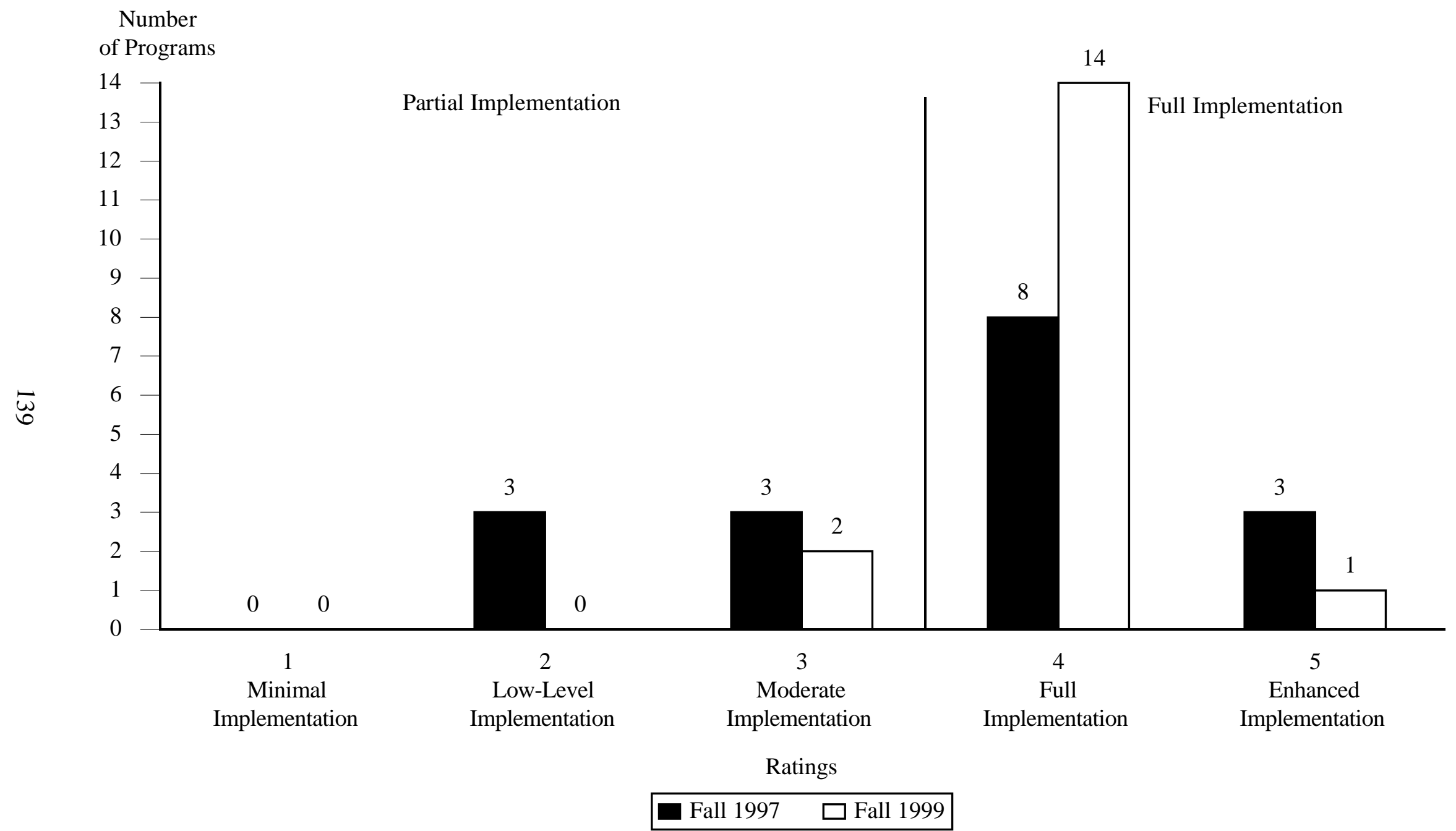

Source: $\quad$ Site visits conducted in fall 1997 and fall 1999 to 17 Early Head Start research programs.

Note: Implementation ratings for staff development represent the average rating across all the dimensions we examined. Programs rated as fully implemented achieved full implementation in most of the dimensions we examined, but did not necessarily achieve full implementation in every dimension. 
EXTENT TO WHICH FIVE EARLY HEAD START STAFF DEVELOPMENT ACTIVITIES WERE FULLY IMPLEMENTED

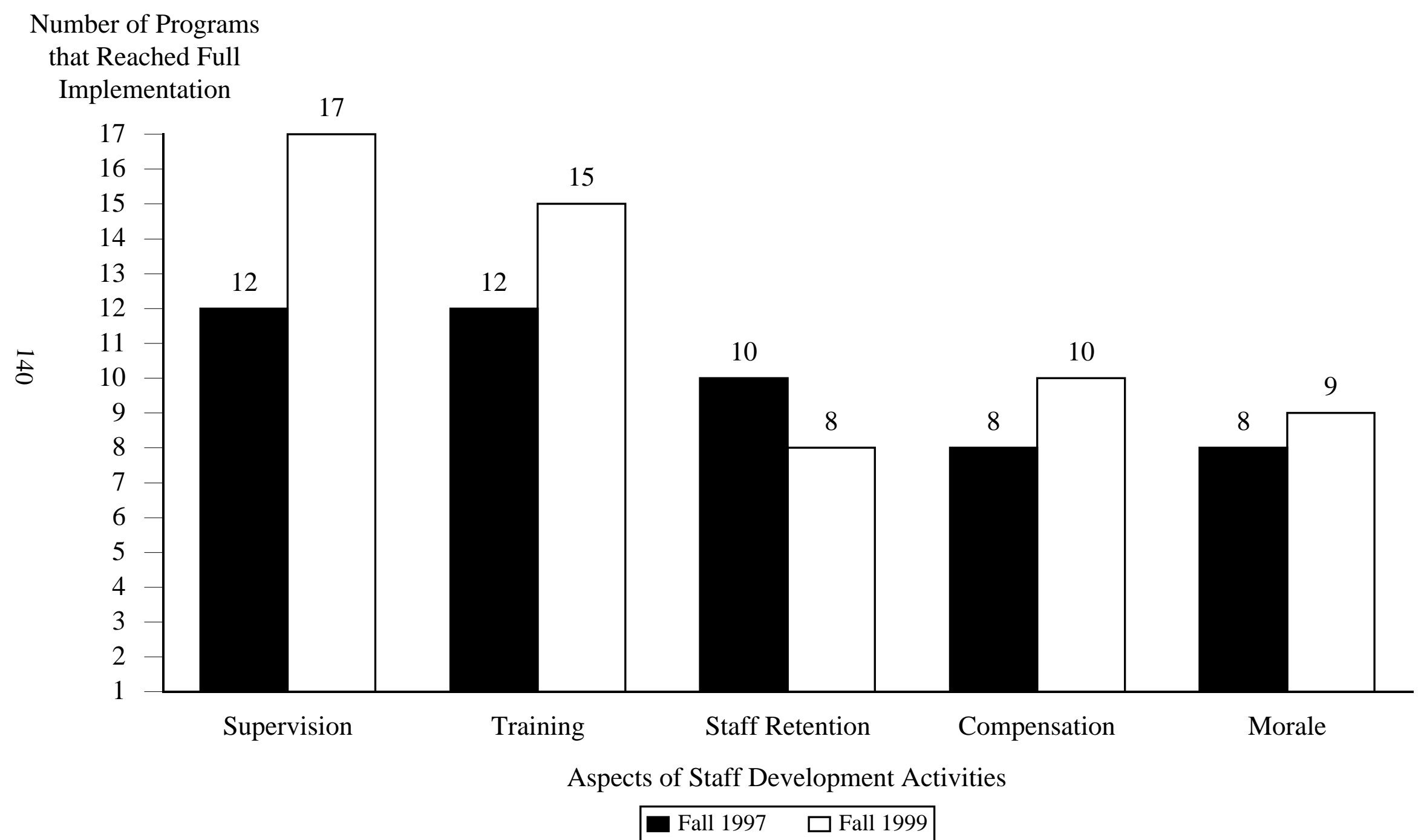

Source: Site visits conducted in fall 1997 and fall 1999 to 17 Early Head Start research programs. 
declined slightly over time, the number experiencing very high rates of staff turnover decreased between fall 1997 and fall 1999. In fall 1997, three programs had experienced staff turnover rates of 40 percent or more in the previous year, while in fall 1999, no programs had experienced staff turnover rates that high in the past year.

Unfortunately, high turnover rates are common among early childhood programs. Among all staff, turnover in the majority of Early Head Start research programs was in the 15 to 32 percent range in fall 1999. Among Early Head Start direct care staff across the 11 programs that offered all or some center-based care, turnover averaged 39 percent, and ranged from 6 percent to 66 percent across the programs. These levels of turnover are comparable to estimates of turnover rates for frontline staff in child care centers nationally, which range from 25 percent (Kisker et al. 1991) to 43 percent (Cost, Quality, and Child Outcomes Study Team 1995).

Programs reported a number of reasons for staff turnover, including:

- Personal reasons, such as health problems, family moves, or decisions to stop working and stay home with children

- Career reasons, such as returning to school, moving for job advancement, or finding a higher-paying job (often with the public schools)

- Performance reasons, such as dismissal for poor performance

- Programmatic reasons, such as program reorganization, changing program skill needs

Program staff sometimes viewed staff turnover positively, because it sometimes created openings that allowed program managers to hire staff members who were better suited to the position.

Some staff members who left the Early Head Start programs took similar jobs with other agencies in the community. Program managers often reported that the training and experience that those staff members had received during their tenure with the Early Head Start program continued to benefit the program through new or improved working relationships among 
agencies. Similarly, some program managers noted that the training and experience provided to the staff members who left Early Head Start continued to benefit the community by increasing the qualifications and competence of staff members in social service agencies more generally.

Many of the research programs maintained continuity in program leadership staff, but slightly more than half of them (nine programs) experienced turnover of directors during the evaluation period. In three of these instances, however, the change was developmental, as directors moved to higher positions within their agencies and another Early Head Start staff member assumed the role of director. The experience of the other six sites showed the variety of processes involved in leadership transitions. For example, in one case, the position was vacant for nine months while the program searched for a new director, and then administrative details initially occupied a large share of the new director's time. In another program, turnover was particularly disruptive, as the first director was promoted and a new director was hired but then resigned and had to be replaced. During this same period—between the 1997 and 1999 site visits—all home visitors and child care teachers at that program left and had to be replaced.

\section{Staff Training and Educational Attainment}

The revised Head Start Program Performance Standards require programs to establish and implement a structured approach to staff training that is designed to help build relationships among staff and provide them with the skills they need to do their jobs. We rated programs as fully implemented in this area if all staff received training in multiple areas and if training was provided according to a plan based on an assessment of staff training needs. The 1998 Head Start reauthorization required that, by September 2003, at least 50 percent of all Head Start and Early Head Start teachers nationwide in centerbased programs have an associate's degree, a bachelor's degree, or an advanced degree in early childhood education or development, or a degree in a related field and experience in teaching preschool children. In addition, the standards require that Early Head Start teachers obtain a CDA credential for infant and toddler caregiver within one year of their hire as a teacher of infants and toddlers. ${ }^{5}$

${ }^{5}$ The CDA credential is designed to ensure that the CDA is able to meet the specific needs of children and is able to work with parents and other adults to nurture children's physical, social, emotional, and intellectual growth in a child development framework. CDAs must be high 
Based on information gathered in site visit interviews and focus groups with program staff, we rated each program's degree of implementation in the area of training by considering the extent to which programs provided staff with training in multiple areas according to a plan based on an assessment of staff training needs. In fall 1999, 15 research programs had fully implemented the staff training requirements (Figure VII.2), up from 12 programs in fall 1997. Thirteen research programs had reached an enhanced level of implementation in this area-their approach to staff training extended to emphasizing relationship-building and provided opportunities for practice, feedback, and reflection. One program was rated as moderately implemented in this area because part-time staff did not participate in most staff training sessions, and another program was rated as moderately implemented because it provided initial training but did not provide adequate opportunities for ongoing training throughout the year.

Most programs reported conducting assessments of staff training needs. Almost all surveyed their staff members annually so that the individual staff members could give their perceptions of areas in which they needed additional training and support. Center-based programs also observed teachers working in their classroom settings, and supervisors in homebased programs accompanied home visitors to observe home visit activities directly. Program

\section{(continued)}

school graduates or have a GED, be 18 years or older, and have 480 hours of experience working with children within the previous 5 years. They must attend 120 hours of formal education/training at an approved institution. Training must include at least 10 hours in each of 8 content areas: (1) planning a safe, healthy, learning environment; (2) advancing children's physical and intellectual development; (3) supporting children's social and emotional development, (4) establishing productive relationships with families; (5) managing an effective program operation; (6) maintaining a commitment to professionalism; (7) observing and recording children's behavior; and (8) understanding principles of child growth and development. Each CDA's advisor observes the candidate working with children for a minimum of two hours and completes an assessment that is forwarded to the national CDA office, which then schedules a written test and oral interview. The CDA office forwards results to the Council for Professional Recognition, which issues the CDA credential. 
directors and coordinators also used their group and individual supervision meetings to assess areas in which staff development was needed. Several program supervisors maintained a professional development plan for each staff member. Staff training needs were also typically judged in relation to the needs of the families the program served. For example, a program serving families whose children presented particular disabilities would offer specialized training for its staff.

We obtained information on staff educational attainment from the staff survey and report it here to augment the picture of Early Head Start staffing based on the site visits. It was not included in the implementation ratings. Responses to the staff survey show that Early Head Start staff members in the research sites were generally highly educated (Table VII.2). In fact, overall, the 17 research programs were more than meeting the requirement of the Head Start reauthorization: 55 percent of frontline staff and 62 percent of all staff had at least a two-year degree. Furthermore, 50 percent of all staff had completed at least a four-year college degree in 1999 (this includes 3 percent who had taken some graduate courses, 13 percent with a graduate degree, and 6 percent with some other post-baccalaureate or master's certificate). Eleven percent held a two-year college degree as their highest level of education, 14 percent had taken some college courses, and only 3 percent had not completed high school.

Educational attainment and certification of staff varied by program approach and by site, with home-based and mixed-approach programs having the highest average educational attainment. The percentage of staff with a four-year degree or higher was 28 percent in centerbased, 60 percent in mixed-approach, and 63 percent in home-based programs. Site-to-site variation was wide, with, at the high end, 100 percent and 85 percent of staff having a four-year or higher degree at two home-based programs, and 84 percent at a mixed-approach program; in two programs—both center-based—just 24 percent of staff had a bachelor's or higher degree. In 
TABLE VII.2 EARLY HEAD START STAFF EDUCATIONAL ATTAINMENT AND PARTICIPATION IN TRAINING,
FOR THE FULL SAMPLE AND BY PROGRAM APPROACH (PERCENTAGES)

\begin{tabular}{|c|c|c|c|c|c|}
\hline & \multirow[b]{2}{*}{$\begin{array}{c}\text { Full } \\
\text { Sample }\end{array}$} & \multirow[b]{2}{*}{$\begin{array}{c}\text { Range of } \\
\text { Percentage } \\
\text { Across Programs }\end{array}$} & \multicolumn{3}{|c|}{ Program Approach in 1997} \\
\hline & & & $\begin{array}{c}\text { Center- } \\
\text { Based }\end{array}$ & $\begin{array}{c}\text { Home- } \\
\text { Based }\end{array}$ & $\begin{array}{c}\text { Mixed } \\
\text { Approach }\end{array}$ \\
\hline \multicolumn{6}{|l|}{ All Staff } \\
\hline At Least a Two-Year Degree & 62 & $28-100$ & 38 & 74 & 73 \\
\hline At Least a Four-Year Degree & 50 & $24-100$ & 28 & 63 & 60 \\
\hline \multicolumn{6}{|l|}{ Participated in at Least One } \\
\hline Professional Training in Past Year & 87 & $74-100$ & 82 & 89 & 91 \\
\hline Training Rated "Very Beneficial" & 76 & $44-100$ & 76 & 86 & 67 \\
\hline \multicolumn{6}{|l|}{ Frontline Staff } \\
\hline Completed CDA or Higher & 76 & $20-100$ & 62 & 85 & 83 \\
\hline Currently in CDA Training & 18 & $0-100$ & 19 & 24 & 11 \\
\hline At Least a Two-Year Degree & 55 & $13-100$ & 34 & 73 & 65 \\
\hline At Least a Four-Year Degree & 41 & $7-100$ & 21 & 61 & 48 \\
\hline \multicolumn{6}{|l|}{ Participated in at Least One } \\
\hline Professional Training in Past Year & 88 & $75-100$ & 84 & 92 & 91 \\
\hline Rated Training "Very Beneficial" & 73 & $40-100$ & 74 & 86 & 63 \\
\hline
\end{tabular}

SOURCE: Survey of program staff conducted in fall 1999.

${ }^{a}$ Frontline staff members are all staff who work directly with children, typically teachers in center-based, home visitors in home-based, and both in mixed-approach programs $(\mathrm{N}=242)$. 
one home-based program, 56 percent of staff had a master's or other graduate degree, while there were eight programs in which fewer than 10 percent of staff had advanced degrees.

Of particular interest is the degree to which programs succeeded in having their frontline staff credentialed. In 1999, we were able to examine CDA credentialing separately for frontline staff. Seventy-six percent of frontline staff reported having a CDA credential or a higher degree. ${ }^{6}$ According to the staff members' self-reports, in 1999, center-based programs appeared not to be meeting the performance standards with respect to frontline staff attaining their CDA credential. Among frontline center-based staff who had been in their position for at least one year (and therefore required to have their CDA credential), 61 percent reported having a CDA credential or higher degree (associate's, bachelor's, or graduate degree) (not shown in table). Nineteen percent of center-based frontline staff members were currently participating in CDA training, and another 29 percent reported planning to do so.

Most staff ( 87 percent overall, 88 percent of frontline staff) reported having participated in at least one professional training activity in the past 12 months. Although training participation was reported to be high in all types of programs, it was somewhat more common in mixedapproach and home-based programs (91 and 89 percent of staff, respectively) than in centerbased programs ( 82 percent) (see top portion of Table VII.2). Three-fourths of all staff found the training "very beneficial," and almost 90 percent said they were somewhat or very likely to change what they did in their work based on the training; staff in the three program approaches differed little in this regard. Perception of the value of training varied considerably by the

\footnotetext{
${ }^{6}$ In 1997, we were not able to provide data separately for frontline staff. Then, 14 percent of all staff reported having completed a CDA credential; an additional 14 percent reported currently participating in CDA training. In 1999, 24 percent of all staff reported having their CDA credential (a 71 percent increase over the two-year period), and an additional 12 percent were in training.
} 
individual program, however, with more than 90 percent of staff in four programs finding training to be "very beneficial"; in only two programs was this figure less than 60 percent. In general, home-based staff members reported not only higher levels of educational attainment but higher rates of participation in training (both CDA and other professional training) and rated their training as more beneficial than did staff in other programs. This was especially the case among frontline staff who work directly with children and families.

Many programs make special efforts to tailor their training to the needs of their staff and their families. Researchers Joseph Stowitschek and Eduardo Armijo, working with the Washington State Migrant Council's Early Head Start program, have documented the training opportunities that the program has provided to its largely Hispanic farm-working families, as well as the results they have achieved. Their research is summarized in the box below and reported in greater detail in Appendix C.

\section{Compensation}

The Advisory Committee on Services to Families with Infants and Toddlers noted that high-quality staff performance and development are associated with salary, compensation, and career advancement (U.S. Department of Health and Human Services 1994). The Early Head Start grant announcement emphasizes the importance of adequate staff compensation to promote staff retention and to reward high-quality performance and professional development. We rated programs as fully implemented in this area if directors reported that staff salaries and benefits were above the average level for similar staff in other community programs.

Ten research programs were rated as fully implemented in the area of staff compensation, up from eight in fall 1997 (Figure VII.2). Of these, six had achieved an enhanced level of implementation-in addition to above-average staff compensation, their staff received tuition reimbursement, child care, or other "family-friendly" benefits. Seven programs were rated as moderately implemented in this area in fall 1999 because staff salaries and benefits were not reported to be higher than the average level for similar staff in community programs. 


\title{
OUTCOMES IN STAFF DEVELOPMENT AT THE WASHINGTON STATE MIGRANT COUNCIL EARLY HEAD START PROGRAM
}

\author{
Joseph J. Stowitschek and Eduardo J. Armijo \\ University of Washington
}

Staff development is identified as one of the "cornerstones" of Early Head Start (along with an emphasis on children, families, and communities), and is a major component of the Washington State Migrant Council's (WSMC) Early Head Start project. A qualified, well-trained staff with opportunities for growth and development would be essential to ensure that the diverse needs displayed by the program's migrant and Hispanic farm-working families are met.

The WSMC staff has received training, as well as educational incentives, to promote competence in such areas as brain development, conflict and anger management, proper food preparation, disabilities, and transition services. A staff development interview provided data on staff members' educational goals and career aspirations, training, and incentives and disincentives for personal and professional growth. A family services questionnaire provided data pertaining to service delivery focus areas and methods. Respondents were six home educators, two case managers, and WSMC project coordinator, and the project director. Findings center on staff educational goals and career aspirations, training, and incentives and disincentives.

Staff Educational Goals/Career Aspirations. To help staff meet their goals of attaining bachelor's degrees, WSMC offered incentives to encourage staff to continue with their education. These included an education-reimbursement package for tuition, books, mileage, and child care, and flex time schedules to accommodate coursework. On a 5-point scale of degree of encouragement, staff uniformly gave WSMC's efforts the highest possible rating, a "5." Many staff educational goals directly related to career aspirations. When asked about the future, staff mentioned positions included running a certified day care center, full-time case management, Head Start or public school teaching, family program coordination, and program or public school administration.

Training. WSMC emphasized staff development through training, both within and outside the agency, in the areas mentioned above. Staff received an average of nearly 55 hours of training in the preceding year. Staff members rated their training as significantly contributing both to their professional skills and to career advancement.

Incentives and Disincentives. Personnel were asked about job-related incentives (such as pay and outside trainings), in-service training provided by WSMC, attitudes of coworkers, and attitudes of WSMC supervisors and administrators. On a 5-point scale, staff rated job-related incentives at 4.1, WSMC training at 3.9, coworker attitudes at 3.2, and supervisors/administrators attitudes at 4.0. In open-ended questions, staff indicated that WSMC strongly encouraged growth in these areas. In addition, many staff feel they have been personally enriched by the program in such areas as raising their own children, reaching out to families in need, and increasing their own self-esteem and self-confidence.

Discussion. WSMC Early Head Start is highly committed to the staff development cornerstone as a means of improving services for families. Staff uniformly indicated that the incentives received as part of their jobs had a positive effect with the families they worked with. For example, over a three-year period, staff reported 26 percent average increases in hours spent with families as part of regular visits, as well as over 300 percent average increases in hours spent training families in project-related areas (such as child development and proper food preparation). In addition, staff reported nearly 400 percent average increases in contact with families over the phone.

During the same three-year period, the focus has increased in the percentage of time spent in the areas of mental health, nutrition, child language development, and father involvement. Staff also reported an increase in the percentage of time spent in the specific areas of coaching families, providing praise and feedback to families, problem solving, assessing and evaluation, providing verbal pointers, and arranging resources for families. Because most of the Early Head Start staff have the same Hispanic roots as the families they served, their professional successes and advancements reflect the hopes, aspirations, and opportunities that are strived for with these younger, poorer Hispanic families. 
At the time of the fall 1999 site visits, several programs were in the process of increasing salaries and revising them to reward staff who obtained associate's degrees. In most of these programs, however, the new rates had not yet been implemented or had been implemented only recently. Nevertheless, according to the staff survey, the average hourly wage of frontline staff increased by 9 percent over two years, from $\$ 9.77$ per hour in 1997 to $\$ 10.68$ in 1999 (Table VII.3). ${ }^{7}$ Wages differed greatly across the individual programs and by program approach. Classroom teachers in center-based programs received the lowest average wage among frontline staff (\$9.86 per hour). Center-based programs also had the greatest variation of any program approach, ranging from $\$ 7.76$ per hour in a Southern site to $\$ 16.41$ at a program in the Northeast). Home visitors were the highest-paid frontline workers, averaging $\$ 12.00$ per hour, but hourly wages of home visitors ranged widely across the seven home-based programs, from a low of $\$ 9.43$ in one site to $\$ 15.12$ in another. As might be expected, frontline staff in mixedapproach programs averaged in the middle, earning a reported $\$ 10.70$ per hour, with a range across these programs from $\$ 7.73$ to $\$ 13.34$.

Several programs significantly increased compensation for frontline staff between 1997 and 1999 , with the number of programs paying above $\$ 14.00$ on average increasing from one to three. However, in 1999 four programs paid frontline staff less than \$10 per hour, on average. Across all staff, including program administrators, the 1999 average hourly wage was $\$ 12.59$.

According to staff reports, Early Head Start programs provided a range of important fringe benefits (Figure VII.3). At least three-fourths of all staff reported receiving six different benefits. The most common were paid holidays (which 95 percent of staff reported receiving),

\footnotetext{
${ }^{7}$ Frontline staff members were those whose job titles reported on the survey indicated that they worked directly with children and/or families. Of the 356 staff responding to the survey in 1997, 228 were considered frontline (64 percent). Of the 416 responding in 1999, 242 (58 percent) were classified as frontline staff.
} 
TABLE VII.3

EARLY HEAD START STAFF COMPENSATION AND FRINGE BENEFITS, FOR THE FULL SAMPLE AND BY PROGRAM APPROACH

\begin{tabular}{|c|c|c|c|c|c|}
\hline & \multirow[b]{2}{*}{$\begin{array}{c}\text { Full } \\
\text { Sample }\end{array}$} & \multirow[b]{2}{*}{$\begin{array}{c}\text { Range Across } \\
\text { Programs }\end{array}$} & \multicolumn{3}{|c|}{ Program Approach in 1997} \\
\hline & & & $\begin{array}{l}\text { Center- } \\
\text { Based }\end{array}$ & $\begin{array}{c}\text { Home- } \\
\text { Based }\end{array}$ & $\begin{array}{c}\text { Mixed } \\
\text { Approach }\end{array}$ \\
\hline \multicolumn{6}{|l|}{ All Staff } \\
\hline Hourly Wage & $\$ 12.59$ & $\$ 8.25-\$ 17.73$ & $\$ 11.43$ & $\$ 13.47$ & $\$ 12.99$ \\
\hline \multicolumn{6}{|l|}{ Percentage of Staff Reporting: } \\
\hline Health Insurance & 83 & $50-100$ & 76 & 85 & 86 \\
\hline Health Insurance for Dependents & 54 & $20-91$ & 42 & 61 & 59 \\
\hline Life Insurance & 67 & $13-100$ & 33 & 81 & 87 \\
\hline Dental Insurance & 66 & $0-100$ & 47 & 67 & 84 \\
\hline Paid Vacation Time & 88 & $63-100$ & 77 & 96 & 91 \\
\hline Paid Holidays & 95 & $75-100$ & 96 & 97 & 91 \\
\hline Compensation for Overtime & 42 & $0-77$ & 46 & 31 & 50 \\
\hline Paid Sick Leave & 88 & $55-100$ & 79 & 89 & 95 \\
\hline Educational Stipends & 71 & $35-91$ & 61 & 65 & 85 \\
\hline Paid Release Time for Training & 95 & $85-100$ & 90 & 96 & 97 \\
\hline Retirement Plan & 77 & $0-100$ & 56 & 89 & 85 \\
\hline Child Care for Own Children & 10 & $0-39$ & 16 & 1 & 14 \\
\hline \multicolumn{6}{|l|}{ Frontline Staff } \\
\hline Hourly Wage & $\$ 10.68$ & $\$ 7.73-\$ 16.41$ & $\$ 9.86$ & $\$ 12.00$ & $\$ 10.70$ \\
\hline
\end{tabular}

SOURCE: Survey of program staff conducted in fall 1999. 


\section{FIGURE VII.3}

FRINGE BENEFITS RECEIVED BY STAFF

IN EARLY HEAD START RESEARCH PROGRAMS,

FALL 1997 AND FALL 1999

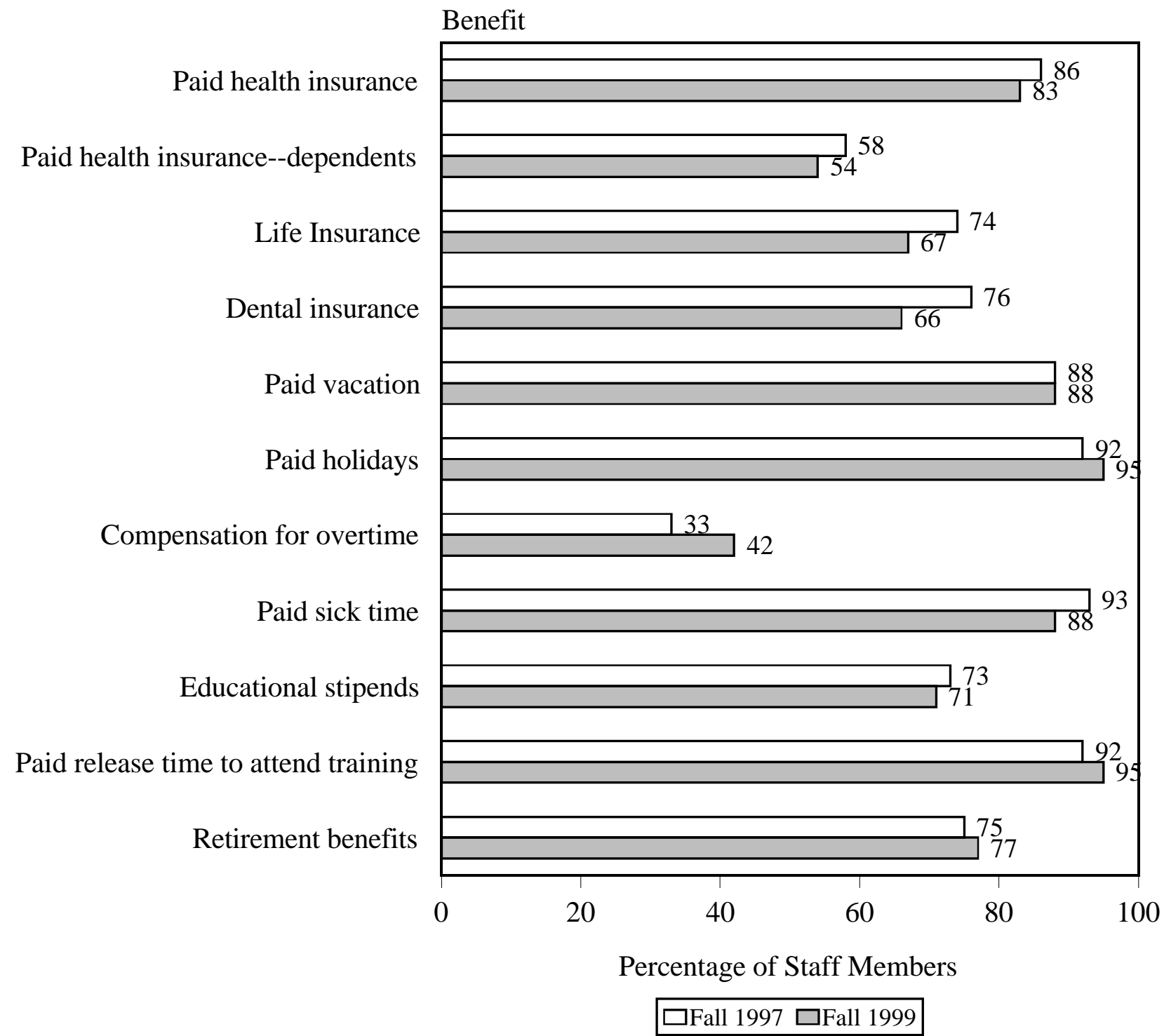

SOURCE: Self-administered surveys of staff completed during visits to the Early Head Start research programs in fall 1997 and fall 1999. 
paid release time to attend training (also 95 percent), paid sick leave (88 percent), paid vacation time (88 percent), health insurance (83 percent), and retirement benefits ( 77 percent). Seventyone percent reported receiving educational stipends. Fewer staff reported receiving dental insurance, health insurance for their dependents, life insurance, or compensation for overtime work. The benefit picture did not change substantially between 1997 and 1999 (8 of the 11 benefits we asked about did not change by more than 5 percentage points). The exceptions were paid life and dental insurance, which declined by 7 and 10 percentage points, respectively, and compensation for paid overtime, which increased substantially across all programs, from 33 to 42 percent of all staff reporting that they received this benefit).

The benefits picture for Early Head Start staff was somewhat dependent on the program approach of the program in which they worked. Of the 11 benefits shown in Figure VII.3 and Table VII.3, 7 were most prevalent in mixed-approach programs, and in 4 cases it was staff in home-based programs that were most likely to report receiving a benefit. However, in most cases the difference between these two program approaches was small (Table VII.3). In most areas, center-based programs provided benefits to a substantially smaller percentage of staff than did either of the other two program approaches. For example, 56 percent of center-based staff reported receiving a retirement or pension plan, whereas 85 percent of mixed and 89 percent of home-based staff reported retirement benefits; 47 percent of center-based staff received dental insurance, compared with 67 percent of home-based staff and 84 percent of staff in mixedapproach programs. A few benefits that were very common overall differed little by program approach: in all three types of programs, more than 90 percent of staff reported receiving paid holidays and paid release time to attend training. One of the less-common benefits was provision of free child care for children of the staff. Center-based and mixed-approach programs were most likely to provide this benefit (reported by 16 and 14 percent of staff, respectively), while 
only 1 percent of home-based staff reported receiving a child care benefit. In a number of ways, benefits are therefore seen to parallel wages and education levels across the program approaches.

\section{Staff Morale}

Staff morale is not specifically addressed in the revised Head Start Program Performance Standards. We included it in the implementation ratings, however, because it is an important measure of the extent to which programs created supportive environments that enable staff to perform and develop. We rated programs as fully implemented in this area if morale was high or very high at the time of the site visit.

Based on staff reports during site visits and in staff surveys, nine programs were rated as "fully implemented" in the area of staff morale in fall 1999, up from eight in fall 1997. Eight programs were rated as moderately implemented in this area, because staff morale appeared to be average.

To obtain detailed information about this important aspect of program operations, we assessed "workplace climate" by including on the staff survey a number of questions that would tell us how staff members in the research programs perceived key aspects of their employment circumstances. Staff members generally reported a very positive view of their workplace (Figure VII.4 and Table VII.4). Most reported that Early Head Start is a pleasant place to work. Program directors received high marks from their staff: a large percentage of staff saw their director as communicating a clear vision, providing realistic job expectations, keeping the staff informed, and recognizing when the staff member does "a good job." Similarly, very few staff reported that they are required to follow rules that conflict with their best professional judgment;

only about one-quarter felt that routine duties and paperwork interfered with doing their jobs. The area in which staff members were least satisfied, as might be expected, is salary: 42 percent reported that they agreed or strongly agreed with the survey item, "I am satisfied with my salary." This percentage, however, increased from 1997 to 1999, while most of the responses to workplace climate items changed little over this time (Figure VII.4). 
FIGURE VII.4

WORKPLACE CLIMATE, FALL 1997 AND FALL 1999

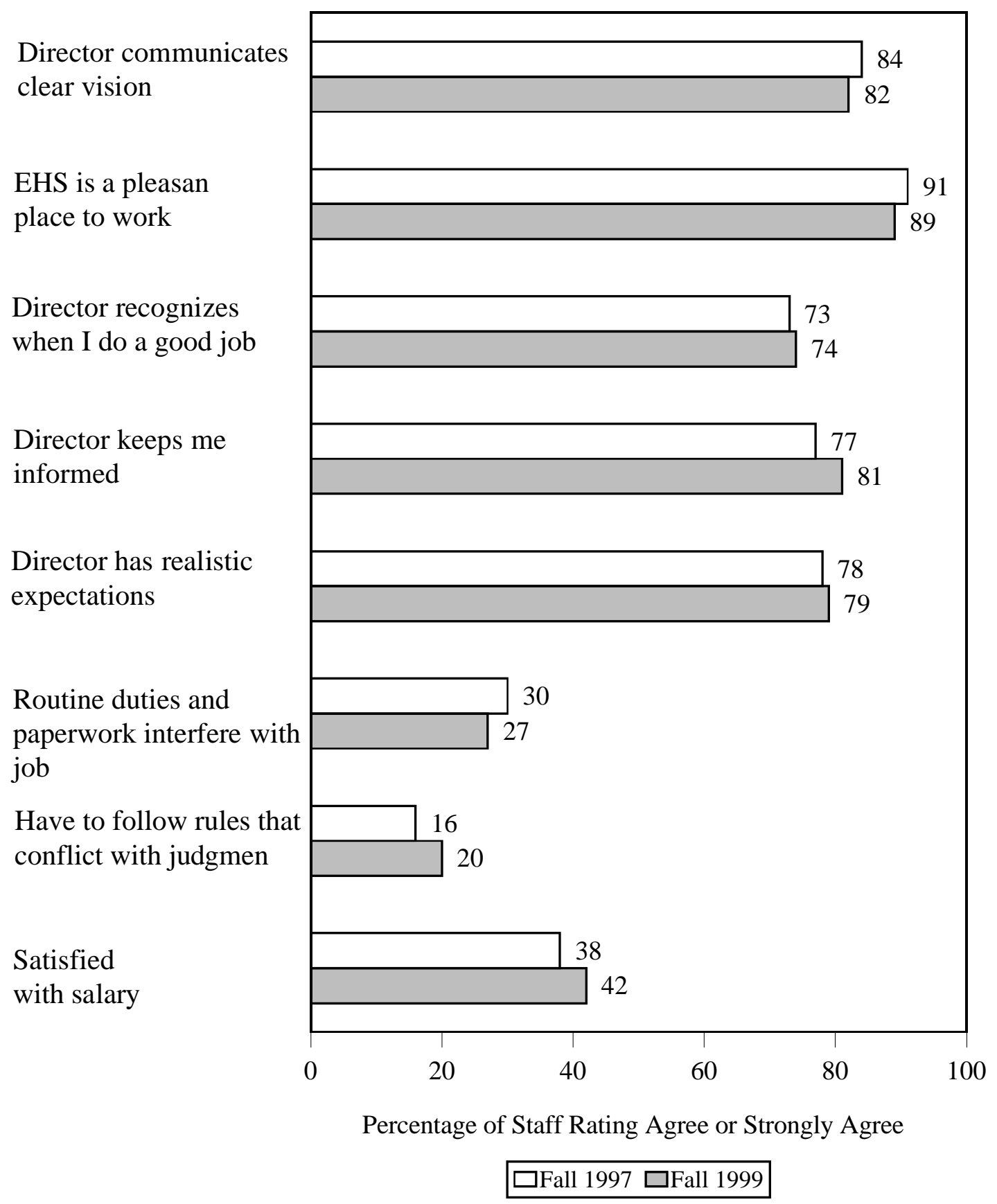

SOURCE: Self-administered surveys of staff completed during visits to the Early Head Start research programs in fall 1997 and fall 1999. 
TABLE VII.4

PERCENTAGE OF EARLY HEAD START STAFF AGREEING OR STRONGLY AGREEING WITH STATEMENTS REGARDING THEIR PROGRAM'S WORKPLACE CLIMATE, FOR THE FULL SAMPLE AND BY PROGRAM APPROACH

\begin{tabular}{|c|c|c|c|c|c|}
\hline & \multirow[b]{2}{*}{$\begin{array}{c}\text { Full } \\
\text { Sample }\end{array}$} & \multirow[b]{2}{*}{$\begin{array}{c}\text { Range of } \\
\text { Percentage } \\
\text { Across Programs }\end{array}$} & \multicolumn{3}{|c|}{ Program Approach in 1997} \\
\hline & & & $\begin{array}{l}\text { Center- } \\
\text { Based }\end{array}$ & $\begin{array}{c}\text { Home- } \\
\text { Based }\end{array}$ & $\begin{array}{l}\text { Mixed } \\
\text { Approach }\end{array}$ \\
\hline Director Communicates Clear Vision & 82 & $56-100$ & 79 & 79 & 87 \\
\hline Early Head Start Is Pleasant Place to Work & 89 & $55-100$ & 93 & 82 & 94 \\
\hline Director Recognizes when I Do a Good Job & 74 & $44-86$ & 75 & 70 & 77 \\
\hline Director Keeps Me Informed & 81 & $17-100$ & 82 & 79 & 82 \\
\hline Director Has Realistic Expectations & 79 & $64-88$ & 78 & 80 & 78 \\
\hline $\begin{array}{l}\text { Routine Duties and Paperwork Interfere with } \\
\text { Job }\end{array}$ & 27 & $4-64$ & 25 & 26 & 31 \\
\hline Have to Follow Rules That Conflict with & & & & & \\
\hline Own Judgment & 20 & $0-40$ & 25 & 15 & 21 \\
\hline Satisfied with Salary & 42 & $14-82$ & 42 & 46 & 38 \\
\hline Administrators Encourage Staff Development & & & & & \\
\hline Activities & 86 & $73-100$ & 80 & 88 & 88 \\
\hline $\begin{array}{l}\text { Staff Frequently Share Ideas with Each Other } \\
\text { Staff and Administrators Work }\end{array}$ & 86 & $55-100$ & 83 & 82 & 92 \\
\hline Collaboratively for Program Improvement & 78 & $64-96$ & 74 & 81 & 78 \\
\hline $\begin{array}{l}\text { Administrators Collaborate with Other Staff } \\
\text { to Make Decisions }\end{array}$ & 69 & $52-86$ & 65 & 74 & 68 \\
\hline $\begin{array}{l}\text { Staff and Administrators Are Receptive to } \\
\text { Change }\end{array}$ & 64 & $36-86$ & 66 & 65 & 61 \\
\hline $\begin{array}{l}\text { Staff Have Enough Opportunity to Influence } \\
\text { Decisions Affecting Their Work }\end{array}$ & 55 & $35-82$ & 50 & 60 & 56 \\
\hline
\end{tabular}

SOURCE: $\quad$ Survey of program staff conducted in fall 1999. 
A number of questions about workplace climate focused on the interrelationships of staff and directors, collaboration, and decision making (Figure VII.5 and Table VII.4). Most staff members (86 percent in both 1997 and 1999) felt that the program encouraged staff development, a critical element for any human services program. A large percentage of staff members (86 percent in 1999) worked in programs where their colleagues shared ideas with each other, and 78 percent reported that staff and administrators worked together for program improvement. Somewhat smaller numbers (about two-thirds) saw their program administrators as collaborating with staff in decision making and being receptive to change. Slightly more than half (55 percent) of all staff felt that they had "enough opportunity" to influence decisions that affected their work. Although the percentage who perceived that they had to follow rules they didn't agree with was small (20 percent), it increased 4 percentage points from 1997.

Through two years of program growth and with increasing programmatic complexity, staff members in the research programs generally maintained their positive view of Early Head Start as a place to work, a view that we reported in Leading the Way. Two survey items about workplace climate that staff members rated somewhat lower in 1999 than in 1997 related to collaborative decision-making. The percentage agreeing that "administrators collaborate with other staff to make decisions" fell from 75 to 69 percent, and the percentage saying "staff and administrators work collaboratively for program improvement" declined from 83 to 78 percent. These declines, though not large, might reflect a number of factors operating over this period, including the increasing complexity of program designs, growth in the size of program staffs, turnover of directors and frontline staff, and the evolving program designs.

Through our staff interviews, we learned about several key factors that appeared to account for this generally good staff morale. Staff members talked about their conviction that they were 
FIGURE VII.5

WORKPLACE CLIMATE: COLLABORATION, SHARING, AND DECISION MAKING FALL 1997 AND FALL 1999

Administrators encourage staff development activities

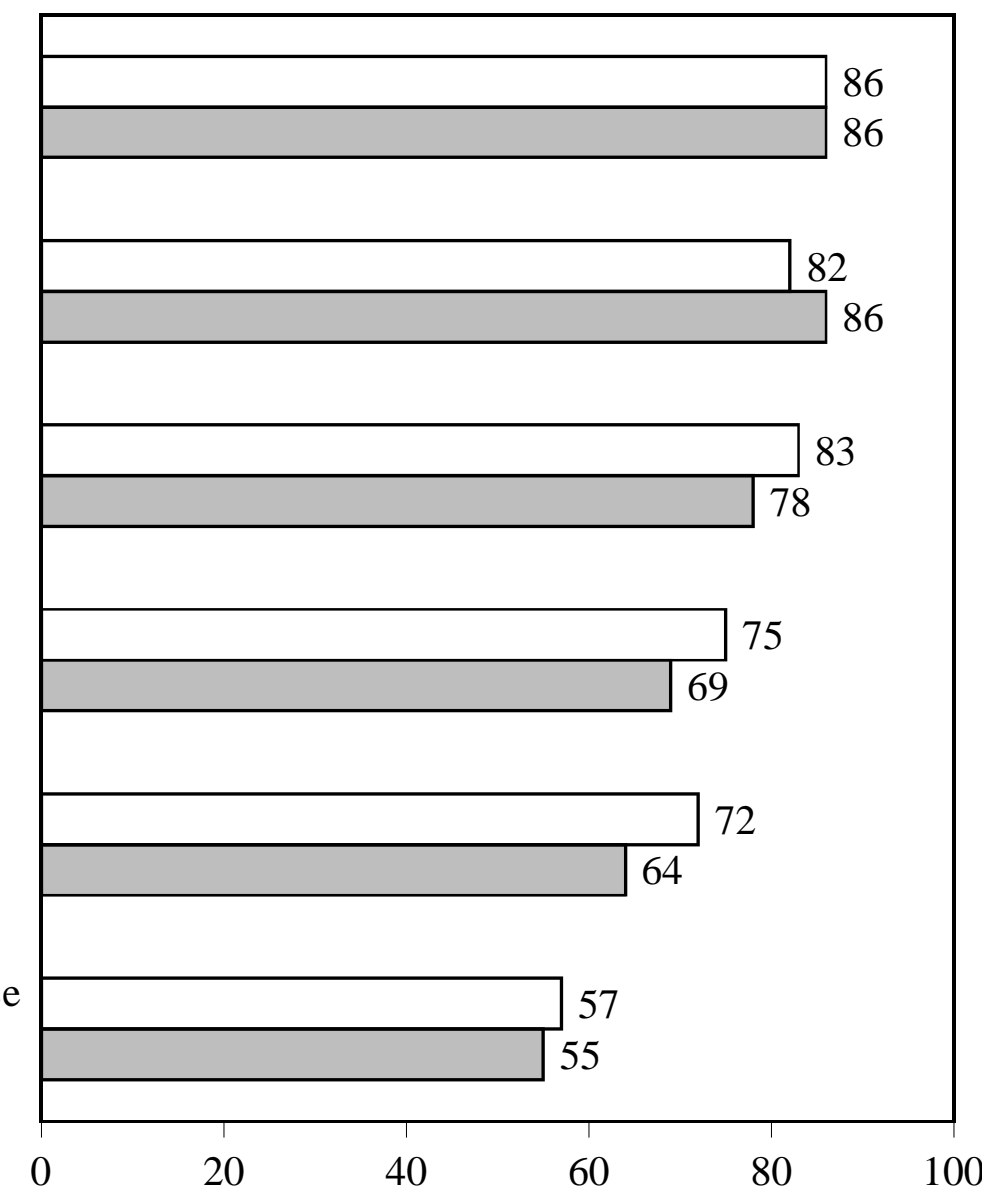

Staff frequently share ideas with each other

Staff and administrators work collaboratively for program improvemen

Administrators collaborate with other staff to make decisions

Staff and administrators are receptive to change

Staff have opportunity to influence decisions affecting their work

Percentage of Staff Rating Agree or Strongly Agree

$\square$ Fall $1997 \square$ Fall 1999

SOURCE: Self-administered surveys of staff completed during visits to the Early Head Start research programs in fall 1997 and fall 1999. 
making a difference in the lives of children and families, felt that they got along well and supported each other, received generous benefits, and had flexible work schedules. When morale was poor, staff attributed it to such factors as the stress resulting from dealing with the difficult problems their families faced, inadequate communication within the program, the departure of a program director, and program expansions or moves.

\section{Staff Health and Mental Health}

Early Head Start staff members are generally healthy (Table VII.5). More than two-thirds (71 percent) described their health as "very good" or "excellent" on a 5-point scale; only 3 percent reported it to be "fair" or "poor." Furthermore, 31 percent reported their health as being somewhat or much better than one year earlier, with only 8 percent saying it was somewhat or much worse than a year ago (health stayed "about the same" for 61 percent of the staff). Health problems did not appear to be a significant interference with work: one-fifth or fewer of Early Head Start staff indicated that any of four problems with work were a result of their physical health "during the past four weeks" (Table VII.5). Staff responded in a similar fashion to a question as to whether, in the past four weeks, they had a number of work difficulties "as a result of emotional problems, such as feeling depressed or anxious" (Table VII.5).

Finally, staff members reported on the extent to which their "physical health or emotional problems" interfered with their normal social activities with family, friends, neighbors, or groups. Ninety percent reported that they interfered "slightly" or "not at all." Although considerable site-to-site variation appeared, there were no systematic differences in reported physical and emotional health by staff in the three program approaches. 
TABLE VII.5

STAFF HEALTH AND MENTAL HEALTH: PERCENTAGE OF EARLY HEAD START STAFF
RESPONDING "YES” TO SURVEY STATEMENTS, FOR THE FULL SAMPLE
AND BY PROGRAM APPROACH

\begin{tabular}{|c|c|c|c|c|c|}
\hline & \multirow[b]{2}{*}{$\begin{array}{c}\text { Full } \\
\text { Sample }\end{array}$} & \multirow[b]{2}{*}{$\begin{array}{c}\text { Range of } \\
\text { Percentage } \\
\text { Across Programs }\end{array}$} & \multicolumn{3}{|c|}{ Program Approach in 1997} \\
\hline & & & $\begin{array}{l}\text { Center- } \\
\text { Based }\end{array}$ & $\begin{array}{l}\text { Home- } \\
\text { Based }\end{array}$ & $\begin{array}{l}\text { Mixed } \\
\text { Approach }\end{array}$ \\
\hline Overall Health & & & & & \\
\hline $\begin{array}{l}\text { Health Is "Very Good" or "Excellent" } \\
\text { Health Is Somewhat or Much Better than One }\end{array}$ & 71 & $38-91$ & 76 & 66 & 71 \\
\hline Year Ago & 31 & $15-45$ & 19 & 36 & 28 \\
\hline $\begin{array}{l}\text { Problems as Result of Physical Health } \\
\text { "During Past Four Weeks" }\end{array}$ & & & & & \\
\hline $\begin{array}{l}\text { Did you cut down the amount of time you } \\
\text { spent on work or other activities? }\end{array}$ & 9 & $0-16$ & 7 & 10 & 8 \\
\hline $\begin{array}{l}\text { Did you accomplish less than you would } \\
\text { have liked? }\end{array}$ & 20 & $9-31$ & 21 & 18 & 22 \\
\hline $\begin{array}{l}\text { Were you limited in the kind of work or other } \\
\text { activities you were able to do? }\end{array}$ & 10 & $0-17$ & 9 & 12 & 10 \\
\hline $\begin{array}{l}\text { Did you have difficulty performing work or } \\
\text { other activities, for example, did it take } \\
\text { extra effort? }\end{array}$ & 12 & $0-29$ & 10 & 15 & 11 \\
\hline $\begin{array}{l}\text { Problems as Result of Emotional Problems } \\
\text { "During Past Four Weeks" }\end{array}$ & & & & & \\
\hline $\begin{array}{l}\text { Did you cut down the amount of time you } \\
\text { spent on work or other activities? }\end{array}$ & 7 & $0-29$ & 6 & 10 & 4 \\
\hline $\begin{array}{l}\text { Did you accomplish less than you would } \\
\text { have liked? }\end{array}$ & 16 & $4-35$ & 19 & 17 & 13 \\
\hline $\begin{array}{l}\text { Did you not work or perform other activities } \\
\text { as carefully as usual? }\end{array}$ & 11 & $0-27$ & 14 & 14 & 6 \\
\hline $\begin{array}{l}\text { In Past Four Weeks, Physical Health or } \\
\text { Emotional Problems Interfered with Normal } \\
\text { Social Activities Slightly or Not at All }\end{array}$ & 90 & $84-100$ & 88 & 88 & 93 \\
\hline
\end{tabular}

SOURCE: Survey of program staff conducted in fall 1999. 


\section{Job Satisfaction and Commitment}

Responses to a number of questions about job satisfaction indicated that Early Head Start staff members enjoyed their work, found it worthwhile, and agreed that their jobs used their skills; few found their work boring. A sizable proportion said their work was "hard," yet overall, more than three-fourths were satisfied with their position in the program. Table VII.6 shows the percentage of staff reporting that they agreed or strongly agreed with the job satisfaction statements on the survey.

In spite of being generally happy with their jobs, at least some Early Head Start staff members nevertheless found them stressful. About one-fourth of all staff members ( 24 percent) reported that their jobs were usually or always stressful. This varied considerably across programs, ranging from a low of just 9 or 10 percent of staff saying their jobs were usually or always stressful at three sites to 50 and 56 percent with this response at two sites. The latter two programs were home-based and, overall, the highest levels of stress were reported by homebased program staff (on average, 31 percent rated their jobs as usually or always stressful) and the lowest for center-based staff (18 percent). This is consistent with the fact that home-based staff are faced with coping directly with families' day-to-day problems more often than are center-based staff.

Early Head Start staff generally had somewhat mixed feelings about their position with their program (Table VII.6). While 71 percent responded, "no," they did not intend to "leave this field" in the next year (just 4 percent said yes to that question), 45 percent responded that they did not "feel committed to working in this field" (26 percent indicated they did feel committed to their field). As the job satisfaction responses also indicated, however, staff members put a lot of effort into their work and generally did not feel like quitting (only 7 percent indicated they frequently felt like quitting). 
TABLE VII.6

JOB SATISFACTION AND COMMITMENT: PERCENTAGE OF EARLY HEAD START STAFF
RESPONDING TO SURVEY STATEMENTS, FOR THE FULL SAMPLE
AND BY PROGRAM APPROACH

\begin{tabular}{|c|c|c|c|c|c|}
\hline & \multirow[b]{2}{*}{$\begin{array}{c}\text { Full } \\
\text { Sample }\end{array}$} & \multirow[b]{2}{*}{$\begin{array}{l}\text { Range of Mean } \\
\text { Percentage } \\
\text { Across Programs }\end{array}$} & \multicolumn{3}{|c|}{ Program Approach in 1997} \\
\hline & & & $\begin{array}{c}\text { Center- } \\
\text { Based }\end{array}$ & $\begin{array}{l}\text { Home- } \\
\text { Based }\end{array}$ & $\begin{array}{c}\text { Mixed } \\
\text { Approach }\end{array}$ \\
\hline \multicolumn{6}{|l|}{ Percentage Agreeing or Strongly Agreeing } \\
\hline I enjoy my work & 95 & $81-100$ & 99 & 93 & 91 \\
\hline I find my work worthwhile & 94 & $84-100$ & 95 & 95 & 93 \\
\hline I find the work that I do is hard & 41 & $0-70$ & 30 & 47 & 45 \\
\hline I find my work boring & 3 & $0-17$ & 5 & 9 & 2 \\
\hline The work I do uses my skills & 91 & $76-100$ & 90 & 90 & 93 \\
\hline \multicolumn{6}{|l|}{ I am satisfied with my position with the Early } \\
\hline Head Start program & 77 & $56-100$ & 77 & 79 & 74 \\
\hline \multicolumn{6}{|l|}{ Percentage Responding "Yes" } \\
\hline I intend to leave this field in the next year & 4 & $0-13$ & 4 & 5 & 2 \\
\hline I put a lot of effort into my work & 99 & $93-100$ & 99 & 99 & 99 \\
\hline I frequently feel like quitting & 7 & $0-24$ & 6 & 8 & 6 \\
\hline I feel committed to working in this field & 26 & $14-50$ & 30 & 20 & 27 \\
\hline $\begin{array}{l}\text { I feel stuck in this position due to few other } \\
\text { employment opportunities }\end{array}$ & 14 & $0-32$ & 13 & 17 & 13 \\
\hline Job is usually or always stressful & 24 & $9-56$ & 18 & 31 & 22 \\
\hline
\end{tabular}

SOURCE: Survey of program staff conducted in fall 1999. 
Although responses varied by site, this variation was not as great as on some of the other staff survey questions. Differences by program approach are not substantial, with the percentage of staff agreeing to these items differing by only a few percentage points across the three program approaches, but a trend suggests that staff of home-based programs experience greater stress than staff in other programs.

\section{IMPLEMENTATION OF MANAGEMENT SYSTEMS AND CHANGES FROM 1997 TO 1999}

The Early Head Start research programs' implementation of management systems improved substantially during the evaluation period. The number of programs that had achieved full implementation of management systems doubled from 7 programs in fall 1997 to 14 in fall 1999 (Figure VII.6).

\section{Policy Councils}

The revised Head Start Program Performance Standards require programs to establish Policy Councils that develop and approve key program policies and procedures. Policy Councils must include parents and community members. At least 51 percent of the members must be parents of currently enrolled children.

The number of research programs that had fully implemented these Policy Council requirements doubled between fall 1997 and fall 1999, from 8 to 16 (Figure VII.7). Ten programs had reached an enhanced level of implementation by fall 1999-their Policy Councils met regularly and made decisions about many aspects of the program. One research program received a low implementation rating on this dimension because, although it had established a Policy Council, it did not meet regularly.

\section{Goals, Objectives, and Plans}

To ensure careful and inclusive planning, the revised Head Start Program Performance Standards require programs to develop multiyear goals, short-term objectives, and written plans for implementing program services. 
FIGURE VII.6

\section{EARLY HEAD START MANAGEMENT SYSTEMS \\ IMPLEMENTATION RATINGS}

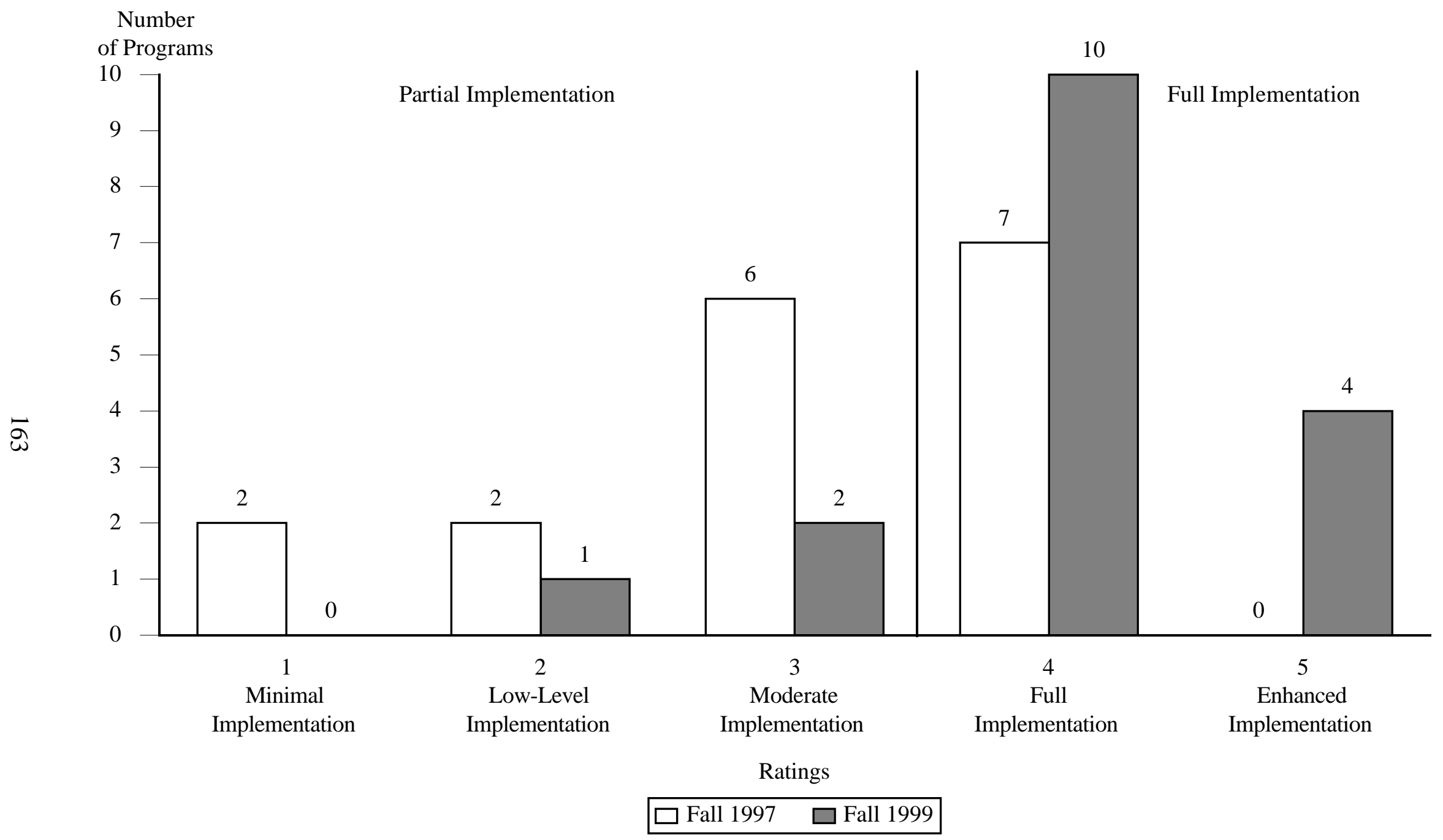

Source: $\quad$ Site visits conducted in fall 1997 and fall 1999 to 17 Early Head Start research programs.

Note: Implementation ratings for management systems represent the average rating across all the dimensions we examined. Programs rated as fully implemented achieved full implementation in most of the dimensions we examined, but did not necessarily achiev full implementation in every dimension. 
FIGURE VII.7

EARLY HEAD START MANAGEMENT SYSTEMS

ASPECTS THAT WERE FULLY IMPLEMENTED

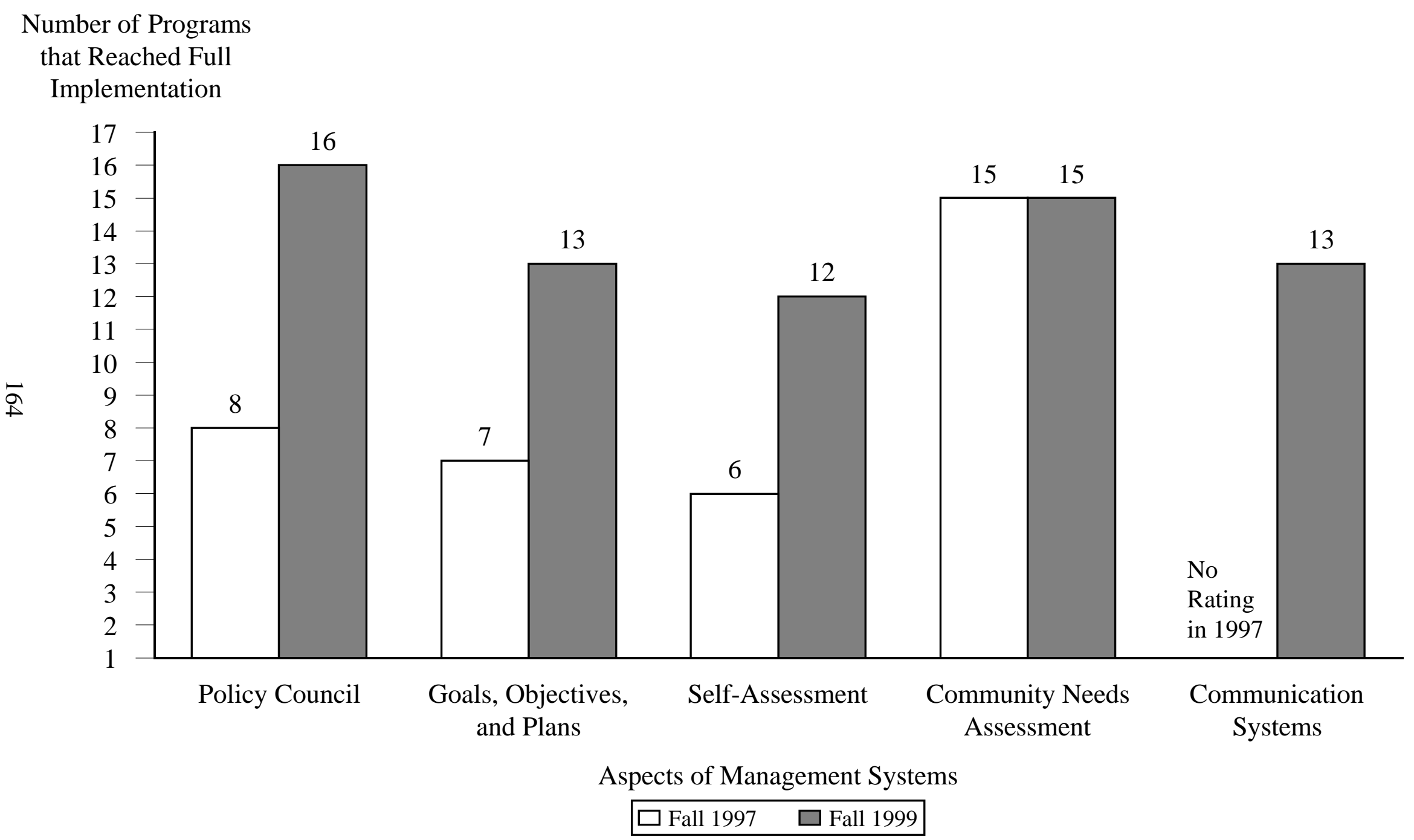

Source: Site visits conducted in fall 1997 and fall 1999 to 17 Early Head Start research programs. 
In fall 1999, 13 research programs had fully implemented these planning requirements, almost doubling from the 7 programs that were fully implemented in fall 1997 (Figure VII.7). Seven programs had reached an enhanced level of implementation of the planning requirements in fall 1999 - they developed their goals and plans in consultation with Policy Councils, advisory groups, parents, staff, and community members. Two programs received a rating of "moderately implemented" because their goals, objectives, and plans needed to be updated. Two programs received a low implementation rating in fall 1999 because, although they had implemented a planning process, their goals and plans had been only partially implemented.

\section{Program Self-Assessment}

To promote continuous improvement, the revised Head Start Program Performance Standards require programs to assess annually their progress toward achieving their goals and their compliance with the standards. The self-assessment should include Policy Council members, parents, staff, and other community members.

The number of programs that had fully implemented these self-assessment requirements doubled between fall 1997 and fall 1999, from 6 to 12 (Figure VII.7). Six programs had reached an enhanced level of implementation of the self-assessment requirements in fall 1999; these programs had used the results of their self-assessments to make specific program improvements. Three programs reached a moderate level of implementation in this area in fall 1999; while they had conducted some self-assessment activities in the past year, the self-assessment process needed to be formalized and documented in program records. One program received a low implementation rating in this area in fall 1999 because it had developed a plan for conducting a self-assessment but had not yet implemented it. One program had not yet planned for or conducted a self-assessment. 


\section{Community Needs Assessment}

The revised Head Start Program Performance Standards require programs to conduct an assessment of community strengths, needs, and resources at least once every three years.

Fifteen research programs had fully implemented the community needs assessment requirements in both fall 1997 and fall 1999 (Figure VII.7). Seven had reached an enhanced level of implementation of the community needs assessment requirements in fall 1999-they involved a wide range of Policy Council and advisory group members, staff, parents, and community members in the assessment process. One program had conducted a community needs assessment, but it had not updated the assessment within the past three years. Another program had not yet carried out its plans for conducting a community needs assessment.

\section{Communications Systems}

We rated programs as fully implementing communication systems if systems were in place for communication among program staff, between staff and parents, with the grantee agency, and with the Policy Council and other governing bodies. ${ }^{8}$

In fall 1999, 13 programs had fully implemented communication systems, including meetings and written communications on paper and through e-mail. Eight programs reached an enhanced level of implementation of communication systems-their systems facilitated two-way communication in which staff, parents, the Policy Council, and the grantee provided information and input and also received it from each other. Four programs received a rating of "moderately implemented" in fall 1999 because they did not have adequate systems in place for communicating with the grantee agency, Policy Council, or other governing bodies.

\footnotetext{
${ }^{8}$ We did not rate this dimension in 1997 . We added the scale for communication systems in 1999 based on the recommendation of a member of the training and technical assistance network.
} 


\section{SUMMARY}

The Early Head Start research programs made significant strides in staff development and program management. Almost all (15 out of 17) achieved a rating of full or enhanced implementation in staff development by fall 1999, and the 3 programs that had been rated "low" in 1997 improved by 1999. Fourteen programs were rated as fully implemented in Early Head Start management systems in 1999, and 3 of the 4 that had been "minimal" or "low" in 1997 received higher ratings in 1999. The strongest areas across staff development and management were supervision, staff training, Policy Councils, and community needs assessments—in each of these, 15 or more programs were rated as fully implemented in 1999. Although staff retention was lower in 1999 than in 1997, most programs experienced annual turnover in the 15 to 32 percent range, and improvement was seen in the fact that fewer programs experienced very high turnover rates. A number of programs focused on improving wages, and the average compensation for frontline staff improved by 9 percent over that two-year period. Staff responses to a survey administered in fall 1999 showed that staff morale was generally high. Staff reported positive workplace climates and valued their directors.

The three program approaches differed in some aspects of staff development. Staff in homebased and mixed-approach programs had higher levels of educational attainment than those in center-based programs, the frontline staff in these programs received higher wages, and homebased and mixed-approach programs provided better benefits packages. Overall, programs were successful in meeting the requirement of the performance standards that at least 50 percent of frontline staff have a two-year or higher degree, even before the 2003 deadline. However, center-based programs were not achieving the required goal of having all teachers CDA-certified within a year of being hired. The three program approaches did not differ substantially in staff health and mental health, nor did they differ greatly in their staff's job satisfaction ratings, 
although satisfaction was somewhat lower among home-based staff. Many staff across the research programs believed they were making a difference in the lives of children and families. 


\section{THE QUALITY OF SELECTED CHILD DEVELOPMENT SERVICES}

An important dimension of program implementation is the degree to which programs offer high-quality services. The Early Head Start program guidelines specifically require programs to provide high-quality early education services, home visits, and parent education, and to ensure that infants and toddlers who need child care receive high-quality care. The guidelines also require programs to ensure that the full range of family-oriented services is of high quality.

Our examination of quality focuses on two important child development services-child care and child development home visits—-because these are core Early Head Start services, and measurement tools existed or could be developed for assessing their quality. We begin this chapter by describing our methods for assessing the quality of core child development services, and then report on the progress programs made in improving the quality of these services between fall 1997 and fall 1999.

\section{A. METHODS FOR ASSESSING QUALITY}

We used two main methods for assessing the quality of core child development services. First, we assessed the quality of child care used by Early Head Start families using data from observations of the child care settings used by Early Head Start children. Second, we developed rating scales and a rating process similar to those used for assessing implementation (see Chapter IV) to rate inputs to the quality of child care in Early Head Start centers, programs' efforts to assess and monitor quality in community child care settings and to support child care providers, and inputs to the quality child development home visits. In this section we describe the data sources and analytic methods we used to rate inputs to the quality of child care and home visits and to assess child care quality. 


\section{Rating Inputs to Quality}

We developed scales for rating the "inputs to quality" of child care and child development home visits. The literature on child care research indicates that researchers take a variety of approaches to defining quality in child care (Love, Schochet, and Meckstroth 1996). Some define quality as including such factors as staff qualifications and retention or stability (Ferrar 1996; Ferrar et al. 1996; and Phillips and Howes 1987); others consider these as contributors to program quality (for example, Layzer et al. 1993). We adopted the latter approach in the Early Head Start evaluation, considering elements that support what happens in classrooms or in home visits to be "inputs to quality." For child care, the inputs we rated were curriculum, assignment of primary caregivers, educational attainment of teachers, and teacher turnover. For home visits, the inputs we rated were supervision, home visitor training, home visitor hiring, planning home visits, frequency of home visits, emphasis on child development, and integrating home visits with other services. We also developed a scale for rating all programs on the extent to which they monitored the quality of child care arrangements and provided training and support for child care teachers.

We used data from site visits conducted in fall 1997 and fall 1999 to assign ratings to programs. To facilitate the assignment of ratings, we assembled site visit data into checklists organized according to the inputs to quality we rated (Appendix A).

\section{Observations of Child Care Quality}

We used data from observations of Early Head Start children's child care settings (including Early Head Start centers, community child care centers, and family child care homes) conducted 
when they were 14 and 24 months old to assess the quality of child care that children received. ${ }^{1}$ These observations include data collected using a slightly shortened version of the InfantToddler Environment Rating Scale (ITERS; Harms et al. 1990) and the Family Day Care Rating Scale (FDCRS; Harms and Clifford 1989), as well as observed child-teacher ratios and group sizes. These scales are widely used and consist of 35 items to assess the quality of care. ${ }^{2}$ These scales produce scores on each item ranging from 1 to 7 , in which 3 is described as minimal care, 5 as good care, and 7 as excellent care.

To compute average ITERS scores for Early Head Start centers, we began by averaging the observations for each classroom. ${ }^{3}$ Classrooms were observed as often as once per quarter (or more often if staff or children had changed since the last observation), depending on when Early Head Start children were in care. We then averaged the classroom scores for each center. If a program operated multiple centers, we averaged the center scores to generate an average program score. Thus, the average ITERS scores reported here do not reflect the average quality of care received by individual children. Rather, they represent the average quality of Early Head Start centers, determined at the classroom level.

To compute average ITERS scores for community child care centers, we computed an average score for each center, and then averaged the center scores to compute an average site score. Likewise, to compute average FDCRS scores, we computed an average score for each family child care home, and then averaged these home scores to compute an average site score.

\footnotetext{
${ }^{1}$ Observations subsequently conducted when children were 36 months old are reported in a separate paper on child care.

${ }^{2}$ The shortened version of the ITERS we used excludes three items from the adult needs category (opportunities for professional growth, adult meeting area, and provisions for parents).

${ }^{3}$ The average ITERS and FDCRS scores reported here have not been weighted to reflect the number of program children participating in each classroom, center, or home.
} 
Observed child-teacher ratios and group sizes were calculated based on child and adult counts taken during structured observations of child care settings.

\section{B. INPUTS TO CHILD CARE QUALITY}

In fall 1999, more than half of the 12 Early Head Start research programs with child care centers received good or high ratings on several inputs to child care quality, including curriculum, assignment of primary caregivers, and educational attainment of Early Head Start teachers (Figure VIII.1). However, only two programs received a good or high rating on staff turnover.

To receive a good rating for curriculum as an input to child care quality, Early Head Start centers had to use a curriculum strongly integrated into the center's daily activities and appropriate for the population served. Centers that individualized their curriculum for each child received a high quality rating. Eight out of the 12 research programs with centers received a good or high quality rating on this dimension in fall 1999 (Figure VIII.1).

To receive a good rating for assignment of primary caregivers, Early Head Start centers had to assign primary caregivers to children and adhere to these assignments throughout the day. In addition, primary caregivers had to conduct almost all routine care activities for the children in their group. To receive a high rating, primary caregivers had to communicate regularly with parents and plan the activities for children in their group. Eight out of the 12 research programs with centers met the criteria for a good or high quality rating on this dimension in fall 1999.

To receive a good rating for educational attainment of teachers, most teaching staff in Early Head Start centers had to have a CDA, an associate's degree, or a bachelor's degree, or be in CDA training. To receive a high rating, all teaching staff had to have a CDA, an associate's degree, or a bachelor's degree, or be in CDA training. Seven out of the 12 research programs with centers met the criteria for a good or high quality rating on this dimension in fall 1999. On 
NUMBER OF PROGRAMS WITH CENTERS IN WHICH INPUTS TO QUALITY WERE RATED AS GOOD OR HIGH

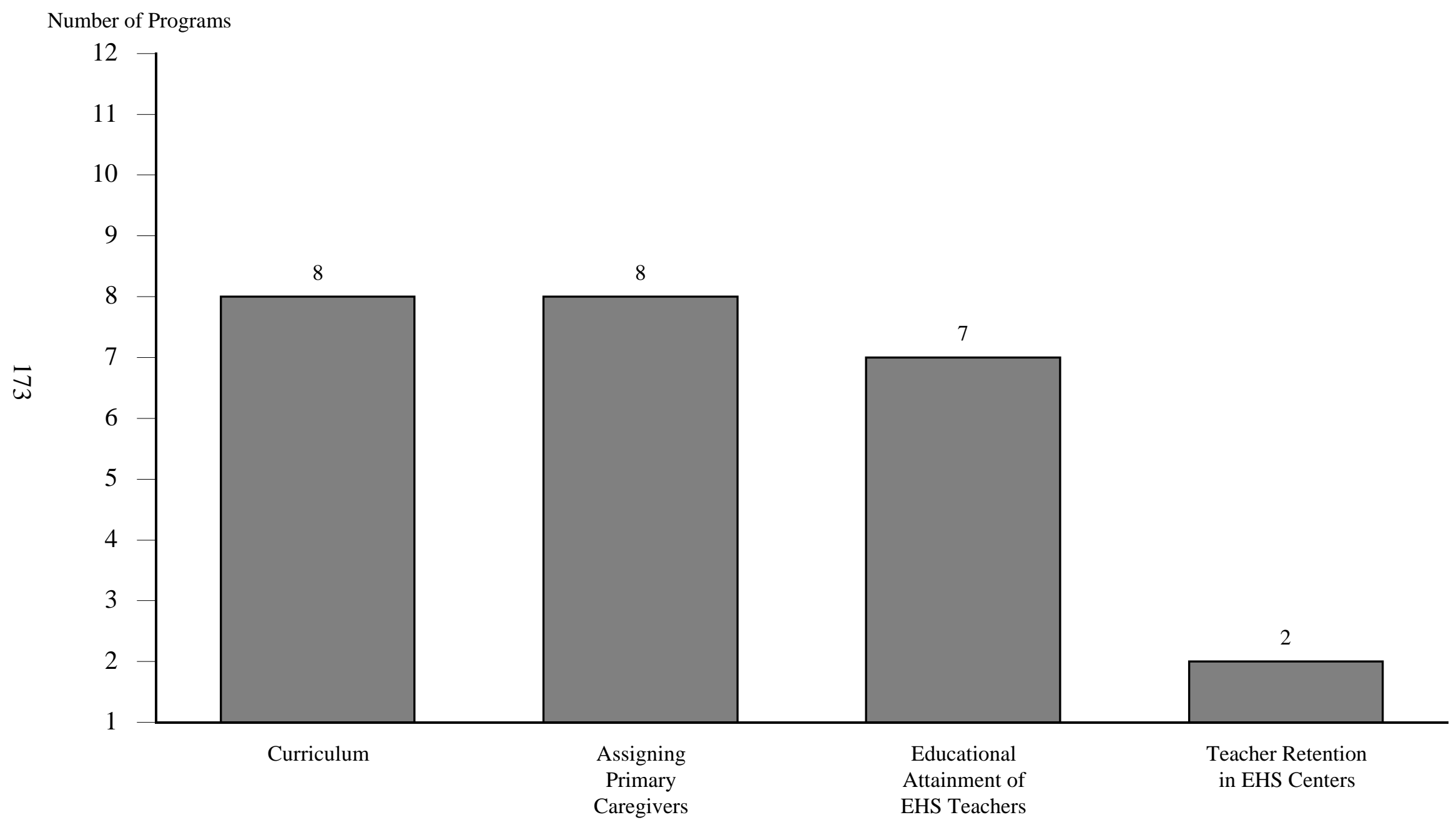

Aspects That Were of Good or High Quality 
average, 58 percent of center staff had their CDA or higher degree in fall 1999, and an additional 19 percent were working on obtaining a CDA.

Only two programs with centers received a good or high rating in the area of teacher retention, which required the centers' teacher turnover rate to be below 20 percent for the previous year. On average, about 39 percent of full-time and part-time staff working directly with children in Early Head Start centers left and were replaced during the year prior to the fall 1999 site visits.

We rated all 17 research programs on two types of inputs to child care quality-quality monitoring and training and support for providers - and in these areas, between one-fourth and one-half of the programs received a good or high rating (Figure VIII.2). These ratings encompass monitoring and teacher training and support in both Early Head Start centers and other community child care settings.

To receive a good rating for quality monitoring, Early Head Start centers had to carry out ongoing quality assessments and give feedback to staff about the care they were providing. To receive a high rating, the approach to quality improvement had to be systematic. To receive a good rating, programs in which some or all children received child care in community centers or family child care homes had to (1) assess the quality of child care settings before referring children, and (2) monitor child care quality regularly for most children in care, whether or not the program placed the children in their child care settings. To receive a high rating, these programs had to take a comprehensive approach to assessing quality and had to monitor quality regularly for all children in child care. Seven out of the 17 research programs, including the 4 centerbased programs, met the criteria for a good or high quality rating on this dimension in fall 1999.

To receive a good rating for training and support of child care providers, programs had to provide regular training to nearly all child care teachers and family child care providers caring 
FIGURE VIII.2

\section{EARLY HEAD START INPUTS TO CHILD CARE QUALITY THAT WERE RATED GOOD OR HIGH \\ FALL 1999}

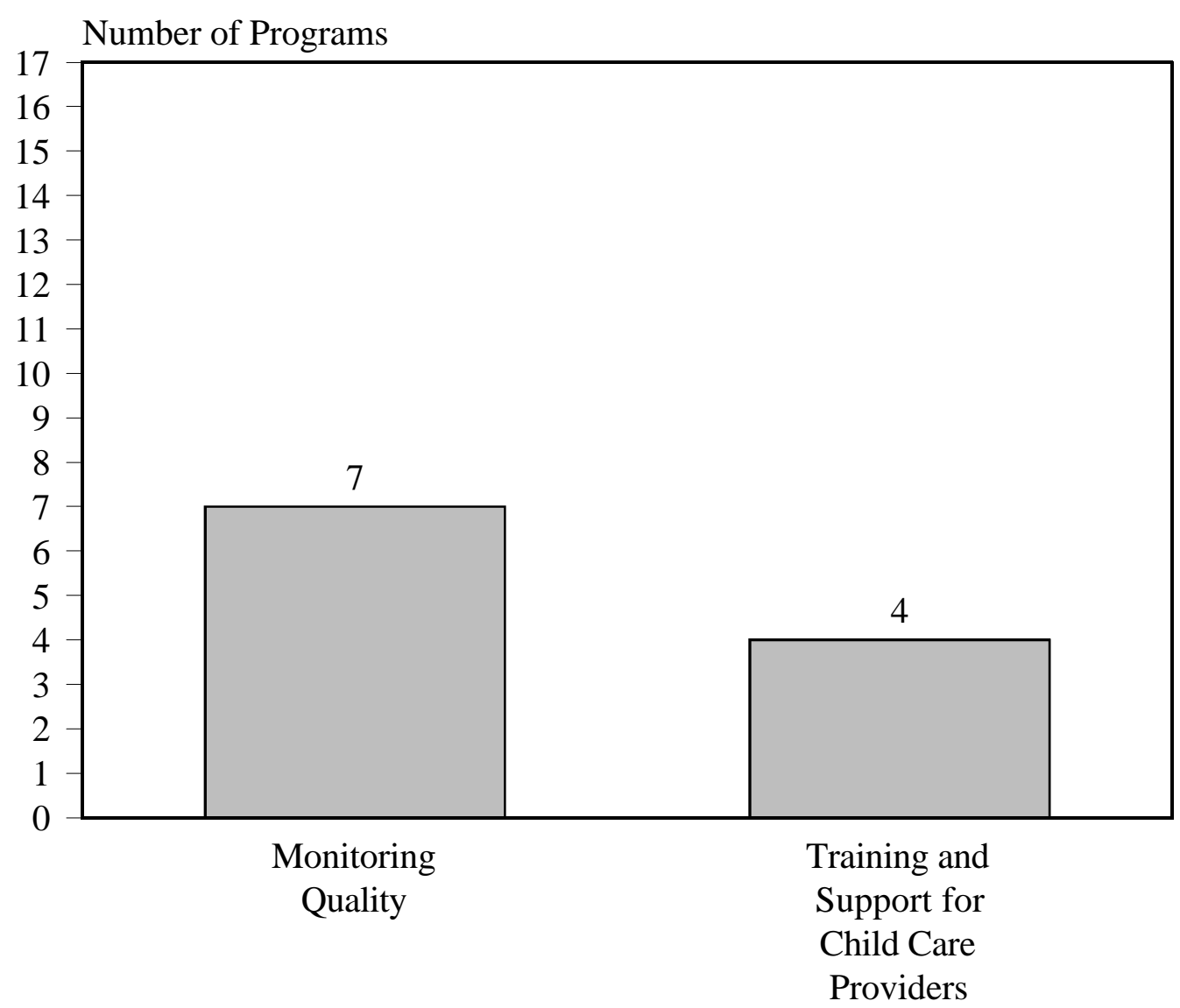

Aspects That Were of Good or High Quality

SOURCE: Information gathered during visits to the Early Head Start research programs in fall 1999. 
for Early Head Start children, and if some children were in relative care, the program had to provide support and training to some of them as well. To receive a high rating, the program had to provide the training according to individual needs and to base training activities on an individualized training plan. Four out of the 17 research programs (the four center-based programs) met the criteria for a good or high quality rating on this dimension in fall 1999.

\section{OBSERVED CHILD CARE QUALITY}

Child care observations were conducted in three settings that represent the range of arrangements that Early Head Start children were in: (1) Early Head Start centers, (2) community child care centers that Early Head Start children attended, and (3) family child care homes (both regulated and unregulated) that Early Head Start children attended. In this section, we report on child care observations conducted between October 1997 and September 1999 in Early Head Start centers in 9 research sites, community child care centers in 16 research sites, and family child care homes in 14 sites.

\section{Quality in Early Head Start Centers}

Our analysis indicates that the quality of care provided by Early Head Start centers during their first three years of serving families was good (Table VIII.1). All programs scored above 4 on average, on the ITERS, with the average being 5.3 (in the good range) in both the first and second years after the fall 1997 site visits. $^{4}$

In most programs, the average ITERS score changed by only a few points, but in one program it fell substantially (from 6.3 in the first year to 5.6 in the second year, still well within

\footnotetext{
${ }^{4}$ The average for the first year has been updated since preliminary findings were presented in Leading the Way, Volume III: Program Implementation (ACYF 2000a), because more observations were received from data collectors.
} 


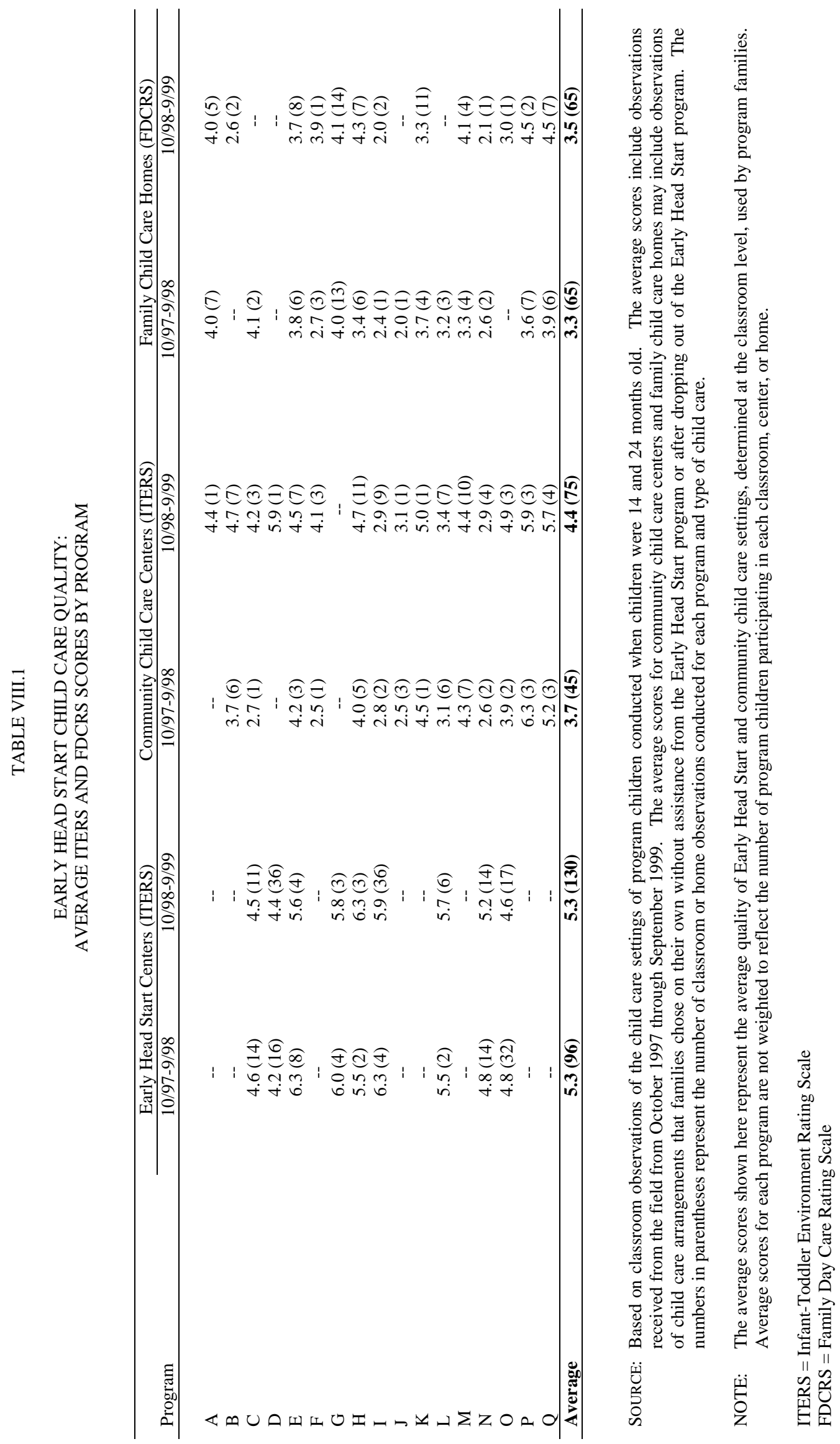


the good range), and in one program it rose substantially (from 5.5 to 6.3). Early Head Start centers in several programs received average ITERS scores of 6 or above, which indicates good to excellent care. Comparisons with other child care quality studies show that Early Head Start centers were doing very well. For example, the Cost, Quality, and Child Outcomes Study Team (1995) found that the average ITERS score across infant-toddler classrooms in the four states studied was only 3.4, and 40 percent of the classrooms in that study received ratings below 3.0; no Early Head Start center had an average score below 4.2 in 1997-1998 or 4.4 in 1998-1999 (Table VIII.1).

We also examined scores on subscales of the ITERS. The programs achieved good quality, on average, in all areas, although scores were somewhat lower in three areas: learning activities, adult needs, and furnishings (Figure VIII.3). Thus, programs may want to focus on these areas in future quality enhancement efforts. Programs were particularly strong in the area of interactions: three had average scores of 7.0 on this subscale.

Observed child-teacher ratios and group sizes were good in both time periods. Over time, as the centers became fully enrolled and as more children were being observed at 24 months of age rather than 14 months, average observed group sizes and ratios tended to increase slightly, but they remained well below the thresholds set by the revised Head Start Program Performance Standards (four children per teacher and eight children per group). Average child-teacher ratios rose slightly, from 2.3 in the first year to 2.9 in the second year (Table VIII.2). Average group sizes also rose slightly, from 5.3 to 5.9 (Table VIII.3).

\section{Observed Child Care Quality in Community Child Care Centers}

Our analyses suggest that the quality of child care received by Early Head Start children in 
FIGURE VIII.3

\section{EARLY HEAD START CENTERS}

AVERAGE ITERS SUBSCALE SCORES, 1998-99

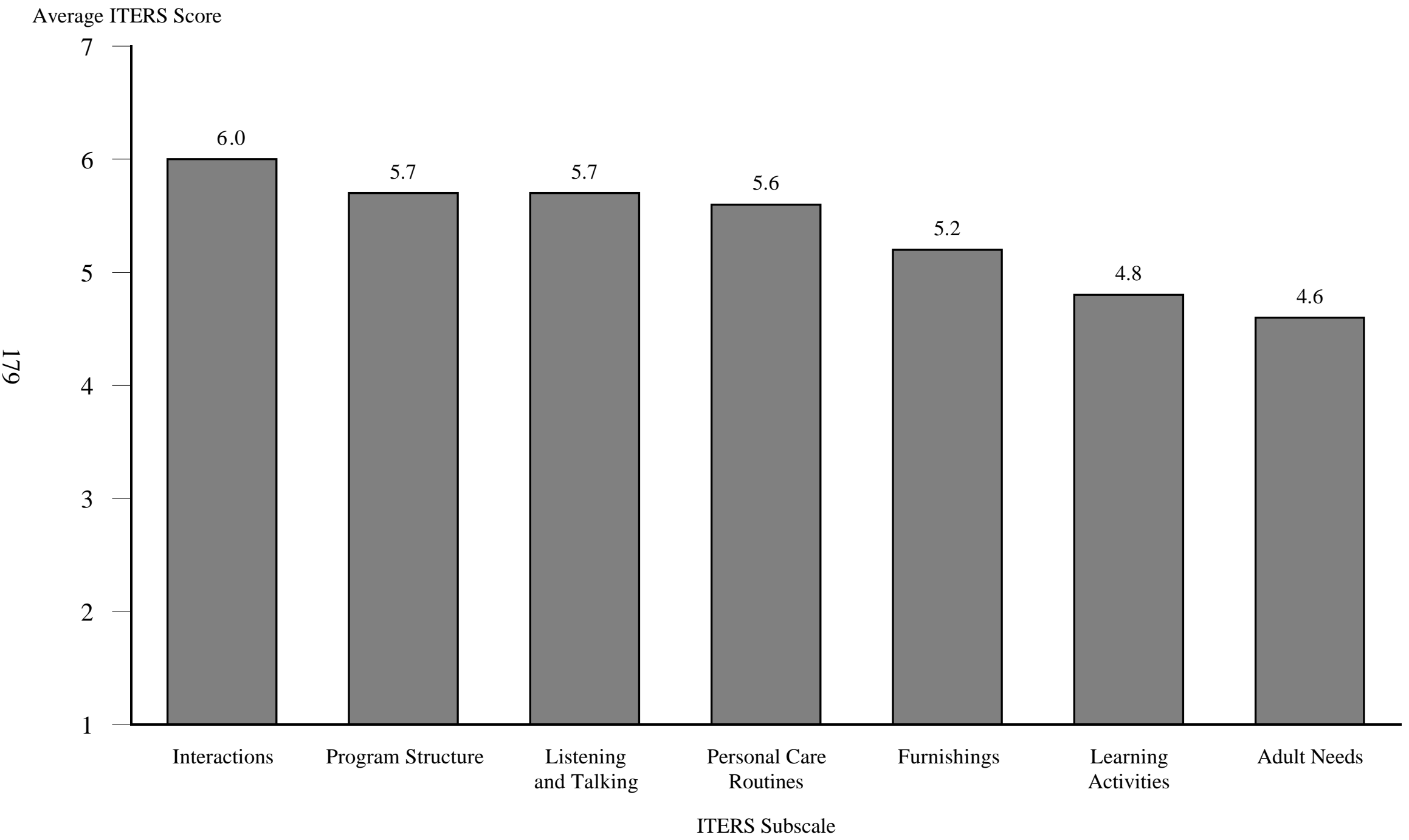

Source: $\quad$ Observations of Early Head Start classrooms conducted in conjunction with child assessments at 14 and 24 months of age.

Note: $\quad$ Based on observations in 130 classrooms in 9 programs with centers. 


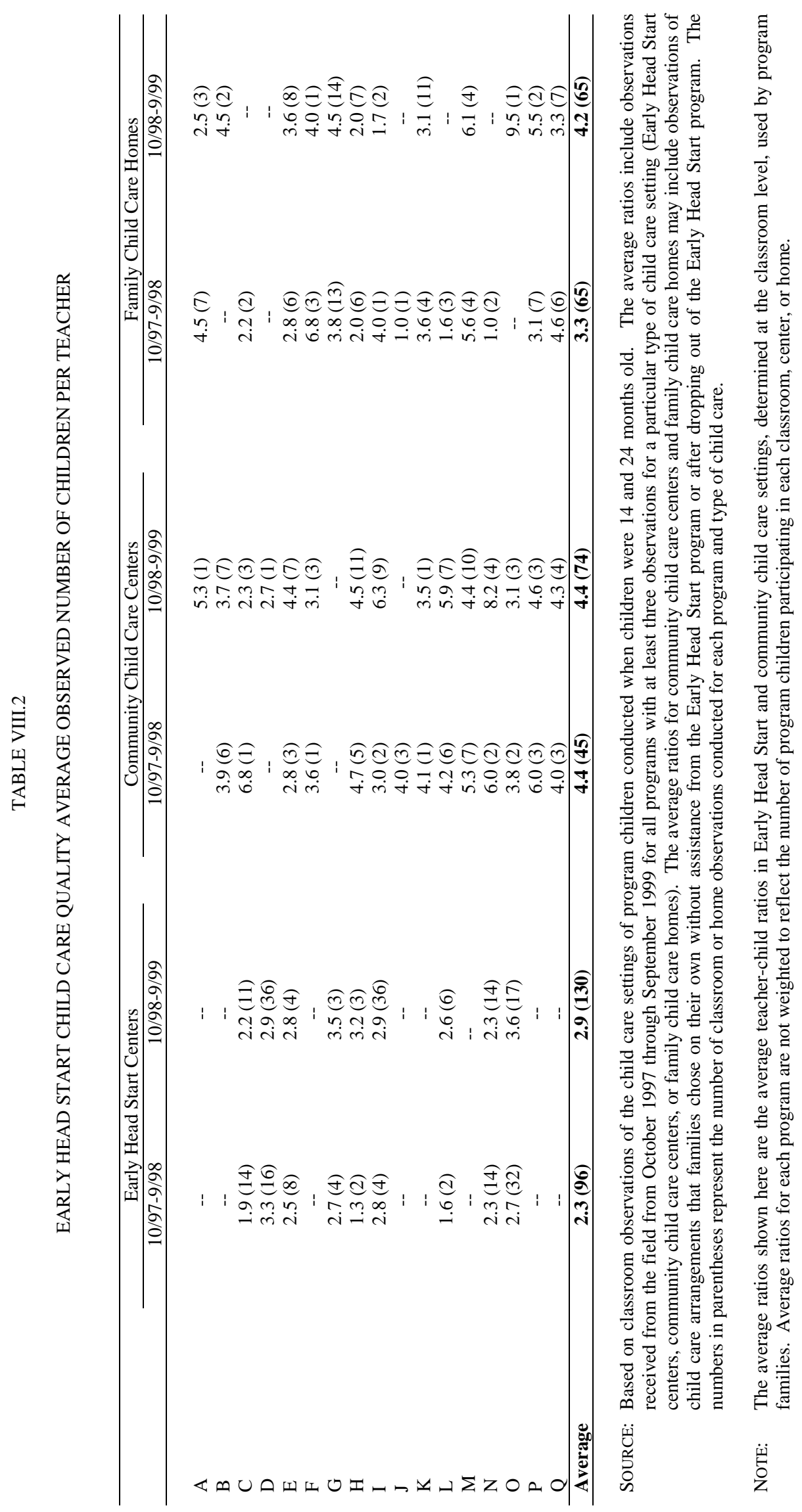




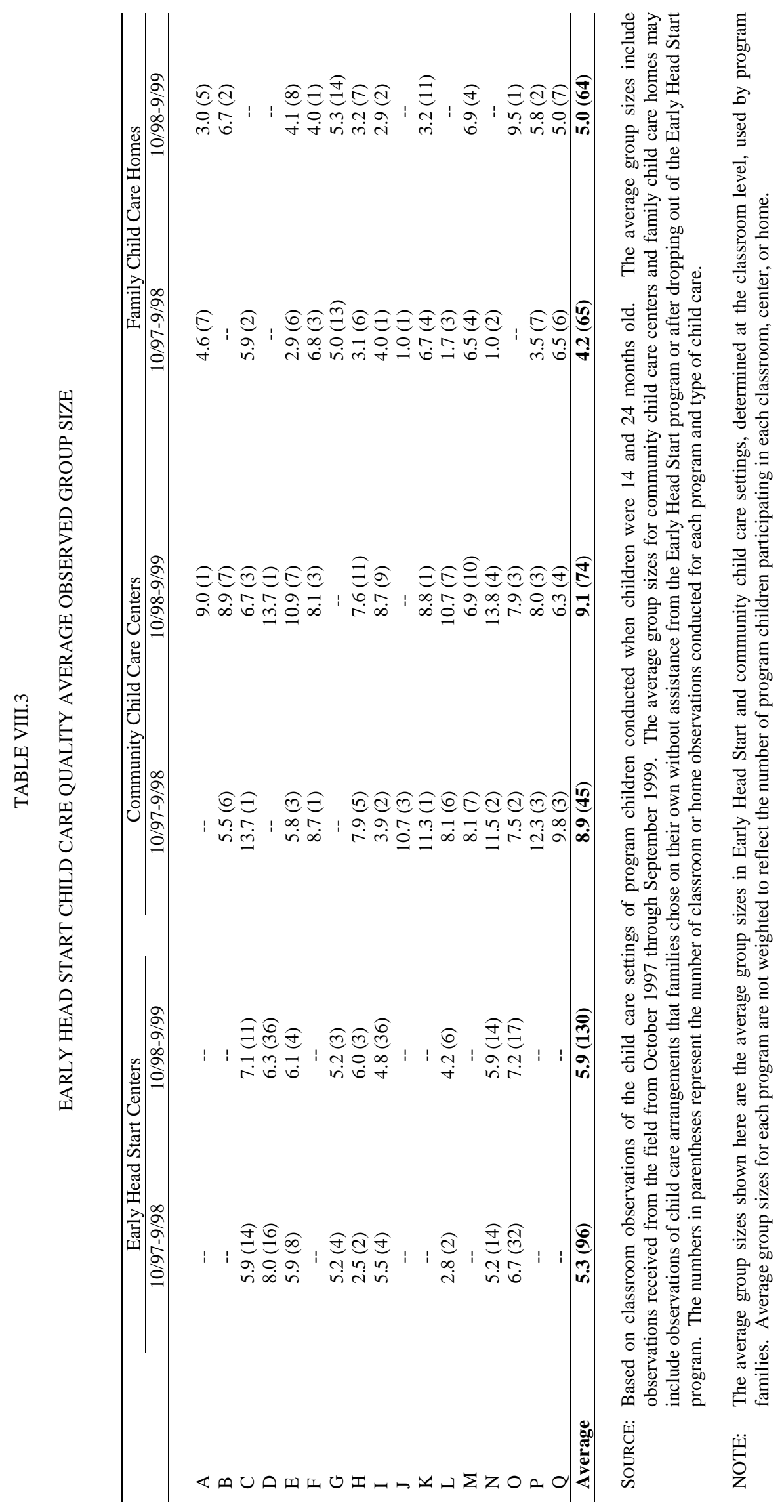


community child care centers varied widely, but was consistently minimal, on average (Table VIII.1). ${ }^{5}$ However, the average ITERS score for classrooms that we observed in community child care centers was 3.7 in 1997-1998 and 4.4 in 1998-1999, indicating that the quality of care in community child care settings may have improved over time. ${ }^{6}$ However, average quality remained lower than the quality of care provided in Early Head Start centers.

The average child-teacher ratios in classrooms in community child care centers, 4.4 in both the first and second years, exceeded the maximum ratio of four children per teacher specified in the revised Head Start Program Performance Standards (Table VIII.2). Similarly, the average group size in community child care centers, 8.9 in 1997-1998 and 9.1 in 1998-1999, exceeded the maximum group size of eight children specified in the standards (Table VIII.3).

\section{Observed Child Care Quality in Family Child Care Settings}

Observational data suggest that the observed quality of child care that Early Head Start children received in family child care settings was consistently minimal, but ratios and group sizes were good. ${ }^{7}$ The average FDCRS score for the family child care settings was 3.3 in 19971998 and 3.5 in 1998-1999 (Table VIII.1), both in the minimal quality range. The average childcaregiver ratio in the family child care settings that we were able to observe was 3.3 in the first

\footnotetext{
${ }^{5}$ The community child care centers that we observed include both those that Early Head Start assessed and monitored and those that parents selected without help from Early Head Start.

${ }^{6}$ This change may indicate real improvement over time, but we are cautious in making this interpretation because response rates were low in some sites. With fewer than three observations in a number of sites, we may not have sufficient data to consider this to be a representative sample of Early Head Start children's community child care arrangements. In addition, it is possible that higher quality scores are somewhat easier for centers to attain when serving older children.

${ }^{7}$ The family child care settings that were observed include both family child care homes that Early Head Start assessed and monitored and family child care homes that parents selected without help from Early Head Start.
} 
year and 4.2 in the second (Table VIII.2). The average group size in the family child care settings that we were able to observe was 4.2 children in the first year and 5.0 in the second observation period (Table VIII.3).

\section{INPUTS TO THE QUALITY OF CHILD DEVELOPMENT HOME VISITS}

The inputs to the quality of child development home visits that we rated indicate that overall, the quality of child development home visits improved substantially between the fall 1997 and fall 1999 site visits. By fall 1999, the quality of child development home visits in 11 research programs that served some or all families in a home-based option was rated as good or high, up from 9 programs in fall 1997 (Figure VIII.4).

The greatest improvements in inputs to the quality of child development home visits were in the areas of supervision, emphasis on child development, and home visit planning. In other areas, most programs received high ratings in both fall 1997 and fall 1999.

The number of programs that were rated as providing good- or high-quality supervision of home visitors increased from 8 programs in fall 1997 to all 13 programs in fall 1999 (Figure VIII.5). The programs rated as providing good-quality home visitor supervision provided regular individual and group supervision that included support, teaching, and evaluation; they also provided mentoring. Supervisors paid some attention to child development, tracked the frequency of home visits carefully, and accompanied home visitors on some home visits. Programs rated as providing high-quality supervision also provided regular opportunities for home visitors to discuss their experiences with peers, and supervisors had a regular plan for accompanying home visitors on home visits.

The number of programs rated as providing good or high quality in terms of the number of completed home visits per month increased from six to eight. The relatively small improvement 
FIGURE VIII.4

EARLY HEAD START CHILD DEVELOPMENT HOME VISITS

OVERALL RATINGS OF QUALITY INPUTS

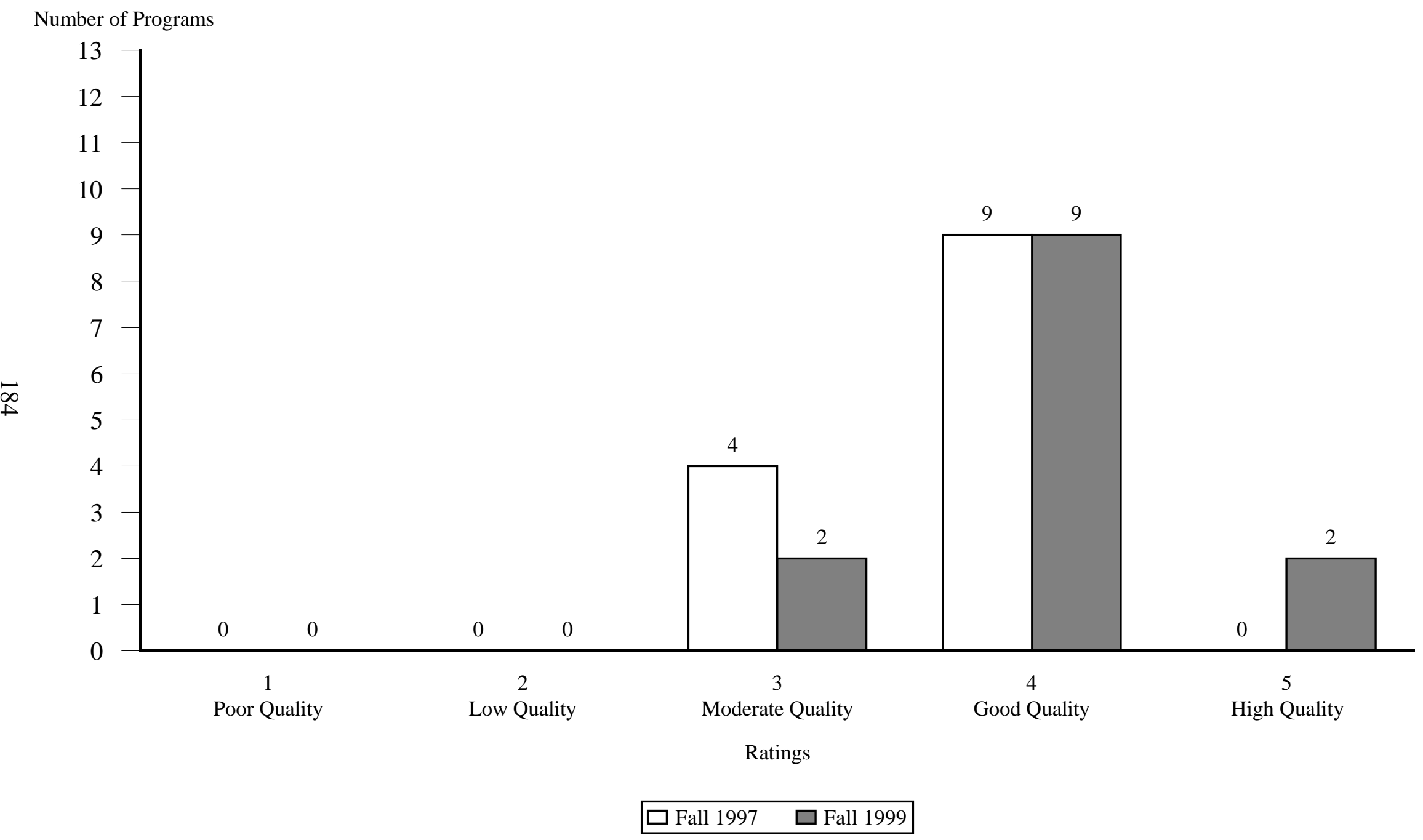

Source: $\quad$ Site visits conducted in fall 1997 and fall 1999 to 13 Early Head Start research programs providing home-based services to some or all families. 
FIGURE VIII.5

EARLY HEAD START CHILD DEVELOPMENT HOME VISITS RATINGS OF QUALITY INPUTS

Number of Programs
Rated as Good or

High Qualit 13

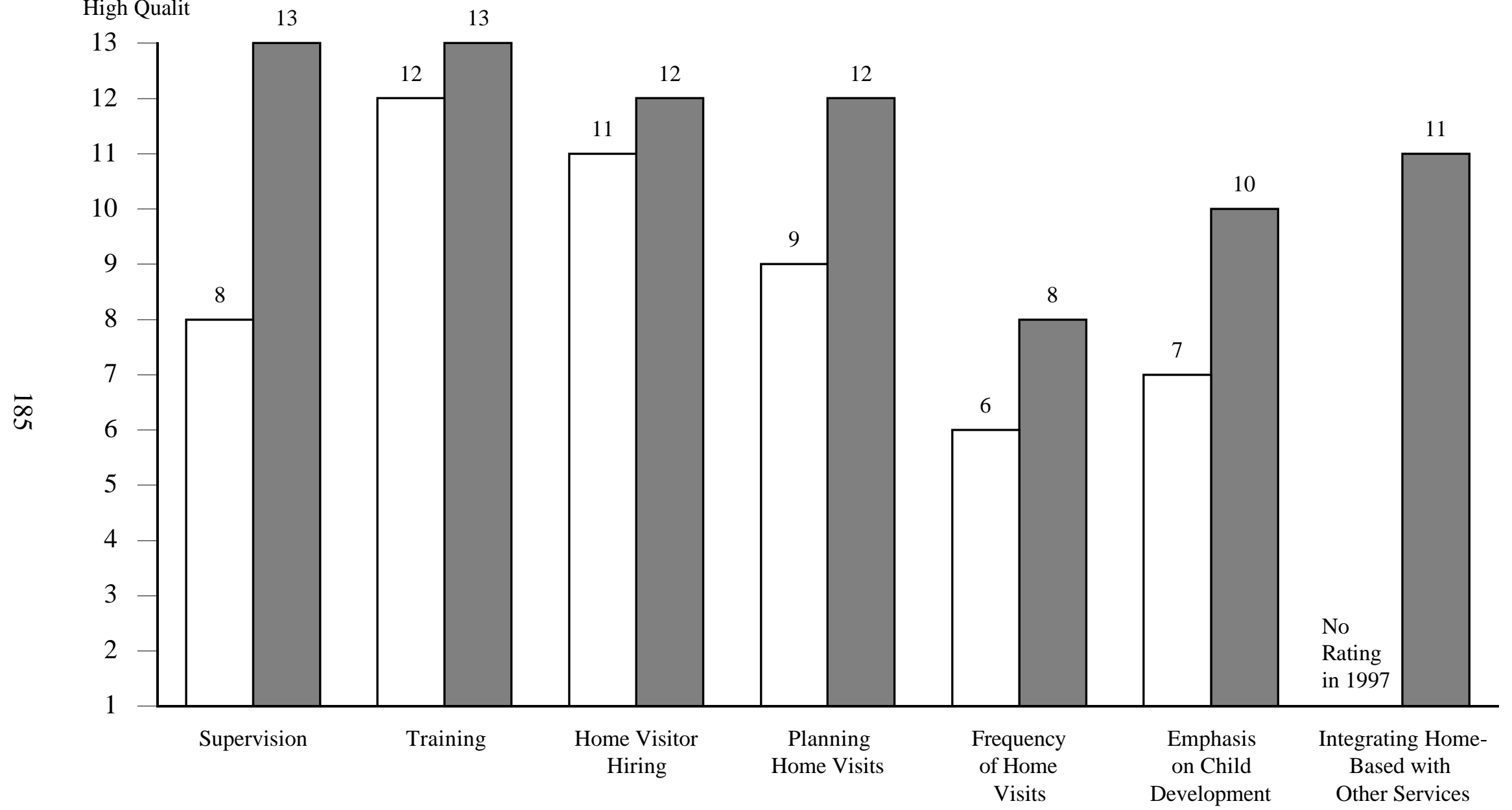

Aspects of Child Development Home Visits

$$
\square \text { Fall } 1997 \quad \square \text { Fall } 1999
$$

Source: $\quad$ Site visits conducted in fall 1997 and fall 1999 to 13 Early Head Start research programs providing home-based services to some or all families. 
in the number of programs with quality rated as good or high on this dimension reflects in part the increase between 1997 and 1999 in the number of completed home visits required for a good rating (from two to three per month). Thus, the small increase in the number of programs rated as providing good or high quality understates the progress programs made in this area

The number of programs that were rated as good or high quality in terms of their emphasis on child development during home visits increased from 7 to 10 . In these programs, home visitors were reported to spend at least half an hour during each home visit on child development activities either with the child or with the child and parent together.

With respect to home visit planning, the number of programs rated as good or high quality increased from 9 to 12 . In programs receiving a good rating, home visits were planned based on program goals and expected outcomes, and home visitors developed plans for each visit using a curriculum or protocol to guide child development activities, which were then individualized to meet the needs of individual parents and children. In programs that received a high quality rating, home visitors also worked in partnership with parents to plan child development activities.

\section{E. SUMMARY}

Between fall 1997 and fall 1999, the 17 research programs had notable success in providing consistently good-quality care in Early Head Start centers. Although the observed quality of care in community child care settings was somewhat lower, observation data indicate that quality in community child care centers may have improved over time. In addition, programs made considerable progress in improving key inputs to the quality of child care and child development home visits between fall 1997 and fall 1999. The pathways that programs took as they worked towards improving quality are examined in the next chapter. 


\section{PROGRAM PARTICIPATION AND FAMILIES' SERVICE NEEDS AND USE}

The previous chapters examined the extent to which the Early Head Start research programs implemented services that met the revised Head Start Program Performance Standards in key areas. This chapter examines Early Head Start program services from the perspective of families and their needs and goals (see descriptive data on families in Chapter I). We describe the data used to examine participation and service needs and use; provide an overview of family characteristics and needs; assess families' levels and intensity of participation in Early Head Start during the first 16 months after enrollment; detail their service needs and use in specific areas, including the match between service needs and use; describe family engagement; and relate families' goals approximately 16 months after they enrolled in Early Head Start. ${ }^{1}$ We also include brief reports from local research and program staff that provide local perspectives on family engagement and participation in services.

\section{A. DATA SOURCES}

We drew on several data sources for analyses of service needs and use. These include:

- Head Start Family Information System application and enrollment forms completed at the time of enrollment

- Parent services follow-up interviews targeted for 6 and 15 months after program enrollment (completed an average of 7 and 16 months after enrollment). We included in our analyses only families for whom data were available for both follow-up periods (75 percent of research sample members).

\footnotetext{
${ }^{1}$ The final report on early head start program impacts, Making a Difference in the Lives of Infants and Toddlers and Their Families: The Impacts of Early Head Start (Administration for Children and Families 2002), updates information in this chapter on levels and intensity of program participation through 28 months after enrollment.
} 
- Ratings of each family's engagement with the program provided by program staff in summer 2000, after most families had left the program and most children had reached 36 months of age

- Data on program characteristics and ratings of program implementation developed in the implementation study

The follow-up period varied over a wide range for each of the parent services interviews. The length of followup ranged from 4 to 15 months and averaged 7 months after enrollment for the first follow-up interview. It ranged from 9 to 27 months and averaged 16 months after enrollment for the second follow-up interview. However, approximately 90 percent of the first follow-up interviews were conducted between 5 and 9 months after enrollment, and 88 percent of the second follow-up interviews were conducted between 14 and 19 months after enrollment.

The questions on service use were broad, and to avoid substantial recall error, most did not require families to recall detailed aspects of the services they received. For example, for most services, families were asked whether or not they had received the service and how often they received it, in broad ranges of frequency (such as weekly or monthly or on some other interval).

Because the parent services follow-up interviews were conducted according to the length of time since families enrolled, the ages of the research sample children at the interview time varied. ${ }^{2}$ On average, the focus children were 10 months old when the first follow-up interview was completed and 20 months old when the second followup was completed. Children's ages ranged from 0 (unborn) to 25 months at the time of the first follow-up interview, and from 7 to 36 months at the second.

\footnotetext{
${ }^{2}$ Parent interviews and child assessments were also conducted to measure child and family outcomes when children were 14, 24, and 36 months of age; see the interim and final reports to Congress (Administration on Children, Youth and Families 2001; Administration for Children and Families 2002).
} 


\section{B. INVOLVING FAMILIES IN SERVICES: LEVELS AND INTENSITY OF PROGRAM PARTICIPATION}

Not only is it important for programs to implement and offer high-quality services, they must also enroll families and engage them in program services. Engaging them in services entails getting them to participate in program activities and gaining and sustaining their attention and commitment to the goals of those activities. The following subsections examine levels of participation by research families in program services during the first 16 months, on average, after they enrolled in the Early Head Start research programs. ${ }^{3}$

\section{Overall Participation Levels}

Levels of participation in Early Head Start services were high during the first 16 months after program enrollment. Overall, 93 percent of the research families received at least one Early Head Start home visit, participated in Early Head Start child development centers, met with an Early Head Start case manager at least once, and/or participated in Early Head Start group activities (group parenting education, group parent-child activities, or a parent support group) (Table IX.1). Nearly all these families received more than minimal services (more than one home visit, more than one case management meeting, center-based child care, and/or group parenting activities). Most families (86 percent) received core services through which child development services were provided—home visits or center-based child development services.

Overall participation rates were high in most of the research programs. They exceeded 90 percent in 13 of the 17 programs (not shown), and in 2 of the remaining programs overall participation rates were only slightly lower (88 percent).

\footnotetext{
${ }^{3}$ Additional follow-up interviews were conducted approximately 26 months after enrollment and at the time of program exit.
} 
TABLE IX.1

RECEIPT OF KEY EARLY HEAD START SERVICES DURING THE FIRST 16 MONTHS, FOR THE FULL SAMPLE AND KEY PROGRAM SUBGROUPS

\begin{tabular}{|c|c|c|c|c|}
\hline & \multicolumn{3}{|c|}{ Average Percentage of Families Who Received: } & \multirow[b]{2}{*}{ Sample Sizes } \\
\hline & $\begin{array}{c}\text { At Least One Key } \\
\text { Early Head Start } \\
\text { Service } \\
\end{array}$ & $\begin{array}{c}\text { More than } \\
\text { Minimal Early } \\
\text { Head Start } \\
\text { Services }\end{array}$ & $\begin{array}{c}\text { More than Minimal } \\
\text { Early Head Start Core } \\
\text { Services }^{c}\end{array}$ & \\
\hline Full Sample & 93 & 91 & 86 & $1,052-1,133$ \\
\hline \multicolumn{5}{|l|}{ Program Approach in 1997} \\
\hline Center-based & 87 & 83 & 75 & $224-232$ \\
\hline Home-based & 94 & 93 & 89 & $487-534$ \\
\hline Mixed-approach & 94 & 93 & 90 & $341-367$ \\
\hline \multicolumn{5}{|l|}{ Pattern of Implementation } \\
\hline Early implementers & 97 & 96 & 94 & $368-389$ \\
\hline Later implementers & 92 & 90 & 86 & $387-427$ \\
\hline Incomplete implementers & 88 & 86 & 78 & $298-317$ \\
\hline
\end{tabular}

SOURCE: Parent Services Follow-Up Interviews conducted an average of 7 and 16 months after enrollment.

NOTE: Percentages are average percentages across programs in the given group and are weighted for survey nonresponse.

${ }^{a}$ Key services include home visits, case management meetings, center-based child development/child care services and/or group activities such as parenting classes or group socializations.

${ }^{b}$ More than one Early Head Start home visit, more than one Early Head Start case management meeting, at least two weeks of center-based child development/child care, and/or Early Head Start group activities.

${ }^{\mathrm{c}}$ More than one Early Head Start home visit and/or at least two weeks of center-based child development/child care. 
Levels of participation were higher in home-based and mixed-approach programs. Because the two programs with the lowest participation rates (66 and 77 percent) were center-based, center-based programs overall had the lowest participation rates. In one of these programs, several factors contributed to these low rates, including some families' need for full-time child care before the program expanded to offer it, decisions to go to other programs that were more convenient, and overwhelming life stress that interfered with families' ability to take advantage of program services. ${ }^{4}$ In the other, a very rapid initial recruiting process and a delay in opening one center may have led some program families to make other child care arrangements.

Early, full program implementation appears to have promoted high participation rates. Programs that were fully implemented by fall 1997 (the early implementers) involved 94 percent of families in home visits and/or center-based services, compared with the 86 percent involved by the later implementers and 78 percent by the incomplete implementers (Table IX.1).

\section{Home Visits}

All Early Head Start programs are required to visit families at home, whether they are home-based, center-based, or mixed-approach. While in center-based programs, services are delivered primarily in the center, and staff are required to visit children and their families at home at least twice a year. They may meet with families in other places if staff safety would be endangered or families prefer not to meet at home. Home visitors are required to visit families receiving home-based services at home weekly, or at least 48 times per year. In mixed-approach programs, some families receive homebased services, some families receive center-based services, and some families may receive a combination of center-based services and home visits.

Nearly all families enrolled in the home-based Early Head Start programs received more than one home visit. In these programs, 92 percent of families reported receiving at least one Early Head Start home visit, and 89 percent reported receiving more than one, which indicates at

\footnotetext{
${ }^{4}$ Most center-based programs offered full-time care; however, this center initially offered part-time care (later the program expanded to provide full-time care).
} 
least minimal program participation (Table IX.2). ${ }^{5}$ Levels of receipt of more than one Early Head Start home visit in the seven home-based research programs ranged from 84 percent to 95 percent (not shown).

Receipt of Early Head Start home visits remained high throughout the first two follow-up periods but declined modestly in the second period as some families left the program. ${ }^{6}$ On average, 70 percent of families reported receiving more than one Early Head Start home visit by the time of the first followup. Reported home visit receipt declined to an average of 58 percent of families during the second follow-up period (not shown).

As noted earlier, the research programs found it very challenging to complete the required weekly home visits with many families. Among the home-based research programs, 57 percent of families, on average, reported receiving Early Head Start home visits at least weekly during the first follow-up period, and 52 percent reported Early Head Start home visits at least weekly during the second follow-up period (Table IX.2). An additional one-fifth of families reported receiving visits less than weekly but more than monthly, and 13 percent reported monthly or less frequent visits (not shown). In contrast to this information from parent reports, the Early Head Start programs reported that they increased home visit intensity to each family on average from

${ }^{5}$ Those who reported one Early Head Start home visit may have been visited once as part of the enrollment process to complete the application and enrollment forms, and they may never have received any substantive services.

${ }^{6}$ In summer 2000, program directors reported the last date on which they had contact with each family. Approximately one-fourth of the program group members in the research sample left the program within the first year after enrolling. See Section IX.D for a discussion of families' duration of participation. 
TABLE IX.2

RECEIPT OF EARLY HEAD START HOME VISITS BY PROGRAM FAMILIES DURING THE FIRST 16 MONTHS, FOR THE FULL SAMPLE AND KEY PROGRAM SUBGROUPS

\begin{tabular}{|c|c|c|c|c|c|c|c|c|}
\hline & \multicolumn{6}{|c|}{ Average Percentage of Families Who Received } & \multirow[b]{2}{*}{$\begin{array}{c}\text { Among } \\
\text { Families Who } \\
\text { Received } \\
\text { Home Visits, } \\
\text { Percentage for } \\
\text { Whom Typical } \\
\text { Home Visit } \\
\text { Lasted at Least } \\
\text { One Hour }\end{array}$} & \multirow[b]{2}{*}{$\begin{array}{l}\text { Sample } \\
\text { Sizes }\end{array}$} \\
\hline & $\begin{array}{c}\text { Any Early } \\
\text { Head Start } \\
\text { Home Visits }\end{array}$ & $\begin{array}{l}\text { More than } \\
\text { One Early } \\
\text { Head Start } \\
\text { Home Visit }\end{array}$ & $\begin{array}{l}\text { Early Head } \\
\text { Start Home } \\
\text { Visits at Least } \\
\text { Weekly (1st } \\
\text { Follow-Up } \\
\text { Period) }\end{array}$ & $\begin{array}{l}\text { Early Head } \\
\text { Start Home } \\
\text { Visits at Least } \\
\text { Weekly (2nd } \\
\text { Follow-Up } \\
\text { Period) }\end{array}$ & $\begin{array}{c}\text { Early Head } \\
\text { Start Home } \\
\text { Visits at } \\
\text { Least } \\
\text { Monthly } \\
\text { (1st Follow- } \\
\text { Up Period) }\end{array}$ & $\begin{array}{c}\text { Early Head } \\
\text { Start Home } \\
\text { Visits at } \\
\text { Least } \\
\text { Monthly } \\
\text { (2nd } \\
\text { Follow-Up } \\
\text { Period) }\end{array}$ & & \\
\hline Full Sample & 85 & 75 & 43 & 35 & 65 & 56 & 82 & $820-1,138$ \\
\hline \multicolumn{9}{|l|}{ Program Approach in 1997} \\
\hline Center-based & 64 & 34 & 4 & 1 & 16 & 12 & 62 & $108-232$ \\
\hline Home-based & 92 & 89 & 57 & 52 & 84 & 75 & 84 & $429-537$ \\
\hline Mixed-approach & 90 & 86 & 54 & 38 & 74 & 63 & 91 & $283-369$ \\
\hline \multicolumn{9}{|l|}{ Pattern of Implementation } \\
\hline Early implementers & 89 & 78 & 53 & 41 & 68 & 58 & 84 & $287-389$ \\
\hline Later implementers & 87 & 78 & 35 & 31 & 63 & 55 & 79 & $303-428$ \\
\hline Incomplete implementers & 77 & 67 & 42 & 31 & 62 & 54 & 84 & $219-319$ \\
\hline
\end{tabular}

SOURCE: Parent Services Follow-Up Interviews completed an average of 7 and 16 months after enrollment.

NOTE: The percentages are average percentages across programs in the group and are weighted for survey nonresponse. 
two home visits a month in 1997 to three a month in $1999 .^{7}$ These levels of completed home visits are generally consistent with the experiences of other home-visiting programs, which have found that on average, they are able to complete about half the intended number of home visits (Gomby 1999).

The reported levels and intensity of completed home visits were very similar in the mixedapproach programs, which provided home-based services to most families. In these programs, 86 percent of families received more than one Early Head Start home visit by the time of the second followup. In addition, 54 percent of families, on average, reported receiving Early Head Start home visits at least weekly during the first follow-up period, and 38 percent reported receiving Early Head Start home visits at least weekly during the second (Table IX.2).

Most parents in home-based and mixed-approach programs who received Early Head Start home visits reported that a typical visit lasted from one to two hours (Table IX.2). The reported length of the typical visit did not change between the first and second follow-up periods.

Among the home-based and mixed-approach programs, earlier full implementation was associated with providing home visits to a higher percentage of families and providing weekly home visits to more families during the first two follow-up periods (Table IX.2). On average, in the home-based and mixed-approach programs that reached early full implementation, 93 percent of families reported receiving more than one Early Head Start home visit by the time of the second followup, and 78 percent reported receiving Early Head Start home visits at least weekly (not shown). In contrast, among later and incomplete implementers, 85 percent of families

\footnotetext{
${ }^{7}$ The likely reason for this discrepancy is that programs reported on services for families that continued to be engaged in the program, whereas the evaluation surveys tapped families that had applied to Early Head Start, whether or not they continued to be enrolled or participate in program activities.
} 
reported receiving more than one Early Head Start home visit, and 46 percent of families reported receiving Early Head Start home visits at least weekly.

\section{Case Management}

The revised Head Start Program Performance Standards require programs to work with parents to obtain needed services and useful resources, and all the research programs provide case management to link families with services and resources in the community. In some home-based programs, the home visitors who work with parents and children on child development also provide case management during home visits. In other homebased programs, each family has two home visitors, one who works with them on child development, the other on family development. In center-based programs, families may work with a designated staff person on family development during meetings at the center or at their home.

Home visits and case management services overlapped substantially. Most program families

reported receiving both home visits and case management (71 percent in the first follow-up period and 56 percent in the second). More than 90 percent of these families reported that the person they met with for case management was the same person who visited them at home. Thus, not surprisingly, patterns of case management receipt mirror those of home visit receipt.

The average proportion of families who reported meeting with a case manager more than once was highest in home-based and mixed-approach programs ( 83 percent, on average, by the time of the second followup) and lowest in center-based programs (57 percent, on average, by the time of the second followup) (Table IX.3). Similarly, receipt of weekly case management was highest in the home-based programs and lowest in the center-based programs. Overall, nearly half the families, on average, reported receiving case management at least weekly during the first follow-up period, almost two-thirds at least monthly. Some programs, however, planned case management meetings less often than weekly. Some home-based programs provided child development services and case management in separate home visits, and case management meetings were planned on a less frequent schedule, often biweekly. Center-based programs also 
TABLE IX.3

RECEIPT OF EARLY HEAD START CASE MANAGEMENT BY PROGRAM FAMILIES DURING FIRST 16 MONTHS, FOR THE FULL SAMPLE AND KEY PROGRAM SUBGROUPS

\begin{tabular}{|c|c|c|c|c|c|c|c|}
\hline & \multicolumn{6}{|c|}{ Average Percentage of Families Who Received: } & \multirow[b]{2}{*}{ Sample Sizes } \\
\hline & $\begin{array}{l}\text { Any Early } \\
\text { Head Start } \\
\text { Case } \\
\text { Management } \\
\text { Meetings }\end{array}$ & $\begin{array}{l}\text { More than } \\
\text { One Early } \\
\text { Head Start } \\
\text { Case } \\
\text { Management } \\
\text { Meeting }\end{array}$ & $\begin{array}{c}\text { Early Head } \\
\text { Start Case } \\
\text { Management } \\
\text { Meetings at } \\
\text { Least Weekly } \\
\text { (1st Follow-Up } \\
\text { Period) }\end{array}$ & $\begin{array}{l}\text { Early Head Start } \\
\text { Case Management } \\
\text { Meetings at Least } \\
\text { Weekly (2nd } \\
\text { Follow-Up } \\
\text { Period) }\end{array}$ & $\begin{array}{c}\text { Early Head Start } \\
\text { Case } \\
\text { Management } \\
\text { Meetings at } \\
\text { Least Monthly } \\
\text { (1st Follow-Up } \\
\text { Period) }\end{array}$ & $\begin{array}{c}\text { Early Head Start } \\
\text { Case } \\
\text { Management } \\
\text { Meetings at } \\
\text { Least Monthly } \\
\text { (2nd Follow-Up } \\
\text { Period) }\end{array}$ & \\
\hline Full Sample & 81 & 77 & 44 & 34 & 65 & 52 & $1,067-1,137$ \\
\hline \multicolumn{8}{|l|}{ Program Approach in 1997} \\
\hline Center-based & 66 & 57 & 17 & 8 & 38 & 24 & $228-234$ \\
\hline Home-based & 85 & 83 & 56 & 45 & 77 & 61 & $496-535$ \\
\hline Mixed-approach & 87 & 83 & 49 & 38 & 70 & 60 & $343-368$ \\
\hline \multicolumn{8}{|l|}{ Pattern of Implementation } \\
\hline Early implementer & 86 & 82 & 55 & 42 & 66 & 60 & $357-390$ \\
\hline Later implementers & 74 & 70 & 33 & 26 & 62 & 41 & $407-428$ \\
\hline Incomplete implementers & 82 & 79 & 46 & 33 & 68 & 56 & $298-319$ \\
\hline
\end{tabular}

SOURCE: Parent Services Follow-Up Interviews completed an average of 7 and 16 months after enrollment.

NOTE: The percentages are average percentages across programs in the group and are weighted for survey nonresponse. 
planned case management meetings less frequently, and families in center-based programs, not surprisingly, reported less-frequent receipt of case management.

Levels of case management receipt also tended to be highest, on average, in programs that became fully implemented early. For example, in the early-implemented programs, 82 percent of families, on average, received case management during their first 16 months in the program, compared with 70 percent of families in later-implemented programs and 79 percent in programs that were incomplete implementers (Table IX.3). The higher proportion among incomplete implementers reflects the emphasis some of the programs in this group placed on family support.

\section{Parenting Information Services and Group Parenting Activities}

The Early Head Start program guidelines specified that programs must provide parent education and parent-child activities. Consistent with their stated priority expected outcomes, programs offered a variety of services that would potentially achieve these outcomes. ${ }^{8}$ Most programs offering home-based services to some or all families invited families to regular group activities at least once a month. (The revised Head Start Program Performance Standards recommend two group socializations [parent-child group activities] per month for programs offering home-based services.) In centerbased and mixed-approach programs, group parenting activities were more likely to be parent education meetings.

Although most group activities for parents focus exclusively on parenting, some focus more broadly. The interview excerpts in the following box show the increase over time in one parent's interest in attending group meetings at the KCMC Early Head Start program in Kansas City, Missouri.

While most families (93 percent) received parenting information from Early Head Start, often during home visits (85 percent) or in discussions with case managers (82 percent), fewer received such information in Early Head Start group activities-parenting classes (45 percent),

\footnotetext{
${ }^{8}$ As seen in Chapter III, most Early Head Start programs identified enhancing parent-child relationships as a priority outcome.
} 
group parent-child activities (25 percent), and/or parent support groups (10 percent). Overall, slightly more than half of families, 53 percent on average, reported that they had attended any type of Early Head Start group activity by the time of the second followup (Table IX.4).

Program approaches differed in how parenting education was delivered. Participation in parenting classes or events was highest in center-based programs (51 percent in center-based programs compared with 43 to 44 percent in other programs). As would be expected, participation in parent-child group activities was highest in home-based and mixed-approach programs (27 and 28 percent, respectively, compared with 17 percent in center-based programs). Parents in home-based and mixed-approach programs also reported the highest levels of receiving parenting information during home visits (93 and 90 percent, respectively), discussing parenting with a case manager ( 90 and 86 percent), and receiving any parenting information from the program (95 and 96 percent). Ten percent of families, on average, had participated in a parent support group, with little variation across program approaches.

Success in implementing the performance standards was related to parent participation in parenting and other group activities. The programs that were fully implemented early achieved higher participation in any Early Head Start group activities than the later and incomplete implementers (Table IX.4). By the time of the second followup, nearly two-thirds of families in the early implementers had attended an Early Head Start group activity, compared with 44 percent of families in the later implementers and 52 percent in the incomplete implementers (Table IX.4). Parents in programs that became fully implemented early reported the highest levels of participation in all types of parenting education measured, compared with parents in the later and incomplete implementers. These differences are greatest for participation in parenting classes or events (56 percent in early implementers, compared with 34 and 45 percent in later and incomplete implementers, respectively), although parents in the early-implemented programs 
TABLE IX.4

RECEIPT OF PARENTING INFORMATION AND PARTICIPATION IN EARLY HEAD START PARENT EDUCATION AND OTHER GROUP ACTIVITIES BY PROGRAM FAMILIES DURING THE FIRST 16 MONTHS, FOR THE FULL SAMPLE AND KEY PROGRAM SUBGROUPS

\begin{tabular}{|c|c|c|c|c|c|c|c|c|}
\hline & \multicolumn{7}{|c|}{ Average Percentage of Parents Who: } & \multirow[b]{2}{*}{$\begin{array}{c}\text { Sample } \\
\text { Sizes }\end{array}$} \\
\hline & $\begin{array}{c}\text { Received } \\
\text { Any } \\
\text { Parenting } \\
\text { Information } \\
\text { from Early } \\
\text { Head Start }\end{array}$ & $\begin{array}{c}\text { Participated } \\
\text { in Any Early } \\
\text { Head Start } \\
\text { Group } \\
\text { Activity }^{\mathrm{a}} \\
\end{array}$ & $\begin{array}{c}\text { Participated } \\
\text { in Any Early } \\
\text { Head Start } \\
\text { Parenting } \\
\text { Class or } \\
\text { Event }\end{array}$ & $\begin{array}{c}\text { Participated } \\
\text { in Any Early } \\
\text { Head Start } \\
\text { Parent-Child } \\
\text { Group } \\
\text { Activity } \\
\end{array}$ & $\begin{array}{l}\text { Participated in } \\
\text { Any Early } \\
\text { Head Start } \\
\text { Parent Support } \\
\text { Group } \\
\end{array}$ & $\begin{array}{c}\text { Discussed } \\
\text { Parenting } \\
\text { with a Case } \\
\text { Manager } \\
\end{array}$ & $\begin{array}{c}\text { Received } \\
\text { Parenting } \\
\text { Information } \\
\text { During Home } \\
\text { Visits } \\
\end{array}$ & \\
\hline Full Sample & 93 & 53 & 45 & 25 & 10 & 82 & 85 & $1,118-1,136$ \\
\hline \multicolumn{9}{|l|}{ Program Approach in 1997} \\
\hline Center-based & 86 & 59 & 51 & 17 & 14 & 63 & 63 & $232-234$ \\
\hline Home-based & 95 & 51 & 43 & 27 & 7 & 90 & 93 & $524-537$ \\
\hline Mixed-approach & 96 & 52 & 42 & 28 & 10 & 86 & 90 & $362-365$ \\
\hline \multicolumn{9}{|l|}{ Pattern of Implementation } \\
\hline Early implementers & 97 & 64 & 56 & 29 & 11 & 82 & 89 & $384-388$ \\
\hline Later implementers & 92 & 44 & 34 & 25 & 8 & 82 & 86 & $420-429$ \\
\hline Incomplete implementers & 90 & 52 & 45 & 21 & 10 & 82 & 79 & $314-319$ \\
\hline
\end{tabular}

SOURCE: Parent Services Follow-Up Interviews completed an average of 7 and 16 months after enrollment.

NOTE: The percentages are average percentages across programs in the group and are weighted for survey nonresponse. 


\section{Encouraging Parent Group Participation: A Case Study \\ Kathy Thornburg, Jean Ispa, and Mark Fine \\ University of Missouri at Columbia}

The following are excerpts from interviews that researchers at the University of Missouri at Columbia conducted with Lakeisha over a one-year period. In Interviews 2 and 3, Lakeisha is not interested in going to parent meetings, even if dinner and transportation are provided. By Interview 5, however, she is proudly attending the parent meetings and explains to the interviewers how the group chooses a secretary to help mothers get involved and feel connected.

\section{Interview 2}

Q. Were you invited to the parent group meeting a couple of weeks ago?

A. Yeah.

Q. Did you get to go?

A. I didn't want to go.

Q. What were they doing?

A. They just had a dinner. It was two things that Sunday, they had a dinner, I don't know if it was last month.

$Q$. Yeah, I came all the way from Columbia to that dinner. It was really very good. It was nice ... and all the babies came, it was so much fun. We held the babies.

A. I know.

Q. If they have a dinner the next time, you might want [to go]; they can even come pick you up.

A. I know, but I didn't want to go.

Q. Well, do you want to go next time? Go with us. We'll come get you, all the way from Columbia.

A. Well, you went to the last one.

Q. Well, if we come to town, we'll for sure come get you. But they can come, they can provide transportation, and Takiyah will go too. That was really fun. So, just think about going next time.

A. I probably had already ate and everything anyway.

\section{Interview 3}

Q. Okay, so you did get to go to one parent meeting?

A. Yeah, I went to one.

Q. What did they talk about?

A. Housing. They was talking about housing. All different kinds of stuff, you know.

Q. Do you think you'll go to any more?

A. There's one coming up. I think it's next week . . . what is her name? I forgot her name, but she just came over here the other day and she wanted me to come down, I mean to go to the other parent meeting. . . She wanted me to go to the other parent meeting. So I might go ahead and go.

\section{Interview 5}

Q. What about parents' night? Have you gone?

A. Uh, yeah. We have one Saturday.

Q. Are you going?

A. Uh huh.

Q. Oh good. What's the topic?

A. I've been going. I don't know what the topic is this Saturday. We don't know until we get there. But we have different kind of people. Last time, I mean, we had this one guy that's in our class, his mother, she's an entrepreneur, and she came to talk to us. You know, she's a caterer, and all that. You know, she came and talked to us at our last parent meeting. So, we've been having some good topics. You know, and they're nice.

Q. How many Early Head Start moms are there usually?

A. Oh, it's a lot of them. 'Cause see, it's like they trying to get all the moms involved [and] being something. Like, it's a secretary. You know, it's different, you know, it's different people of those different things. So, they trying to get everybody involved into something. You know, instead of us just sitting around listening to 'em, you know. 
reported slightly higher rates of participation in any Early Head Start parent-child group activity and receiving parenting information during home visits (see Table IX.4).

\section{Child Care and Center-Based Child Development Services}

Four of the research programs offered center-based child development services directly to all enrolled families. In addition, two programs provided center-based services directly to a substantial proportion of enrolled families, and four programs offered center-based child development services directly to a small number of families by fall 1999. Many programs also developed partnerships with community centers and family child care providers to provide goodquality child care to Early Head Start children.

\section{a. Child Care Use}

Levels of child care use were high across all three program types, and child care use increased over time as children got older. Two-thirds of children had received child care services by the time of the first followup (not shown). By the time of the second followup, when children were, on average, 20 months old, the percentage of program children who had received child care services increased to nearly 80 percent (Table IX.5).

The proportion of families who had ever used any center-based child care increased over time. One-third of all program children received care in child care centers during the first follow-up period (not shown). By the time of the second followup, the percentage of children who had been enrolled in center-based care increased to 43 percent (Table IX.5). The percentage of children who received Early Head Start center-based care increased from 22 to 25 percent (Table IX.5).

During the first two follow-up periods, many children received child care in more than one arrangement, and sometimes they received care in multiple arrangements concurrently. On 


\section{TABLE IX.5}

RECEIPT OF CHILD CARE DURING THE FIRST 16 MONTHS, FOR THE FULL SAMPLE AND KEY PROGRAM SUBGROUPS

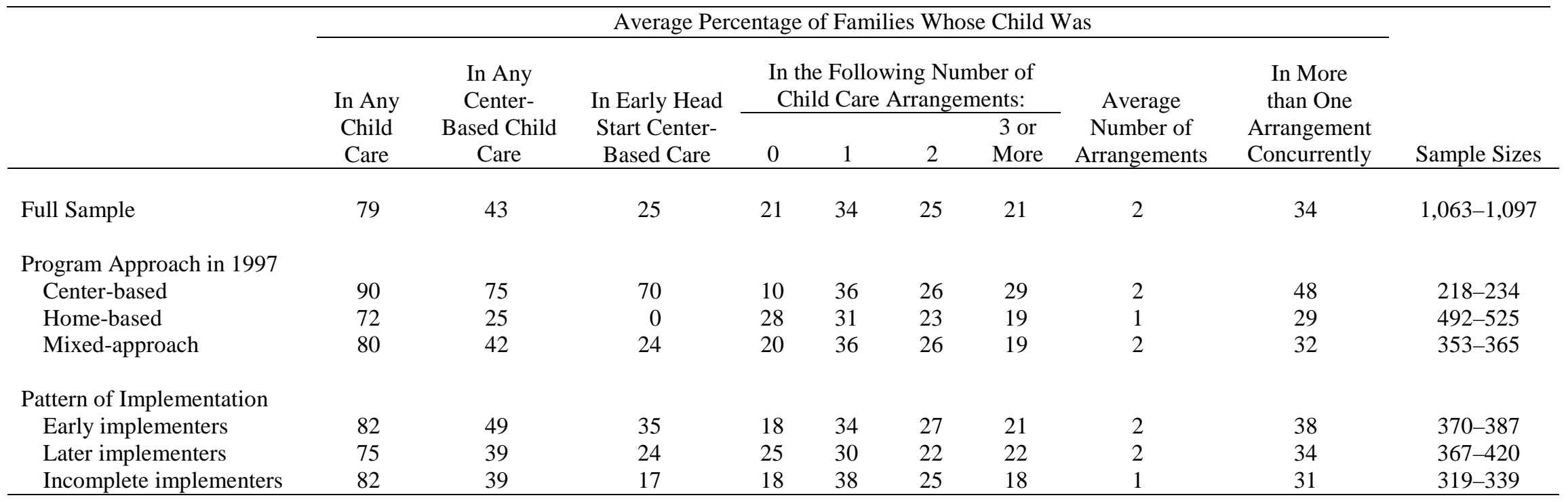

SOURCE: Parent Services Follow-Up Interviews conducted an average of 7 and 16 months after enrollment.

NOTE: $\quad$ Percentages are average percentages across programs in the given group and are weighted for survey nonresponse. 
average, children received child care in two different arrangements (Table IX.5). One-third of program children received care in multiple arrangements concurrently.

Program families used a wide range of providers for their primary child care arrangement (the arrangement used for the most hours during the follow-up period) during the first 15 months after enrollment. ${ }^{9}$ One-third of all program families used center-based care for their primary child care arrangement -20 percent of families used an Early Head Start center and 14 percent used other child care centers (Table IX.6). Another one-third of families relied on a relativemost often a grandparent or great-grandparent—as their primary child care provider. Twelve percent of families used a nonrelative child care provider as their primary child care arrangement. Finally, 21 percent of families did not use any child care arrangements during the first 15 months after enrollment.

A substantial proportion of children received some child care from their primary provider during nonstandard work hours. Almost half the children received care from their primary child care provider during early morning hours. Twenty-seven percent received care during evenings. Smaller proportions received care during weekends and overnight (Table IX.6).

Families enrolled in the center-based programs were most likely to have used child care during the first two follow-up periods (90 percent), followed by families enrolled in mixedapproach programs (80 percent) and home-based programs (72 percent) (Table IX.5). Seventy percent of the families in the center-based programs received Early Head Start center-based care.

\footnotetext{
${ }^{9}$ The follow-up surveys collected detailed information on child care use during the follow-up period, and it was possible to construct measures pertaining to the first 15 months of followup for each sample member, even though the full length of followup varied. These measures are more comparable across sample members than measures pertaining to the full follow-up period, which varies in length across sample members.
} 
TABLE IX.6

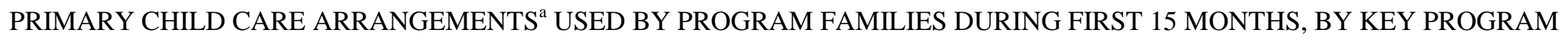
SUBGROUPS

\begin{tabular}{|c|c|c|c|c|c|c|c|}
\hline & $\begin{array}{c}\text { All } \\
\text { Programs } \\
\end{array}$ & $\begin{array}{c}\text { Center- } \\
\text { Based } \\
\text { Programs } \\
\end{array}$ & $\begin{array}{c}\text { Home-Based } \\
\text { Programs }\end{array}$ & $\begin{array}{c}\text { Mixed- } \\
\text { Approach } \\
\text { Programs } \\
\end{array}$ & $\begin{array}{c}\text { Early } \\
\text { Implementers } \\
\end{array}$ & $\begin{array}{c}\text { Later } \\
\text { Implementers } \\
\end{array}$ & $\begin{array}{c}\text { Incomplete } \\
\text { Implementers }\end{array}$ \\
\hline \multicolumn{8}{|l|}{$\begin{array}{l}\text { Percentage of children whose primary } \\
\text { arrangement was: }\end{array}$} \\
\hline No child care arrangement & 21 & 10 & 29 & 20 & 18 & 26 & 19 \\
\hline Head Start/Early Head Start & 20 & 54 & 1 & 19 & 26 & 17 & 14 \\
\hline Child care center & 14 & 6 & 17 & 14 & 13 & 12 & 16 \\
\hline Grandparent or great-grandparent & 18 & 15 & 19 & 20 & 18 & 20 & 16 \\
\hline Another relative & 6 & 4 & 7 & 7 & 4 & 9 & 6 \\
\hline Parent at school or work & 1 & 0 & 1 & 0 & 1 & 0 & 1 \\
\hline \multicolumn{8}{|l|}{$\begin{array}{l}\text { Percentage of children whose primary } \\
\text { arrangement included care during: }\end{array}$} \\
\hline Sample Sizes & 970-1,079 & $207-220$ & 431-499 & $332-360$ & 330-367 & 337-371 & $300-336$ \\
\hline
\end{tabular}

SOURCE: Parent Services Follow-Up Interviews conducted an average of 7 and 16 months after enrollment.

NOTE: $\quad$ Percentages are average percentages across programs in the group and are weighted for survey nonresponse.

${ }^{a}$ The primary child care arrangement is the arrangement in which the focus child received care for the most hours during the follow-up period. 
The remaining 20 percent of families who received child care received it from other sources and did not use the Early Head Start center (Table IX.5). Many of these families are likely to be those who had dropped out of Early Head Start by the time of the second follow-up interview (but were still participating in the research).

In center-based programs, nearly half of children received care in concurrent arrangements (Table IX.5). This suggests that Early Head Start centers did not provide child care during all the hours that families needed care, and many families supplemented Early Head Start center care with secondary arrangements.

Families in programs that were early implementers were more likely than families in other programs to use center-based care and to use Early Head Start center-based care (Table IX.5).

This pattern of child care use reflects in part the fact that two out of the four center-based programs - those with the highest participation rates—were early implementers.

\section{b. Intensity of Child Care Use}

Many program children received child care for substantial amounts of time during the first 15 months after enrollment. On average, children received child care for 16 hours a week. Onethird of program children were in child care for an average of 20 hours a week or more (Table IX.7). About half of these children-15 percent overall—attended center-based care for at least 20 hours a week, on average, during the first 15 months. Twelve percent attended Early Head Start centers for at least 20 hours a week, on average (Table IX.7).

Many program children were in child care arrangements during a large portion of the first 16 months after enrollment in Early Head Start. Approximately half the children received child care for at least 60 percent of the combined follow-up period (Table IX.8). 
TABLE IX.7

\section{AVERAGE HOURS PER WEEK IN CHILD CARE DURING FIRST 15 MONTHS, BY PROGRAM APPROACH IN 1997}

\begin{tabular}{|c|c|c|c|c|c|c|c|}
\hline & $\begin{array}{c}\text { All } \\
\text { Programs } \\
\end{array}$ & $\begin{array}{c}\text { Center- } \\
\text { Based } \\
\text { Programs }\end{array}$ & $\begin{array}{c}\text { Home- } \\
\text { Based } \\
\text { Programs }\end{array}$ & $\begin{array}{l}\text { Mixed- } \\
\text { Approach } \\
\text { Programs }\end{array}$ & $\begin{array}{c}\text { Early } \\
\text { Implementers }\end{array}$ & $\begin{array}{c}\text { Later } \\
\text { Implementers }\end{array}$ & $\begin{array}{l}\text { Incomplete } \\
\text { Implementers }\end{array}$ \\
\hline Average hours per week in any child care & 16 & 25 & 12 & 15 & 17 & 15 & 17 \\
\hline \multicolumn{8}{|l|}{ Percentage of children in any child care for: } \\
\hline 0 hours per week, on average & 22 & 10 & 29 & 21 & 19 & 27 & 19 \\
\hline 1-9 hours per week, on average & 28 & 21 & 31 & 30 & 29 & 29 & 28 \\
\hline 10-19 hours per week on average & 16 & 14 & 16 & 16 & 16 & 14 & 17 \\
\hline 20-29 hours per week on average & 16 & 19 & 13 & 16 & 15 & 15 & 18 \\
\hline $30+$ hours per week on average & 18 & 36 & 10 & 17 & 22 & 15 & 18 \\
\hline Average hours per week in any center-based care & 7 & 17 & 3 & 6 & 10 & 5 & 6 \\
\hline $\begin{array}{l}\text { Percentage of children in any center-based child } \\
\text { care }\end{array}$ & 63 & 27 & 81 & 66 & 55 & 67 & 68 \\
\hline \multicolumn{8}{|l|}{0 hours per week on average } \\
\hline 1-9 hours per week on average & 13 & 19 & 8 & 14 & 15 & 12 & 11 \\
\hline 10-19 hours per week on average & 8 & 12 & 5 & 9 & 7 & 9 & 8 \\
\hline $20-29$ hours per week on average & 7 & 18 & 4 & 5 & 8 & 7 & 7 \\
\hline $30+$ hours per week on average & 8 & 24 & 1 & 6 & 15 & 5 & 6 \\
\hline $\begin{array}{l}\text { Average hours per week in Early Head Start center- } \\
\text { based care }\end{array}$ & 5 & 16 & 0 & 4 & 8 & 3 & 3 \\
\hline \multicolumn{8}{|l|}{$\begin{array}{l}\text { Percentage of children in any Early Head Start } \\
\text { center-based care }\end{array}$} \\
\hline 0 hours per week on average & 77 & 32 & 100 & 79 & 67 & 79 & 85 \\
\hline $1-9$ hours per week on average & 7 & 17 & 0 & 8 & 8 & 7 & 6 \\
\hline 10-19 hours per week on average & 5 & 11 & 0 & 6 & 4 & 6 & 3 \\
\hline 20-29 hours per week on average & 5 & 16 & 0 & 3 & 6 & 5 & 2 \\
\hline $30+$ hours per week on average & 7 & 24 & 0 & 3 & 14 & 2 & 4 \\
\hline Sample Sizes & 974-1071 & 193-225 & $396-499$ & 273-347 & $335-365$ & $343-405$ & 298-324 \\
\hline
\end{tabular}

SOURCE: Parent Services Follow-Up Interviews conducted an average of 7 and 16 months after enrollment.

NOTE: Percentages are average percentages across programs in the group and are weighted for survey nonresponse. 
TABLE IX.8

PROPORTION OF THE FOLLOW-UP PERIOD THAT CHILDREN ATTENDED CHILD CARE DURING FIRST 16 MONTHS, BY PROGRAM APPROACH IN 1997

\begin{tabular}{|c|c|c|c|c|c|c|c|}
\hline & All Programs & $\begin{array}{c}\text { Center- } \\
\text { Based } \\
\text { Programs }\end{array}$ & $\begin{array}{c}\text { Home-Based } \\
\text { Programs }\end{array}$ & $\begin{array}{c}\text { Mixed-Approach } \\
\text { Programs }\end{array}$ & $\begin{array}{c}\text { Early } \\
\text { Implementers } \\
\end{array}$ & $\begin{array}{c}\text { Later } \\
\text { Implementers } \\
\end{array}$ & $\begin{array}{c}\text { Incomplete } \\
\text { Implementers }\end{array}$ \\
\hline \multicolumn{8}{|c|}{ Percentage of Period in Any Child Care } \\
\hline 0 percent & 21 & 10 & 29 & 2 & 18 & 26 & 19 \\
\hline 1-19 percent & 3 & 2 & 3 & 5 & 4 & 4 & 2 \\
\hline 20-39 percent & 11 & 6 & 12 & 12 & 9 & 10 & 12 \\
\hline 40-59 percent & 13 & 9 & 14 & 14 & 13 & 14 & 11 \\
\hline $60-79$ percent & 12 & 11 & 10 & 17 & 13 & 10 & 15 \\
\hline $80-99$ percent & 19 & 30 & 13 & 18 & 22 & 17 & 18 \\
\hline 100 percent & 21 & 32 & 19 & 16 & 21 & 19 & 25 \\
\hline \multicolumn{8}{|c|}{$\begin{array}{l}\text { Percentage of Period in Any Center- } \\
\text { Based Care }\end{array}$} \\
\hline 0 percent & 59 & 26 & 77 & 60 & 52 & 62 & 63 \\
\hline 1-19 percent & 3 & 3 & 3 & 5 & 4 & 4 & 2 \\
\hline 20-39 percent & 6 & 5 & 6 & 8 & 7 & 5 & 8 \\
\hline $40-59$ percent & 7 & 10 & 5 & 8 & 7 & 9 & 6 \\
\hline $60-79$ percent & 6 & 9 & 3 & 7 & 6 & 6 & 6 \\
\hline 80-99 percent & 11 & 25 & 5 & 7 & 13 & 9 & 9 \\
\hline 100 percent & 8 & 23 & 3 & 5 & 12 & 6 & 6 \\
\hline \multicolumn{8}{|c|}{$\begin{array}{l}\text { Percentage of Period in Early Head Start } \\
\text { Center-Based Care }\end{array}$} \\
\hline 0 percent & 75 & 30 & 100 & 76 & 66 & 77 & 83 \\
\hline 1-19 percent & 2 & 3 & 0 & 2 & 2 & 1 & 0 \\
\hline 20-39 percent & 3 & 3 & 0 & 4 & 2 & 3 & 3 \\
\hline 40-59 percent & 4 & 11 & 0 & 5 & 5 & 5 & 2 \\
\hline $60-79$ percent & 3 & 6 & 0 & 4 & 3 & 3 & 2 \\
\hline $80-99$ percent & 7 & 24 & 0 & 5 & 11 & 6 & 4 \\
\hline 100 percent & 7 & 23 & 0 & 3 & 12 & 4 & 3 \\
\hline Sample Sizes & $1,049-1,071$ & 214-221 & $485-494$ & $350-356$ & $363-366$ & 364-377 & 323-330 \\
\hline
\end{tabular}

SOURCE: Parent Services Follow-Up Interviews conducted an average of 7 and 16 months after enrollment.

NOTE: Percentages are average percentages across programs in the group and are weighted for survey nonresponse. 
As would be expected, children in center-based programs received more intensive child care services, on average, than children in home-based or mixed-approach programs. Over half of children in center-based programs received at least 20 hours of child care a week, on average, compared with one-third of children in mixed-approach programs and slightly less than onequarter of children in home-based programs (Table IX.7). Nearly three-quarters of children in center-based programs received child care for at least 60 percent of the follow-up period, compared with half the children in mixed-approach programs and 42 percent in home-based programs (Table IX.8).

Children in programs that were early implementers received more hours of center-based child care and Early Head Start center-based care, on average, than children in other programs (Table IX.7). They were also more likely to receive care for the entire 15 months after enrollment (Table IX.8).

\section{c. Child Care Costs}

Three-fourths of families reported no out-of-pocket child care costs. Some families received free child care from relatives or an Early Head Start center, and some families received child care subsidies to cover the cost. One-quarter of all program families reported receiving a child care subsidy for any arrangement during the first 15 months after enrollment (Table IX.9). Eleven percent reported receiving a subsidy to pay for care in a center-based arrangement, and 6 percent reported receiving a subsidy for pay for care in an Early Head Start center. ${ }^{10}$

${ }^{10}$ Approximately one-fifth of families in center-based programs who received Early Head Start center care reported receiving a subsidy to help defray the costs of that care. Several Early Head Start programs offering center-based care required that families eligible for state child care subsidies apply for them. The families reporting subsidies for Early Head Start care were probably families who were eligible and worked with the program to obtain child care subsidies. 
TABLE IX.9

OUT-OF-POCKET CHILD CARE COSTS DURING FIRST 15 MONTHS,

BY KEY PROGRAM SUBGROUPS

\begin{tabular}{|c|c|c|c|c|c|c|c|}
\hline & $\begin{array}{c}\text { All } \\
\text { Programs } \\
\end{array}$ & $\begin{array}{c}\text { Center-Based } \\
\text { Programs } \\
\end{array}$ & $\begin{array}{c}\text { Home-Based } \\
\text { Programs }\end{array}$ & $\begin{array}{l}\text { Mixed- } \\
\text { Approach } \\
\text { Programs }\end{array}$ & $\begin{array}{c}\text { Early } \\
\text { Implementers }\end{array}$ & $\begin{array}{c}\text { Later } \\
\text { Implementers }\end{array}$ & $\begin{array}{l}\text { Incomplete } \\
\text { Implementers }\end{array}$ \\
\hline \multicolumn{8}{|l|}{ Average Weekly Out-Of-Pocket Child } \\
\hline \multicolumn{8}{|l|}{ Care Costs For: } \\
\hline Any child care arrangement & $\$ 5.41$ & $\$ 4.87$ & $\$ 5.41$ & $\$ 5.77$ & $\$ 5.78$ & $\$ 5.14$ & $\$ 5.34$ \\
\hline Head Start/Early Head Start program & $\$ 0.54$ & $\$ 1.81$ & $\$ 0.00$ & $\$ 0.33$ & $\$ 0.60$ & $\$ 0.40$ & $\$ 0.00$ \\
\hline Other child care center & $\$ 3.31$ & $\$ 5.50$ & $\$ 2.23$ & $\$ 3.12$ & $\$ 4.02$ & $\$ 1.70$ & $\$ 2.79$ \\
\hline Nonrelative provider & $\$ 7.55$ & $\$ 9.37$ & $\$ 7.96$ & $\$ 5.86$ & $\$ 15.98$ & $\$ 4.01$ & $\$ 7.42$ \\
\hline Parent or stepparent & $\$ 0.06$ & $\$ 0.00$ & $\$ 0.15$ & $\$ 0.00$ & $\$ 0.00$ & $\$ 0.00$ & $\$ 0.18$ \\
\hline Grandparent or great-grandparent & $\$ 5.43$ & $\$ 13.28$ & $\$ 3.07$ & $\$ 2.97$ & $\$ 6.01$ & $\$ 3.57$ & $\$ 3.84$ \\
\hline Other relative & $\$ 3.22$ & $\$ 5.93$ & $\$ 3.19$ & $\$ 1.46$ & $\$ 3.29$ & $\$ 5.54$ & $\$ 2.82$ \\
\hline \multicolumn{8}{|l|}{$\begin{array}{l}\text { Percentage of Families Who Received a } \\
\text { Subsidy To Pay For The Focus Child's } \\
\text { Care in: }\end{array}$} \\
\hline Any arrangement & 26 & 20 & 32 & 22 & 28 & 21 & 29 \\
\hline A center-based arrangement & 11 & 11 & 12 & 10 & 17 & 7 & 8 \\
\hline $\begin{array}{l}\text { An Early Head Start center-based } \\
\text { arrangement }\end{array}$ & 6 & 19 & 0 & 3 & 7 & 3 & 1 \\
\hline Sample Sizes & 727-1,122 & 155-234 & $285-523$ & 244-365 & 233-384 & $265-420$ & 228-318 \\
\hline
\end{tabular}

SOURCE: Parent Services Follow-Up Interviews conducted an average of 7 and 16 months after enrollment.

NOTE: Percentages are average percentages across programs in the group and are weighted for survey nonresponse. 
On average, program families reported paying $\$ 5.41$ per week out of pocket for child care during the first 15 months after enrollment (Table IX.9). The variation in child care costs was only slight across different types of programs.

\section{Services for Children with Disabilities}

According to the revised Head Start Program Performance Standards, at least 10 percent of programs' caseloads must consist of children with identified disabilities.

By the time of the second followup, 5 percent of program families reported that their child had an identified disability (Table IX.10). The proportion of children with identified disabilities ranged from 0 to 13 percent across programs (not shown). The parents' reports of identified disabilities may underreport them, however. ${ }^{11}$ It is also important to keep in mind that the follow-up interviews were conducted over a fairly long period (because enrollment in the research sample occurred over an approximately two-year period), during which the programs also served nonresearch families; thus these percentages do not necessarily reflect the percentage of children with identified disabilities served by the program at any given point in time.

Reported rates of identification of disabilities varied by program approach and degree of implementation. On average, center-based programs had the highest proportion of children with identified disabilities (6 percent), possibly as a result of increased opportunities for observing children in center-based settings. Parents in fully implemented programs were only slightly

\footnotetext{
${ }^{11}$ Parent-reported rates of identification of children with disabilities are substantially lower than programs' reports of children's disability status. According to program staff, by summer 2000 (when most children had reached age 3) 13 percent of children, on average, had been identified as eligible for early intervention services (ranging from 4 to 30 percent across programs). Children were considerably older in summer 2000 than at the time of the second followup, when they were, on average, only 20 months old, so it is likely that more children were identified as they got older, and that the parent-reported proportion of identified children may increase in later rounds of data collection. It is also possible that parents did not accurately report their children's disability status, in part because a variety of names are used across states to refer to services for children with disabilities.
} 
TABLE IX.10

RECEIPT OF SERVICES FOR CHILDREN WITH DISABILITIES DURING THE FIRST 16 MONTHS, FOR THE FULL SAMPLE AND KEY PROGRAM SUBGROUPS

\begin{tabular}{|c|c|c|c|c|}
\hline & \multicolumn{3}{|c|}{ Average Percentage of Families Whose: } & \multirow[b]{2}{*}{$\begin{array}{c}\text { Sample } \\
\text { Sizes }\end{array}$} \\
\hline & $\begin{array}{c}\text { Child Was } \\
\text { Eligible for Early } \\
\text { Intervention } \\
\text { Services } \\
\end{array}$ & $\begin{array}{c}\text { Child Received } \\
\text { Early Intervention } \\
\text { Services } \\
\end{array}$ & $\begin{array}{c}\text { Child's Early } \\
\text { Intervention Services } \\
\text { Were Coordinated with } \\
\text { Early Head Start }\end{array}$ & \\
\hline Full Sample & 5 & 3 & 2 & $1,091-1,109$ \\
\hline \multicolumn{5}{|l|}{ Program Approach in 1997} \\
\hline Center-based & 6 & 4 & 4 & $219-223$ \\
\hline Home-based & 5 & 4 & 3 & $514-520$ \\
\hline Mixed-approach & 3 & 2 & 1 & $358-366$ \\
\hline \multicolumn{5}{|l|}{ Pattern of Implementation } \\
\hline Early implementers & 5 & 4 & 3 & $372-380$ \\
\hline Later implementers & 5 & 3 & 3 & 387-389 \\
\hline Incomplete implementers & 4 & 2 & 2 & $332-340$ \\
\hline
\end{tabular}

SOURCE: Parent Services Follow-Up Interviews conducted an average of 7 and 16 months after enrollment.

NOTE: Percentages are average percentages across programs in the given group and are weighted for survey nonresponse.

${ }^{a}$ Key services include home visits, case management meetings, center-based child development/child care services, and/or group activities such as parenting classes or group socializations.

${ }^{b}$ More than one Early Head Start home visit, more than one Early Head Start case management meeting, at least two weeks of center-based child development/child care, and/or Early Head Start group activities.

${ }^{\mathrm{c}}$ More than one Early Head Start home visit and/or at least two weeks of center-based child development/child care. 
more likely ( 5 percent) to report that their children had identified disabilities and received early intervention services, but although the percentages are small, children in the early implementers were twice as likely to have received intervention services (4 versus 2 percent) (Table IX.10).

Not all families who reported that their child had an identified disability had received early intervention services by the time of the second followup, perhaps partly because of the time required to set up services after identification. On average, 3 percent of families reported that their child had received early intervention services. The percentage who reported receiving early intervention services ranged from 0 to 8 percent across programs. Two percent of families reported that their child's early intervention services were being coordinated with the Early Head Start program (Table IX.10), also ranging from 0 to 8 percent of families across programs.

\section{Child Health Services}

The revised Head Start Program Performance Standards require programs to ensure that all children have a regular health care provider and access to needed health, dental, and mental health services. Within 90 days of enrollment, programs must assess whether each child has an ongoing source of continuous, accessible health care; obtain a professional determination as to whether each child is up-to-date on preventive and primary health care; and develop and implement a follow-up plan for any health conditions identified.

All children had received some health services by the second followup (Table IX.11). Nearly all children received some immunizations by the time of the second followup (97 percent of all program children). More than 90 percent of children had visited a doctor. Program families reported that 88 percent of children had visited a doctor for at least one checkup, and 71 percent had visited a doctor for treatment of an acute or chronic health problem (Table IX.11). Differences by program approach or pattern of implementation were not great for most of the health services, although children in the early-implemented programs had substantially higher rates of visiting a doctor for illness or injury (85 percent, compared with two-thirds or less for families in later-implemented and incompletely implemented programs). By the time of the 
TABLE IX.11

\section{RECEIPT OF CHILD HEALTH SERVICES BY PROGRAM FAMILIES DURING FIRST 16 MONTHS, FOR THE FULL SAMPLE AND KEY PROGRAM SUBGROUPS}

\begin{tabular}{|c|c|c|c|c|c|c|c|c|c|}
\hline & \multicolumn{8}{|c|}{ Average Percentage of Focus Children Who: } & \multirow[b]{2}{*}{$\begin{array}{c}\text { Sample } \\
\text { Sizes }\end{array}$} \\
\hline & $\begin{array}{l}\text { Received } \\
\text { Any } \\
\text { Health } \\
\text { Services }\end{array}$ & $\begin{array}{l}\text { Visited a } \\
\text { Doctor }\end{array}$ & $\begin{array}{l}\text { Visited a } \\
\text { Doctor for } \\
\text { a Checkup }\end{array}$ & $\begin{array}{l}\text { Visited a } \\
\text { Doctor for } \\
\text { Illness or } \\
\text { Injury } \\
\end{array}$ & $\begin{array}{c}\text { Visited an } \\
\text { Emergency } \\
\text { Room }\end{array}$ & $\begin{array}{l}\text { Visited a } \\
\text { Dentist }\end{array}$ & $\begin{array}{c}\text { Received } \\
\text { Immunizations }\end{array}$ & $\begin{array}{c}\text { Were } \\
\text { Tested or } \\
\text { Screened }\end{array}$ & \\
\hline Full Sample & 100 & 92 & 88 & 71 & 42 & 11 & 97 & 55 & $\begin{array}{l}982- \\
1,110\end{array}$ \\
\hline \multicolumn{10}{|l|}{ Program Approach in 1997} \\
\hline Center-based & 100 & 95 & 89 & 71 & 49 & 17 & 98 & 60 & $201-223$ \\
\hline Home-based & 100 & 93 & 89 & 68 & 42 & 11 & 96 & 53 & $463-521$ \\
\hline Mixed-approach & 100 & 89 & 85 & 74 & 38 & 8 & 98 & 55 & $318-366$ \\
\hline \multicolumn{10}{|l|}{ Pattern of Implementation } \\
\hline Early implementers & 100 & 97 & 92 & 85 & 47 & 12 & 99 & 53 & $372-381$ \\
\hline Later implementers & 99 & 86 & 81 & 66 & 34 & 10 & 96 & 51 & $385-390$ \\
\hline Incomplete implementers & 100 & 95 & 91 & 61 & 45 & 10 & 97 & 63 & $332-340$ \\
\hline
\end{tabular}

SOURCE: Parent Services Follow-Up Interviews completed an average of 7 and 16 months after enrollment.

NOTE: $\quad$ The percentages are average percentages across programs in the group and are weighted for survey nonresponse. 
second followup, when children were 20 months old, on average, few children (11 percent) had visited a dentist (Table IX.11). The low percentage of children receiving dental care reflects in large part the fact that dental care and insurance providers often do not recommend dentist visits before age 3. Slightly more children in early-implemented programs (12 percent) had visited a dentist, compared to children in later-implemented and incompletely implemented programs (10 percent each). Although children in center-based programs were twice as likely to have visited a dentist as children in mixed-approach programs (17 versus 8 percent) differences by implementation pattern were small.

More than half of program children received at least one diagnostic or screening test, such as a hearing test, lead test, or urinalysis (Table IX.11). Across programs, the proportion of children who were tested or screened by the second followup varied widely, ranging from 37 to 78 percent (not shown). In center-based programs, 60 percent of children received testing or screening, compared with 53 percent in home-based programs and 55 percent in mixed-approach programs (Table IX.11). Interestingly, children in incompletely implemented programs were more likely (63 percent) than early- (53 percent) or later-implemented programs (51 percent) to complete testing or screening. One of those programs was housed in a health facility.

Many program children (42 percent) had visited an emergency room by the time of the second followup (Table IX.11). Across programs, the proportion of children who had visited an emergency room ranged from 22 to 66 percent (not shown). Nearly half of children in centerbased programs visited an emergency room, compared with 42 percent in home-based programs and 38 percent in mixed-approach programs (Table IX.11). More children in early-implemented programs visited an emergency room (47 percent), compared to later-implemented (34 percent) and incompletely implemented programs (45 percent). 


\section{Family Health Services}

The Head Start Program Performance Standards require programs to develop family partnerships and work collaboratively with families to identify and continually access, either directly or by referral, community services and resources that respond to the families' needs and goals. These include services to meet families' physical and mental health care needs and goals.

Nearly all families (98 percent) received some health services by the time of the second followup (Table IX.12). The proportion of families who received any health services ranged from 85 to 100 percent across programs (not shown), but did not differ very much for families in different types of programs or in programs with different implementation patterns.

At least one family member in 68 percent of families had visited a dentist by the time of the second followup. Similarly, at least one family member in nearly two-thirds of program families visited an emergency room by the second followup (Table IX.12). Families in center- and homebased programs were somewhat more likely than families in mixed-approach programs to have had a family member visit a dentist. More families visited a dentist in early-implemented programs than in later-implemented or incompletely implemented programs.

Fewer families reported receiving mental health services. By the time of the second followup, 16 percent of families reported that at least one family member had received treatment for an emotional or mental health problem, and 3 percent reported that at least one family member had received drug or alcohol treatment (Table IX.12). Early-implemented programs led in families' receipt of mental health services over later-implemented and incompletely implemented programs.

\section{Other Family Development Services}

As noted in the last section, the Head Start Program Performance Standards require programs to form partnerships with families and provide or link them with community services and resources that will help them meet their goals. The performance standards specifically direct programs to help parents identify and access, either directly or by referral, education- and employment-related programs and resources. 
TABLE IX.12

RECEIPT OF FAMILY HEALTH SERVICES BY PROGRAM FAMILIES DURING FIRST 16 MONTHS, FOR THE FULL SAMPLE AND KEY PROGRAM SUBGROUPS

\begin{tabular}{|c|c|c|c|c|c|c|c|c|}
\hline & \multicolumn{7}{|c|}{ Average Percentage of Families With at Least One Member Who: } & \multirow[b]{2}{*}{ Sample Sizes } \\
\hline & $\begin{array}{c}\text { Received } \\
\text { Any Health } \\
\text { Services }\end{array}$ & $\begin{array}{c}\text { Visited a } \\
\text { Doctor }\end{array}$ & $\begin{array}{c}\text { Visited a } \\
\text { Dentist }\end{array}$ & $\begin{array}{c}\text { Visited an } \\
\text { Emergency } \\
\text { Room }\end{array}$ & $\begin{array}{c}\text { Received } \\
\text { Treatment for an } \\
\text { Emotional or } \\
\text { Mental Problem }\end{array}$ & $\begin{array}{c}\text { Received Drug } \\
\text { or Alcohol } \\
\text { Treatment } \\
\end{array}$ & $\begin{array}{c}\text { Received Any } \\
\text { Mental Health } \\
\text { Services } \\
\end{array}$ & \\
\hline Full Sample & 98 & 96 & 68 & 62 & 16 & 3 & 17 & $1,014-1,111$ \\
\hline \multicolumn{9}{|l|}{ Program Approach in 1997} \\
\hline Center-based & 99 & 98 & 71 & 67 & 15 & 1 & 16 & $203-224$ \\
\hline Home-based & 97 & 96 & 73 & 61 & 17 & 5 & 20 & $480-521$ \\
\hline Mixed-approach & 98 & 96 & 60 & 60 & 14 & 4 & 16 & $331-366$ \\
\hline \multicolumn{9}{|l|}{ Pattern of Implementation } \\
\hline Early implementers & 99 & 98 & 73 & 68 & 22 & 4 & 24 & $374-384$ \\
\hline Later implementers & 96 & 93 & 62 & 56 & 11 & 3 & 13 & $329-390$ \\
\hline Incomplete implementers & 99 & 98 & 70 & 61 & 14 & 3 & 15 & $328-340$ \\
\hline
\end{tabular}

SOURCE: Parent Services Follow-Up Interviews completed an average of 7 and 16 months after enrollment.

NOTE: The percentages are average percentages across programs in the group and are weighted for survey nonresponse. 
Most primary caregivers (83 percent) reported receiving education-related services by the time of the second followup (Table IX.13). Two-thirds of primary caregivers reported talking to a case manager about education services, and slightly more than half reported attending school or a job training program (Table IX.13). The proportion of families who reported talking to a case manager about education was substantially higher in home-based and mixed-approach programs (73 percent) than in center-based programs (47 percent) (Table IX.13).

Two-thirds of program families reported receiving some employment-related services by the time of the second followup (Table IX.13). Twenty-two percent of families reported receiving job search assistance by the second followup, and 61 percent of families reported talking to a case manager about finding a job or job training (Table IX.13). Two-thirds of families in homebased and mixed-approach programs reported talking to a case manager about employment, compared with 44 percent in center-based programs (Table IX.13).

Families enrolled in programs that were incomplete implementers were most likely to receive education- and employment-related services by the time of the second followup. Eighty-eight percent received education services (talked to a case manager about education and/or attended an education or training program), and 73 percent received employment-related services (talked to a case manager about finding a job or received job search assistance). Families enrolled in the programs that were early implementers received slightly lower levels of education- and employment-related services (Table IX.13). The high levels of service receipt in these areas in the incomplete implementers reflects the strong emphasis that some programs in this group placed on family support.

Many families received other family support services. Nearly 30 percent of program families received transportation assistance (Table IX.13). More families in mixed-approach and home-based programs than in center-based programs received transportation assistance. Half of 
TABLE IX.13

RECEIPT OF EDUCATION, EMPLOYMENT, AND TRANSPORTATION SERVICES BY PROGRAM FAMILIES DURING THE FIRST 16 MONTHS, FOR THE FULL SAMPLE AND KEY PROGRAM SUBGROUPS

\begin{tabular}{|c|c|c|c|c|c|c|c|c|}
\hline & \multicolumn{7}{|c|}{ Average Percentage of Families Who: } & \multirow[b]{2}{*}{ Sample Sizes } \\
\hline & $\begin{array}{l}\text { Received } \\
\text { Any } \\
\text { Education } \\
\text { Services } \\
\end{array}$ & $\begin{array}{c}\text { Attended } \\
\text { School or } \\
\text { Job Training }\end{array}$ & $\begin{array}{c}\text { Discussed } \\
\text { Education } \\
\text { with a Case } \\
\text { Manager }\end{array}$ & $\begin{array}{c}\text { Received Any } \\
\text { Employment- } \\
\text { Related } \\
\text { Services } \\
\end{array}$ & $\begin{array}{c}\text { Received Job } \\
\text { Search } \\
\text { Assistance }\end{array}$ & $\begin{array}{c}\text { Discussed } \\
\text { Finding a Job } \\
\text { with a Case } \\
\text { Manager }\end{array}$ & $\begin{array}{c}\text { Received Any } \\
\text { Transportation } \\
\text { Assistance }\end{array}$ & \\
\hline Full Sample & 83 & 52 & 67 & 68 & 22 & 61 & 29 & $818-1,111$ \\
\hline \multicolumn{9}{|l|}{ Program Approach in 1997} \\
\hline Center-based & 77 & 56 & 47 & 55 & 21 & 44 & 22 & $160-224$ \\
\hline Home-based & 83 & 48 & 73 & 71 & 25 & 66 & 30 & $393-521$ \\
\hline Mixed-approach & 85 & 54 & 73 & 72 & 19 & 67 & 32 & $265-366$ \\
\hline \multicolumn{9}{|l|}{ Pattern of Implementation } \\
\hline Early implementers & 84 & 51 & 67 & 68 & 21 & 63 & 28 & $379-381$ \\
\hline Later implementers & 77 & 46 & 63 & 62 & 19 & 57 & 31 & $387-390$ \\
\hline Incomplete implementers & 88 & 59 & 71 & 73 & 27 & 64 & 27 & $338-340$ \\
\hline
\end{tabular}

SOURCE: Parent Services Follow-Up Interviews completed an average of 7 and 16 months after enrollment.

NoTE: The percentages are average percentages across programs in the group and are weighted for survey nonresponse. 
program families received housing assistance (public housing, rent subsidy, help finding housing, and/or energy assistance) by the time of the second followup (Table IX.14). Families in home-based programs were more likely to receive any housing assistance, help finding housing, emergency housing, and energy assistance, but families in center-based programs were more likely to receive assistance with public housing or with rent subsidies. Receipt of housing assistance, especially receipt of public housing or rent subsidies, was higher among families in incompletely implemented programs, which might reflect the greater emphasis on family support in these programs or greater needs for housing assistance in the areas served by the incompletely implemented programs.

\section{ENGAGEMENT IN SERVICES}

To achieve their goals and influence child and family outcomes, Early Head Start programs must engage families in program services and activities (that is, they must gain the parent's and child's attention and involve them actively in program activities) and continue engaging them over time. The extent to which children and families benefit from Early Head Start participation is likely to depend in part on the quality and duration of their involvement in program services and activities during their enrollment.

In addition to asking parents about their participation in Early Head Start and other services and activities, we asked program staff in summer 2000 to rate each family's engagement in the program during the time they were enrolled. Staff members were asked to use the following ratings for each family:

- Consistent High Engagement: The family was consistently highly engaged in the program throughout its enrollment - the family kept most appointments, was actively engaged in home visits and group activities, and (when applicable) the child attended the center regularly. 
TABLE IX.14

RECEIPT OF HOUSING ASSISTANCE BY PROGRAM FAMILIES DURING THE FIRST 16 MONTHS, FOR THE FULL SAMPLE AND KEY PROGRAM SUBGROUPS

\begin{tabular}{|c|c|c|c|c|c|c|}
\hline & \multicolumn{5}{|c|}{ Average Percentage of Families Who Received: } & \multirow[b]{2}{*}{ Sample Sizes } \\
\hline & $\begin{array}{c}\text { Any Housing } \\
\text { Assistance }\end{array}$ & $\begin{array}{c}\text { Public Housing or } \\
\text { Rent Subsidy }\end{array}$ & $\begin{array}{l}\text { Help Finding } \\
\text { Housing }\end{array}$ & Energy Assistance & Emergency Housing & \\
\hline Full Sample & 50 & 31 & 17 & 17 & 3 & $1,013-1,109$ \\
\hline \multicolumn{7}{|l|}{ Program Approach in 1997} \\
\hline Center-based & 49 & 37 & 14 & 13 & 1 & $205-224$ \\
\hline Home-based & 56 & 31 & 20 & 22 & 4 & $477-520$ \\
\hline Mixed-approach & 45 & 28 & 17 & 13 & 3 & $331-365$ \\
\hline \multicolumn{7}{|l|}{ Pattern of Implementation } \\
\hline Early implementers & 52 & 27 & 17 & 22 & 5 & $374-380$ \\
\hline Later implementers & 40 & 26 & 15 & 11 & 2 & $379-389$ \\
\hline Incomplete implementers & 62 & 43 & 21 & 17 & 3 & $326-340$ \\
\hline
\end{tabular}

SOURCE: Parent Services Follow-Up Interviews completed an average of 7 and 16 months after enrollment.

NOTE: $\quad$ The percentages are average percentages across programs in the group and are weighted for survey nonresponse. 
- Variable Engagement: The family's engagement varied during its enrollment-the family was sometimes highly engaged in the program, and at other times, the family's engagement was low.

- Consistent Low Engagement: The family's engagement in the program was consistently low throughout its enrollment - the family kept some appointments but missed and canceled frequently, did not engage actively in home visits and group activities, and (when applicable) the child was often absent from the center.

- No Engagement: The family was not engaged in the program at all.

- Can't Remember: Staff could not remember how engaged the family was.

Staff provided the ratings in summer 2000, when more than 80 percent of the research families had left the program because their child turned 3 years old or for other reasons (the remaining families were still engaged in the program). ${ }^{12}$ Thus, the ratings pertain to a longer period than is covered by the first two parent services follow-up interviews. Sixteen of the 17 research programs provided ratings for their research families.

The engagement ratings provided by program staff show that on average, slightly more than one-third of the research families became highly engaged in program services (Table IX.15). Consistent with the families' reports of their program participation, the staff reported that only 7 percent of families, on average, did not become engaged in the program at all.

The extent to which program staff rated families as highly engaged varied substantially across sites, however, ranging from 20 to 74 percent (not shown). The staffs of three programs reported that at least half the research families enrolled in their program were highly engaged.

Center-based programs were more likely than home-based or mixed-approach programs to report that families were highly engaged. Center-based programs reported that 47 percent of families, on average, were highly engaged in Early Head Start throughout their enrollment. In

\footnotetext{
${ }^{12}$ Staff rated all families who had ever been enrolled even though some families had left the program at the time of the ratings.
} 
TABLE IX.15

STAFF RATINGS OF PROGRAM ENGAGEMENT, FOR THE FULL SAMPLE AND KEY PROGRAM SUBGROUPS

\begin{tabular}{|c|c|c|c|c|c|c|}
\hline & \multicolumn{5}{|c|}{ Average Percentage of Families Who Were Rated As: } & \multirow[b]{2}{*}{ Sample Sizes } \\
\hline & $\begin{array}{c}\text { Consistently } \\
\text { Highly Engaged }\end{array}$ & $\begin{array}{c}\text { Engaged at Varying } \\
\text { Levels over Time }\end{array}$ & $\begin{array}{c}\text { Consistently } \\
\text { Engaged at a Low } \\
\text { Level } \\
\end{array}$ & $\begin{array}{c}\text { Not Engaged at } \\
\text { All }\end{array}$ & $\begin{array}{l}\text { Could Not } \\
\text { Remember }\end{array}$ & \\
\hline Full Sample & 37 & 32 & 18 & 7 & 6 & 1,408 \\
\hline $\begin{array}{l}\text { Program Approach in } 1997 \\
\text { Center-based } \\
\text { Home-based } \\
\text { Mixed-approach }\end{array}$ & $\begin{array}{l}47 \\
39 \\
38\end{array}$ & $\begin{array}{l}32 \\
29 \\
32\end{array}$ & $\begin{array}{c}7 \\
24 \\
20\end{array}$ & $\begin{array}{l}5 \\
8 \\
8\end{array}$ & $\begin{array}{c}8 \\
10 \\
3\end{array}$ & $\begin{array}{l}306 \\
603 \\
499\end{array}$ \\
\hline $\begin{array}{l}\text { Pattern of Implementation } \\
\text { Early implementers } \\
\text { Later implementers } \\
\text { Incomplete implementers }\end{array}$ & $\begin{array}{l}44 \\
31 \\
37\end{array}$ & $\begin{array}{l}29 \\
38 \\
27\end{array}$ & $\begin{array}{l}19 \\
17 \\
15\end{array}$ & $\begin{array}{l}8 \\
7 \\
7\end{array}$ & $\begin{array}{c}1 \\
6 \\
14 \\
\end{array}$ & $\begin{array}{l}521 \\
528 \\
457\end{array}$ \\
\hline
\end{tabular}

SOURCE: Ratings of program engagement provided by program staff in summer 2000 .

NotE: The percentages are average percentages across programs in the group. 
contrast, 39 percent of families, on average, in home-based (and 38 percent in mixed-approach) programs were reported to have been consistently highly engaged (Table IX.15).

Early full implementation is associated with higher levels of program engagement. The early-implemented programs reported that a higher proportion of families became highly engaged in the program (44 percent, on average). The later-implemented programs reported the smallest percentage of families, on average, as highly engaged (31 percent) (Table IX.15).

The engagement ratings provided by program staff are generally consistent with the information families provided in the first two parent services follow-up interviews. Nearly all families (93 percent) who reported receiving more than minimal Early Head Start services (more than one home visit, more than one case management meeting, center-based child development services, and/or group activities) during the first two follow-up periods were rated by program staff to have had low, variable, or high program engagement. Staff members were unable to rate the engagement of 4 percent of these families, probably because the staff members who worked with them were no longer employed by the program. ${ }^{13}$

The duration of families' participation in the program also varied. According to program records, among the research families who had left the program, approximately half participated for at least two years, and half participated for less time. In 3 of the 16 programs (one centerbased, one home-based, and one mixed-approach), nearly two-thirds of the research families participated for at least two years. In contrast, in three other programs, only slightly more than

\footnotetext{
${ }^{13} \mathrm{~A}$ few families (1 percent) did not report receiving more than minimal Early Head Start services during the first two follow-up periods, but were rated by program staff as highly involved. An additional 2 percent of families did not report receiving more than minimal Early Head Start services in the first two parent services follow-up interviews, but were rated by program staff as having variable engagement in the program. These families may have become more involved in the program later, but may also have underreported Early Head Start services in the interviews.
} 
one-third of the research families participated for at least two years. A higher proportion of families were enrolled for at least two years in the mixed-approach programs (61 percent) than in the home-based and center-based programs (47 percent).

Research families left the programs for a variety of reasons. Of the families who had left when staff rated their engagement, approximately one-third had graduated or transitioned out of the program and one-fourth moved before completing the program. Nearly one-third of the families either were terminated by staff because of poor attendance or lack of cooperation or asked to be removed from the program rolls. Families' reasons for leaving were similar among the home-based, center-based, and mixed-approach programs, except that home-based programs were much more likely to report that they terminated families' enrollment for poor attendance or lack of cooperation, while other types of programs were more likely to report that families asked to be removed from the program rolls.

\section{Local Research on Program Engagement}

Several researchers working in partnership with Early Head Start research programs have studied families' engagement in program services. In three boxes, we see examples of local research studies that have delved more deeply into understanding levels of engagement and exploring the nature of program engagement. In the first box, Paul Spicer of the University of Colorado describes the meaning of participation in the Early Head Start program at Family Star in Denver. Using ethnographic research methods, he describes how parents attributed changes in their children to their participation in Family Star, a center-based program. This in turn led parents to become more engaged with the program and to implement elements of program practices at home.

Maggie McKenna, a research partner of the Families First Early Head Start program in Kent, Washington, has also conducted ethnographic research to better understand program 
engagement. In the next box, she describes home visits with one family and what these home visits meant to this family. This example shows that for some families, what appears to be a low level of family engagement may in fact be very meaningful for the family.

In the third box, Beth Green and Carol McAllister, researchers working with the University of Pittsburgh Early Head Start program, use a combination of quantitative and qualitative methods to understand the reasons that some families have low levels of participation.

\section{Family Risk Factors and Program Participation}

Some programs' local research partners have worked with program staff to understand family risk factors that may interfere with families' participation in Early Head Start. In the following box, the University of Kansas researchers who are working with the Project EAGLE Early Head Start in Kansas City, Kansas, describe the risk factors they have identified.

\section{THE MATCH BETWEEN FAMILIES' EARLY NEEDS AND SERVICE USE IN SPECIFIC AREAS}

Identifying and articulating needs and goals often requires getting to know families over time and developing relationships with them. Interactions with staff members over time may also lead families to recognize needs that they did not perceive at the time they enrolled. Needs also change. For this study, we obtained "snapshots" of families' needs at the time they enrolled in Early Head Start (as part of the application and enrollment process with staff) and when they completed the follow-up parent services interviews approximately 7 and 16 months after enrollment. Care must be taken in interpreting the information below on families' levels of need, especially in sensitive areas such as social support, for two reasons: (1) these survey-based snapshots may miss frequent changes in family situations; and (2) some families may not have revealed all their needs, particularly at the time of enrollment. 


\title{
Ethnographic Perspectives on Engagement at Family Star Early Head Start
}

\author{
Paul Spicer \\ University of Colorado Health Sciences Center
}

The Early Head Start program at Family Star built upon the program's established commitment to Montessori early childhood education for children aged 0 to 5. Full-day child development services for Early Head Start children were provided in eight classrooms: two infant environments, five toddler environments, and a Bridge classroom designed to expose older children to more advanced Montessori materials. Family Star also provided a comprehensive set of health and family services, including a substantial commitment to mental health services for children and families, in addition to a monthly educational parent night. At the center of the program's model, though, was a commitment to change families by changing their children; the ethnographic research was designed to examine the extent to which the program was able to accomplish these ends.

Following a year of participant-observation in the program's classrooms, 12 families were recruited into the home visit component of the ethnographic research. These families were selected only if their children had participated in the program over their first year of enrollment. Thus, this research cannot address the meaning of the program for those families who withdrew during their first year of program enrollment. While we have alternative sources of information for these families (such as program reports on reasons for withdrawal), we focus here on the meaning of the intervention for families whose children regularly attended the program. With only one exception, the 12 families that participated in this intensive ethnographic work remained enrolled in the program until their children turned 3 and moved on to other settings.

The ethnographic study design involved three visits to participating families' homes over the course of their child's second year in the program. These visits began when the family had been in the program for one year, with two additional visits at six-month intervals after that. In all cases, mother and child participated, but if fathers were involved in the lives of their children, every effort was also made to include them. The focus of conversation during these visits was on the meaning of the program to the family, especially the changes in their children that they attributed to the program and the ways in which they were attempting to use elements of program philosophy in their own parenting.

This ethnographic work underscored the value that these families placed on the program approach. All parents emphasized positive aspects of their children's development that they attributed to the program, especially the independence that their children demonstrated and the pace of their children's developing interest in and engagement with the world around them. Many of these parents pointed to how much more advanced their child seemed to be compared to their other children at the same age or other children in their families and neighborhoods. Seeing their children develop in these ways often made these parents quite ardent advocates for the program's philosophy, and all of them had tried to incorporate elements of the program's classroom design in their homes (for example, by keeping their children's toys in a place where they could get them on their own or by setting up a small table and chair at which the child could work and/or eat). They also made efforts to reinforce classroom behavior that the child brought to the home (for example, cleaning up after play or after a meal).

The experience of this group of parents at Family Star underscores the potential effectiveness of their program model, which held that it would be possible to reach parents through their children. Our ethnographic work on the reception of the program - its meaning and value to participating families-emphasizes that this program's approach has the potential to powerfully impress parents and to instill in them a commitment to learning how to amplify these program effects in their own homes. 


\title{
RELUCTANT HOME VISIT IS A MAJOR ACCOMPLISHMENT FOR PARENT
}

\author{
Maggie McKenna \\ University of Washington
}

The Child Development home visitor's repeated requests to schedule a home visit with a 19-year-old mother would be met with the mother's unenthusiastic "O.K." The home visitor drove weekly to an apartment complex of three-story buildings where children stood in the parking lot kicking rocks and stopped to look at any car that drove into the lot and infringed on their play area. The home visitor would walk up a flight of stairs covered with torn indoor/outdoor carpet toward a second-story apartment. The home visitor's loud knocks at the mother's apartment door were met by the mother, who wordlessly motioned to the home visitor to enter. The home visitor sat on the floor in a living room furnished only with one tired old plaid-upholstered sofa. The 4-month-old infant was in an infant carrier placed on the floor, out of the mother's touch, but the mother could see her son as she sat on the sofa.

The home visitor talked to the young mother about the child's eating patterns and usual daily activity. The home visitor's eager questions about the child's wiggling fingers and reaching for a bottle were met by the mother's reply that she fed the infant as quickly as possible and discouraged the child from reaching or grasping. This reply and what the home visitor assessed as a lack of tactile stimulation for the infant prompted the home visitor to encourage the mother to hold the child and stimulate the infant's motor development. The mother did slowly demonstrate the touches and gentle positioning shown by the home visitor, but did not talk to the home visitor of feeling more at ease with the infant. The home visitor's continued weekly visits always met with the mother's very brief verbal responses.

When the mother announced that she was moving to be near relatives in another state, she agreed to a closing interview with another person from the program staff. The interviewer met the mother, and they sat and talked for an hour on the stairs outside the apartment, watching and listening to older children playing in the parking lot. This mother who had responded only with one-word replies on weekly visits stated that she had actually looked forward to the visits. The mother looked up and smiled as she said the home visitor had been the only person who ever listened to what she said, who had provided her with information, and who asked her how she was and showed patience to hear the mother's reply. The mother replied, "She [the home visitor] talked to me. My boyfriend never does that. She supported me, and she acted like she had all the time in the world to be here." The mother volunteered that she appreciated how the home visitor showed her to hold and feed her son. The parent did not know how to express to the home visitor that she had learned more in their time together than she could recall ever spending with anyone else.

The mother's hesitation and nonverbal behavior that the home visitor struggled to assess were really the result of the young mother not having any social experience or previous interactions that prepared her to receive a friendly and knowledgeable visitor into her home. In separate interviews, the Program Staff learned that the mother had grown up in relatives' homes and in foster families and that her memories were of moving to another place whenever she was too much to care for. She did not recall any person as influencing her or helping her as a child. The relationship-building time invested by the home visitor had brought a sense of confidence to the parent she had never experienced before. The home visits were the only meaningful interaction that the mother had experienced and helped her to interact more appropriately with her own son to break the cycle and prevent a recurrence of detached, withdrawn parenting in another generation. 


\title{
Which Families Are Engaged, and Why?
}

\author{
Beth L. Green and Carol McAllister \\ NPC Research, Inc., and University of Pittsburgh
}

Researchers and practitioners in the Pittsburgh Early Head Start program have been working to understand the factors associated with families' participation in program services. Although Early Head Start services are designed to be comprehensive and intensive, delivered over a three-year time span, many families leave the program before they have received many services and are difficult to engage actively. Using both quantitative and qualitative methods, we investigated reasons for low participation in services and examined family and contextual characteristics that may be related to program engagement.

Following training provided by the research team, two sets of program staff rated each family $(n=101)$ on scales measuring engagement in program services. Staff rated each family in terms of their (1) ease of engagement in services (easy, difficult, or very difficult to engage); and (2) level of engagement (never, somewhat, or very involved). Correlations between ratings made by the two different groups of staff were high (ranging from $r=.67$ to $r=.93$ ), so ratings were averaged for final analysis.

Families' ratings were then correlated with a number of measures collected through a baseline interview. These interviews were collected within 60 days of program enrollment, and included measures of social support, self-efficacy, depression, coping style, sense of cultural identity, and relationship with the child's father. Eight families and the Early Head Start program staff that they work with were also given open-ended, qualitative interviews to explore in greater depth issues regarding participation and family needs.

Results indicated that families tended to be either easy to engage (49\%) and very involved (39\%) or difficult to engage (32\%) and never involved (35\%). Further, a large percentage of families (44\%) remained in the program for less than one year; in fact, the program dropped 27 percent of the families because of a lack of participation. Clearly, participation was a significant problem for a substantial number of families.

We examined correlations between engagement ratings and the parent reports from the baseline interviews. Results indicated that families who were easier to engage tended to be less able to afford things for their families $(r=.29)$. However, they also showed a more positive coping style $(r=.21)$ and sense of cultural identity $(r=.32)$, were higher in social support $(r=.33)$, and were more likely to have an involved father figure ( $r=.27)$ (all correlations significant, $p<.05)$.

Qualitative interviews suggested that engaged families entered the program with a clear sense of their goals and a better ability to seek out support when needed. Staff also identified a group of parents who entered the program with concrete needs and were engaged initially, but became less engaged over time. Staff identified two key reasons for a lack of family engagement, including (1) a lack of time, usually related to work and school schedules (especially since the onset of welfare reform); and (2) a lack of social/emotional resources to establish relationships with program staff and other families.

Results of both quantitative and qualitative data collection suggest that "easy to engage" families are those who enter with more social/emotional resources, such as existing social support networks, positive coping skills, and the ability to seek help when needed. Further, it is clear that there is a significant subgroup of parents who are difficult to engage and at high risk for dropping out of program services. These parents appear to enter the program with different social/emotional characteristics, compared to highly engaged parents. Clearly, it is important for both researchers and practitioners to continue to try to understand more about the reasons that families participate or not, and how varying levels of participation and engagement may influence program outcomes. 


\section{Family Risk Factors and Participation in Early Head Start \\ Jean Ann Summers, Jane Atwater, and Judith Carta \\ University of Kansas}

A study completed by the Kansas Research Partners identified types of risk factors that appear to impede parents' ability to participate fully in Early Head Start programs. ${ }^{1}$ Researchers observed case conferences in the Project EAGLE Early Head Start program from May through July of 1998. At that time, Project EAGLE served families primarily in home visits, and supervision consisted in part of weekly case conferences with each home visitor to discuss each family in her caseload. ${ }^{2}$ The primary purpose of each case conference was to identify emerging problem areas for the family and to brainstorm possible resources or actions to address the issues. As a result, the case conferences did not focus on family strengths or general characteristics, nor did they provide a summary of all interventions provided to each family, since those that were going well were not discussed. The case conferences provided, however, an opportunity to learn more about the risk factors program staff perceived as interfering with the family's abilities to reach their goals and engage in the program's parenting curriculum. Risk factors discussed in these conferences fell into two categories: (1) self-sufficiency issues, and (2) mental health and socio-emotional issues.

Of the 128 self-sufficiency issues or needs that were mentioned in case conferences for 73 families, 25 percent involved a need or goal to move off TANF assistance, and 22 percent involved a need for employment. Training needs or goals were discussed for 20 percent of the families. Other issues or needs discussed included no transportation (19\%), inadequate housing (15\%), poor budgeting skills (5\%), and legal problems (10\%).

Project EAGLE staff had previously identified nine family characteristics or risk factor categories that they used to design assessments and interventions. During the case conferences for 73 families, references to these risk factors occurred 210 times. These included mental health issues (21\%); age/maturity issues (7\%); family conflict or support issues (14\%); cognitive level issues (5\%); problems with physical appearance (4\%); parent health issues $(14 \%)$; and social behavior issues (for example, motivation level, problem-solving skills, and social skills) (12\%).

A total of 59 mental health issues were discussed for 44 families. These involved depression (19\%); substance abuse $(25 \%)$; domestic violence (31\%); socio-emotional problems, such as anger control (8\%), self-esteem (3\%), and other specific mental health diagnoses (including bipolar, manic-depressive, grief issues, and suicidal tendencies) (14\%). In addition, specific issues related to poor problem-solving or coping skills were discussed for 23 families. These included poor follow-through on planned actions (17\%), poor planning and organizational skills (17\%), low motivation or expectations (13\%), impulsivity (13\%), resistance to the program (13\%), passivity (9\%), poor short-term memory (9\%), poor social skills (4\%), and actively engaged in denial (4\%).

Some families had fewer risk factors than others. Because Early Head Start serves low-income families, the self-sufficiency risk factors were fairly common among the families. With respect to the nine more-intangible risk factors, the number mentioned in case conferences ranged from none (for seven families) to seven identified issues (for two families). The mean number of risk factors was 0.97 . The modal number of risk factors was 2 and 3 , with 18 families identified with 2 and 3 factors, respectively.

${ }^{1}$ Summers, J. A., Atwater, J. E., and Carta, J. C. (1999). "Issues and Characteristics of Families Served in an Early Head Start Program." University of Kansas Juniper Gardens Children's Program, Early Head Start Research Project Working Paper No. 1.

${ }^{2}$ Case conferences lasted approximately three hours each week and involved between 8 and 12 families in each session. The Local Researchers attended 12 conferences, involving 8 program Advocates. The total unduplicated number of active cases reviewed in these conferences was 73. Transcripts of the case conferences were analyzed using a coding sheet covering the primary research questions for the study, which included, among others, a tally of types of risk factors or issues mentioned in each of the program areas. 


\section{Summary of Needs}

When they enrolled, families were most likely to report having needs in the areas of education and employment. ${ }^{14}$ Slightly more than half the families indicated that the job they or their partner had was inadequate or that they were unemployed and thus had needs for education or employment (Table IX.16). Similarly, slightly more than half the families reported that they did not have a high school diploma or GED, or that they had limited English-speaking skills. For these caregivers, improving English-speaking skills and completing more education may have been important for increasing their employment opportunities and for helping them gain access to other services they needed.

For many families, the needs expressed when they enrolled also included child care, family health care, and transportation. Approximately one-third of the families reported that the babysitting or child care for their children was inadequate or an urgent need (Table IX.16). For most families, obtaining child care is essential for enabling parents to participate in education programs or go to work. While some families have family members or relatives who can provide child care while primary caregivers work or go to school, many do not. ${ }^{15}$

All the families who enrolled in the Early Head Start research programs had health care needs - all of them included a pregnant woman or had infants who needed regular well-child examinations, immunizations, and screening tests. When they enrolled, nearly 30 percent reported that their health care was inadequate to meet their needs or that it was an urgent need (Table IX.16).

\footnotetext{
${ }^{14}$ Many of the study families enrolled in Early Head Start around the time new welfare rules were being implemented. These new rules included work requirements as a condition for receiving cash assistance, as well as lifetime time limits on cash assistance. For many, the early months of program participation were a time when families and staff were learning about the new rules and exploring ways to meet the requirements and work toward self-sufficiency.

${ }^{15}$ At the time of enrollment, about one-fourth of the applicants were pregnant.
} 
TABLE IX.16

SELECTED NEEDS REPORTED BY PROGRAM FAMILIES AT BASELINE, FOR THE FULL SAMPLE AND KEY PROGRAM SUBGROUPS

\begin{tabular}{|c|c|c|c|c|c|c|c|c|c|}
\hline & \multicolumn{8}{|c|}{ Average Percentage of Families Who Reported a Need for: } & \multirow[b]{2}{*}{$\begin{array}{c}\text { Sample } \\
\text { Sizes } \\
\end{array}$} \\
\hline & $\begin{array}{c}\text { Parenting } \\
\text { Information }\end{array}$ & $\begin{array}{c}\text { Services for } \\
\text { Children } \\
\text { With } \\
\text { Disabilities }\end{array}$ & $\begin{array}{l}\text { Child } \\
\text { Care }\end{array}$ & Education & Employment & $\begin{array}{c}\text { Family } \\
\text { Health } \\
\text { Care }\end{array}$ & $\begin{array}{c}\text { Housing } \\
\text { or } \\
\text { Utilities }\end{array}$ & Transportation & \\
\hline Full Sample & 13 & 8 & 35 & 53 & 53 & 29 & 14 & 25 & $872-1,039$ \\
\hline \multicolumn{10}{|l|}{ Program Approach in 1997} \\
\hline Center-based & 6 & 7 & 51 & 47 & 50 & 28 & 11 & 20 & $204-221$ \\
\hline Home-based & 15 & 8 & 24 & 55 & 53 & 29 & 14 & 25 & $313-482$ \\
\hline Mixed-approach & 14 & 7 & 37 & 56 & 55 & 31 & 16 & 29 & $275-336$ \\
\hline \multicolumn{10}{|l|}{ Pattern of Implementation } \\
\hline Early implementers & 8 & 7 & 36 & 44 & 46 & 32 & 13 & 23 & $312-362$ \\
\hline Later implementers & 17 & 7 & 29 & 67 & 55 & 32 & 13 & 27 & $344-406$ \\
\hline Incomplete implementers & 13 & 9 & 39 & 50 & 58 & 20 & 17 & 26 & $247-295$ \\
\hline
\end{tabular}

SOURCE: Parent Services Follow-Up Interviews completed an average of 7 and 16 months after enrollment.

NOTE: The percentages are average percentages across programs in the group and are weighted for survey nonresponse. 
Having a reliable means of transportation is essential for obtaining and maintaining employment, taking family members to health care appointments, attending Early Head Start program activities, and gaining access to other important services and opportunities. When they enrolled, one-quarter of all families reported that their transportation was inadequate or an urgent need (Table IX.16).

Social support from family, friends, and community members is also important to the success of low-income families who are striving toward self-sufficiency and effective parenting. Nine percent of primary caregivers indicated that the availability of someone to talk to was inadequate or an urgent need, 19 percent reported that their opportunities to participate in community groups were inadequate or an urgent need, and 13 percent reported that the availability of friends or family to help them was inadequate or an urgent need. Altogether, nearly one-third of the primary caregivers who enrolled in Early Head Start with their children expressed a social support need when they enrolled (not shown).

Fewer families expressed needs in other key areas. For example, 14 percent reported that their housing or utilities were inadequate, and 13 percent reported that their information or access to information about parenting was inadequate (Table IX.16).

Families' reported needs at enrollment generally did not differ substantially by program approach or implementation pattern. One exception, however, is that families who enrolled in the center-based programs were much more likely to express a need for child care (51 percent, compared with 24 and 37 percent in home-based and mixed-approach programs, respectively) (Table IX.16). Families enrolling in center-based programs and programs that were implemented early were also less likely to report a need for parenting information or access to parenting information (for example, 6 percent of center-based programs compared with 14 to 15 percent in the other types of programs). 


\section{Match Between Needs and Services}

To assess the extent to which the services families received during their first 16 months of enrollment met the needs they expressed at the beginning or their enrollment, we divided families into four groups for assessing each key potential area of need:

1. Those who reported a need at baseline and received a service in that need area during the follow-up period

2. Those who reported a need at baseline and did not receive a service in that area during the follow-up period

3. Those who reported no need at baseline but received a service in that area during the follow-up period

4. Those who reported no need at baseline and did not receive a service in that area during the follow-up period

Overall, by the second followup, most families had received services related to the needs they expressed at enrollment. At least 85 percent of families who expressed a need reported receiving services they needed in the areas of family health care, parenting information, child care, and education (Table IX.17). Most families who expressed a need for employment and housing reported receiving related services. However, in two areas-transportation and services for children with disabilities-fewer than half of families with a need received services within the first 16 months, on average, after enrollment.

In most areas of need, the match between reported service needs and use did not change much after the first follow-up period. Most families who received services related to their reported needs at enrollment began receiving them in the initial follow-up period. In child care and education, some families who had a need at enrollment and did not receive services during the first follow-up period began receiving services in the second follow-up period.

A high proportion of families who did not report a need at enrollment nevertheless received related services. Some services, such as parenting information, are core Early Head Start 
TABLE IX.17

\section{MATCH BETWEEN SELECTED BASELINE NEEDS AND SERVICES USED BY PROGRAM FAMILIES DURING THE FIRST 16 MONTHS}

\begin{tabular}{|c|c|c|c|c|c|c|}
\hline \multirow[b]{2}{*}{ Need Area } & \multicolumn{4}{|c|}{ Average Percentage of Families Who Had: } & \multirow[b]{2}{*}{$\begin{array}{l}\text { Among Families } \\
\text { with a Need, } \\
\text { Average } \\
\text { Percentage Who } \\
\text { Received Services }\end{array}$} & \multirow[b]{2}{*}{$\begin{array}{c}\text { Among Families } \\
\text { Without a Need, } \\
\text { Average } \\
\text { Percentage Who } \\
\text { Received Services }\end{array}$} \\
\hline & $\begin{array}{l}\text { A Need at Baseline } \\
\text { and Received } \\
\text { Services }\end{array}$ & $\begin{array}{c}\text { A Need at Baseline } \\
\text { but Did Not } \\
\text { Receive Services }\end{array}$ & $\begin{array}{c}\text { No Need at } \\
\text { Baseline but } \\
\text { Received Services }\end{array}$ & $\begin{array}{c}\text { No Need at } \\
\text { Baseline and } \\
\text { Received No } \\
\text { Services } \\
\end{array}$ & & \\
\hline Parenting Information & 12 & 1 & 81 & 6 & 92 & 93 \\
\hline $\begin{array}{l}\text { Services for Children w } \\
\text { Disabilities }^{\mathrm{a}}\end{array}$ & 2 & 6 & 1 & 91 & 25 & 1 \\
\hline Child Care $^{\mathrm{b}}$ & 30 & 5 & 55 & 10 & 86 & 85 \\
\hline Education & 45 & 8 & 38 & 9 & 85 & 81 \\
\hline Employment & 38 & 15 & 30 & 17 & 72 & 64 \\
\hline Family Health Care & 28 & 1 & 70 & 1 & 97 & 99 \\
\hline Housing & 9 & 6 & 41 & 45 & 60 & 48 \\
\hline Transportation & 10 & 16 & 20 & 55 & 38 & 27 \\
\hline Sample Sizes & $878-1,024$ & 878-1,024 & 878-1,024 & 878-1,024 & 878-1,024 & 878-1,024 \\
\hline
\end{tabular}

SOURCE: Parent Services Follow-Up Interviews completed an average of 7 and 16 months after enrollment.

NOTE: The percentages are average percentages across programs in the group and are weighted for survey nonresponse.

${ }^{a}$ Families are coded as having a need for disability services if they reported that someone suspected that the child was experiencing a developmental delay, the child had been evaluated for early intervention services, the child was identified as eligible for early intervention services, or the child was receiving early intervention services.

${ }^{\mathrm{b}}$ Families were coded as having a child care need if the family reported needing child care for any child in the household. 
services provided to virtually all families regardless of reported need. Thus, the proportion of families who received services is similar among families who did and did not express a need when they enrolled (Table IX.17). In other areas of need, families may have identified a need after enrollment, or families' needs may have changed as they progressed in the program, and they received services to meet these emerging needs.

\section{E. SUMMARY}

The 17 Early Head Start research programs served diverse families with widely varying needs and circumstances, and were successful in achieving high levels of participation among them. Family participation patterns differed across programs. Like other home-visiting programs, the Early Head Start home-based programs had difficulty providing the required frequency of home visits—-they succeeded in completing weekly visits with just over half their families. The pattern was very similar for the mixed-approach programs. Case management services overlapped considerably with home visitation, with the majority of families receiving both. Family meetings with case managers occurred more frequently in home-based and mixedapproach programs. Programs provided parenting education in different ways: center-based programs used predominantly parenting classes or events, while home-based and mixedapproach programs held more group activities with parents and children together.

Ten of the Early Head Start research programs provided center-based child development services to some or all of their families, and many also arranged for quality care by working with community partners. This meets important family needs, as quality, affordable, and accessible child care is scarce for low-income families in the United States. Although children in centerbased programs received more intensive child care (at least 20 hours a week for more than half of them) and child care for longer periods, children in all programs were in child care 
arrangements for substantial time during their first 15 months in the program. Largely because of Early Head Start, three-fourths of the families reported no out-of-pocket child care costs.

Serving families with disabilities is as important to Early Head Start programs as it has traditionally been throughout the history of Head Start. Program staff reported that 13 percent of children across all programs had been identified as eligible for early intervention services (the percentage is lower according to parent reports, but the interview question may have meant something different to many parents). Parents in center-based programs reported the highest identification rates. Programs were successful in ensuring that children and families received health services-parents reported that all children had received some health services during the evaluation period, with extremely high rates of immunizations and doctor visits for checkups. Programs ensured that families received other health services as well, with about two-thirds of all families having at least one member who received dental services. Early Head Start also linked families with community services, and high percentages received education- and employment-related services.

Program staff rated more than one-third of their families as being highly engaged in program services. In both engagement and service receipt, the Early Head Start research programs often showed considerable variation across the sites, with the variation associated with program approaches and levels of implementation of the revised Head Start Program Performance Standards. Based on the parents' self-reports, programs that became fully implemented early generally succeeded in delivering more frequent and intense services to their families than the later-implemented or incompletely implemented programs. 


\section{PATHWAYS TO IMPLEMENTATION AND QUALITY}

Early Head Start programs are expected to grow and improve over time. In fact, the Head Start Bureau has taken significant steps to ensure that staff monitor programs' compliance with the Head Start Program Performance standards, and the bureau provides guidance to programs from the monitoring results. More important, however, programs are required to engage in continuous improvement activities, and the Head Start Bureau has established a training and technical-assistance system to support programs in their efforts to improve. New programs are especially apt to grow and improve during their early years of operation, as they learn more about families' needs and the services and strategies that best address them.

Beyond the normal growth and development that programs are likely to experience over time, changes in the context in which they operate have required them to adjust and adapt. The research programs, as well as all programs funded in the early waves of Early Head Start funding, have had to adjust to several major changes. For example, the new welfare policies that took effect in late 1997 drastically changed the needs and prospects of some families. Resources for child care often increased, and the implementation of child care subsidies changed in some places. Other significant policy changes occurred in particular states and communities.

Thus, we expected to observe changes as the research programs adapted their approaches and made both adjustments in the implementation of particular services and improvements in the implementation of key services. In fact, we saw substantial changes. The implementation and quality ratings presented in the previous chapters reveal the substantial growth that the Early Head Start research programs experienced between fall 1997 and fall 1999.

Stepping back from all the individual ratings and the particular areas of implementation and quality, it is possible to discern trends in the directions that programs moved and identify 
common strategies that programs used to respond to changing family needs and to meet the performance standards. Other common program experiences, key events, and circumstances also influenced the directions that programs took and the strategies they adopted. In this chapter, we summarize the major changes in approach and progress in implementation that programs made during their early years, identify the common themes that characterize their early development, note other common experiences that influenced the programs, and identify other key events and circumstances that influenced program pathways. The following sections also examine the strategies that the programs adopted to accomplish needed changes, highlight noteworthy accomplishments, and identify challenges that still lie ahead.

\section{A. CHANGES IN APPROACH AND IMPLEMENTATION LEVELS OVER TIME}

The research programs began with very different amounts of experience both in serving families with infants and toddlers and in operating Head Start programs (Administration on Children, Youth and Families 1999a). They also began with different plans for serving families with infants and toddlers, based on the varying needs of these families in their communities.

Although we tried to identify a few common developmental pathways followed by the Early Head Start research programs, the complexity of program services and the variations in communities in which they operate made it impossible to do so. Although the research programs share common pathways along particular dimensions, when we look across dimensions and examine different combinations of changes, each of the 17 programs emerges as unique. It is possible, however, to identify common types of changes the programs made or experienced along particular dimensions. We describe these next. 


\section{Evolution in Program Approaches}

Over time, program approaches to delivering services increased in complexity. The research programs were initially divided about equally among center-based, home-based, and mixedapproach strategies. By fall 1997, however, the home-based approach predominated. Nevertheless, by fall 1999, only two home-based programs continued to rely exclusively on the home-based approach; the others began delivering center-based services to some families either directly or through formal partnerships with child care providers. The four exclusively centerbased programs remained center-based throughout the evaluation period.

\section{Progress in Overall Program Implementation Over Time}

According to our implementation ratings, all the research programs made progress toward full implementation of key elements of the performance standards during the evaluation period. The patterns of change and growth, however, were quite diverse.

Six programs—-the early implementers—reached full implementation in fall 1997 and maintained that level in fall 1999. These programs benefited from experience, started with a strong focus on child development, and were not hampered by early staff turnover or leadership changes. They continued to refine and improve the quality of their services. Many also expanded by adding children or services. The early implementers also built in greater accountability over time by improving internal monitoring or staff supervision, or by improving their service-tracking systems. Figure X.1 shows the growth of one of these programs.

Six programs were not fully implemented in fall 1997 but by fall 1999 had made significant improvements and reached full implementation. These programs-the later implementersoften received key feedback from Head Start Bureau monitors and promptly improved services to meet the Head Start Program Performance Standards. They often had to shift the primary 
FIGURE X.1

\section{TIMELINE OF AN EARLY IMPLEMENTER}

Families

Served

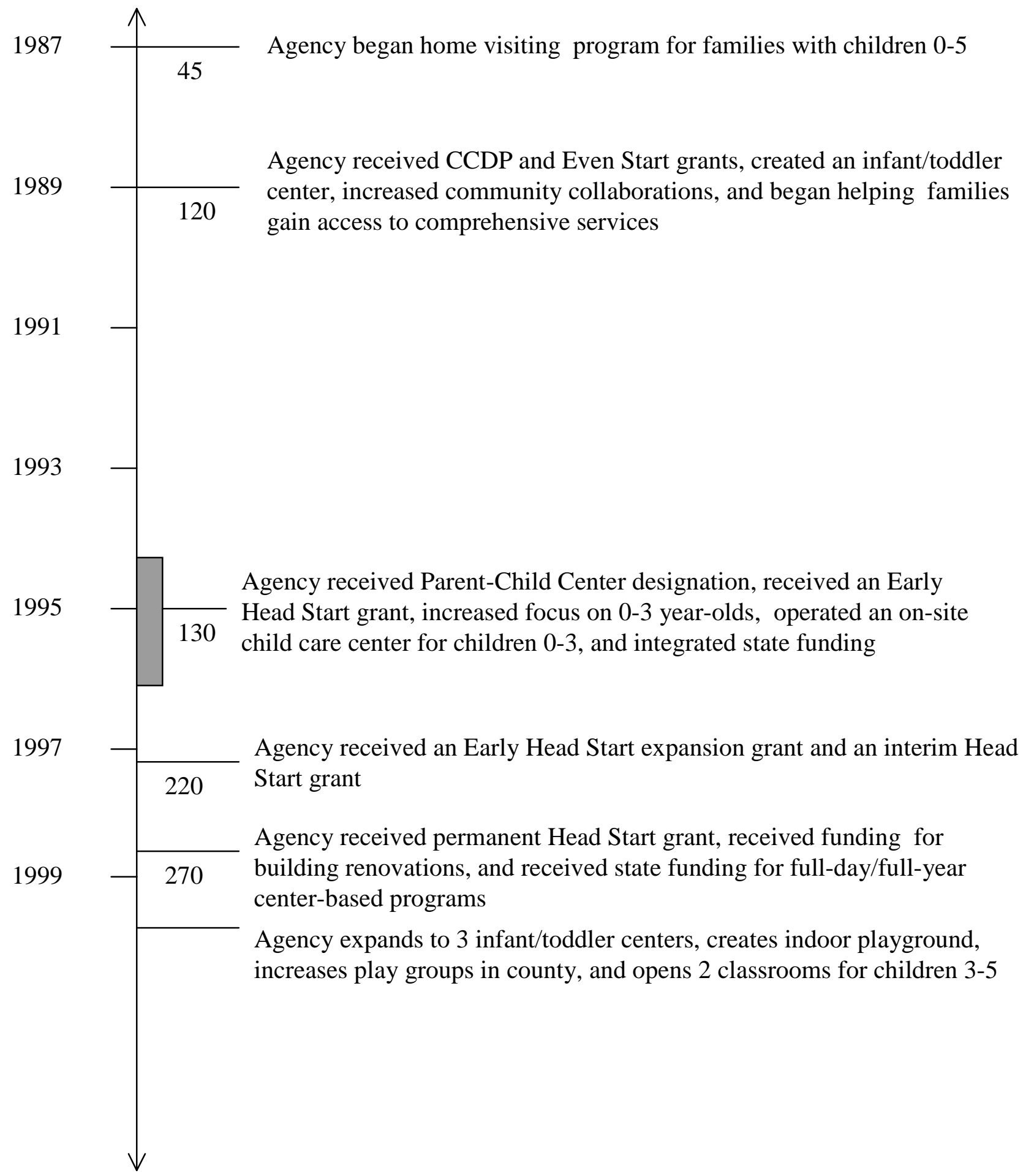


focus of their services from the family to the child. The home-based programs in this group increased their attention over time to ensuring that child care for children who needed it was of good quality. Early leadership changes were more common among the later implementers.

The remaining five programs-the incomplete implementers-were moderately implemented in both fall 1997 and fall 1999. These were more likely to be new programs serving families with infants and toddlers for the first time. They often received important feedback from Head Start Bureau monitors but sometimes had trouble responding to it. They frequently had to increase their focus on child development. The incomplete implementers were more likely to experience high rates of staff turnover during their first year of operation and to experience leadership changes. They were also more likely to have to change course midstream as a result of difficulties with community partnerships. Like other programs, the incomplete implementers increased their accountability over time by improving internal monitoring of program services or staff supervision, and improving their tracking of service receipt.

\section{B. THEMES CHARACTERIZING EARLY PROGRAM DEVELOPMENT}

We asked program staff to look back over their early years and identify the key events that had made a difference in their program's growth and development. From these reports and our own observations of changes that were common across programs, we identified a number of themes that characterized the early development of the Early Head Start research programs.

\section{Increased Attention to the Revised Head Start Program Performance Standards}

Programs received ongoing guidance from the Head Start Bureau and technical-assistance providers to help them interpret the performance standards. In addition, the research programs received Head Start Bureau monitoring visits between our 1997 and 1999 visits. These visits clarified the standards in the context of each program, identified areas that programs needed to 
change in order to comply with the standards, and motivated staff to address these areas. Staff in about half the research programs mentioned visits by their federal project officer or other technical-assistance consultants as key events in their program's development.

\section{Increased Service Intensity}

Many programs increased the frequency of home visits, the hours of child care they provided in their centers, and/or the frequency of group socializations as the requirements of the Head Start Program Performance Standards became clearer and as family needs changed. One home-based program planned initially to conduct home visits biweekly, but changed to weekly to meet the revised Head Start Program Performance Standards, which took effect in January 1998. One of the center-based programs initially offered part-time day care in its main child development center, but increased its hours to help the growing number of families that needed full-time child care in order to work toward self-sufficiency. Many programs increased the frequency of group socialization activities to accommodate the varied schedules of families and increase participation levels in group activities.

\section{Increased Focus on Child Development}

Some programs began with a family support focus and had to go through a process of studying the performance standards, reevaluating their theories of change, and reexamining their services. Increasing the child development focus of services often involved increasing the time that was devoted to child development activities during home visits and parent activities, changing curricula or emphases in home visits, engaging staff in intensive training on relevant topics, and providing supervision to help staff focus more consistently on child development and parent-child relationships during home visits. The increase in focus on child development occurred, at least in part, in response to strong messages from Head Start Bureau monitors that 
although Early Head Start rests on four cornerstones, Early Head Start is a child development program and the focus of services needs to be the child.

\section{Refocused Efforts to Improve Child Care Quality and Availability}

As it became clearer to programs that the Head Start Bureau required them to take responsibility for the quality of child care arrangements that program children are in, many programs began focusing on improving the availability and quality of that child care. Several programs refocused their efforts to improve child care quality and availability from community-level collaborations with child care providers and agencies. Either by helping Early Head Start families find good child care arrangements or by working with providers to improve the quality of their existing arrangements, they improved Early Head Start children's access to high-quality child care. Sometimes these efforts resulted in improvements in the quality of care for other children as well. Section $\mathrm{C}$ describes some of the strategies that programs used to improve child care availability and quality for enrolled children.

\section{Enhanced Participation in Program Services/Activities}

Some programs made strong efforts to increase family involvement in services-for example, participation in home visits and group socializations, and involvement of males in program activities—and succeeded to some extent in doing so. Because the new welfare requirements often led families to give priority to work-related activities, some programs experienced low levels of participation in program services and searched for strategies for improving it. In addition, programs recognized the importance of involving fathers as well as mothers in program activities and devoted resources to reaching out to them. 


\section{Expansion of Services}

Many of the programs expanded their services during the evaluation period. To meet the demand for Early Head Start services in their communities, some programs expanded the number of children they served through new grants, either Head Start Bureau expansion grants or state grants. In response to changing family needs, and applying lessons from their initial experiences serving families, other programs expanded their options for providing child development services to children and families, helping them meet their child care needs, and ensuring that those who needed child care received high-quality care. In particular, for some families, several programs added a center-based option, either through partnerships with community child care providers or by opening their own center. Other home-based programs added an option in which they conducted visits to children both at home and in their child care setting. This expansion of program options, which increased program complexity, improved the fit between program services and family needs.

\section{Evolution of Community Partnerships}

As programs gained experience working with community partners and increased their focus on child development services, they sometimes found that their initial partnerships had become unproductive or that they were unable to overcome difficulties that had arisen with their partners. Some ended partnerships that had become unnecessary or were unsuccessful. Over time, most of the programs developed new community partnerships and joined interagency collaborative groups, often with child care providers or Part $\mathrm{C}$ agencies.

Changes in partnerships sometimes caused setbacks or required programs to redesign services, and sometimes they enabled programs to solve problems more quickly. Regardless, staff often saw these changes as key events in their programs' development. For example, one 
program initially worked with the local resource and referral agency on strategies to improve child care quality, but staff members encountered problems in their relationship with the agency, ended this partnership, and went back to the drawing board to develop new strategies for promoting quality in Early Head Start children's child care settings. In another program, after staff encountered difficulties in working with their partners in continuous program improvement and ended that relationship, they eventually hired a continuous program improvement researcher to work with them.

\section{Leadership Changes}

Nine programs experienced director turnover during the evaluation period, although in three cases the director moved to a higher position within the agency. Leadership changes sometimes set back or stalled program progress. However, sometimes they also created opportunities for positive change. For example, the newly hired program director in one program was unable to build necessary relationships within the grantee agency and overcome staff morale problems, and left the program after about one year. Other staff also left around the same time. The new director, an employee with a long history with the grantee agency, hired new people who were better suited to their jobs and in time created a staff with high morale and strong commitment to the program. In other programs, the departure of the program director caused some activities to be put on hold while the program sought a new director.

\section{Staff Changes}

Nearly all the research programs mentioned staff changes as key events in their program's development, including the addition of new staff members, staff turnover in key positions, new training for staff, and reallocations of staff responsibilities. 
Many programs experienced moderate or high levels of staff turnover, which often disrupted services. When programs were unable to fill staff openings quickly, families receiving homebased services experienced periods of less-intensive or no services. Children and families also lost the trusting relationships they had built with the staff members who left, and new staff had to establish new relationships with them. Staff turnover sometimes required programs to "start over" with training staff and helping them obtain their CDA credential.

\section{Shift Toward Providing Training and Technical Assistance}

Some programs reported that in addition to receiving training and technical assistance, they began providing it to other, newer Early Head Start programs. Because they were in the initial waves of program funding and further along the pathway to full implementation, the research programs were often called on to share what they had learned and provide help to newer programs in their region.

\section{STRATEGIES FOR CHANGE}

The common themes described above, as well as other changes that individual programs made, generally came about through the conscious and concerted efforts of program staff. These efforts employed some common strategies, which are described below. The strategies refer to the types of actions that programs took, often as a result of the key events just described.

\section{Using New Curricula and Assessment Tools}

One strategy for increasing the emphasis on child development or strengthening the focus of program services on the child was to add or change curricula. A number of programs added the Creative Curriculum for Infants and Toddlers. One mixed-approach program began using a common curriculum in its centers and in home visits to promote consistency and continuity when families move between center-based and home-based services. 
Some programs added to or changed the child assessment tools they were using. Several programs added the Ages and Stages Questionnaires, because they are parent-friendly and offer an opportunity for parents to participate in and learn from the assessment process.

One program designed and implemented an outcomes/best practices tool for working with families. It was designed to improve service quality and make services more consistent across families.

\section{Creating Early Head Start Child Care Centers}

Several programs expanded their child development services by creating a child care center for some program children and to provide a model for high-quality child care in the community. In one case, the center was designed to provide respite child care services for a limited time to families who needed it. In another case, the center had spaces for eight children, and plans were in place for adding additional spaces.

\section{Developing New Approaches to Improving Quality in Community Child Care Settings}

During the evaluation period, the research programs began many efforts to improve the quality of child care for Early Head Start children in the community. Program staff devoted substantial time to these efforts, and worked hard to overcome the challenges presented by the limited supply of good-quality infant and toddler child care in their communities and the limited capacity of many community child care providers to make the changes necessary to meet the Head Start Program Performance Standards. Because of these challenges, some programs focused on training strategies for improving child care quality. Several programs and their community partners began offering free training and materials to child care providers. One program also offered a monetary payment for attending monthly training sessions. 
Several programs began assessing quality and working with center-based and family child care providers to improve it. One program, as it worked with providers that cared for Early Head Start children, created individual quality enhancement plans and offered incentives, materials, and training to encourage and enable them to develop their plan. Staff members in that program were also beginning to visit informal neighbor and relative caregivers monthly. Another program began paying for child care for some children and worked with the funded providers individually to improve quality. Most of these were family child care providers.

In addition to or in place of some home visits, several programs began visiting children in their community child care settings. During these visits, staff members shared child development information with the providers and, when possible, offered feedback on the care of the program child. Through these visits, program staff built relationships with Early Head Start children's care providers and encouraged them to work in partnership with Early Head Start on behalf of the child.

\section{Creating Systems for Tracking Services More Effectively}

Several research programs made changes in their management information system and/or their data collection procedures to facilitate access to information about families' receipt of services, especially health services. One program hired a consultant who helped them implement the Head Start Family Information System (HSFIS) and streamline their data collection procedures. Several other programs began using the HSFIS to track services or made improvements to their existing tracking systems. The transition to using the HSFIS was sometimes difficult for program staff, especially when staff were not accustomed to using a computerized management information system or were used to a different system. 


\section{Ending Partnerships}

As already noted, changing partnerships was an important theme of change for Early Head Start programs. Sometimes partnerships ended or changed as a result of circumstances outside the program's control. Sometimes the programs accomplished important changes by ending partnerships or forming new ones. As programs gained a better understanding of the importance of focusing on child development services, they sometimes found that the initial partnerships they had formed no longer met their needs and should be ended. For example, one program initially relied on a collaborative agreement with another agency to provide child development home visits, but the agency did not provide the number of visits Early Head Start required, nor did it provide the needed support for Early Head Start staff in this area. The program ended its partnership with the agency, and staff members took direct responsibility for child development services.

\section{Forming New Partnerships and Strengthening Existing Ones}

The breadth of partnerships the programs had with other community programs and agencies increased over time. Programs found new partners to help them meet families' needs. Programs also continued participating in interagency collaborative groups, and in some cases increased their leadership role in these groups (for example, one program became more visible and accepted in the community over time, and the director gained leadership roles in new community and statewide early childhood initiatives).

Many of the programs and their Part $\mathrm{C}$ partners began participating together in SpecialQuest ${ }^{1}$ and working together on joint goals for improving services to families and

\footnotetext{
${ }^{1}$ SpecialQuest refers to five-day workshops conducted as part of the Hilton/Early Head Start Training Program, which is now part of the Head Start T/TA system. These began in 1998 with funding from the Conrad N. Hilton Foundation. SpecialQuest emphasizes inclusion of infants
} 
children with disabilities. In fall 1999, program staff reported that participation in SpecialQuest had improved their relationships with Part $\mathrm{C}$ staff and that frontline staff in both programs worked more effectively together on behalf of children with disabilities.

In their work on improving the quality of child care for enrolled children, many of the research programs began developing partnerships with child care providers during the evaluation period. These partnerships were both formal (involving contracts in which child care providers agreed to meet the performance standards) and informal.

\section{Reorganizing or Creating New Staff Positions}

To strengthen their focus on child development, some programs created new positions and either promoted existing staff or hired child development specialists or coordinators to support frontline staff in this area. To boost efforts to ensure that children received immunizations and needed health care and that staff had access to infant mental health expertise, some programs created positions for nurses or infant mental health specialists.

\section{Hiring New Staff into Existing Positions}

Staff turnover presented opportunities for filling positions with new staff who better met the needs of the program. Several programs experienced turnover and saw it as an opportunity to fill positions with staff better suited for the job. For example, in one program, many families who enrolled in the program were headed by teenage parents (even though teenage parents were not explicitly the target of program recruiting efforts). Many existing frontline staff did not like

\section{(continued)}

and toddlers with significant disabilities, nurturing relationships with families, and building/maintaining relationships with early intervention partners. SpecialQuest teams are formed in local communities and comprise Early Head Start staff, parents of infants/toddlers with disabilities, and early intervention staff. The teams attend the workshops and are expected to continue working together when they return to their communities. 
working with teenage parents, who present a unique set of challenges. As these staff left, the program hired new staff members who were interested in and qualified to work with these younger parents.

\section{Providing Intensive Staff Training}

A key strategy for programs that increased their emphasis on child development and strengthening child development services was providing intensive training in that area to staff. In one program, for example, the program's continuous program improvement partner (university researchers) provided an eight-week course on child development and working with families and children at risk, for which staff received college credit. The program's partner also helped program managers arrange a Child Development Associate (CDA) class for staff and providers who cared for Early Head Start children.

During the evaluation period, the Head Start Bureau notified programs that by September 2003, at least 50 percent of all teachers in center-based programs nationwide must have at least an associate's degree in early childhood or a related field. ${ }^{2}$ Many of the research programs began providing more support for staff members to work toward their degree, such as developing individual plans for meeting this requirement, providing tuition support, and offering release time. One program began sponsoring a community college course in child development and gave enrollment priority to program staff and participants. Because some local colleges and universities did not offer degrees in early childhood development, several programs had to work with them to establish such a course of study.

\footnotetext{
${ }^{2}$ Head Start Act, Section 648A (a) (2), October 1998.
} 


\section{Strengthening Staff Supervision}

Some programs strengthened their supervision and support for frontline staff by hiring additional supervisory staff, spending more time with staff in supervisory activities such as case conferences and observations of service delivery, and improving the consistency of supervision. In one program, managers began providing monthly feedback on performance to individual home visitors. Another program made staff supervision more systematic and developed forms to facilitate feedback to home visitors after managers observed visits. Yet another implemented a new schedule for meetings and supervision sessions and refocused them on substantive issues (versus systems and process issues).

\section{Increasing Staff Salaries}

Several programs revised their salary scales in an effort to increase staff retention and attempt to establish pay equity. Two programs developed new scales based on years of experience and level of education, which in one of the programs dramatically increased the pay of Early Head Start teachers with degrees. Another program, which operated multiple sites, developed a new salary scale to make compensation equitable across sites and ensure that all staff received medical benefits. Another increased salaries for teachers and assistants to make them competitive with those of other child care professionals in the area.

\section{Seeking Additional Funding}

Some programs successfully sought additional grants to support their efforts to improve child care quality or enhance their services in other ways. For example, one program obtained state funds to expand the number of children it could serve and to hire additional staff members who provide intensive training and supervision to home visitors and implement continuous quality improvement activities. Another program recently received a state grant to develop 
formal partnerships with community child care providers to help them improve the quality of care they provide and work toward meeting the Head Start Program Performance Standards. Another strategy that some programs offering center-based care implemented for obtaining additional funds was to require families to apply for child care subsidies. The subsidies freed up Early Head Start funds for enhancing or expanding other services. Not only did additional funding increase program resources, it diversified programs' sources of funding and made them less dependent on a single funding source.

\section{PROGRAM EXPERIENCES INFLUENCING PATHWAYS}

Other aspects of the research programs' experiences, beyond the conscious strategies they adopted, also influenced their directions and pathways. These include their experiences prior to becoming Early Head Start programs.

\section{Conversion from Comprehensive Child Development Programs}

Some former Comprehensive Child Development Programs (CCDPs) had to shift the focus of program services from the family to the child. As CCDPs, some of the Early Head Start research programs emphasized family support and focused on supporting parents in their parenting role. In these programs, staff had substantial knowledge of community resources and experience in linking families with community services that address a broad range of parenting issues and barriers to self-sufficiency. As Early Head Start programs, they were expected to increase their focus on child development services and take responsibility for the quality of children's child care arrangements. In some programs, staff resisted this shift in emphasis, and program managers had to work with them over a period of time to get them to accept the changes. 
The former CCDP programs also had to regain confidence after disappointing CCDP evaluation results were released soon after they received Early Head Start funding. These results showed that the CCDP programs had no enduring impacts five years after families enrolled in the programs, although a pattern of positive impacts was found in one of the evaluation sites (St. Pierre, Layzer, Goodson, and Bernstein 1997).

\section{Addition of Early Head Start to Head Start Programs}

The Early Head Start grantees that operated Head Start programs brought experience with many components of the Head Start program—such as parent involvement activities, policy councils, and community and family partnerships-to the new program. To incorporate Early Head Start, these grantees had to shift their focus to include infants and toddlers. Staff who moved from Head Start to Early Head Start had to adjust to new responsibilities and new work schedules, and they needed to shift their focus to the special needs of infants and toddlers. When training for Early Head Start and Head Start staff was integrated, training activities needed to be reoriented to focus on infants and toddlers as well as preschool children.

Some Head Start programs had to learn to reallocate resources and promote effective communication among staff members to become a seamless 0 to 5 program. Adding Early Head Start to Head Start was not necessarily difficult, but when there were staffing or administrative problems within the Head Start program, and Early Head Start was perceived as competing for resources, tensions sometimes arose between staff members. Lack of communication between Early Head Start and Head Start staffs also presented difficulties in some programs.

\section{Community Programs Becoming Early Head Start Programs}

Some new grantees brought substantial experience in serving families with infants and toddlers to Early Head Start, but the programs did not have experience with Head Start 
requirements, such as one to establish a policy council. These programs had to become familiar with the Head Start Program Performance Standards and figure out how to meet them in the context of their agency and community. For example, one program that operated in a university setting had to reconcile university rules for program decision making with the Head Start requirement that the Policy Council make the decisions.

\section{E. CHANGES IN THE POLICY AND PROGRAM CONTEXT}

The dynamic nature of the early implementation of the Early Head Start research programs reflects in part their responses to a few key events and circumstances in their community, at the state level, and nationwide. These include revisions to the Head Start Program Performance Standards after programs were funded, welfare reform, changes in Medicaid programs, and changes in local child care markets.

\section{Revised Head Start Program Performance Standards}

The enactment of the revised Head Start Program Performance Standards required some programs to make changes in order to come into compliance. Sixteen of the research programs were funded in the first wave of Early Head Start programs (all were in the first two waves), before the revised Head Start Program Performance Standards went into effect. Thus, they were at the forefront in seeking clarification of the new performance standards, and their experiences and questions led to increased clarity in Head Start Bureau expectations.

\section{Welfare Reform}

Welfare reform was enacted in August 1996, shortly after the research programs were funded, and took effect a year later. It was accompanied by consolidation of child care funding streams and increased levels of child care funding. Many low-income parents are now required to work or participate in work-related activities. Time limits on cash assistance and the clear 
message that welfare recipients must work caused many parents enrolled in Early Head Start to give priority to looking for jobs and working, rather than to participating in program activities, including home visits. Increased participation in work and related activities also increased parents' needs for child care.

Welfare reform led some research programs to adjust their service delivery approaches and modify specific services to meet the changing needs of families struggling to meet the new welfare requirements. Some programs also built new partnerships with welfare agencies and other community organizations that worked with parents on welfare. In response to families' increased child care needs, some programs began working with eligible families to obtain child care subsidies or applying for direct grants from state child care subsidy funds.

\section{Changes in State Medicaid Programs}

Changes in Medicaid programs sometimes required programs to change their approaches to ensuring that children receive needed health care. The changes included shifts to managed care, which required families to select new health care providers and follow new procedures. One program initially formed a partnership with a local health care provider to deliver care for all program families without a medical home, but could not rely on that partnership for health care after the Medicaid program changed and many program families selected other health care providers for their Medicaid managed care. Programs often helped families obtain information and navigate the changes in the Medicaid program.

\section{Local Child Care Markets}

The availability and quality of child care for infants and toddlers in the community influenced the starting point of many programs in taking responsibility for ensuring that Early Head Start children who need it receive good-quality child care. In many of the research sites, 
program staff described the availability of child care for infants and toddlers in the community as insufficient and the quality of care as poor. Because good quality child care did not exist in the community, some programs did not have the option of referring families to it or of forming partnerships with providers to ensure that Early Head Start children received it. These programs had to consider ways to improve the quality of existing child care, such as providing training for child care providers, adding child care centers that could be models for good quality child care in the community, and working on quality improvements individually with providers that cared for Early Head Start children.

\section{F. SOURCES OF GUIDANCE RECEIVED BY EARLY HEAD START PROGRAMS}

The Early Head Start research programs learned the way to provide high-quality services with help from a number of sources, including:

- Lessons from Experience. Lessons from their own and others' experiences (such as those of Comprehensive Child Development Programs, Parent Child Centers, and other early intervention programs) helped the programs design and implement their Early Head Start programs.

- Revised Head Start Program Performance Standards. Even though the new standards did not become official until more than a year after most of the programs began serving families, they guided the programs in their development because they were available soon after programs were funded. Over time, the Head Start Bureau and technical-assistance providers clarified and explained the new performance standards.

- Training and Technical Assistance. The programs received varying amounts of help and guidance from the Head Start technical-assistance network, including Quality Improvement Center representatives, Disabilities Services Quality Improvement Center consultants, and infant-toddler consultants from the Early Head Start National Resource Center at ZERO TO THREE, as well as other sources of training and technical assistance to which the programs had access.

- Head Start Bureau Monitoring Visits. Feedback and guidance from their federal program officers helped programs find their way and sometimes led them to explore directions they may not have considered otherwise.

- Feedback from Continuous Program Improvement Partners. Interactions with and reports from continuous program improvement partners, often including the 
university-based local research partners, helped many programs reflect on the services they were providing, identify needed improvements, and garner support they needed to make changes. The nature and intensity of the program-research partnerships varied greatly. A few research teams had regular, active involvement with program staff, while others had little or no involvement with program staff beyond data collection. Most researchers were not involved in program activities.

- Program Self-Assessment. Many programs conducted regular and intensive self-assessments and used information from them to make changes.

- Participation in the National Research and Evaluation Project. Participation in the national evaluation and local research studies provided opportunities for directors of the research programs to meet and discuss implementation issues, and discussions with researchers provided opportunities for directors to reflect on their programs.

\section{G. CONCLUSIONS: MAJOR ACCOMPLISHMENTS AND REMAINING CHALLENGES}

The early implementation of the Early Head Start research programs has been dynamic. The programs' development and change were fast-paced, and not always in directions that were (or could have been) anticipated. Throughout their first four years, programs made significant progress, achieved noteworthy successes, and encountered important challenges.

\section{Noteworthy Accomplishments}

The programs achieved many important successes over the first several years of implementation. Looking back, several accomplishments stand out.

- Nearly three-quarters of the research programs became fully implemented. Twelve out of 17 research programs, according to our strictest measures, were fully implemented within four years of being funded. Most programs were able to reach full implementation within four years of their initial funding. About a third reached full implementation within the first year of serving families; another third became fully implemented within four years of initial funding. The others made considerable progress in a number of program areas but were not able to become fully implemented within the first four years.

- Implementation progress occurred even while program complexity increased and program emphases changed over time. Programs often altered their basic approaches to providing child development services to accommodate the changing needs of families. The changes in approaches usually entailed adding service options. Over time, programs offered a more complex set of options to families. 
Programs' theories of change evolved to increasing emphasis on expected outcomes in child development and parent-child relationships.

- The infrastructure to support Early Head Start grew alongside the programs. The revised Head Start Program Performance Standards took effect in January 1998, and the first monitoring visits by Head Start Bureau staff took place during spring 1998. During this period, the training and technical-assistance system was growing to accommodate the rapidly expanding number of Early Head Start programs. Even in the midst of these changes, however, the research programs often cited guidance received from Head Start Bureau monitors and training and technical-assistance providers as key to their growth and development.

- To a large extent, the programs delivered the required services. Overall, 91 percent of parents met at least a minimal criterion for being considered participants, and programs delivered child development and other services to them in centers, during home visits and case management meetings, and in group parenting activities. Services included child development services (including child care, assessments and screening, activities with children during home visits and group socializations), parenting education, and family development services (including case management, health services [mostly by referral], and transportation assistance [directly and by referral]). Furthermore, by 16 months after enrollment, most families had received the services that related to the needs they expressed at the time they enrolled.

- The programs succeeded in providing more intense child development services. Programs providing home visits increased the intensity of home visits, moving from two to three visits a month on average. Programs offering center-based services all increased to full-day, full-year services, if they had not been offering these services initially.

- The Early Head Start centers provided good-quality care to infants and toddlers, and many efforts were initiated to enhance quality in community child care programs that Early Head Start children attended. Between the fall 1997 and fall 1999 site visits, the ITERS scores consistently averaged 5.3 (in the good range). Several programs were rated as providing excellent care. All the programs received ITERS scores above 4, well into the minimal-to-good range. In contrast, only 31 percent of centers with infant/toddler classrooms received ITERS scores of 4 or above in the Cost, Quality and Outcomes Study (Cost, Quality and Outcomes Study Team 1995). Programs initiated many efforts to enhance quality in community child care centers attended by Early Head Start children.

- Attention to staff training, supervision, and support sustained high ratings of staff satisfaction and commitment. Over time, many programs have continued to refine their training and supervisory approaches, and several have adapted forms and created tools to support staff in providing consistent, high-quality services to families. The research programs have invested a lot in staff and succeeded in creating workplace environments that staff rated highly in the surveys they completed at the time of our site visits. During the fall 1999 site visits, staff noted how much they have learned and expressed confidence that they now have a much clearer idea of what they are trying to accomplish and how to go about it. 
- Early Head Start programs contributed to their communities. In a number of ways, maturing programs began making a difference for the larger communities in which they are located. For example, staff training increased the number of infant and toddler experts in their communities; when staff move to other organizations, their Early Head Start training and experience benefits the community; efforts to improve child care quality are an investment in the quality of child care for all children in the community; program efforts to help families obtain needed services lead to greater integration of services in the community; and efforts to establish degree programs in early childhood development at local colleges add community resources in early childhood.

- Community partnerships grew in number and effectiveness. Early Head Start programs have become better known and more accepted in their communities. Special Quest has played a key role in strengthening partnerships between Early Head Start programs and Part $\mathrm{C}$ providers. In addition, more programs have contracts or agreements with child care providers.

\section{Looking Ahead: Noteworthy Challenges}

Looking beyond the Early Head Start research programs' first four years of operation, several challenges remain:

- Continuing to adjust to changing family needs. During their first four years, the research programs adapted their services to family needs that changed as a result of welfare reform. They are likely to continue doing so. In many states, families are just beginning to reach time limits on cash assistance, and programs may face new challenges if they need to help families cope with the loss. If the economy weakens, it may become harder for families to meet the work requirements, and programs may need to do more to help them with their employment and child care needs.

- Finding effective strategies for engaging families in parenting education and group socializations. During their first four years, most of the research programs providing home-based services to some or all families were unable to achieve high participation rates in group socializations, even with efforts to vary schedules, create structured and relevant activities for the socializations, and provide incentives for participating. With only about half the parents in center-based programs participating in group parent education activities, programs that were exclusively or partially center-based continued to have difficulty engaging parents more fully in parent education classes and support groups.

- Increasing father involvement. In searching for effective approaches to involving parents in group socializations and parenting education, as well as in other program activities, the programs may also discover creative ways to involve fathers.

- Ensuring that children's child care arrangements meet the revised Head Start Program Performance Standards. As the Head Start Bureau clarified its expectation 
that Early Head Start programs are responsible for ensuring that the child care arrangements of Early Head Start children meet the performance standards, the research programs began responding in diverse ways. In many programs, this effort was starting to gain momentum in fall 1999. Some programs set out to provide center-based child development services and consistently provided child care that met the standards and received good quality ratings in the research. Other programs added center-based services to help meet the child care needs of some program families. One program also organized a network of Early Head Start family child care providers. Programs that had to rely on community child care settings to meet their families' child care needs developed a range of strategies for ensuring quality. However, most programs that were not center-based Early Head Start programs were not able to ensure quality child care for nearly all children who needed it and will be challenged to continue to increase the number of community child care partnerships to ensure quality child care.

- Balancing program needs and the needs of staff. Programs' staffing needs are likely to continue changing as programs evolve and services change, which will require programs to prepare staff for new responsibilities and sometimes to change their staff structure. In this context, programs also must meet the financial and other needs of a more professional workforce to minimize staff turnover, which can affect programs negatively.

The experience of the research programs shows that reaching full implementation quickly presents a significant challenge for some programs. Reaching full implementation takes time, and not all programs will be successful within the first three or four years of funding. All programs and the infrastructure that supports them need to work together toward the goal of reaching full implementation as quickly as possible.

\section{Summary}

The first four years of Early Head Start saw fledgling programs accept the challenges of extending the Head Start concept to low-income pregnant women and families with infants and toddlers. By the end of this period, 17 research programs, representing diverse approaches to delivering comprehensive Early Head Start services, were effectively implementing significant portions of the performance standards, while almost two-thirds of them achieved "full implementation." The pathways that programs followed to achieving implementation and 
quality of services included evolving program approaches characterized by adaptation to changing needs and circumstances in the many ways described in this report. This dynamic process meant increasing focus, complexity, and intensity, in working both with families and within the programs' communities. At the conclusion of the evaluation, the programs have accomplished much, but they continue to face significant challenges. The opportunities these challenges create provide the promise of continued growth and improvement for Early Head Start programs. 


\section{REFERENCES}

Administration for Children and Families. Making a Difference in the Lives of Infants and Toddlers and Their Families: The Impacts of Early Head Start. Washington, DC: DHHS, June 2002.

Administration on Children, Youth and Families. Building Their Futures: How Early Head Start Programs Are Enhancing the Lives of Infants and Toddlers in Low-Income Families. Washington, DC: DHHS, June 2001.

Administration on Children, Youth and Families. Leading the Way: Characteristics and Early Experiences of Selected First-Wave Early Head Start Programs. Volume III: Program Implementation. Washington, DC: DHHS, 2000a.

Administration on Children, Youth and Families. Leading the Way: Characteristics and Early Experiences of Selected First-Wave Early Head Start Programs. Executive Summary. Washington, DC: DHHS, 2000b.

Administration on Children, Youth and Families. Leading the Way: Characteristics and Early Experiences of Selected First-Wave Early Head Start Programs. Volume I: Cross-Site Perspectives. Washington, DC: DHHS, 1999a.

Administration on Children, Youth and Families. Leading the Way: Characteristics and Early Experiences of Selected First-Wave Early Head Start Programs. Volume II: Program Profiles. Washington, DC: DHHS, 1999b.

Administration on Children, Youth, and Families. Head Start Program Performance Measures: Second Progress Report. Washington, DC: DHHS, June 1998.

Birckmayer, Johanna D., and Carol H. Weiss. "Theory-Based Evaluation in Practice: What Do We Learn?" Evaluation Review, vol. 24, no. 4, 2000.

Blank, Helen, Andrea Behr, and Karen Schulman. State Developments in Child Care, Early Education, and School-Are Care 2000. Washington, DC: Children's Defense Fund, March 2001.

Carnegie Corporation of New York. Starting Points: Meeting the Needs of Our Youngest Children. New York: Carnegie Corporation of New York, 1994.

Connell, James P., and Anne C. Kubish. "Applying a Theory of Change Approach to the Evaluation of Comprehensive Community Initiatives: Progress, Prospects, and Problems." In New Approaches to Evaluating Community Initiatives: Volume 2, Theory, Measurement, and Analysis, edited by Karen Fulbright-Anderson, Anne C. Kubish, and James P. Connell. Washington, DC: Aspen Institute, 1998. 
Cost, Quality, and Child Outcomes Study Team. Cost, Quality, and Child Outcomes in Child Care Centers; Public Report. Denver: University of Colorado at Denver, January 1995.

Ferrar, Heidi M. Places for Growing: How to Improve Your Child Care Center. Princeton, NJ: Mathematica Policy Research, Inc., 1996.

Ferrar, Heidi M., Thelma Harms, and Debby Cryer. Places for Growing: How to Improve Your Family Child Care Home. Princeton, NJ: Mathematica Policy Research, Inc., 1996.

Gomby, Deanna S., P.L. Culross, and R.E. Behrman. "Home Visiting: Recent Program Evaluations-Analysis and Recommendations." The Future of Children, vol. 9, no. 1, spring/summer 1999, pp. 4-26.

Harms, T., and R. Clifford. Family Day Care Rating Scale. New York: Teachers College Press, 1989.

Harms, T., D. Cryer, and R. Clifford. Infant-Toddler Environment Rating Scale. New York: Teachers College Press, 1990.

Kisker, Ellen Eliason, Sandra L. Hofferth, Deborah A. Phillips, and Elizabeth Farquhar. A Profile of Child Care Settings: Early Education and Care in 1990. Washington, DC: U.S. Department of Education, 1991.

Layzer, Jean I., Barbara D. Goodson, and Marc Moss. Observational Study of Early Childhood Programs, Final Report Volume 1: Life in Preschool. Washington, DC: U.S. Department of Education, 1993.

Love, John M., Peter Z. Schochet, and Alicia L. Meckstroth. "Are They in Any Real Danger? What Child Care Research Does-and Doesn't_-Tell Us About Child Care Quality and Children's Well-Being."

Mitchell, Anne. Prekindergarten Programs in the States: Trends and Issues. Climax, NY: Early Childhood Policy Research, October 18, 2000.

Olds, David L., Charles R. Henderson, Jr., Harriet Kitzman, John Eckenrode, Robert Cole, and Robert Tatelbaum. "The Promise of Home Visitation: Results of Two Randomized Trials." Journal of Community Psychology, vol. 26, no. 1, January 1998, pp. 5-21.

Phillips, Deborah A., and Carollee Howes. "Indicators of Quality in Child Care: Review of Research." In Quality in Child Care: What Does Research Tell Us? edited by Deborah A. Phillips. Washington, DC: National Association for the Education of Young Children, 1987.

Raikes, H., K. Boller, W. van Kammen, J. Summers, A. Raikes, D. Laible, B. Wilcox, L. Ontai, and L. Christensen. "Father Involvement in Early Head Start Programs: A Practitioners Study." Lincoln, NE, and Princeton, NJ: The Gallup Organization, University of NebraskaLincoln, and Mathematica Policy Research, August 2002. 
Shonkoff, Jack and Deborah Phillips. From Neurons to Neighborhoods: The Science of Early childhood Development. Washington, DC: National Academy Press, 2000.

St. Pierre, R.G., J.I. Layzer, B.D. Goodson, and L. Bernstein. National Impact Evaluation of the Comprehensive Child Development Program: Final Report. Cambridge, MA: Abt Associates, Inc., 1997.

U.S. Department of Health and Human Services, Administration for Children and Families. "Head Start Program: Final Rule." Federal Register, vol. 61, no. 215, November 5, 1996.

U.S. Department of Health and Human Services, Administration for Children and Families. "Early Head Start Program Grant Availability: Notice." Federal Register, vol. 60, no. 52, March 17, 1995, pp. 14,548-14,578.

U.S. Department of Health and Human Services. The Statement of the Advisory Committee on Services for Families with Infants and Toddlers. Washington, DC: U.S. Government Printing Office, September 1994b.

U.S. Department of Health and Human Services. Head Start Act (As Amended May 18, 1994). Washington, DC: Government Printing Office, 1994a.

U.S. Department of Health and Human Services. Creating a 21st Century Head Start: Final Report of the Advisory Committee on Head Start Quality and Expansion. Washington, DC: U.S. Government Printing Office, December 1993.

Weiss, Carol H. "Nothing as Practical as a Good Theory: Exploring Theory-Based Evaluation for Comprehensive Community Initiatives for Children and Families." In New Approaches to Evaluating Community Initiatives: Concepts, Methods, and Contexts, edited by J.P. Connell, A.C. Kubisch, L.B. Schorr, and C.H. Weiss. Washington, DC: The Aspen Institute, 1995. 



\section{APPENDIX A}

1999 CHECKLISTS 



\section{INDICATORS OF FULL IMPLEMENTATION FOR EHS PROGRAMS}

Program:

Date of Site Visit:

\begin{tabular}{|c|c|c|}
\hline Dimension & Specific Indicators & Data Sources \\
\hline \multicolumn{3}{|c|}{ CHILD DEVELOPMENT CORNERSTONE } \\
\hline $\begin{array}{l}\text { Frequency of child } \\
\text { development services: } \\
\text { services for children }\end{array}$ & $\begin{array}{l}\text { Enrolled children receive child development services through the following modes of service delivery: } \\
\text { Center-based child care/child development services provided directly by the EHS program } \\
\text { Average hours per week } \\
\text { _ Proportion of enrolled children who receive this service } \\
\text { Other developmentally appropriate child care } \\
\text { _ Pverage hours per week } \\
\text { - Poportion of enrolled children who receive this service } \\
\text { _ Average number of child development home visits completed per month } \\
\text { - Percentage of enrolled children who received any child development services within the past month } \\
\text { SOURCES OF ESTIMATES: } \\
\text { DESCRIPTION OF MAIN CHILD DEVELOPMENT SERVICES: }\end{array}$ & 20,26 \\
\hline $\begin{array}{l}\text { Frequency of child } \\
\text { development services: } \\
\text { services for parents }\end{array}$ & $\begin{array}{l}\text { Of those parents who have been enrolled in the program for at least one month, percentage who have received any parent } \\
\text { education services within the past month } \\
\text { SOURCE OF ESTIMATE: } \\
\text { DESCRIPTION OF PARENT EDUCATION SERVICES: }\end{array}$ & 20,23 \\
\hline
\end{tabular}




\begin{tabular}{|c|c|c|}
\hline Dimension & Specific Indicators & Data Sources \\
\hline $\begin{array}{l}\text { Developmental } \\
\text { assessments }\end{array}$ & $\begin{array}{l}\text { Program provides age-appropriate developmental assessments } \\
\text { Name of instrument(s): } \\
\text { Schedule for conducting assessments: } \\
\text { — Percentage of children who have received age-appropriate developmental screenings in the past year } \\
\text { — Program staff use assessment results to plan child development services. } \\
\text { SOURCES OF ESTIMATES: } \\
\text { DESCRIPTION OF HOW SERVICES ARE PLANNED USING ASSESSMENT RESULTS: }\end{array}$ & $76-78$ \\
\hline $\begin{array}{l}\text { Follow up on services } \\
\text { for children with } \\
\text { disabilities }\end{array}$ & $\begin{array}{l}\text { — Percentage of children with a suspected or diagnosed disability } \\
\text { Percentage of children with a suspected or diagnosed disability who have been referred to PartC (IF LESS THAN } 100 \\
\text { PERCENT, RECORD THE REASON.) } \\
\text { — Program makes vigorous efforts to recruit children with disabilities. } \\
\text { Program coordinates with the Part C provider to: } \\
\text { - Develop joint individualized family service plans } \\
\text { - Coordinate services that families receive } \\
\text { Ensure follow up on referrals is done quickly. } \\
\text { Average length of time between Part C referral and assessment/service delivery: } \\
\text { SOURCES OF ESTIMATES: } \\
\text { DESCRIPTION RECRUITMENT ACTIVITIES AND COORDINATION WITH PART C : }\end{array}$ & $82-90$ \\
\hline
\end{tabular}




\begin{tabular}{|c|c|c|}
\hline Dimension & Specific Indicators & Data Sources \\
\hline Health services & $\begin{array}{l}\text { The program: } \\
\text { - Provides comprehensive health care directly; and/or } \\
\text { - Refers children to local health care providers and case managers monitor service delivery } \\
\text { - } \\
\text { Collaborates with health care providers and parents to track well child care, immunizations, and treatment plans } \\
\text { Ensures all children have access to dental care } \\
\text { Ensures all children have access to mental health counseling } \\
\text { Ensures that children receive needed follow up services without delay. } \\
\text { Percentage of children who: } \\
\text { - Have a medical home } \\
\text { - Have up-to-date immunizations } \\
\text { - Have had a well-child exam in the past year } \\
\text { SOURCES OF ESTIMATES: }\end{array}$ & $68-75$ \\
\hline $\begin{array}{l}\text { Child care: placement } \\
\text { and referral }\end{array}$ & $\begin{array}{l}\text { Number of program families who: } \\
\text { — } \quad \text { Need child care } \\
\text { Are receiving child care services } \\
\text { — Program provides child care directly. Number of children served: } \\
\text { - } \quad \text { Program refers families to other child care providers. Number of children served: _ } \\
\text { Program helps families find quality child care providers. } \\
\text { - Program helps families apply for child care subsidies. } \\
\text { SOURCES OF ESTIMATES: }\end{array}$ & $\begin{array}{l}\text { 28-31, 33-34 } \\
\text { Parent guide-8 }\end{array}$ \\
\hline
\end{tabular}




\begin{tabular}{|c|c|c|}
\hline Dimension & Specific Indicators & Data Sources \\
\hline $\begin{array}{l}\text { Child care: monitoring } \\
\text { and training }\end{array}$ & $\begin{array}{l}\text { The program: } \\
\text { - Assesses the quality of child care settings to which it refers children to ensure that the setting meets HS performance standards. } \\
\text { Name of assessment tool: } \\
\text { Monitors the quality child care arrangements used by EHS children on a regular basis to ensure that the settings meet HS } \\
\text { performance standards. } \\
\text { Frequency of monitoring: } \\
\text { Provides training and support to the child care providers used by EHS families to improve the quality of child care that EHS } \\
\text { children receive } \\
\text { DESCRIBE THE CHILD CARE ASSESSMENT, MONITORING, AND TRAINING/SUPPORT ACTIVITIES CARRIED OUT BY } \\
\text { THE PROGRAM: }\end{array}$ & $\begin{array}{l}36-38,56,60,66 \\
\text { Parent guide- } 8\end{array}$ \\
\hline $\begin{array}{l}\text { Parent involvement in } \\
\text { child development } \\
\text { services }\end{array}$ & $\begin{array}{l}\text { The program: } \\
\text { - Involves parents in planning child development services } \\
\text { - Involves parents in planning parent education services } \\
\text { Involves parents in planning child development home visits } \\
\text { - Proportion of families in which at least one parent participates in planning and/or delivery of child development services. } \\
\text { Of those families with a father/father figure, proportion in which the father participate in planning and/or delivery of child } \\
\text { development services. } \\
\text { DESCRIPTION OF PARENT INVOLVEMENT IN CHILD DEVELOPMENT SERVICES: }\end{array}$ & $115,145-146$ \\
\hline
\end{tabular}




\begin{tabular}{|c|c|c|}
\hline Dimension & Specific Indicators & Data Sources \\
\hline $\begin{array}{l}\text { Individualization of } \\
\text { services }\end{array}$ & $\begin{array}{l}\text { Percentage of enrolled families: } \\
\text { — Whose primary language is not English } \\
\text { _ Who receive child development services in their primary language } \\
\text { The program: } \\
\text { — Provides child development services in a manner that respects families' cultural and ethnic traditions with regard to child rearing } \\
\text { practices } \\
\text { Provides child development services that are tailored to the circumstances and backgrounds of individual families and children } \\
\text { for_a few children with special needs, _ some children, _ most children, or _ almost all children } \\
\text { DESCRIPTION OF INDIVIDUALIZATION ACTIVITIES: }\end{array}$ & $6,93-95$ \\
\hline Group socializations & $\begin{array}{l}\text { The program provides group socialization activities at least two times a month for parents and children who receive child } \\
\text { development services primarily through home visits. } \\
\text { _ Proportion of families who regularly participate in group socialization activities } \\
\text { SOURCES OF ESTIMATES: } \\
\text { DESCRIPTION OF GROUP SOCIALIZATION ACTIVITIES: }\end{array}$ & $96-102$ \\
\hline
\end{tabular}




\begin{tabular}{|c|c|c|}
\hline Dimension & Specific Indicators & Data Sources \\
\hline \multicolumn{3}{|c|}{ FAMILY DEVELOPMENT CORNERSTONE } \\
\hline $\begin{array}{l}\text { Individualized family } \\
\text { partnership } \\
\text { agreements }\end{array}$ & $\begin{array}{l}\text { Program engages families in a process of developing individualized family partnership agreements that: } \\
\text { - Identify families' goals, strengths, and needed services } \\
\text { - Describe timetables and strategies for achieving goals } \\
\text { - Build upon plans developed by other programs } \\
\text { - Are developed jointly with other programs when appropriate } \\
\text { Are reviewed and updated regularly } \\
\text { Frequency of updates: } \\
\text { - Percentage of enrolled families for whom an individualized family partnership agreement has been developed } \\
\text { SOURCE OF ESTIMATE: } \\
\text { DESCRIPTION OF PLAN DEVELOPMENT PROCESS: }\end{array}$ & $\begin{array}{l}132-139, \text { staff } \\
\text { guide- } 4\end{array}$ \\
\hline $\begin{array}{l}\text { Availability of } \\
\text { services: service } \\
\text { provided directly and } \\
\text { through referral }\end{array}$ & $\begin{array}{l}\text { The program provides the following services directly or through referral to another agency. (INDICATE WHETHER EACH } \\
\text { SERVICES IS PROVIDED DIRECTLY (D), PROVIDED THROUGH REFERRAL (R), OR NOT PROVIDED (N). } \\
\text { - Case Management } \\
\text { - Parent support through peer support groups and other approaches } \\
\text { - Health care for parents and other family members (including contraception/family planning) } \\
\text { - Comprehensive prenatal and postpartum care } \\
\text { - Prenatal education and information about breastfeeding } \\
\text { - Mental health services for parents and other family members } \\
\text { - Information about mental health issues such as substance abuse, child abuse and neglect, and domestic violence } \\
\text { - Services to improve health behavior, such as smoking cessation classes and substance abuse prevention and treatment } \\
\text { Education and job training } \\
\text { - Employment services } \\
\text { - } \\
\text { Emergency assistance } \\
\text { Transportation to program services } \\
\text { Program systematically follows up with families and service providers to ensure that families receive the services they need. } \\
\text { DESCRIPTION OF SERVICE PROVISION AND FOLLOW UP: }\end{array}$ & $140-142$ \\
\hline
\end{tabular}




\begin{tabular}{|c|c|c|}
\hline Dimension & Specific Indicators & Data Sources \\
\hline $\begin{array}{l}\text { Availability of } \\
\text { services: monitoring } \\
\text { quality }\end{array}$ & $\begin{array}{l}\text { DESCRIBE THE PROGRAM'S PROCEDURES FOR MONITORING SERVICE QUALITY, INCLUDING FREQUENCY OF } \\
\text { MONITORING, AND MAKING IMPROVEMENTS WHEN PROBLEMS ARE IDENTIFIED. }\end{array}$ & 143 \\
\hline Receipt of services & $\begin{array}{l}\text { — Percentage of families who have had a meeting with their case manager in the past } 30 \text { days } \\
\text { DESCRIPTION CASE MANAGEMENT ACTIVITIES: }\end{array}$ & 20 \\
\hline Parent involvement & $\begin{array}{l}\text { - Number of staff members who are current or former EHS or HS parents } \\
\text { - Percentage of families in which at least one parent has volunteered for program activities in the past year } \\
\text { Of those families with a father/father figure, percentage of those with fathers who participate in planning or are otherwise } \\
\text { involved in program activities } \\
\text { SOURCES OF ESTIMATES: } \\
\text { DESCRIPTION OF OPPORTUNITIES FOR PARENTS TO BECOME INVOLVED AS DECISION-MAKERS, LEADERS, } \\
\text { VOLUNTEERS, AND STAFF MEMBERS: }\end{array}$ & $20,145-153$ \\
\hline \multicolumn{3}{|c|}{ STAFF DEVELOPMENT CORNERSTONE } \\
\hline Supervision & $\begin{array}{l}\text { DESCRIBE OF SUPERVISORY, MENTORING, AND OTHER STAFF SUPPORT ACTIVITIES DESIGNED TO SUSTAIN } \\
\text { MOTIVATION AND PREVENT BURNOUT. DESCRIBE THE PERFORMANCE REVIEW PROCESS AND THE FREQUENCY } \\
\text { OF REVIEWS. } \\
\text { _ Supervision and performance review activities include observation of staff delivering services. }\end{array}$ & $\begin{array}{l}\text { 198-204, staff } \\
\text { guide-18,21 }\end{array}$ \\
\hline Training & $\begin{array}{l}\text { Staff development plan and curriculum: } \\
\text { - Are based on an assessment of staff training needs } \\
\text { - Emphasize relationship building } \\
\text { - Employ techniques and opportunities for practice, feedback, and reflection } \\
\text { DESCRIPTION OF STAFF DEVELOPMENT ACTIVITIES: }\end{array}$ & $\begin{array}{l}\text { 190-197, staff guide } \\
23-24\end{array}$ \\
\hline
\end{tabular}




\begin{tabular}{|c|c|c|}
\hline Dimension & Specific Indicators & Data Sources \\
\hline Turnover & $\begin{array}{l}\text { Percentage of staff who have left the program during the past } 12 \text { months due to reasons other than program downsizing. } \\
\text { REASONS FOR STAFF TURNOVER: }\end{array}$ & 189 \\
\hline Compensation & $\begin{array}{l}\text { - In the program director's opinion, staff salaries and benefits for EHS staff positions are at or above the average level for similar } \\
\text { staff in other area programs. } \\
\text { Staff can access the following benefits: } \\
\text { - Tuition reimbursement } \\
\text { C Child care } \\
\text { Other "family friendly" benefits (DESCRIBE) } \\
\text { DESCRIPTION OF HOW STAFF SALARIES AND BENEFITS COMPARE TO SIMILAR POSITIONS IN THE AREA: }\end{array}$ & 205, Staff guide- 25 \\
\hline Morale & DESCRIBE STAFF MORALE. & Staff guide-15-16 \\
\hline \multicolumn{3}{|c|}{ COMMUNITY BUILDING CORNERSTONE } \\
\hline $\begin{array}{l}\text { Collaborative } \\
\text { relationships }\end{array}$ & $\begin{array}{l}\text { Estimated number of other community providers with which the program communicates regularly } \\
\text { Average frequency of communications with other community providers } \\
\text { — Program participates in a coordinating group of community service providers } \\
\text { Program has in place: } \\
\text { - Written collaborate agreements } \\
\text { SOURCES OF ESTIMATES: } \\
\text { DESCRIPTION OF COLLABORATION ACTIVITIES: }\end{array}$ & $158-160$ \\
\hline
\end{tabular}




\begin{tabular}{|c|c|c|}
\hline Dimension & Specific Indicators & Data Sources \\
\hline Advisory committees & $\begin{array}{l}\text { The program has established the following advisory committees: } \\
\text { — Health advisory committee } \\
\text { The health advisory committee: } \\
\text { Meets regularly } \\
\text { Frequency of meetings: } \\
\text { - Involves other community health services providers } \\
\text { - Discusses infant and toddler health issues } \\
\text { DESCRIPTION OF ADVISORY COMMITTEE ACTIVITIES: }\end{array}$ & $171-178$ \\
\hline Transition plans & $\begin{array}{l}\text { - Of those children who are within } 6 \text { months of their third birthday, percentage who have a transition plan in place } \\
\text { Parents are active participants in the transition planning process. } \\
\text { DESCRIPTION OF TRANSITION PLANNING: }\end{array}$ & $174-178$ \\
\hline \multicolumn{3}{|c|}{ MANAGEMENT SYSTEMS AND PROCEDURES } \\
\hline Policy council & $\begin{array}{l}\text { A parent policy council has been established and meets regularly } \\
\text { Frequency of meetings: } \\
\text { - The policy council is involved in making decisions about the EHS program. } \\
\text { DESCRIPTION OF POLICY COUNCIL ACTIVITIES: }\end{array}$ & $206-208$ \\
\hline
\end{tabular}




\begin{tabular}{|c|c|c|}
\hline Dimension & Specific Indicators & Data Sources \\
\hline $\begin{array}{l}\text { Communication } \\
\text { systems }\end{array}$ & $\begin{array}{l}\text { A system of regular communication exists: } \\
\text { - Among staff } \\
\text { - Between staff and parents } \\
\text { - Between the program and the grantee agency } \\
\text { Between the program and the policy council and other governing bodies } \\
\text { - The communication system facilitates two-way communication among staff, parents, the grantee agency, the policy council, and } \\
\text { others. } \\
\text { DESCRIPTION OF COMMUNICATION SYSTEMS: }\end{array}$ & 209-212 \\
\hline $\begin{array}{l}\text { Goals, objectives, and } \\
\text { plans }\end{array}$ & $\begin{array}{l}\text { The program has developed a set of goals and objectives for the EHS program. } \\
\text { - The program has developed written plans for implementing services in each program area. } \\
\text { Goals, objectives, and plans were developed through a collaborative planning process that included staff, parents, the policy } \\
\text { council, advisory councils, and other community members. } \\
\text { Date of most recent plan revision: } \\
\text { DESCRIPTION OF THE PROGRAM'S PROCESS FOR DEVELOPING GOALS, OBJECTIVES, AND PLANS: }\end{array}$ & $213-216$ \\
\hline Self-assessment & $\begin{array}{l}\text { The program has conducted an annual self-assessment within the past } 12 \text { months } \\
\text { Dare of most recent self-assessment: } \\
\text { Results of the self-assessment have been recorded in program records. } \\
\text { - The self-assessment process involved staff, parents, and community members. } \\
\text { - The results of the self-assessment have been used to make program improvements. } \\
\text { DESCRIPTION OF SELF-ASSESSMENT PROCESS AND RECOMMENDATIONS FOR PROGRAM IMPROVEMENTS: }\end{array}$ & $217-220$ \\
\hline
\end{tabular}




\begin{tabular}{|l|l|l|}
\hline Dimension & \multicolumn{1}{c|}{ Specific Indicators } \\
\hline $\begin{array}{l}\text { Community needs } \\
\text { assessment }\end{array}$ & $\begin{array}{l}\text { The program has conducted an in-depth assessment of community resources and needs within the past three years. } \\
\text { Staff, parents, the policy council, advisory committees, and other community members were involved in the community } \\
\text { assessment process. }\end{array}$ \\
$\begin{array}{l}\text { Date of most recent assessment: } \\
\text { DESCRIPTION OF COMMUNITY ASSESSMENT PROCESS: } \\
\text { Describe the community assessment process. }\end{array}$ & \\
\hline
\end{tabular}




\section{INDICATORS OF QUALITY FOR CHILD DEVELOPMENT HOME VISITS \\ Program: \\ Date of Site Visit:}

\begin{tabular}{|c|c|c|}
\hline Dimension & Specific Indicators & Data Sources \\
\hline Supervision & $\begin{array}{l}\text { Home visitors receive supervision that includes: } \\
\text { — } \\
\text { - } \quad \text { Teapport } \\
\text { Evaluation } \\
\text { - } \\
\text { Individual supervision } \\
\text { Frequency of individual supervision sessions: } \\
\text { Group supervision } \\
\text { Frequency of group supervision sessions: } \\
\text { In-field supervision } \\
\text { Frequency of in-field supervision: } \\
\text { Supervisor has a plan or schedule for regular in-field supervision. } \\
\text { - Home visitors report regular opportunities to discuss their experiences as home visitors with each other during staff meetings or } \\
\text { other group supervision activities. } \\
\text { DESCRIPTION OF HOME VISITOR SUPERVISION: }\end{array}$ & $123-124,203$ \\
\hline Training & 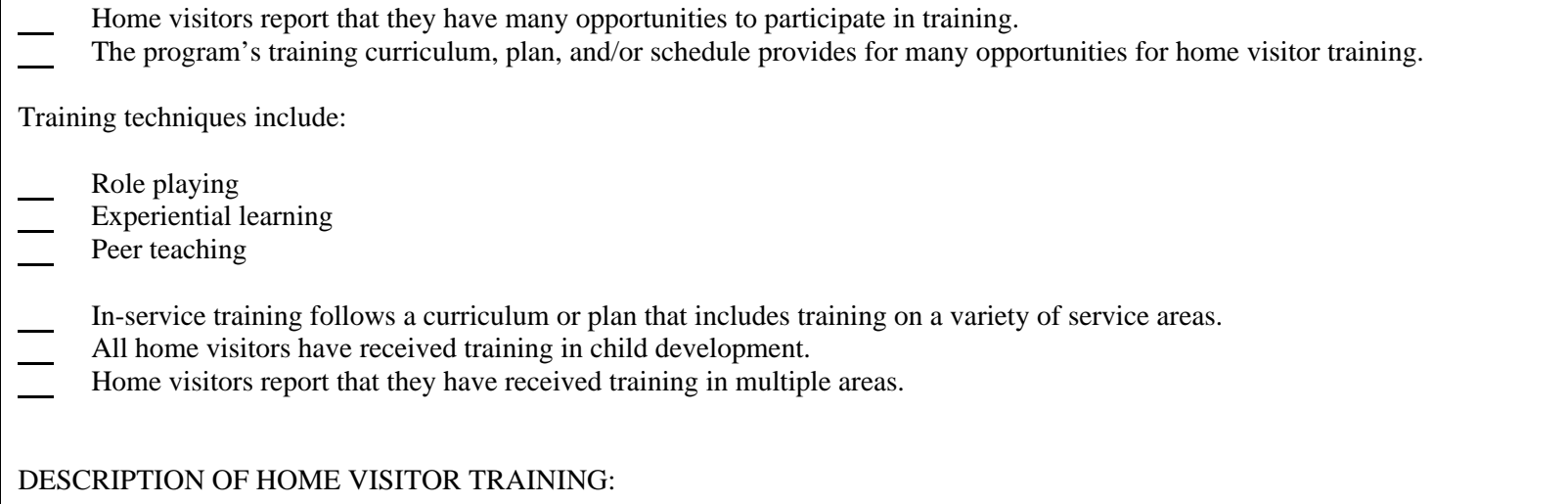 & $126-128$ \\
\hline
\end{tabular}




\begin{tabular}{|c|c|c|}
\hline $\begin{array}{l}\text { Home visitor hiring } \\
\text { and matching }\end{array}$ & $\begin{array}{l}\text { When hiring home visitors, the program has considered the following: } \\
\text { _ Specific program goals } \\
\text { The complexity of families' needs } \\
\text { - Roles and responsibilities of home visitors } \\
\text { Other (Describe.) } \\
\text { The program requires home visitors: } \\
\text { - To have strong interpersonal and communication skills } \\
\text { To be mature (based on previous relevant experience and age) } \\
\text { To respect the values and beliefs of people from diverse background and cultures and to be able to respond in an appropriate and } \\
\text { sensitive manner to people from a variety of backgrounds } \\
\text { The program matches home visitors with families according to home visitors' skills, families' needs, and the individual } \\
\text { characteristics of both home visitors and families. } \\
\text { Of those families whose first language is not English, percentage who are matched with a home visitor who speaks their language } \\
\text { or involves other staff who share the linguistic and cultural background of the families in the home visits } \\
\text { SOURCES OF ESTIMATES: } \\
\text { DESCRIPTION OF HOME VISITOR HIRING AND MATCHING WITH FAMILIES: }\end{array}$ & $119-122$ \\
\hline
\end{tabular}




\begin{tabular}{|c|c|c|}
\hline Planning home visits & $\begin{array}{l}\text { Home visits are planned based on: } \\
\text { _ Clear objectives and program goals } \\
\text { Expected outcomes } \\
\text { Home visitors develop plans for each visit using a curriculum or protocol that: } \\
\text { — Includes defined child development activities that take place during home visits } \\
\text { - Is responsive to the individual needs of families and children } \\
\text { Name of curriculum: } \\
\text { The program's home visiting curriculum and training materials: } \\
\text { - Encourage home visitors to build on the strengths of parents and children } \\
\text { - Encourage home visitors to work in partnership with parents to provide child development services } \\
\text { Emphasize the importance of building strong relationships with parents and children and the skills needed for relationship- } \\
\text { building. } \\
\text { Home visitors report that they are able to be flexible during home visits and modify planned activities when necessary to respond } \\
\text { to families' needs. } \\
\text { Parents report that: } \\
\text { They are satisfied with their home visitor } \\
\text { - They regularly participate in planning home visits } \\
\text { DESCRIPTION OF HOME VISIT PLANNING: }\end{array}$ & $\begin{array}{l}\text { 113-117, 126 Staff } \\
\text { guide-13-15, Parent } \\
\text { guide-13, } 17\end{array}$ \\
\hline
\end{tabular}




\begin{tabular}{|c|c|c|c|c|}
\hline $\begin{array}{l}\text { Frequency of home } \\
\text { visits and caseload } \\
\text { sizes }\end{array}$ & $\begin{array}{l}- \\
- \\
- \\
\text { SOL } \\
- \\
- \\
- \\
\text { SOL } \\
\text { DES }\end{array}$ & \multicolumn{2}{|c|}{$\begin{array}{l}\text { Average number of families per home visitor reported during site visit } \\
\text { Average number of hours per home visitor per week spent on home visiting } \\
\text { Average number of hours per home visitor per week spent on supervision/staff development activities } \\
\text { Average number of hours per home visitor per week spent on record keeping } \\
\text { JRCES OF ESTIMATES: } \\
\text { Home visitors report having adequate time for completing home visits and other duties. } \\
\text { Average number of completed child development home visits per family per year reported during site visit } \\
\text { Average number of completed child development home visits per family per month reported during site visit } \\
\text { Percentage of families who receive at least one child development home visit per month } \\
\text { JRCES OF ESTIMATES: }\end{array}$} & $\begin{array}{l}20,103,107-110, \\
\text { Staff guide- } 15-16\end{array}$ \\
\hline $\begin{array}{l}\text { Emphasis on child } \\
\text { development activities }\end{array}$ & \multicolumn{3}{|c|}{$\begin{array}{l}\text { Time devoted to child development and other activities in a typical child development home visit is appropriated as follows: } \\
\text { Percent of time spent directly with the child } \\
\text { Percent of time spent with the parent and child together } \\
\text { Percent of time spent directly with the parent for parenting education } \\
\text { Percent of time spent on family social services } \\
\text { Percent of time spent on other activities (describe other activities) } \\
\text { SOURCES OF ESTIMATES: } \\
\text { DESCRIPTION OF CHILD DEVELOPMENT ACTIVITIES CONDUCTED DURING HOME VISITS: }\end{array}$} & 118 \\
\hline $\begin{array}{l}\text { Addressing multiple } \\
\text { needs }\end{array}$ & - & $\begin{array}{l}\text { Home visitors provide comprehensive services that address } \\
\text { Home visitors perform some case management functions, co } \\
\text { providers to needed services that are not provided during the }\end{array}$ & $\begin{array}{l}\text { le family needs. } \\
\text { ting referrals to other program services or other service } \\
\text { visit. } \\
\text { NEEDS: }\end{array}$ & 104,113 \\
\hline
\end{tabular}





\section{APPENDIX B}

1999 RATING SCALES 



\section{EARLY HEAD START NATIONAL EVALUATION IMPLEMENTATION RATINGS--CHILD DEVELOPMENT CORNERSTONE}

\begin{tabular}{|c|c|c|c|c|c|}
\hline Dimension & 1 & 2 & 3 & 4 & 5 \\
\hline $\begin{array}{l}\text { Frequency of } \\
\text { child } \\
\text { development } \\
\text { services }\end{array}$ & $\begin{array}{l}\text { Little or no evidence that } \\
\text { families receive child } \\
\text { development and parent } \\
\text { education services on a regular } \\
\text { basis (at least monthly). }\end{array}$ & $\begin{array}{l}\text { Some families receive child } \\
\text { development services and } \\
\text { parent education on a regular } \\
\text { basis. }\end{array}$ & $\begin{array}{l}\text { Most families receive child } \\
\text { development services at least } \\
\text { two times per month and } \\
\text { parent education at least } \\
\text { monthly. }\end{array}$ & $\begin{array}{l}\text { Almost all families receive } \\
\text { child development services } \\
\text { at least three times per month } \\
\text { and parent education services } \\
\text { at least monthly. }\end{array}$ & $\begin{array}{l}\text { Almost all families receive } \\
\text { child development services } \\
\text { at least four times per month } \\
\text { and parent education services } \\
\text { at least monthly. }\end{array}$ \\
\hline $\begin{array}{l}\text { Developmental } \\
\text { assessments }\end{array}$ & $\begin{array}{l}\text { Little or no evidence that the } \\
\text { program conducts or arranges } \\
\text { for development assessments } \\
\text { for children. }\end{array}$ & $\begin{array}{l}\text { Program staff conduct or } \\
\text { arrange for developmental } \\
\text { assessments for some } \\
\text { children or assessments } \\
\text { occur only at program entry. }\end{array}$ & $\begin{array}{l}\text { Program staff conduct or } \\
\text { arrange for periodic } \\
\text { developmental assessment } \\
\text { for most children. }\end{array}$ & $\begin{array}{l}\text { Program staff conduct or } \\
\text { arrange for periodic } \\
\text { developmental assessments } \\
\text { for almost all children. } \\
\text { Program staff use the results } \\
\text { of these assessments to plan } \\
\text { child development services } \\
\text { for each child. }\end{array}$ & $\begin{array}{l}\text { Program staff conduct or } \\
\text { arrange for periodic } \\
\text { developmental assessments } \\
\text { for almost all children. All } \\
\text { program staff who work with } \\
\text { a child use the results of his } \\
\text { or her assessment to plan } \\
\text { child development services. }\end{array}$ \\
\hline $\begin{array}{l}\text { Follow-up } \\
\text { services for } \\
\text { children with } \\
\text { disabilities }\end{array}$ & $\begin{array}{l}\text { Little or no evidence of } \\
\text { coordination with Part } \mathrm{C} \\
\text { providers. Little or no evidence } \\
\text { of efforts to recruit children } \\
\text { with disabilities. }\end{array}$ & $\begin{array}{l}\text { The program makes some } \\
\text { effort to coordinate with Part } \\
\text { C providers. The program } \\
\text { makes some efforts to recruit } \\
\text { children with disabilities. }\end{array}$ & $\begin{array}{l}\text { When a disability is } \\
\text { suspected, program staff } \\
\text { refer the family to a Part C } \\
\text { provider. The program } \\
\text { makes somewhat vigorous } \\
\text { efforts to recruit children } \\
\text { with disabilities. Almost } 10 \\
\text { percent of enrolled families } \\
\text { have a child with an } \\
\text { identified disability. }\end{array}$ & $\begin{array}{l}\text { When a disability is } \\
\text { suspected, staff refer the } \\
\text { family to a Part C provider } \\
\text { and follow up is relatively } \\
\text { fast. Program staff work } \\
\text { closely with the Part C } \\
\text { provider to coordinate } \\
\text { services for the family. The } \\
\text { program makes vigorous } \\
\text { efforts to recruit children } \\
\text { with disabilities, or at least } \\
10 \text { percent of enrolled } \\
\text { families have a child with an } \\
\text { identified disability. }\end{array}$ & $\begin{array}{l}\text { When a disability is } \\
\text { suspected, staff refer the } \\
\text { family to a Part } C \text { provider } \\
\text { and work closely with the } \\
\text { provider to coordinate } \\
\text { services that the family } \\
\text { receives and to develop joint } \\
\text { service plans when } \\
\text { appropriate. Follow up on } \\
\text { referrals is relatively fast. } \\
\text { The program makes } \\
\text { vigorous efforts to recruit } \\
\text { children with disabilities, or } \\
\text { more than } 10 \text { percent of } \\
\text { enrolled families have a } \\
\text { child with an identified } \\
\text { disability. }\end{array}$ \\
\hline
\end{tabular}




\begin{tabular}{|c|l|l|l|l|l|}
\hline Dimension & \multicolumn{1}{|c|}{$\mathbf{1}$} & \multicolumn{1}{|c|}{$\mathbf{2}$} & \multicolumn{1}{|c|}{$\mathbf{3}$} & \multicolumn{1}{|c|}{$\mathbf{4}$} \\
\hline Health services & $\begin{array}{l}\text { Little or no evidence that the } \\
\text { program assists families in } \\
\text { accessing child health, dental, } \\
\text { and mental health services and } \\
\text { tracks well child visits, } \\
\text { immunizations, and treatment } \\
\text { plans. }\end{array}$ & $\begin{array}{l}\text { Program staff help some } \\
\text { families access child health, } \\
\text { dental, and mental health } \\
\text { services. }\end{array}$ & $\begin{array}{l}\text { Program staff ensure that all } \\
\text { families have a medical } \\
\text { home and have access to } \\
\text { health, dental, and mental } \\
\text { health services. }\end{array}$ & $\begin{array}{l}\text { Program staff ensure that all } \\
\text { families have a medical } \\
\text { home and have access to } \\
\text { health, dental, and mental } \\
\text { health services. The } \\
\text { program follows up to ensure } \\
\text { that children receive needed } \\
\text { services and immunizations. }\end{array}$ & $\begin{array}{l}\text { Program staff ensure that all } \\
\text { families have a medical } \\
\text { home and have access to } \\
\text { health, dental, and mental } \\
\text { health services. The } \\
\text { program follows up to ensure } \\
\text { that children receive needed } \\
\text { services without delay. The } \\
\text { program systematically } \\
\text { tracks well child visits, } \\
\text { immunizations, and } \\
\text { treatment plans for any } \\
\text { identified conditions or } \\
\text { illnesses. }\end{array}$ \\
\hline
\end{tabular}


Draft Implementation Ratings--Child Development Cornerstone (continued)

\begin{tabular}{|c|c|c|c|c|c|}
\hline Dimension & 1 & 2 & 3 & 4 & 5 \\
\hline Child care & $\begin{array}{l}\text { Little or no evidence that the } \\
\text { program assists families who } \\
\text { need child care in making child } \\
\text { care arrangements or the } \\
\text { program provides poor-quality } \\
\text { child care. }\end{array}$ & $\begin{array}{l}\text { The program provides some } \\
\text { assistance to families who } \\
\text { need child care by providing } \\
\text { some child care directly, } \\
\text { providing referrals to child } \\
\text { care providers, and/or } \\
\text { helping families apply for } \\
\text { child care subsidies or the } \\
\text { program provides minimal } \\
\text { quality child care. }\end{array}$ & $\begin{array}{l}\text { The program assists most } \\
\text { families who need child care } \\
\text { by providing child care } \\
\text { directly, providing referrals } \\
\text { to child care providers, } \\
\text { and/or helping families find } \\
\text { child care and apply for child } \\
\text { care subsidies. When the } \\
\text { program refers families to } \\
\text { other child care providers, } \\
\text { staff make an initial } \\
\text { assessment of quality or } \\
\text { monitor the quality of care } \\
\text { provided, but may not do } \\
\text { both. Or the program may } \\
\text { assess and monitor care for } \\
\text { some EHS children in child } \\
\text { care but not others. Or the } \\
\text { program provides a range of } \\
\text { quality of child care, } \\
\text { including some "low-good" } \\
\text { quality. If child care } \\
\text { subsidies are used, there are } \\
\text { attempts to prevent } \\
\text { interruptions in service. }\end{array}$ & $\begin{array}{l}\text { The program assists nearly } \\
\text { all families who need child } \\
\text { care by providing child care } \\
\text { directly, providing referrals } \\
\text { to child care centers and } \\
\text { family providers, and/or } \\
\text { helping families find child } \\
\text { care and apply for subsidies. } \\
\text { Program staff assess the } \\
\text { quality of child care before } \\
\text { making referrals and monitor } \\
\text { quality regularly to ensure } \\
\text { that all children receive to } \\
\text { quality child care that meets } \\
\text { Head Start Program } \\
\text { Performance Standards. If } \\
\text { child care subsidies are used, } \\
\text { there are no interruptions in } \\
\text { service. Most children are in } \\
\text { care that the program } \\
\text { assesses and monitors to } \\
\text { ensure care meets the Head } \\
\text { Start Program Performance } \\
\text { Standards. Or the program } \\
\text { provides good-quality child } \\
\text { care. }\end{array}$ & $\begin{array}{l}\text { The program assists all } \\
\text { families who need child care } \\
\text { by providing child care } \\
\text { directly, providing referrals } \\
\text { to child care centers and } \\
\text { family providers, and/or } \\
\text { helping families find child } \\
\text { care and apply for subsidies. } \\
\text { Program staff assess the } \\
\text { quality of child care before } \\
\text { making referrals and monitor } \\
\text { quality regularly to ensure } \\
\text { that all children receive } \\
\text { quality child care that meets } \\
\text { Head Start Program } \\
\text { Performance Standards. If } \\
\text { necessary, the program } \\
\text { provides child care providers } \\
\text { with the training and support } \\
\text { they need to improve the } \\
\text { quality of care that EHS } \\
\text { children receive, including } \\
\text { relative providers. Nearly all } \\
\text { children are in care that the } \\
\text { program assesses and } \\
\text { monitors to ensure care } \\
\text { meets the Head Start } \\
\text { Program Performance } \\
\text { Standards. Or the program } \\
\text { provides high-quality care. }\end{array}$ \\
\hline
\end{tabular}


Draft Implementation Ratings--Child Development Cornerstone (continued)

\begin{tabular}{|c|c|c|c|c|c|}
\hline Dimension & 1 & 2 & 3 & 4 & 5 \\
\hline $\begin{array}{l}\text { Parent } \\
\text { involvement in } \\
\text { child } \\
\text { development } \\
\text { services }\end{array}$ & $\begin{array}{l}\text { Little or no evidence that } \\
\text { program staff involve parents in } \\
\text { planning and delivering child } \\
\text { development services. }\end{array}$ & $\begin{array}{l}\text { Some parents are involved in } \\
\text { planning and carrying out } \\
\text { child development activities } \\
\text { in home visits and/or some } \\
\text { parents are involved in the } \\
\text { Policy Council or center } \\
\text { activities that relate to child } \\
\text { development. }\end{array}$ & $\begin{array}{l}\text { At least one parent in a } \\
\text { number of enrolled families } \\
\text { participates in planning and } \\
\text { delivering child development } \\
\text { services by planning home } \\
\text { visits, carrying out planning } \\
\text { activities through a center } \\
\text { committee related to child } \\
\text { development, or volunteering } \\
\text { in center classrooms. }\end{array}$ & $\begin{array}{l}\text { At least one parent in most } \\
\text { enrolled families participates } \\
\text { in carrying out child } \\
\text { development-related } \\
\text { planning activities and } \\
\text { delivering child development } \\
\text { services by planning home } \\
\text { visits, carrying out planning } \\
\text { activities through a center } \\
\text { committee, or volunteering } \\
\text { in center classrooms. Of } \\
\text { those families with a father } \\
\text { or father figure, some fathers } \\
\text { participate in planning or } \\
\text { delivering child development } \\
\text { services. }\end{array}$ & $\begin{array}{l}\text { At least one parent in almost } \\
\text { all enrolled families } \\
\text { participates in planning and } \\
\text { delivering child development } \\
\text { services by planning home } \\
\text { visits, carrying out planning } \\
\text { activities through a center } \\
\text { committee, or volunteering } \\
\text { in center classrooms. Of } \\
\text { those families with a father } \\
\text { or father figure, many fathers } \\
\text { participate in planning or } \\
\text { delivering child development } \\
\text { services. }\end{array}$ \\
\hline $\begin{array}{l}\text { Individualization } \\
\text { of services }\end{array}$ & $\begin{array}{l}\text { Little or no evidence that child } \\
\text { development services are } \\
\text { individualized according to the } \\
\text { unique circumstances, } \\
\text { background, and developmental } \\
\text { progress of each child and } \\
\text { family. }\end{array}$ & $\begin{array}{l}\text { Child development services } \\
\text { are individualized according } \\
\text { to the unique circumstances, } \\
\text { background, and } \\
\text { developmental progress of } \\
\text { the child and family, but } \\
\text { only for a few children with } \\
\text { special circumstances. }\end{array}$ & $\begin{array}{l}\text { Child development services } \\
\text { are individualized for some } \\
\text { children, according to the } \\
\text { unique circumstances, } \\
\text { background, and } \\
\text { developmental progress of } \\
\text { the child and family. }\end{array}$ & $\begin{array}{l}\text { Child development services } \\
\text { are individualized for most } \\
\text { children, according to the } \\
\text { unique circumstances, } \\
\text { background, and } \\
\text { developmental progress of } \\
\text { the child and family. }\end{array}$ & $\begin{array}{l}\text { Child development services } \\
\text { are individualized for almost } \\
\text { all children, according to the } \\
\text { unique circumstances, } \\
\text { background, and } \\
\text { developmental progress of } \\
\text { each child and family and are } \\
\text { provided in a linguistically } \\
\text { and culturally appropriate } \\
\text { manner. }\end{array}$ \\
\hline $\begin{array}{l}\text { Group } \\
\text { socializations }\end{array}$ & $\begin{array}{l}\text { Little or no evidence that the } \\
\text { program holds regular group } \\
\text { socialization activities for } \\
\text { families participating in home- } \\
\text { based services. }\end{array}$ & $\begin{array}{l}\text { The program holds group } \\
\text { socialization activities at } \\
\text { least two times per month for } \\
\text { families participating in } \\
\text { home-based services, but } \\
\text { few families participate on a } \\
\text { regular basis. }\end{array}$ & $\begin{array}{l}\text { The program holds group } \\
\text { socialization activities at } \\
\text { least two times per month for } \\
\text { families participating in } \\
\text { home-based services, and } \\
\text { some families participate on } \\
\text { a regular basis. }\end{array}$ & $\begin{array}{l}\text { The program holds group } \\
\text { socialization activities at } \\
\text { least two times per month for } \\
\text { families participating in } \\
\text { home-based services, and } \\
\text { most families participate on } \\
\text { a regular basis. }\end{array}$ & $\begin{array}{l}\text { The program holds group } \\
\text { socialization activities at } \\
\text { least two times per month for } \\
\text { families participating in } \\
\text { home-based services, and } \\
\text { almost all families } \\
\text { participate on a regular basis. }\end{array}$ \\
\hline
\end{tabular}




\section{EARLY HEAD START NATIONAL EVALUATION IMPLEMENTATION RATINGS--FAMILY DEVELOPMENT CORNERSTONE}

\begin{tabular}{|c|c|c|c|c|c|}
\hline Dimension & 1 & 2 & 3 & 4 & 5 \\
\hline $\begin{array}{l}\text { Individualized } \\
\text { family } \\
\text { partnership } \\
\text { agreements }\end{array}$ & $\begin{array}{l}\text { Little or no evidence that the } \\
\text { program systematically develops } \\
\text { individualized family } \\
\text { partnership agreements (IFPAs) } \\
\text { with families and provides } \\
\text { ongoing case management. }\end{array}$ & $\begin{array}{l}\text { The program has developed } \\
\text { IFPAs with some families } \\
\text { and provides some case } \\
\text { management to connect } \\
\text { families with the services } \\
\text { they need. }\end{array}$ & $\begin{array}{l}\text { The program has } \\
\text { developed IFPAs with } \\
\text { most families, and most } \\
\text { families meet with their } \\
\text { case manager at least } \\
\text { once a month. IFPAs } \\
\text { include goals, an } \\
\text { assessment of strengths } \\
\text { and needs, and } \\
\text { timetables and strategies } \\
\text { for achieving goals. }\end{array}$ & $\begin{array}{l}\text { The program has developed } \\
\text { IFPAs with almost all families, } \\
\text { and almost all families meet } \\
\text { with their case manager at least } \\
\text { once a month. IFPAs include } \\
\text { goals, an assessment of } \\
\text { strengths and needs, and } \\
\text { timetables and strategies for } \\
\text { achieving goals. Program staff } \\
\text { review IFPAs regularly with } \\
\text { families and update them as } \\
\text { needed. }\end{array}$ & $\begin{array}{l}\text { The program systematically } \\
\text { develops IFPAs with almost } \\
\text { all families that include } \\
\text { goals, an assessment of } \\
\text { strengths and needs, and } \\
\text { timetables and strategies for } \\
\text { achieving goals. Staff } \\
\text { systematically learn about } \\
\text { families' involvement in } \\
\text { other programs and build } \\
\text { upon these programs' plans } \\
\text { whenever possible. Staff } \\
\text { also conduct joint planning } \\
\text { with other service providers } \\
\text { when appropriate. All } \\
\text { IFPAs are reviewed and } \\
\text { updated regularly as needed. }\end{array}$ \\
\hline $\begin{array}{l}\text { Availability of } \\
\text { services }\end{array}$ & $\begin{array}{l}\text { Few family development } \\
\text { services are available from the } \\
\text { program or sought in the } \\
\text { community. }\end{array}$ & $\begin{array}{l}\text { Some family development } \\
\text { services are available from } \\
\text { the program or sought in the } \\
\text { community. }\end{array}$ & $\begin{array}{l}\text { The program either } \\
\text { provides services } \\
\text { directly, contracts with } \\
\text { other service providers, } \\
\text { or refers families to most } \\
\text { of the services they need. }\end{array}$ & $\begin{array}{l}\text { The program either provides } \\
\text { services directly, contracts with } \\
\text { other service providers, or } \\
\text { refers families to most of the } \\
\text { services they need. Staff } \\
\text { systematically follow up with } \\
\text { families and service providers } \\
\text { to ensure that families receive } \\
\text { the services they need. }\end{array}$ & $\begin{array}{l}\text { The program either provides } \\
\text { services directly, contracts } \\
\text { with other service providers, } \\
\text { or refers families to most of } \\
\text { the services they need. Staff } \\
\text { systematically follow up } \\
\text { with families and service } \\
\text { providers to ensure that } \\
\text { families receive the services } \\
\text { they need. Staff also assess } \\
\text { and monitor the quality of } \\
\text { services families receive and } \\
\text { work to make improvements } \\
\text { when problems are } \\
\text { identified. }\end{array}$ \\
\hline $\begin{array}{l}\text { Frequency of } \\
\text { regular family } \\
\text { development } \\
\text { services }\end{array}$ & $\begin{array}{l}\text { Few parents receive family } \\
\text { development services. }\end{array}$ & $\begin{array}{l}\text { Some parents receive family } \\
\text { development services. }\end{array}$ & $\begin{array}{l}\text { Most parents receive } \\
\text { family development } \\
\text { services. }\end{array}$ & $\begin{array}{l}\text { Most parents receive family } \\
\text { development services on a } \\
\text { regular basis. }\end{array}$ & $\begin{array}{l}\text { Almost all families receive } \\
\text { family development services } \\
\text { on a regular basis. }\end{array}$ \\
\hline
\end{tabular}


Draft Implementation Ratings--Family Development Cornerstone (continued)

\begin{tabular}{|c|c|c|c|c|c|}
\hline Dimension & 1 & 2 & 3 & 4 & 5 \\
\hline $\begin{array}{l}\text { Parent } \\
\text { involvement }\end{array}$ & $\begin{array}{l}\text { Few parents are involved in } \\
\text { planning or carrying out } \\
\text { program activities. }\end{array}$ & $\begin{array}{l}\text { Some parents are involved in } \\
\text { planning or carrying out } \\
\text { program activities, and the } \\
\text { program provides some } \\
\text { volunteer opportunities for } \\
\text { parents. }\end{array}$ & $\begin{array}{l}\text { The program encourages } \\
\text { families to become } \\
\text { involved in planning or } \\
\text { carrying out program } \\
\text { activities, and many } \\
\text { parents are involved in } \\
\text { some capacity. In } \\
\text { addition to participation } \\
\text { in policy groups, the } \\
\text { program provides a } \\
\text { variety of volunteer } \\
\text { opportunities for parents. } \\
\text { The program also makes } \\
\text { special efforts to involve } \\
\text { fathers. }\end{array}$ & $\begin{array}{l}\text { The program strongly } \\
\text { encourages families to become } \\
\text { involved in planning or } \\
\text { carrying out program activities } \\
\text { and provides multiple } \\
\text { opportunities for involvement } \\
\text { in policy groups and volunteer } \\
\text { opportunities. Most parents } \\
\text { are involved in the program in } \\
\text { some capacity. The program } \\
\text { also makes special efforts to } \\
\text { encourage father involvement. } \\
\text { Of the families with fathers or } \\
\text { father figures, some of the } \\
\text { fathers participate in planning } \\
\text { or are otherwise involved in } \\
\text { program activities. }\end{array}$ & $\begin{array}{l}\text { The program strongly } \\
\text { encourages families to } \\
\text { become involved in the } \\
\text { program as decision makers, } \\
\text { leaders, volunteers, and staff } \\
\text { members. The program } \\
\text { provides many opportunities } \\
\text { for involvement in planning } \\
\text { or carrying out program } \\
\text { activities and facilitates } \\
\text { families' participation in } \\
\text { meetings and other program } \\
\text { events. Almost all parents } \\
\text { are involved in the program } \\
\text { in some capacity. The } \\
\text { program also makes special } \\
\text { efforts to encourage father } \\
\text { involvement. Of the families } \\
\text { with fathers or father figures, } \\
\text { many of the fathers } \\
\text { participate in planning or are } \\
\text { otherwise involved in } \\
\text { program activities. }\end{array}$ \\
\hline
\end{tabular}




\section{EARLY HEAD START NATIONAL EVALUATION IMPLEMENTATION RATINGS--STAFF DEVELOPMENT CORNERSTONE}

\begin{tabular}{|c|c|c|c|c|c|}
\hline Dimension & 1 & 2 & 3 & 4 & 5 \\
\hline Supervision & $\begin{array}{l}\text { Staff receive minimal } \\
\text { supervision, support, and } \\
\text { feedback on their performance. }\end{array}$ & $\begin{array}{l}\text { Most staff receive some } \\
\text { supervision, support, and } \\
\text { feedback on their } \\
\text { performance. }\end{array}$ & $\begin{array}{l}\text { All staff receive some } \\
\text { supervision, support, and } \\
\text { feedback on their } \\
\text { performance. }\end{array}$ & $\begin{array}{l}\text { All staff receive regular } \\
\text { supervision, adequate support } \\
\text { to sustain motivation and } \\
\text { prevent burnout, and regular } \\
\text { feedback on their performance. }\end{array}$ & $\begin{array}{l}\text { All staff receive intensive } \\
\text { individual and group } \\
\text { supervision, support to } \\
\text { sustain motivation and } \\
\text { prevent burnout, and regular } \\
\text { feedback on their } \\
\text { performance that is based in } \\
\text { part on observation of } \\
\text { service delivery. }\end{array}$ \\
\hline Training & $\begin{array}{l}\text { Staff receive minimal training } \\
\text { from the program. }\end{array}$ & $\begin{array}{l}\text { Most staff have participated } \\
\text { in at least one training } \\
\text { session in the past year. }\end{array}$ & $\begin{array}{l}\text { All staff have received } \\
\text { training in the past year } \\
\text { that is based on an } \\
\text { assessment of their } \\
\text { training needs. }\end{array}$ & $\begin{array}{l}\text { All staff have received training } \\
\text { in multiple areas in the past } \\
\text { year. Training is provided } \\
\text { according to a training plan that } \\
\text { is based on an assessment of } \\
\text { staff training needs. }\end{array}$ & $\begin{array}{l}\text { All staff have received } \\
\text { training in multiple areas in } \\
\text { the past year. Training is } \\
\text { provided according to a } \\
\text { training plan that is based on } \\
\text { an assessment of training } \\
\text { needs. The program's } \\
\text { approach to training } \\
\text { emphasizes relationship } \\
\text { building and provides } \\
\text { opportunities for practice, } \\
\text { feedback, and reflection. }\end{array}$ \\
\hline Turnover & $\begin{array}{l}\text { Staff turnover is very high ( } 40 \\
\text { percent or more). }\end{array}$ & $\begin{array}{l}\text { Staff turnover is high ( } 30 \text { to } \\
\mathbf{3 9} \text { percent). }\end{array}$ & $\begin{array}{l}\text { Staff turnover is } \\
\text { moderate ( } 20 \text { to } 29 \\
\text { percent). }\end{array}$ & $\begin{array}{l}\text { Staff turnover is low (10 to } 19 \\
\text { percent). }\end{array}$ & $\begin{array}{l}\text { Staff turnover is very low } \\
\text { (less than } 10 \text { percent). }\end{array}$ \\
\hline Compensation & $\begin{array}{l}\text { Staff salaries and benefits are } \\
\text { very low. }\end{array}$ & $\begin{array}{l}\text { Staff salaries and benefits are } \\
\text { low. }\end{array}$ & $\begin{array}{l}\text { Staff salaries and } \\
\text { benefits are at the } \\
\text { average level for similar } \\
\text { staff in other programs. }\end{array}$ & $\begin{array}{l}\text { Staff salaries and benefits are } \\
\text { above the average level for } \\
\text { similar staff in other programs. }\end{array}$ & $\begin{array}{l}\text { Staff salaries and benefits are } \\
\text { above the average level for } \\
\text { similar staff in other } \\
\text { programs. Staff can access } \\
\text { enhanced benefits such as } \\
\text { tuition reimbursement, child } \\
\text { care, or other "family } \\
\text { friendly" benefits. }\end{array}$ \\
\hline
\end{tabular}


Draft Implementation Ratings--Staff Development Cornerstone (continued)

\begin{tabular}{|l|l|l|l|l|l|}
\hline Dimension & \multicolumn{1}{|c|}{$\mathbf{1}$} & \multicolumn{1}{|c|}{$\mathbf{3}$} & $\mathbf{4}$ & \multicolumn{1}{|c|}{$\mathbf{5}$} \\
\hline Morale & Staff morale is very low. & Staff morale is low. & Staff morale is average. & Staff morale is high. & Staff morale is very high. \\
\hline
\end{tabular}


EARLY HEAD START NATIONAL EVALUATION IMPLEMENTATION RATINGS--COMMUNITY BUILDING CORNERSTONE

\begin{tabular}{|c|c|c|c|c|c|}
\hline Dimension & 1 & 2 & 3 & 4 & 5 \\
\hline $\begin{array}{l}\text { Collaborative } \\
\text { relationships }\end{array}$ & $\begin{array}{l}\text { The program has established } \\
\text { few collaborative relationships } \\
\text { with other service providers. }\end{array}$ & $\begin{array}{l}\text { The program has established } \\
\text { some collaborative } \\
\text { relationships with other } \\
\text { service providers. }\end{array}$ & $\begin{array}{l}\text { The program has } \\
\text { established many } \\
\text { collaborative } \\
\text { relationships with other } \\
\text { service providers, and } \\
\text { some of them are } \\
\text { formalized through } \\
\text { written agreements. }\end{array}$ & $\begin{array}{l}\text { The program has established } \\
\text { many collaborative } \\
\text { relationships with other service } \\
\text { providers, and some of them } \\
\text { are formalized through written } \\
\text { agreements. Program staff } \\
\text { communicate regularly with } \\
\text { other service providers to } \\
\text { coordinate services for families. }\end{array}$ & $\begin{array}{l}\text { The program has established } \\
\text { many collaborative } \\
\text { relationships with other } \\
\text { service providers, and some } \\
\text { of them are formalized } \\
\text { through written agreements. } \\
\text { Program staff communicate } \\
\text { regularly with other service } \\
\text { providers to coordinate } \\
\text { services for families, and the } \\
\text { program participates in at } \\
\text { least one coordinating group } \\
\text { of community service } \\
\text { providers. }\end{array}$ \\
\hline $\begin{array}{l}\text { Advisory } \\
\text { committees }\end{array}$ & $\begin{array}{l}\text { The program has not established } \\
\text { a health advisory committee. }\end{array}$ & $\begin{array}{l}\text { The program has established } \\
\text { a health advisory committee, } \\
\text { but it does not meet regularly } \\
\text { or is a pre-existing advisory } \\
\text { committee that does not } \\
\text { focus on infants and toddlers. }\end{array}$ & $\begin{array}{l}\text { The program has } \\
\text { established a health } \\
\text { advisory committee } \\
\text { which meets } \\
\text { occasionally to discuss } \\
\text { infant and toddler issues. }\end{array}$ & $\begin{array}{l}\text { The program has established a } \\
\text { health advisory committee } \\
\text { which meets regularly, involves } \\
\text { other community health } \\
\text { services providers, and } \\
\text { discusses infant and toddler } \\
\text { health issues. }\end{array}$ & $\begin{array}{l}\text { The program has established } \\
\text { a health advisory committee } \\
\text { which meets regularly, } \\
\text { involves other community } \\
\text { health services providers, } \\
\text { and discusses infant and } \\
\text { toddler health issues. In } \\
\text { addition, the program has } \\
\text { established at least one other } \\
\text { special advisory committee } \\
\text { that focuses on infant and } \\
\text { toddler issues. }\end{array}$ \\
\hline
\end{tabular}


Draft Implementation Ratings--Community Building Cornerstone (continued)

\begin{tabular}{|c|c|c|c|c|c|}
\hline Dimension & 1 & 2 & 3 & 4 & 5 \\
\hline Transition plans & $\begin{array}{l}\text { The program has not established } \\
\text { procedures for facilitating the } \\
\text { transition from EHS to HS or } \\
\text { other preschool programs. }\end{array}$ & $\begin{array}{l}\text { The program has established } \\
\text { procedures for facilitating } \\
\text { the transition from EHS to } \\
\text { HS or other preschool } \\
\text { programs, but it has not } \\
\text { followed them (for any } \\
\text { children within } 6 \text { months of } \\
\text { their third birthday). }\end{array}$ & $\begin{array}{l}\text { Although the program } \\
\text { has established } \\
\text { procedures for transition } \\
\text { out of EHS and follows } \\
\text { them (for any children } \\
\text { within } 6 \text { months of their } \\
\text { third birthday), the } \\
\text { procedures only address } \\
\text { the transition from EHS } \\
\text { to HS and fail to address } \\
\text { the needs of families } \\
\text { who are not eligible for } \\
\text { HS. Or many children } \\
\text { have a transition plan in } \\
\text { place. }\end{array}$ & $\begin{array}{l}\text { The program has established } \\
\text { procedures for facilitating the } \\
\text { transition from EHS to HS or } \\
\text { other preschool programs. } \\
\text { Almost all children who are } \\
\text { within } 6 \text { months of their third } \\
\text { birthday have a transition plan } \\
\text { in place. }\end{array}$ & $\begin{array}{l}\text { The program has established } \\
\text { procedures for facilitating } \\
\text { the transition from EHS to } \\
\text { HS or other preschool } \\
\text { programs. All children who } \\
\text { are within } 6 \text { months of their } \\
\text { third birthday have a } \\
\text { transition plan in place. } \\
\text { Parents are active } \\
\text { participants in the transition } \\
\text { planning process. }\end{array}$ \\
\hline
\end{tabular}




\section{EARLY HEAD START NATIONAL EVALUATION IMPLEMENTATION RATINGS--MANAGEMENT SYSTEMS}

\begin{tabular}{|c|c|c|c|c|c|}
\hline Dimension & 1 & 2 & 3 & 4 & 5 \\
\hline Policy council & $\begin{array}{l}\text { Little or no evidence of a parent } \\
\text { policy council. }\end{array}$ & $\begin{array}{l}\text { A parent policy council has } \\
\text { been established, but it does } \\
\text { not meet regularly. }\end{array}$ & $\begin{array}{l}\text { A parent policy council } \\
\text { has been established and } \\
\text { meets regularly. }\end{array}$ & $\begin{array}{l}\text { A parent policy council has } \\
\text { been established, meets } \\
\text { regularly, and is involved in } \\
\text { making decisions about the } \\
\text { EHS program. }\end{array}$ & $\begin{array}{l}\text { A parent policy council has } \\
\text { been established, meets } \\
\text { regularly, and is actively } \\
\text { involved in making decisions } \\
\text { about many aspects of the } \\
\text { EHS program. }\end{array}$ \\
\hline $\begin{array}{l}\text { Communication } \\
\text { systems }\end{array}$ & $\begin{array}{l}\text { Little or no evidence of a regular } \\
\text { system of communication } \\
\text { among program staff. }\end{array}$ & $\begin{array}{l}\text { A regular system of } \\
\text { communication exists among } \\
\text { program staff. }\end{array}$ & $\begin{array}{l}\text { A regular system of } \\
\text { communication exists } \\
\text { among program staff and } \\
\text { between staff and } \\
\text { parents. }\end{array}$ & $\begin{array}{l}\text { A regular system of } \\
\text { communication exists among } \\
\text { program staff, between staff } \\
\text { and parents, with the grantee } \\
\text { agency, and with the policy } \\
\text { council and other governing } \\
\text { bodies. }\end{array}$ & $\begin{array}{l}\text { A regular system of } t w o- \\
\text { way communication exists } \\
\text { among program staff, } \\
\text { between staff and parents, } \\
\text { with the grantee agency, and } \\
\text { with the policy council and } \\
\text { other governing bodies. }\end{array}$ \\
\hline $\begin{array}{l}\text { Goals, objectives, } \\
\text { and plans }\end{array}$ & $\begin{array}{l}\text { Little or no evidence that the } \\
\text { program has a plan for } \\
\text { developing written goals, } \\
\text { objectives, and plans for each } \\
\text { service area. }\end{array}$ & $\begin{array}{l}\text { The program has a plan for } \\
\text { developing written goals, } \\
\text { objectives, and plans for } \\
\text { each service area, but these } \\
\text { plans have only been } \\
\text { partially implemented. }\end{array}$ & $\begin{array}{l}\text { The program has } \\
\text { developed goals, } \\
\text { objectives, and plans for } \\
\text { each service area. } \\
\text { However, some of the } \\
\text { goals and plans need to } \\
\text { be updated. }\end{array}$ & $\begin{array}{l}\text { The program has developed } \\
\text { detailed goals, objectives, and } \\
\text { plans for each service area. } \\
\text { These goals and plans have } \\
\text { been updated in written form. }\end{array}$ & $\begin{array}{l}\text { The program has developed } \\
\text { written goals, objectives, and } \\
\text { plans for each service area. } \\
\text { All written goals and plans } \\
\text { are detailed, thorough, and } \\
\text { up-to-date, and were } \\
\text { developed in consultation } \\
\text { with the program's policy } \\
\text { council, advisory } \\
\text { committee(s), staff, parents, } \\
\text { and other community } \\
\text { members. }\end{array}$ \\
\hline
\end{tabular}


Draft Implementation Ratings--Management Systems and Procedures (continued)

\begin{tabular}{|c|c|c|c|c|c|}
\hline Dimension & 1 & 2 & 3 & 4 & 5 \\
\hline Self-assessment & $\begin{array}{l}\text { Little or no evidence that the } \\
\text { program has planned or } \\
\text { conducted an annual self- } \\
\text { assessment. }\end{array}$ & $\begin{array}{l}\text { The program has a plan for } \\
\text { conducting an annual self- } \\
\text { assessment, but it has not } \\
\text { taken significant steps } \\
\text { towards implementing the } \\
\text { plan. }\end{array}$ & $\begin{array}{l}\text { The program has } \\
\text { conducted a self- } \\
\text { assessment in the past } 12 \\
\text { months, but the self- } \\
\text { assessment process needs } \\
\text { to be formalized and } \\
\text { documented in program } \\
\text { records. }\end{array}$ & $\begin{array}{l}\text { The program has conducted a } \\
\text { formal self-assessment in the } \\
\text { past } 12 \text { months. The results of } \\
\text { the assessment have been } \\
\text { documented in program } \\
\text { records. The program involved } \\
\text { a broad range of staff, parents, } \\
\text { and community members in the } \\
\text { self-assessment process. }\end{array}$ & $\begin{array}{l}\text { The program has conducted } \\
\text { a formal self-assessment in } \\
\text { the past } 12 \text { months. The } \\
\text { results of the assessment } \\
\text { have been documented in } \\
\text { program records. The } \\
\text { program involved a broad } \\
\text { range of staff, parents, and } \\
\text { community members in the } \\
\text { self-assessment process. The } \\
\text { results of the annual self- } \\
\text { assessment have been used to } \\
\text { make program } \\
\text { improvements. }\end{array}$ \\
\hline $\begin{array}{l}\text { Community needs } \\
\text { assessment }\end{array}$ & $\begin{array}{l}\text { Little or no evidence of a } \\
\text { community needs assessment. }\end{array}$ & $\begin{array}{l}\text { The program has a plan for } \\
\text { conducting a community } \\
\text { needs assessment. }\end{array}$ & $\begin{array}{l}\text { The program has } \\
\text { conducted an assessment } \\
\text { of community needs and } \\
\text { resources, but the } \\
\text { assessment was } \\
\text { conducted more than } \\
\text { three years ago. }\end{array}$ & $\begin{array}{l}\text { The program has conducted an } \\
\text { assessment of community needs } \\
\text { and resources. This assessment } \\
\text { has been updated in written } \\
\text { form in the past three years. }\end{array}$ & $\begin{array}{l}\text { The program has developed } \\
\text { an in-depth community needs } \\
\text { assessment in the past three } \\
\text { years. The program's policy } \\
\text { council, advisory } \\
\text { committee(s), staff, parents, } \\
\text { and other community } \\
\text { members were involved in } \\
\text { the assessment process. }\end{array}$ \\
\hline
\end{tabular}




\section{EARLY HEAD START NATIONAL EVALUATION \\ CHILD CARE QUALITY RATINGS}

\begin{tabular}{|c|c|c|c|c|c|}
\hline Dimension & 1 & 2 & 3 & 4 & 5 \\
\hline Curriculum & $\begin{array}{l}\text { Little or no evidence that the } \\
\text { program uses a curriculum in its } \\
\text { child care center. }\end{array}$ & $\begin{array}{l}\text { Program has a curriculum for } \\
\text { its child care center, but staff } \\
\text { do not use the curriculum } \\
\text { regularly for planning and } \\
\text { scheduling activities. }\end{array}$ & $\begin{array}{l}\text { The program uses a child } \\
\text { care curriculum regularly } \\
\text { for planning and } \\
\text { scheduling activities. }\end{array}$ & $\begin{array}{l}\text { Child care provider uses a } \\
\text { curriculum that is strongly } \\
\text { integrated into the center's } \\
\text { daily activities and is } \\
\text { appropriate for the population } \\
\text { served. }\end{array}$ & $\begin{array}{l}\text { Child care provider uses a } \\
\text { curriculum that is } \\
\text { individualized for each child. } \\
\text { If some children receive } \\
\text { home-based services and } \\
\text { child care provided directly } \\
\text { by the program, both } \\
\text { curricula are integrated. }\end{array}$ \\
\hline $\begin{array}{l}\text { Turnover of } \\
\text { direct care staff }\end{array}$ & $\begin{array}{l}\text { Turnover among direct care staff } \\
\text { is very high ( } \mathbf{4 0} \text { percent or } \\
\text { more). }\end{array}$ & $\begin{array}{l}\text { Turnover among direct care } \\
\text { staff is high ( } \mathbf{3 0} \text { to } 39 \\
\text { percent). }\end{array}$ & $\begin{array}{l}\text { Turnover among direct } \\
\text { care staff is moderate ( } 20 \\
\text { to } 29 \text { percent). }\end{array}$ & $\begin{array}{l}\text { Turnover among direct care } \\
\text { staff is low (10 to } 19 \text { percent). }\end{array}$ & $\begin{array}{l}\text { Turnover among direct care } \\
\text { staff is very low (less than } \\
\mathbf{1 0} \text { percent). }\end{array}$ \\
\hline $\begin{array}{l}\text { Assigning } \\
\text { primary } \\
\text { caregivers }\end{array}$ & $\begin{array}{l}\text { The program does not assign } \\
\text { primary caregivers. }\end{array}$ & $\begin{array}{l}\text { Program assigns primary } \\
\text { caregivers, but staff do not } \\
\text { adhere to their assignments } \\
\text { on a regular basis. }\end{array}$ & $\begin{array}{l}\text { Program assigns primary } \\
\text { caregivers, and staff } \\
\text { adhere to their } \\
\text { assignments during some } \\
\text { daily activities. }\end{array}$ & $\begin{array}{l}\text { Program assigns primary } \\
\text { caregivers, and staff adhere to } \\
\text { their assignments throughout } \\
\text { the day. Primary caregivers } \\
\text { conduct almost all routine care } \\
\text { activities (feeding, diapering, } \\
\text { nap time, etc.) for the children } \\
\text { in their group. }\end{array}$ & $\begin{array}{l}\text { Program assigns primary } \\
\text { caregivers, and staff adhere } \\
\text { to their assignments } \\
\text { throughout the day. Primary } \\
\text { caregivers conduct almost all } \\
\text { routine care activities } \\
\text { (feeding, diapering, nap } \\
\text { time, etc.) for the children in } \\
\text { their group. Primary } \\
\text { caregivers regularly } \\
\text { communicate with parents } \\
\text { and plan activities for the } \\
\text { children in their group. }\end{array}$ \\
\hline
\end{tabular}


Child Care Quality Ratings (continued)

\begin{tabular}{|c|c|c|c|c|c|}
\hline Dimension & 1 & 2 & 3 & 4 & 5 \\
\hline $\begin{array}{l}\text { Monitoring the } \\
\text { quality of child } \\
\text { care settings that } \\
\text { EHS children } \\
\text { attend. }\end{array}$ & $\begin{array}{l}\text { The program does not monitor } \\
\text { the quality of child care settings } \\
\text { that EHS children attend. If the } \\
\text { program provides on-site care, } \\
\text { there is little ongoing monitoring } \\
\text { of quality. }\end{array}$ & $\begin{array}{l}\text { The program assesses the } \\
\text { quality of child care settings } \\
\text { to which it refers children } \\
\text { and monitors quality in } \\
\text { settings that EHS children } \\
\text { attend at least annually, but } \\
\text { most of the children are } \\
\text { known to be in settings that } \\
\text { the program does not } \\
\text { monitor. If the program } \\
\text { provides on-site care, quality } \\
\text { is monitored at least } \\
\text { annually. }\end{array}$ & $\begin{array}{l}\text { The program may assess } \\
\text { the quality of child care } \\
\text { settings prior to referring } \\
\text { children but monitors } \\
\text { quality regularly for at } \\
\text { least half the children in } \\
\text { care. If the program } \\
\text { provides on-site care, } \\
\text { quality is assessed } \\
\text { regularly. }\end{array}$ & $\begin{array}{l}\text { The program assesses the } \\
\text { quality of child care settings } \\
\text { prior to referring children and } \\
\text { monitors child care quality } \\
\text { regularly for most children in } \\
\text { care, whether or not the } \\
\text { program placed children in } \\
\text { their child care settings. If the } \\
\text { program provides on-site care, } \\
\text { there is ongoing quality } \\
\text { assessment and feedback to } \\
\text { staff. }\end{array}$ & $\begin{array}{l}\text { The program uses } \\
\text { comprehensive measures } \\
\text { and/or procedures to assess } \\
\text { the quality of child care } \\
\text { settings prior to referring } \\
\text { children and to monitor } \\
\text { quality regularly for all } \\
\text { children in care, whether or } \\
\text { not the program placed } \\
\text { children in their child care } \\
\text { settings. If the program } \\
\text { provides on-site care, there is } \\
\text { ongoing quality assessment, } \\
\text { feedback to staff, and a } \\
\text { systematic approach to } \\
\text { quality improvement. }\end{array}$ \\
\hline $\begin{array}{l}\text { Training and } \\
\text { support for } \\
\text { providers in child } \\
\text { care settings that } \\
\text { EHS children } \\
\text { attend }\end{array}$ & $\begin{array}{l}\text { The program does not provide } \\
\text { training and support to child } \\
\text { care teachers and family } \\
\text { providers in settings that EHS } \\
\text { children attend. }\end{array}$ & $\begin{array}{l}\text { The program provides } \\
\text { newsletters or other } \\
\text { communications that address } \\
\text { child care quality issues } \\
\text { and/or has occasional } \\
\text { training for teachers and } \\
\text { family providers who } \\
\text { provide child care in settings } \\
\text { that EHS children attend. }\end{array}$ & $\begin{array}{l}\text { The program provides } \\
\text { some training for most } \\
\text { teachers and family } \\
\text { providers who care for } \\
\text { EHS children, or } \\
\text { provides a great deal of } \\
\text { training for some } \\
\text { teachers who care for } \\
\text { EHS children. }\end{array}$ & $\begin{array}{l}\text { The program provides regular } \\
\text { training to nearly all child care } \\
\text { teachers and family providers } \\
\text { who care for EHS children. If } \\
\text { children are in relative care, the } \\
\text { program provides support and } \\
\text { training to some of them as } \\
\text { well. }\end{array}$ & $\begin{array}{l}\text { The program provides in- } \\
\text { service training for nearly all } \\
\text { teachers and family } \\
\text { providers who care for EHS } \\
\text { children according to their } \\
\text { individual training needs, } \\
\text { and according to } \\
\text { individualized training plans. } \\
\text { If children are in relative } \\
\text { care, the program provides } \\
\text { support and training to some } \\
\text { of them as well. }\end{array}$ \\
\hline $\begin{array}{l}\text { Educational } \\
\text { attainment of } \\
\text { staff in EHS } \\
\text { centers }\end{array}$ & $\begin{array}{l}\text { If the program provides on-site } \\
\text { care, many teaching staff have } \\
\text { neither a CDA, associate's } \\
\text { degree, nor a bachelor's degree. }\end{array}$ & $\begin{array}{l}\text { If the program provides on- } \\
\text { site care, some teaching staff } \\
\text { have a CDA or are in CDA } \\
\text { training, an associate's } \\
\text { degree, or a bachelor's } \\
\text { degree. }\end{array}$ & $\begin{array}{l}\text { If the program provides } \\
\text { on-site care, most } \\
\text { teaching staff have a } \\
\text { CDA or are in CDA } \\
\text { training, an associate's } \\
\text { degree, or a bachelor's } \\
\text { degree. }\end{array}$ & $\begin{array}{l}\text { If the program provides on-site } \\
\text { care, almost all teaching staff } \\
\text { have a CDA or are in CDA } \\
\text { training, an associate's degree, } \\
\text { or a bachelor's degree. }\end{array}$ & $\begin{array}{l}\text { If the program provides on- } \\
\text { site care, all teaching staff } \\
\text { have a CDA or are in CDA } \\
\text { training, an associate's } \\
\text { degree, or a bachelor's } \\
\text { degree. }\end{array}$ \\
\hline
\end{tabular}


Child Care Quality Ratings (continued)

\begin{tabular}{|l|l|l|l|l|}
\hline Dimension & \multicolumn{1}{|c|}{$\mathbf{1}$} & \multicolumn{1}{|c|}{$\mathbf{3}$} & \multicolumn{1}{|c|}{$\mathbf{4}$} \\
\hline Accreditation & $\begin{array}{l}\text { No child care provided by the } \\
\text { program is accredited by } \\
\text { NAEYC or other accrediting } \\
\text { organization }\end{array}$ & $\begin{array}{l}\text { Program is exploring } \\
\text { accreditation by NAEYC or } \\
\text { another accrediting } \\
\text { organization for its child care }\end{array}$ & $\begin{array}{l}\text { Some child care } \\
\text { provided by the program } \\
\text { is accredited by NAEYC } \\
\text { or another accrediting } \\
\text { organization, or program } \\
\text { is in the accreditation } \\
\text { process }\end{array}$ & $\begin{array}{l}\text { Most child care provided by the } \\
\text { program is accredited by } \\
\text { organization }\end{array}$ \\
\hline
\end{tabular}


EARLY HEAD START NATIONAL EVALUATION

QUALITY OF CHILD DEVELOPMENT HOME VISITS

\begin{tabular}{|c|c|c|c|c|c|}
\hline Dimension & 1 & 2 & 3 & 4 & 5 \\
\hline Supervision & $\begin{array}{l}\text { Little or no evidence that } \\
\text { home visitors receive } \\
\text { adequate supervision. }\end{array}$ & $\begin{array}{l}\text { Home visitors receive some } \\
\text { supervision. However, } \\
\text { supervision does not provide } \\
\text { adequate support and } \\
\text { guidance. There is little } \\
\text { systematic supervision for } \\
\text { child development activities. }\end{array}$ & $\begin{array}{l}\text { Home visitors receive regular } \\
\text { supervision, but this } \\
\text { supervision does not include } \\
\text { adequate opportunities for } \\
\text { home visitors to receive } \\
\text { support and evaluation. Some } \\
\text { supervisory attention is paid to } \\
\text { child development } \\
\text { specifically. Supervisors may } \\
\text { not go on home visits. Home } \\
\text { visitors receive some } \\
\text { mentoring. }\end{array}$ & $\begin{array}{l}\text { Home visitors receive } \\
\text { regular individual and group } \\
\text { supervision that includes } \\
\text { support, teaching, and } \\
\text { evaluation. Some } \\
\text { supervisory attention is paid } \\
\text { to child development. The } \\
\text { supervisor goes on some } \\
\text { home visits. Home visit } \\
\text { frequency is carefully } \\
\text { tracked by the supervisor. } \\
\text { Home visitors receive } \\
\text { mentoring. }\end{array}$ & $\begin{array}{l}\text { Home visitors receive regular } \\
\text { individual and group } \\
\text { supervision that includes } \\
\text { support, teaching, and } \\
\text { evaluation. Group supervision } \\
\text { provides home visitors with } \\
\text { regular opportunities to discuss } \\
\text { their experiences with peers. } \\
\text { Particular attention is paid by } \\
\text { supervisors to monitoring child } \\
\text { development activities, and } \\
\text { supervisors have been on home } \\
\text { visits and have a regular plan } \\
\text { for accompanying home } \\
\text { visitors on home visits. Home } \\
\text { visit frequency is carefully } \\
\text { tracked by the supervisor. } \\
\text { Home visitors receive } \\
\text { mentoring. }\end{array}$ \\
\hline Training & $\begin{array}{l}\text { Home visitors receive little } \\
\text { training. }\end{array}$ & $\begin{array}{l}\text { Home visitors receive some } \\
\text { training. }\end{array}$ & $\begin{array}{l}\text { Home visitors receive some } \\
\text { training in several subject } \\
\text { areas. }\end{array}$ & $\begin{array}{l}\text { Home visitors have regular } \\
\text { opportunities to participate in } \\
\text { training. Home visitors have } \\
\text { received training in child } \\
\text { development. }\end{array}$ & $\begin{array}{l}\text { Home visitors have many } \\
\text { opportunities to participate in } \\
\text { training. Training techniques } \\
\text { include role playing, } \\
\text { experiential learning, and peer } \\
\text { teaching. Home visitors are } \\
\text { cross-trained in multiple areas, } \\
\text { including child development. }\end{array}$ \\
\hline
\end{tabular}


Child Development Home Visit Quality Ratings (continued)

\begin{tabular}{|c|c|c|c|c|c|}
\hline Dimension & 1 & 2 & 3 & 4 & 5 \\
\hline $\begin{array}{l}\text { Home visitor } \\
\text { hiring and } \\
\text { matching }\end{array}$ & $\begin{array}{l}\text { Little or no evidence that the } \\
\text { program considered program } \\
\text { goals, needs and } \\
\text { characteristics of parents and } \\
\text { children, and home visitors' } \\
\text { roles when hiring home } \\
\text { visitors. }\end{array}$ & $\begin{array}{l}\text { Some evidence that the } \\
\text { program considered program } \\
\text { goals, needs and } \\
\text { characteristics of parents and } \\
\text { children, and home visitors' } \\
\text { roles when hiring home } \\
\text { visitors. }\end{array}$ & $\begin{array}{l}\text { The program has considered } \\
\text { program goals, needs and } \\
\text { characteristics of parents and } \\
\text { children, and home visitors' } \\
\text { roles when hiring home } \\
\text { visitors. The program seeks to } \\
\text { hire home visitors who are } \\
\text { mature and have strong } \\
\text { interpersonal skills. }\end{array}$ & $\begin{array}{l}\text { The program has considered } \\
\text { program goals, needs and } \\
\text { characteristics of parents and } \\
\text { children, and home visitors' } \\
\text { roles when hiring home } \\
\text { visitors. The program seeks } \\
\text { to hire home visitors who are } \\
\text { mature, have strong } \\
\text { interpersonal skills, value } \\
\text { diversity, and are able to } \\
\text { respond appropriately to } \\
\text { parents and children from a } \\
\text { variety of backgrounds. }\end{array}$ & $\begin{array}{l}\text { The program has considered } \\
\text { program goals, needs and } \\
\text { characteristics of parents and } \\
\text { children, and home visitors' } \\
\text { roles when hiring home } \\
\text { visitors. The program seeks to } \\
\text { hire home visitors who are } \\
\text { mature, have strong } \\
\text { interpersonal skills, value } \\
\text { diversity, are flexible, want to } \\
\text { learn, and are able to respond } \\
\text { appropriately to parent and } \\
\text { children from a variety of } \\
\text { backgrounds. The program } \\
\text { attempts to match parents and } \\
\text { children with home visitors } \\
\text { who share the same linguistic } \\
\text { and cultural background and } \\
\text { who can best respond to the } \\
\text { individual needs and situations } \\
\text { of parents and children. }\end{array}$ \\
\hline $\begin{array}{l}\text { Retention of } \\
\text { home visitors }\end{array}$ & $\begin{array}{l}\text { Turnover among home } \\
\text { visitors is very high (40 } \\
\text { percent or more). }\end{array}$ & $\begin{array}{l}\text { Turnover among home } \\
\text { visitors is high ( } \mathbf{3 0} \text { to } 39 \\
\text { percent). }\end{array}$ & $\begin{array}{l}\text { Turnover among home } \\
\text { visitors is moderate (20 to } 29 \\
\text { percent). }\end{array}$ & $\begin{array}{l}\text { Turnover among home } \\
\text { visitors is low (10 to } 19 \\
\text { percent). }\end{array}$ & $\begin{array}{l}\text { Turnover among home visitors } \\
\text { is very low less than } 10 \\
\text { percent). }\end{array}$ \\
\hline
\end{tabular}


Child Development Home Visit Quality Ratings (continued)

\begin{tabular}{|c|c|c|c|c|c|}
\hline Dimension & 1 & 2 & 3 & 4 & 5 \\
\hline $\begin{array}{l}\text { Planning home } \\
\text { visits }\end{array}$ & $\begin{array}{l}\text { Little or no evidence that } \\
\text { home visits are planned } \\
\text { based on clear goals and } \\
\text { expected outcomes. }\end{array}$ & $\begin{array}{l}\text { Some evidence that home } \\
\text { visits are planned based on } \\
\text { program goals and expected } \\
\text { outcomes, but home visitors } \\
\text { do not use a curriculum or } \\
\text { protocol to guide child } \\
\text { development activities that } \\
\text { take place during the home } \\
\text { visit. }\end{array}$ & $\begin{array}{l}\text { Home visits are planned based } \\
\text { on program goals and } \\
\text { expected outcomes. Home } \\
\text { visitors use a curriculum or } \\
\text { protocol to guide child } \\
\text { development activities that } \\
\text { take place during the home } \\
\text { visit. }\end{array}$ & $\begin{array}{l}\text { Home visits are planned } \\
\text { based on program goals and } \\
\text { expected outcomes. Home } \\
\text { visitors develop plans for } \\
\text { each visit using a curriculum } \\
\text { or protocol to guide child } \\
\text { development activities that } \\
\text { take place during the home } \\
\text { visit, but they individualize } \\
\text { planned activities to meet the } \\
\text { needs of individual parents } \\
\text { and children. }\end{array}$ & $\begin{array}{l}\text { Home visits are planned based } \\
\text { on program goals and expected } \\
\text { outcomes. Home visitors } \\
\text { develop plans for each visit } \\
\text { using a curriculum or protocol } \\
\text { to guide the child development } \\
\text { activities that take place during } \\
\text { the home visit, but they } \\
\text { individualize the visits to meet } \\
\text { the needs of individual parents } \\
\text { and children. Home visitors } \\
\text { strive to develop strong } \\
\text { relationships with parents and } \\
\text { children, build on the strengths } \\
\text { of parents and children, and } \\
\text { work in partnership with } \\
\text { parents to plan child } \\
\text { development activities. }\end{array}$ \\
\hline $\begin{array}{l}\text { Frequency of } \\
\text { home visits } \\
\text { and caseload } \\
\text { sizes }\end{array}$ & $\begin{array}{l}\text { Little or no evidence that } \\
\text { home visitors visit parents } \\
\text { and children receiving home- } \\
\text { based services on a regular } \\
\text { basis. }\end{array}$ & $\begin{array}{l}\text { Home visitors visit most of } \\
\text { the parents and children who } \\
\text { are receiving home-based } \\
\text { services at least monthly. }\end{array}$ & $\begin{array}{l}\text { Home visitors visit most } \\
\text { parents and children who are } \\
\text { receiving home-based services } \\
\text { at least two times per month. }\end{array}$ & $\begin{array}{l}\text { Home visitors visit most } \\
\text { parents and children who are } \\
\text { receiving home-based } \\
\text { services at least three times } \\
\text { per month, and caseload } \\
\text { sizes permit adequate time } \\
\text { for completing home visits } \\
\text { and other duties. }\end{array}$ & $\begin{array}{l}\text { Home visitors visit almost all } \\
\text { parents and children who are } \\
\text { receiving home-based services } \\
\text { at least four times per month, } \\
\text { and caseload sizes permit } \\
\text { adequate time for completing } \\
\text { home visits and other duties. }\end{array}$ \\
\hline $\begin{array}{l}\text { Emphasis on } \\
\text { child } \\
\text { development } \\
\text { activities }\end{array}$ & $\begin{array}{l}\text { Little or no evidence that } \\
\text { home visitors spend time on } \\
\text { child development activities } \\
\text { during home visits. }\end{array}$ & $\begin{array}{l}\text { Home visitors spend some } \\
\text { time during some home visits } \\
\text { on child development } \\
\text { activities. }\end{array}$ & $\begin{array}{l}\text { Home visitors typically spend } \\
\text { some time during each home } \\
\text { visit on child development } \\
\text { activities with the child or the } \\
\text { parent and child together. }\end{array}$ & $\begin{array}{l}\text { Home visitors typically } \\
\text { spend at least half an hour } \\
\text { during each home visit on } \\
\text { child development activities } \\
\text { with the child or the parent } \\
\text { and child together. }\end{array}$ & $\begin{array}{l}\text { Home visitors typically spend } \\
\mathbf{4 5} \text { minutes or more during } \\
\text { each home visit on child } \\
\text { development activities with the } \\
\text { child or the parent and child } \\
\text { together. }\end{array}$ \\
\hline
\end{tabular}


Child Development Home Visit Quality Ratings (continued)

\begin{tabular}{|c|c|c|c|c|c|}
\hline Dimension & 1 & 2 & 3 & 4 & 5 \\
\hline $\begin{array}{l}\text { Integrating } \\
\text { home-based } \\
\text { services with } \\
\text { other services }\end{array}$ & $\begin{array}{l}\text { Little evidence that home } \\
\text { visitors providing child } \\
\text { development services } \\
\text { coordinate with other home } \\
\text { visitors, child care providers, } \\
\text { or other service providers. }\end{array}$ & $\begin{array}{l}\text { Some attempts by home } \\
\text { visitors providing child } \\
\text { development services to } \\
\text { coordinate with other home } \\
\text { visitors, child care providers, } \\
\text { or other service providers, but } \\
\text { coordination is not consistent } \\
\text { or systematic. }\end{array}$ & $\begin{array}{l}\text { Home visitors providing child } \\
\text { development services } \\
\text { coordinate with other home } \\
\text { visitors, child care providers, } \\
\text { Part C staff, and other service } \\
\text { providers, but not on a } \\
\text { systematic basis. }\end{array}$ & $\begin{array}{l}\text { Home visitors providing } \\
\text { child development services } \\
\text { coordinate systematically } \\
\text { and regularly with some } \\
\text { home visitors, child care } \\
\text { providers, and service } \\
\text { providers who are working } \\
\text { with the same children and } \\
\text { families, but they do not } \\
\text { coordinate systematically } \\
\text { with all service providers. }\end{array}$ & $\begin{array}{l}\text { Home visitors providing child } \\
\text { development services } \\
\text { coordinate systematically and } \\
\text { regularly with all service } \\
\text { providers who are working with } \\
\text { the same children and families, } \\
\text { including other home visitors, } \\
\text { child care providers, Part C } \\
\text { staff, and other service } \\
\text { providers. }\end{array}$ \\
\hline
\end{tabular}





\section{APPENDIX C}

EARLY HEAD START OUTCOMES IN STAFF DEVELOPMENT AT THE WASHINGTON STATE MIGRANT COUNCIL 



\title{
EARLY HEAD START OUTCOMES IN STAFF DEVELOPMENT AT THE WASHINGTON STATE MIGRANT COUNCIL
}

\author{
Joseph J. Stowitschek and Eduardo J. Armijo \\ University of Washington
}

\section{OVERVIEW}

A consistent need identified by human service agencies is the recruitment and retention of qualified bilingual and culturally-sensitive personnel. Often, the persons who have the appropriate linguistic and cultural qualifications are not trained to provide the levels of services needed by families. Staff development is identified as one of the "cornerstones" of Early Head Start (along with an emphasis on children, families, and communities), and is a major component of the Washington State Migrant Council's (WSMC) Early Head Start project. Upon receiving funding, WSMC sought to include this component as a priority for the research partnership. WSMC also felt that because of the make-up of the families being served (mostly migrant and Hispanic farmworking families) a qualified, well-trained staff with opportunities for growth and development, would be essential to ensure that the diverse needs displayed by these families are met.

The WSMC staff has received training in several areas over the course of the project, as well as educational incentives as part of an overall staff development effort. Areas of training, which were designed to help families, included: brain development, conflict and anger management, proper food preparation, disabilities training, and transition services. Much of this training was directed at refining and prioritizing focus areas to work with families, and also to enhance overall service delivery methodology.

The following is a summary of findings resulting from surveys and interviews of staff regarding personal and professional growth they feel resulted from being a part of the WSMC Early Head Start project, and how this helped shape their service delivery efforts. These findings 
are based on ongoing research being conducted by the University of Washington as part of the national Early Head Start research initiative.

\section{METHODS USED}

Two protocols, developed by University of Washington staff, were used to provide information: the "Staff Development Interview" and the "Family Services Information Questionnaire." The "Staff Development Interview" provided data pertaining to: staffs' educational goals and career aspirations; training; and incentives and disincentives for personal and professional growth. The "Family Services Information Questionnaire" provided data pertaining to service delivery focus areas and methods. The "Staff Development Interview" was completed in one-on-one interviews with WSMC Early Head Start staff, and the "Family Services Information Questionnaire" was completed by WSMC Early Head Staff during a records review process. Service delivery staff included six Home Educators and two Case Managers, the Project Coordinator, and the Project Director.

\section{STAFF DEVELOPMENT OUTCOMES}

Staff Educational Goals/Career Aspirations. Interviews revealed that four of the WSMC staff had attained some degree of post-secondary education, another four had Associates of Arts degrees, and two had Bachelor's degrees related to their roles. When asked what levels of education they aspired to, seven indicated that attaining a Bachelor's degree was a goal, and six indicated that attaining a Master's level degree was also a goal. One staff member indicated that she would eventually like to obtain a doctorate level degree.

To help staff attain these goals, WSMC offered incentives to their staff to encourage them to continue with their education. This included an education-reimbursement package (including $100 \%$ tuition, books, mileage, childcare) and flex time schedules to accommodate coursework. 
On a scale of 1 to 5, with 1 being "Discourage" and 5 being "Encourage," Early Head Start staff uniformly rated WSMC's efforts in this area with a "5."

Many of the staff's educational goals were directly related to career aspirations. When asked what position(s) they would like to hold in the future, one of the staff indicated that she would like to eventually run a certified daycare center; four would like to transition to a full-time case management position; three would like to become teachers (either with Head Start or a public school); three would like to eventually become coordinators or supervisors of a programs that serve families; one would like to become a higher-level program administrator; and one individual would like to eventually become a public school administrator.

Training. WSMC reported placing a heavy emphasis on staff development through training, both within and outside of the agency. Areas of training received included: child development (e.g., brain development, disabilities); conflict and anger management; transition services; and even proper food preparation. During a given year, staff received an average of nearly fifty-five hours of training, gaining knowledge to help in their service delivery efforts, as well as to pass on to families.

Staff were asked to rate how this training contributed to their professional skills and career advancement. A 1 to 5 scale was used, with 1 being "Not at all Contributive" and 5 being "Very Contributive." In the area of how trainings contributed to their professional skills, staff rated this an average 4.5. In the area of how the trainings contributed to their career advancement, staff rated this an average 4.3 (see Table 1$)$. 
TABLE 1

CONTRIBUTION OF TRAININGS ON A 1 TO 5 SCALE

\begin{tabular}{lcc}
\hline Training Title & Contributes to Profession & Contributes to Career \\
\hline Brain Development & 5.0 & 3.5 \\
YAC Brain Development & 4.5 & 4.5 \\
Developing Capable People & 4.5 & 4.5 \\
Conflict/anger Management & 5.0 & 5.0 \\
Sharing (Early) Horizons & 4.0 & 4.0 \\
Transition & 4.2 & 4.3 \\
Queso Fresco & 4.1 & 3.7 \\
Disabilities & 5.0 & 5.0 \\
Infant/Toddler & 5.0 & 4.0 \\
Special Quest & 4.0 & 4.0 \\
\hline Average & $\mathbf{4 . 5}$ & $\mathbf{4 . 3}$ \\
\hline
\end{tabular}

(1=Not at All Contributive, $5=$ Very Contributive

Incentives and Disincentives. Personnel were queried regarding incentives and disincentives connected with their jobs as Early Head Start staff. Areas of interest included jobrelated incentives (e.g., pay, outside trainings), inservice training provided by WSMC, attitudes of co-workers, and attitudes of WSMC supervisors and administrators. A 1 to 5 scale was used, with 1 being "Discourage" and 5 being "Encourage." On the average, staff rated job-related incentives at 4.1, WSMC training at 3.9, co-worker attitudes at 3.2, and supervisors/administrators attitudes at 4.0 (see Figure 1). 
FIGURE 1

STAFF INCENTIVE AND DISINCENTIVE RATINGS ON A 1 TO 5 SCALE

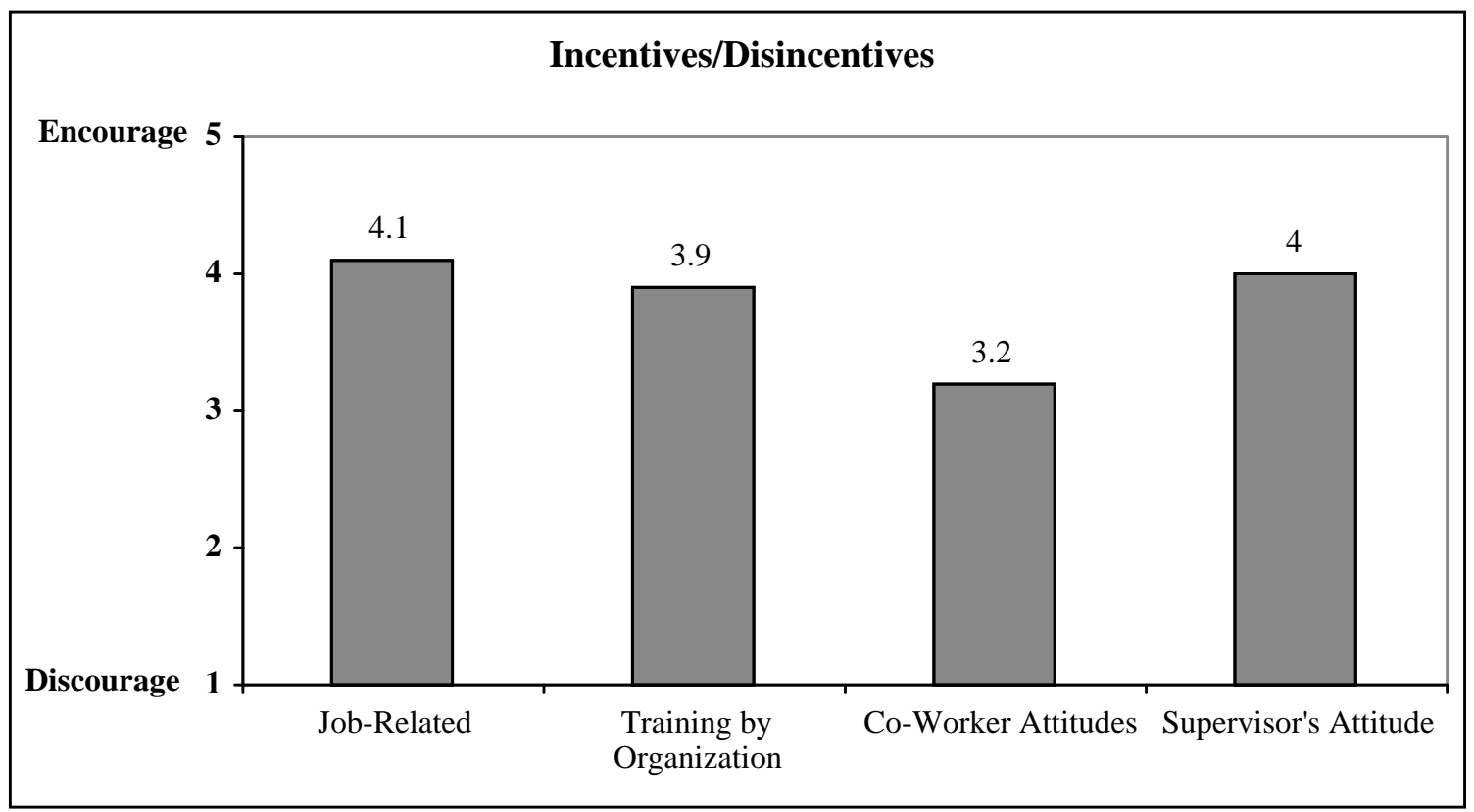

$(1=$ Discourage, $5=$ Encourage $)$

In response to open-ended questions, Early Head Start staff in general indicated that WSMC and the Early Head Start program neither hindered nor otherwise prevented them from acquiring personal or professional goals. Indeed, as seen above, growth in these areas is strongly encouraged by the agency and program. In addition to professional growth, many of the staff feel they have been personally enriched by the program in areas such as raising their own children, reaching out to families in need, and increasing their own self-esteem and selfconfidence.

\section{DISCUSSION}

The staff development features explored in this study suggest that the WSMC Early Head Start project is highly committed to the cornerstone of Staff Development. But how do the above areas relate to services being delivered to families? Early Head Start staff uniformly 
indicated that the incentives received as part of their jobs had a spill-over effect with the families they worked with. For example, over a three-year period staff reported $26 \%$ average increases in hours spent with families as part of regular visits, as well as over $300 \%$ average increases in hours spent training families in project-related areas (e.g., child development issues, proper food preparation). In addition, staff reported nearly $400 \%$ average increases in contact with families over the phone.

There has also been a shift in focus areas during the same three-year period. An increase in the percentage of time spent in the areas of mental health, nutrition, child language development, and father involvement was reported by Early Head Start staff. Additionally, staff reported an increase in the percentage of time spent in specific service delivery methods (both direct and indirect) during this time. Specific areas included coaching families, providing praise and feedback to families, problem solving, assessing and evaluation, verbal pointers, and arranging resources for families.

Most of the Early Head Start staff we studied were derived from the same Hispanic roots as the Early Head Start families they served, only one or two generations removed. Thus, their professional successes and advancements reflect the hopes, aspirations, and opportunities that are strived for with these younger, poorer Hispanic families. For rural Early Head Start, the demonstration of professional growth and advancement is an outcome of critically high import. 